\title{
Effects of Moisture, Salinity and Temperature on Mode I Fracture Toughness of Adhesively-Bonded Composites
}

\author{
André F. Couture
}

A thesis submitted to the Faculty of Graduate and Postdoctoral Affairs in partial fulfillment of the requirements for the degree of

Master of Applied Science

in

Aerospace Engineering

Carleton University

Ottawa, Ontario

(C) 2011 André F. Couture 


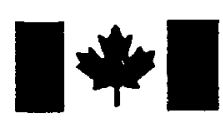

\author{
Library and Archives \\ Canada \\ Published Heritage \\ Branch \\ 395 Wellington Street \\ Ottawa ON K1A ON4 \\ Canada
}

Bibliothèque et

Archives Canada

Direction du

Patrimoine de l'édition

395 , rue Wellington

Ottawa ON K1A ON4

Canada
Your file Votre référence
ISBN: 978-0-494-83059-8
Our file Notre référence
ISBN: $978-0-494-83059-8$
NOTICE:

The author has granted a nonexclusive license allowing Library and Archives Canada to reproduce, publish, archive, preserve, conserve, communicate to the public by telecommunication or on the Internet, loan, distribute and sell theses worldwide, for commercial or noncommercial purposes, in microform, paper, electronic and/or any other formats.

The author retains copyright ownership and moral rights in this thesis. Neither the thesis nor substantial extracts from it may be printed or otherwise reproduced without the author's permission.
AVIS:

L'auteur a accordé une licence non exclusive permettant à la Bibliothèque et Archives Canada de reproduire, publier, archiver, sauvegarder, conserver, transmettre au public par télécommunication ou par l'Internet, prêter, distribuer et vendre des thèses partout dans le monde, à des fins commerciales ou autres, sur support microforme, papier, électronique et/ou autres formats.

L'auteur conserve la propriété du droit d'auteur et des droits moraux qui protège cette thèse. $\mathrm{Ni}$ la thèse ni des extraits substantiels de celle-ci ne doivent être imprimés ou autrement reproduits sans son autorisation.
In compliance with the Canadian Privacy Act some supporting forms may have been removed from this thesis.

While these forms may be included in the document page count, their removal does not represent any loss of content from the thesis.
Conformément à la loi canadienne sur la protection de la vie privée, quelques formulaires secondaires ont été enlevés de cette thèse.

Bien que ces formulaires aient inclus dans la pagination, il n'y aura aucun contenu manquant.

\section{Canadä}


ABSTRACT

The work presented here focused on the effect of various hot and humid environments on the mode I fracture toughness of bonded composite Double Cantilever Beam (DCB) specimens and bonded sandwich Single Cantilever Beam (SCB, also known as "Cracked Sandwich Beam", CSB) specimens.

Fracture tests were performed on the specimens after 3-4 months of exposure to the environments and it was found that conditioning DCB specimens resulted in reductions of at least $22 \%$ in the initiation value of GIC. The propagation value was not affected by conditioning in high-humidity environments, but reduced by approximately $15 \%$ and $6 \%$ when conditioning by immersion at $82^{\circ} \mathrm{C}$ and $70^{\circ} \mathrm{C}$ water, respectively (salt concentration had no effect). In terms of failure mode, all DCB specimens failed I00\% cohesively (within the bond line) when unconditioned, and all had a relatively large proportion of adhesive failure (between the adhesive and the composite laminates) after any type of conditioning.

For SCB specimens, GIC was identically affected by exposure of the specimen to $95 \%$ relative humidity or liquid salt water, the result being a decrease of about $20 \%$ in the propagation GIC compared to unconditioned specimens. All these specimens suffered cohesive failure within the core. 
Many contributed to this work, especially at the National Research Council's Institute for Aerospace Research. The co-op students, especially Kyle, Johnathan and Julieta, were always available to help and Kyle and John even manufactured all the sandwich panels on their own. The Technical Officers, especially Matt Harrison, Tom Kay, Brian Moyes and Denis Beaulieu, were knowledgeable, helpful and hardworking. Tom Benak, thanks for always knowing where everything is and how everything works! Michel Delannoy, ta connaissance des systèmes électroniques et ton aide rapide et efficace ont toujours été très appréciées. Rick Cole, thanks for pointing Lucy and I in the right direction on SCB testing; André Beltempo, for your answers to my many questions and efficient reviews of my abstracts and paper!

My supervisors, Prof. Jeremy Laliberté at Carleton University and Dr. Lucy Li at NRC-IAR were supportive, encouraging and trusting, as well as being knowledgeable and friendly. I very much enjoyed working with you both!

And finally, thanks to my family and friends for their support and encouragement throughout the two-plus years of this endeavour. 


\section{CONTENTS}

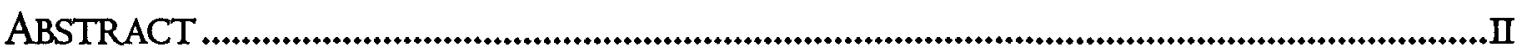

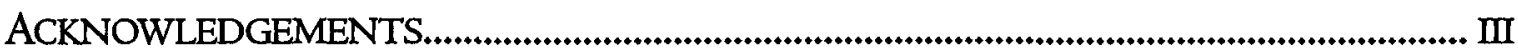

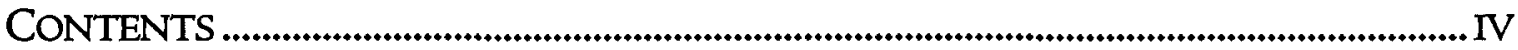

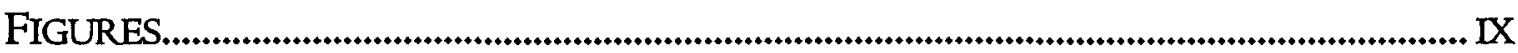

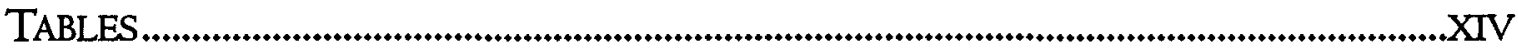

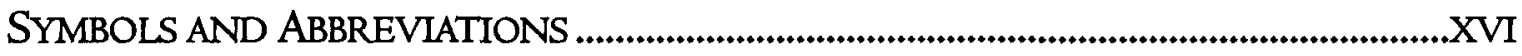

CHAPTER I: LITERATURE REVIEW ............................................................................

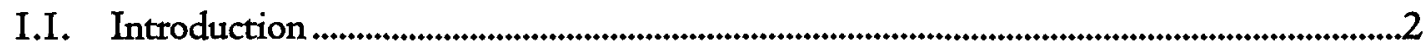

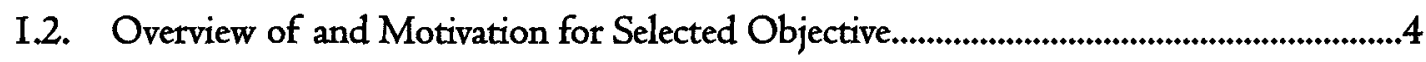

I.2.I. Importance of Adhesive Joints in Aerospace Structures............................................ 5

I.2.2. Effect of Salt Water in Aerospace Applications ..................................................... 8

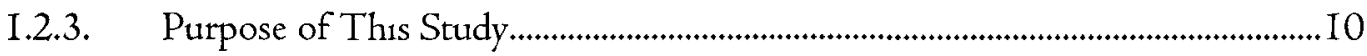

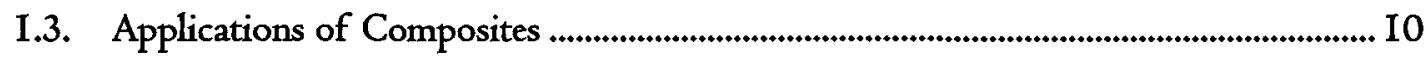

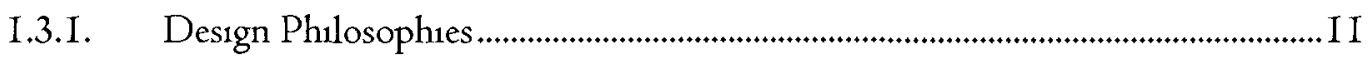

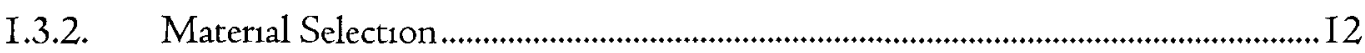

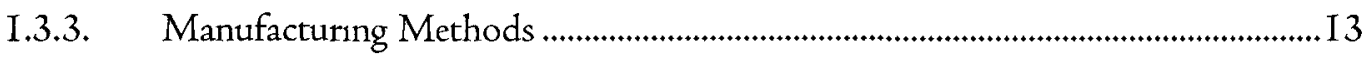

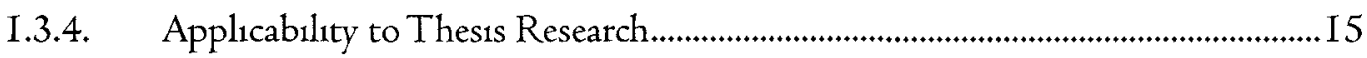

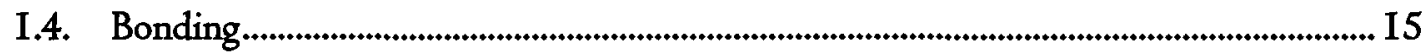

I.4.I. Applications of Adhesive Joints in the Aerospace Industry …............................... I5

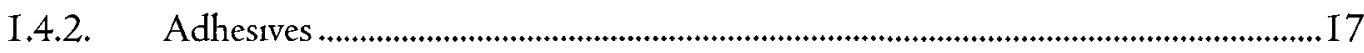

I.4.3. The Nature of Adhesive Bonds ..................................................................... I9

I.4.3.1. Chemical Bonding ..................................................................................................... 19

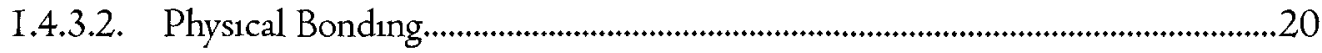

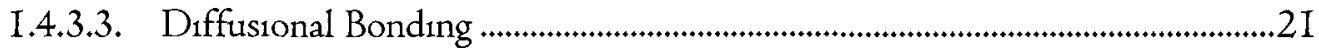

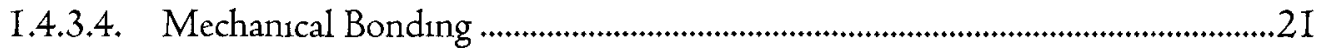

I.4.4. Surface Preparation Procedures for Thermosetting Polymers ...............................22

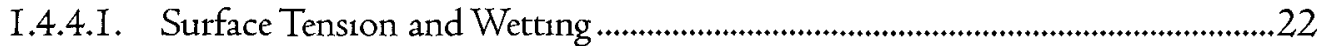

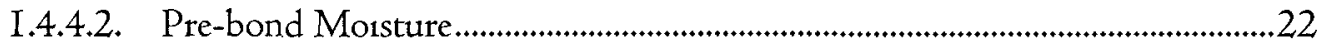

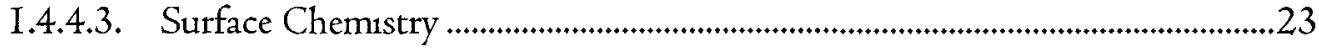

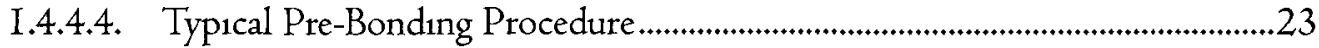

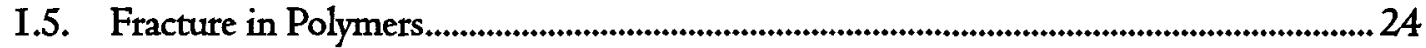


1.6. Effects of Hot/Humid Environments 31

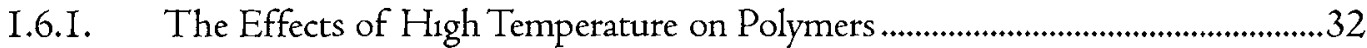

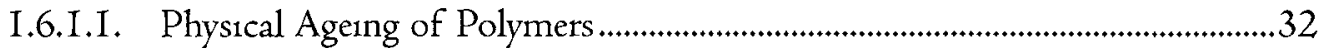

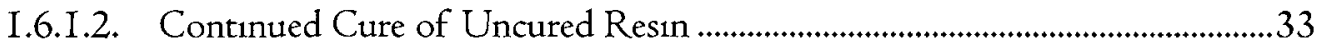

I.6.I.3. Thermo-Oxidative and Other Chemical Reactions .........................................33

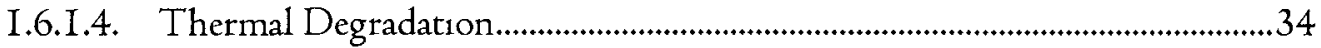

1.6.I.5. Effects of High Temperature on the Fracture of Epoxies.................................34

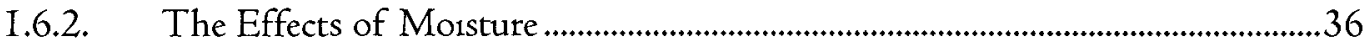

I.6.2.I. The Nature of Moisture Diffusion and Its Effect on $T_{G}$................................36

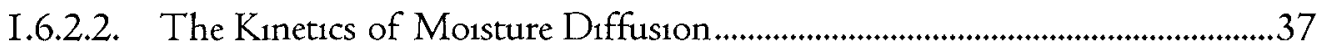

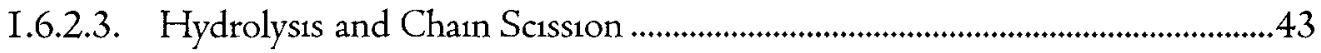

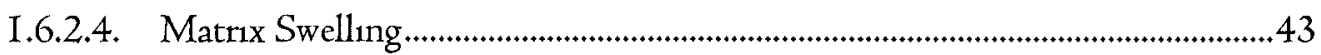

I.6.3. Effects of the Hot/Wet Environment on Bonded Joints.....................................43

I.6.4. Effects of Salt Water versus Fresh Water .................................................................44

1.6.5. Synergistic Effects of Temperature and Morsture ........................................................4

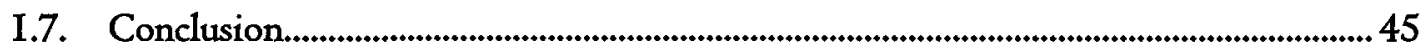

CHAPTER 2: MANUFACTURING OF DCB AND SCB SPECIMENS ................................. 47

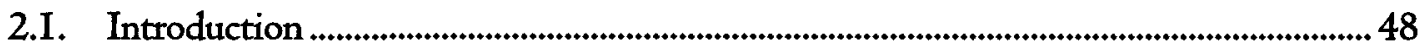

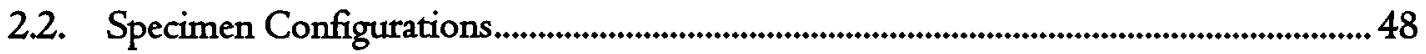

2.2.I. The Double Cantrlever Beam Specimen...................................................................48

2.2.2. The Single Cantilever Beam (SCB) Sandwich Specimen ........................................50

2.2.3. Dimensions of SCB Specimens Used in this Study ………….................................53

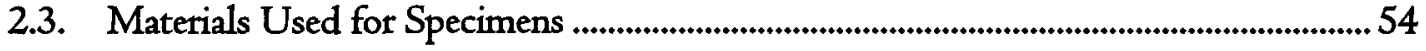

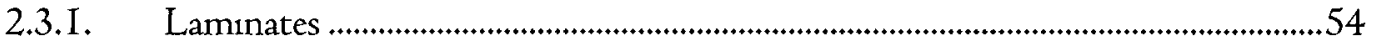

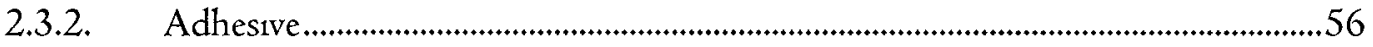

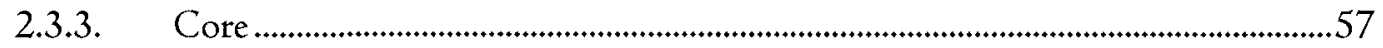

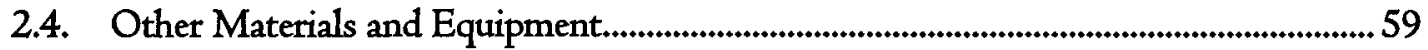

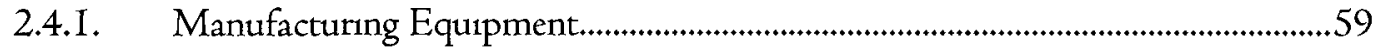

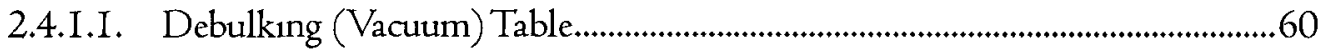

2.4.I.2. Tool Plates, Pressure Plates and Shims ..............................................................6I

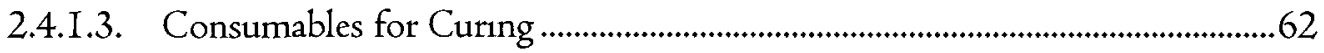

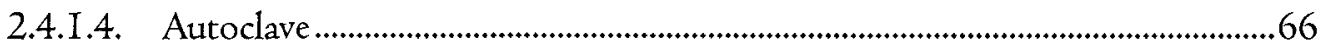

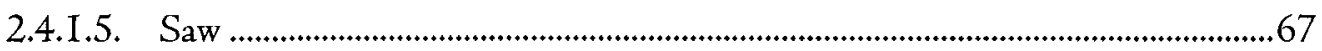


2.4.2. Equipment for Preparation of Specimens for Conditioning and

Mechanical Testing. 68

2.4.2.1. Hinge Bonding Materials and Equipment

2.4.2.2. SCB Edge Sealing Materials. 70

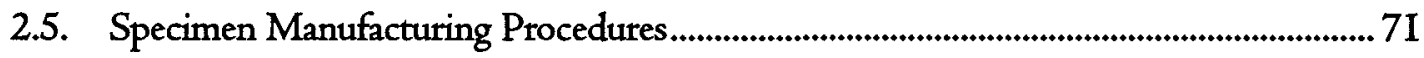

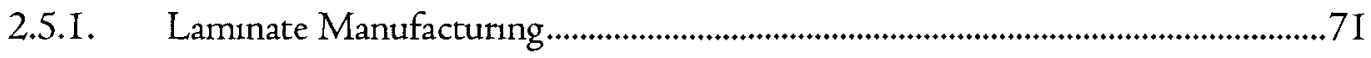

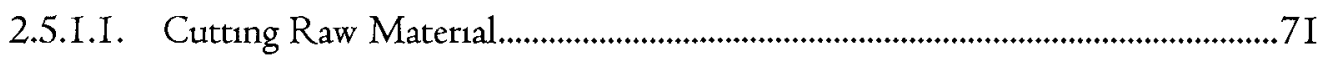

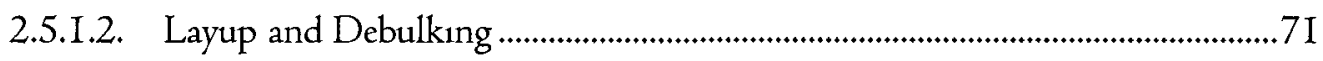

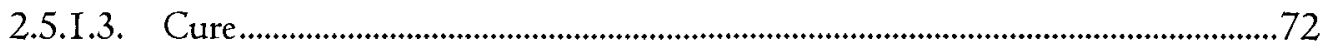

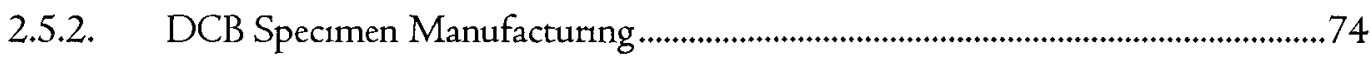

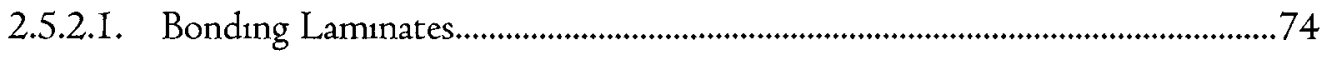

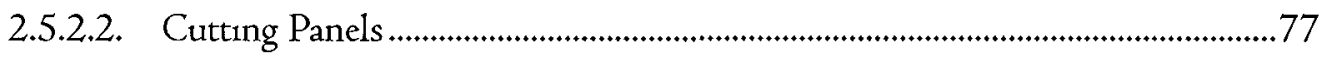

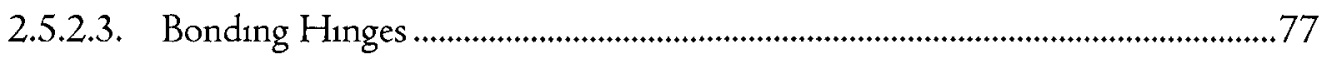

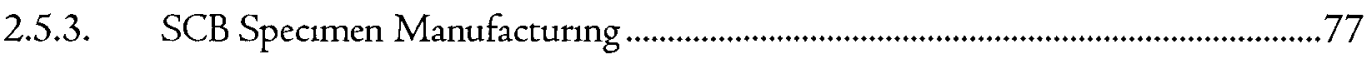

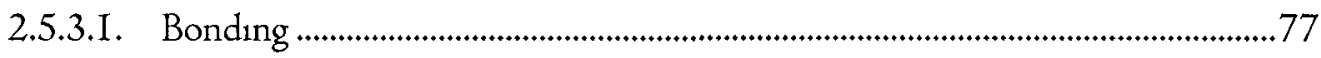

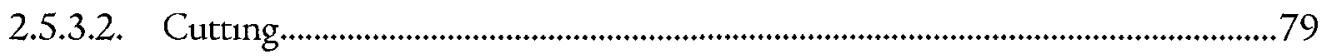

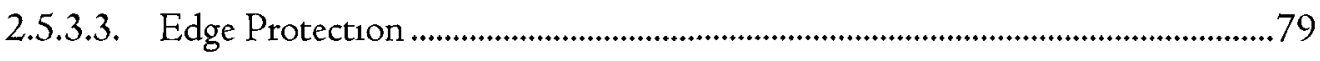

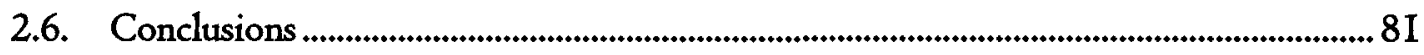

CHAPTER 3: ENVIRONMENTAL CONDITIONING AND DIFFUSION ANALYSIS ........... 83

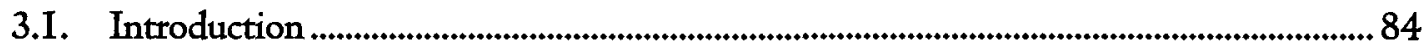

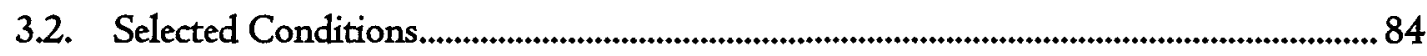

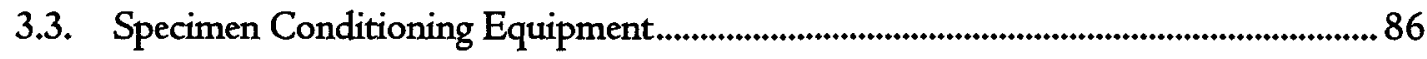

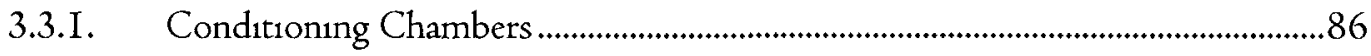

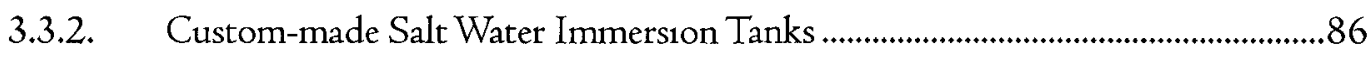

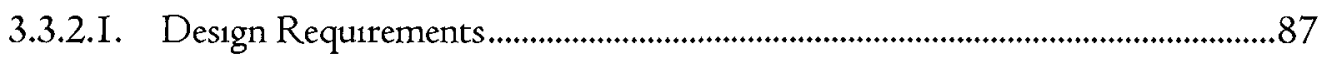

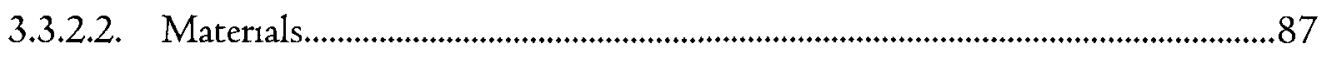

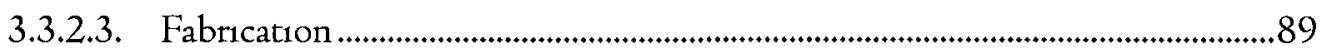

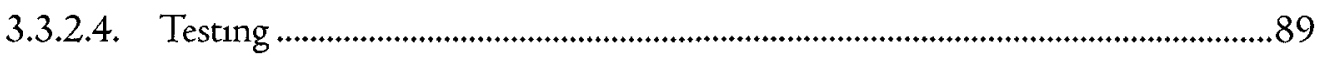

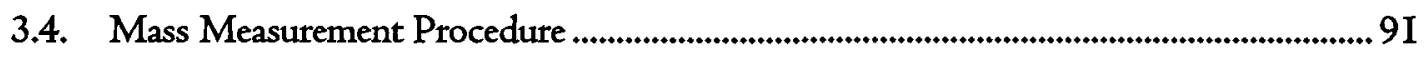

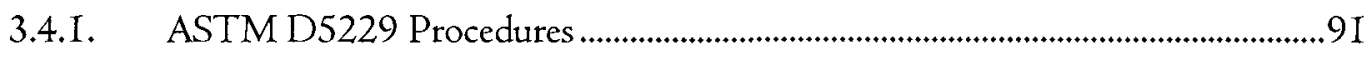

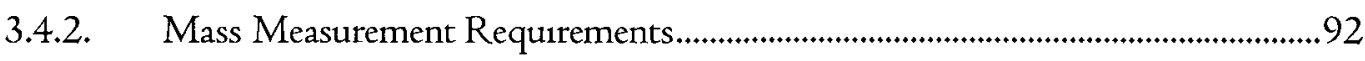

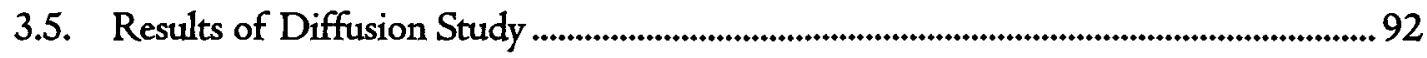

3.5.I. Comparison of Conditioning Environments ...................................................... 92

3.5.I.I. Visual Observation of Polymer Degradation in Water......................................94 


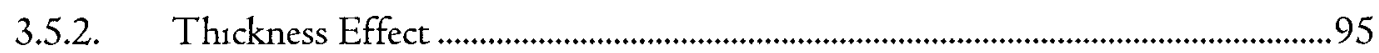

3.5.3. Modelling Diffusion: Fickian or Non-Fickıan?.................................................97

3.5.4. Temperature Effect: How the Artificial Environment Compares to the

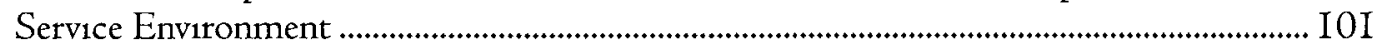

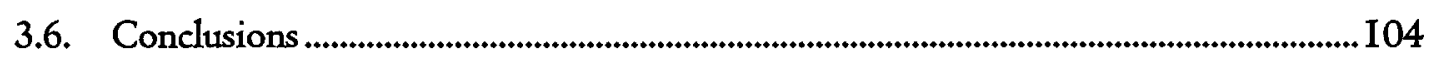

CHAPTER 4: THE EFFECTS OF THE ENVIRONMENT ONTHE FRACTURE TOUGHNESS OF BONDED LAMINATES..................................................................... IOS

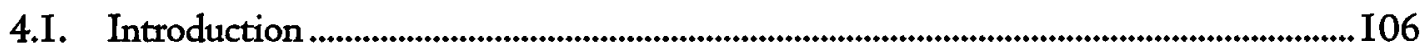

4.2. Mechanical Testing Procedure............................................................................. 108

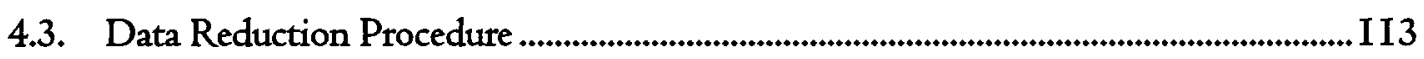

4.3.I. The Modified Beam Theory (MBT) Method...................................................... II I

4.3.2. The Compliance Calibration (CC) Method......................................................... I I 6

4.3.3. The Modified Compliance Calibration (MCC) Method .................................... I I 8

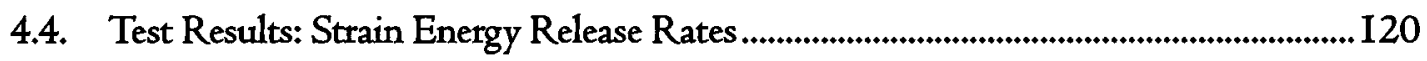

4.4.I. Foreword on Presentation of Strain Energy Release Rate Results .................. I20

4.4.I.I. Summary Data Sheets.................................................................................. I 20

4.4.I.2. Selection of Most Sutable Method of GIC Calculation ............................... I2I

4.4.I.3. The Presentation of Means and Standard Deviations.................................. I22

4.4.I.4. The Presentation of Initiation Strain Energy Release Rates........................ I 23

4.4.I.5. Allocation of Specimens to Environmental Conditions ............................... I25

4.4.2. Results: Strain Energy Release Rate During Initiation ........................................ I 26

4.4.3. Results: Strain Energy Release Rates During Crack Propagation...................... I 28

4.4.3.1. Unconditioned Specimens (RTA) ............................................................... I 28

4.4.3.2. IVWN Specimens (Conditioned at $70^{\circ} \mathrm{C}, 95 \%$ R.H.) ............................ I 30

4.4.3.3. HVWN Specimens (Conditioned at $82^{\circ} \mathrm{C}, 95 \%$ R.H.) ............................... I I I

4.4.3.4. IIWN Specimens (Conditioned at $70^{\circ} \mathrm{C}$, Immersed in Water) ................... I 32

4.4.3.5. HIWN Specimens (Conditioned at $82^{\circ} \mathrm{C}$, Immersed in Water)................ I 33

4.4.3.6. IISN Specimens (Conditioned at $70^{\circ} \mathrm{C}$, Immersed in Salt Water)............. 134

4.4.3.7. HISN Specimens (Conditioned at $82^{\circ} \mathrm{C}$, Immersed in Salt Water).......... I 35

4.4.3.8. Comparison of Conditions ............................................................................ I 136

4.4.4. Possible Sources of Observed Variations ........................................................... I 138

4.4.4.I. Panel of Origin and Position of Specimen within Panel ............................... I38

4.4.4.2. Variability in Bonding Operations ................................................................ 139

4.4.4.3. Varrability of Farlure Mode .............................................................................. I 140 
4.4.4.4. Specimen Drying During Test (Outher Analysı).

4.4.5. Discussion of Mode I Fracture Toughness Results for Bonded DCBs........... I 43

4.5. Test Results: Failure Modes

4.5.I. General Comments on Taking and Editing Specimen Photos.

4.5.2. A Method to Observe Overall Cohesive and Adhesive Fa1lure

4.5.3. A Method to Calculate the Percentage of Cohesive and Adhesive Faulure .... I52

4.5.4. Discussion of Fallure Mode Results. 154

4.6. Conclusions

CHAPTER 5: PRELIMINARY STUDY OF THE EFFECTS OF THE ENVIRONMENT ONTHE DISBOND FRACTURE TOUGHNESS OF SANDWICH STRUCTURES

5.I. Introduction

5.2. Sandwich Failure Modes

5.3. Mechanical Testing Procedure

5.3.I. Specimen Preparations. I 64

5.3.2. Use of Load Frame I 65

5.4. Data Analysis Procedure 167

5.5. Results and Discussion 168

5.5.I. Presentation of Results for SCB Specimens. 168

5.5.2. Farlure Mode 170

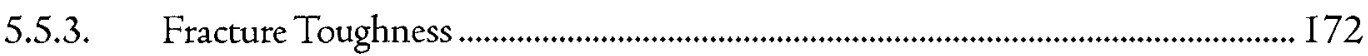

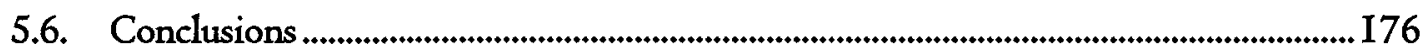

CHAPTER 6: OVERVIEW OF CONTRIBUTION AND FUTURE WORK

6.I. Conclusions

6.I.I. Chapter I: Literature Review. 179

6.I.2. Chapter 2: Specimen Manufacturing 179

6.I.3. Chapter 3: Environmental Conditioning. 180

6.I.4. Chapter 4: DCB Tests 180

6.I.5. Chapter 5: SCB Tests.....

6.2. Contribution

6.2.I. The Effect of Salinity on Joints of Composite Laminates.

6.2.2. Degradation of the Interface in Joints of Composite Laminates 182

6.2.3. Environmental Effects on Sandwich Disbond

6.2.4. Comparing Farlure Mode to Fracture Toughness 
6.3. Future Work

6.3.I. Chemical and Physical Effects of Moisture on Bonds.

6.3.2. Further Probing the Degradation of Bonded Laminate Joints

6.3.3. Changing the Focus of Sandwich Disbond Research.

6.3.4. Increasing the Role of Finite Element Analysis

REFERENCES...

\section{FIGURES}

Figure I: Summary of specimen preparation procedure and outline of Chapters I-5..................... 4

Figure 2: Illustration of improvements in strength and stiffness achieved by the introduction of a core material between laminates [8].

Figure 3: Example of a sandwich structure with carbon fibre-reinforced epoxy face sheets, adhesive and Nomex honeycomb core.

Figure 4: Different crack propagations are possible under loading in the crack-opening mode (mode I). Modified from [7].

Figure 5: Schematic comparison of naval versus aerospace composite materials and manufacturing methods [33].

Figure 6: Chemical structure of DGEBA, TGDDM and TGAP epoxy resins. One epoxide group is highlighted. Modified from [7].

Figure 7: Example reaction between an amine hardener and epoxide group. $\mathrm{R}$ is a general amine backbone and $E$ a general epoxy backbone [7].....

Figure 8: Schematic representations of (a) Chemical bonding; (b) Physical bonding; (c) Interdiffusional bonding; and (d) Mechanical bonding (modified from [35]).....

Figure 9: Load-displacement ( $\mathrm{P}-\mathrm{u})$ curve and resulting energy release (highlighted) for linear-elastic materials [43]

Figure I0: DCB specimen configuration (modified from [44]) ........................................................30

Figure I I: Fracture energy versus Ageing Time for unreinforced epoxy resin [52] 35 
Figure I2: Total Fracture Energy versus Testıng Temperature [52]

Figure 13: (a) Type I binding of water to epoxy main chain, which has a lower activation energy than (b) Type II binding, which occurs over longer times and at higher temperatures $[55]$

Figure I4: Example of Fickian diffusion trend for $D=10^{-4} \mathrm{~mm}^{2} / \mathrm{hr}, \mathrm{M}_{\infty}=\mathrm{I}$ and $\mathrm{L}=\mathrm{I} .3 \mathrm{~mm}$.

Solution based on Equation (33).

Figure I5: Synergistic effect on fracture energy of moisture (shown in key as mass \%), ageing time (shown in days) and testing temperature ( $\mathrm{x}$-axis) [52].

Figure I6: Configuration of DCB specimen in accordance with ASTM D5528 [44]

Figure I7: Bonded DCB specimen used in this study.

Figure 18: Honeycomb is manufactured from sheets that are bonded together. This results in different properties in the two in-plane directions.

Figure 19: Custom-made de-bulking table by Torr Technologies, Inc.

Figure 20: Shims with de-burred edges.

Figure 2I: Schematic of NRC tool plate bagging practice

Figure 22: Picture of tool plate setup prior to sealing the vacuum bag. I: Perforated release film, 2: Breather cloth, 3: Vacuum bag, 4: Solid release film, 5: Sealıng tape, 6: Shims, 7: Wrapped pressure plate (covenng the part), 8: Vacuum valve.

Figure 23: FEP-covered pressure plates

Figure 24: Roll of sealant tape.

Figure 25: Vacuum valve. Prcture at right shows vacuum bagging between the elastomeric and metallic rings of the valve.

Figure 26: NRC's autoclave.

Figure 27: Table saw used to cut specimens from carbon fibre/epoxy and sandwich panels.

Figure 28: The diamond blade consists of a metal disk coated with synthetic diamond along the cutting edge......

Figure 29: The hinge bonding fixture was designed to bond a length of hinge to 6 specimens at once while maintaining a $90^{\circ}$ angle between the hinge and specimens.

Figure 30: Thinky brand mixer. 
Figure 3I: Cure cycle for CYCOM5276-I

Figure 32: Grit blasting a panel before bonding activates its surface and increases its roughness as described in Chapter 1 .

Figure 33: DCB panel cutting plan

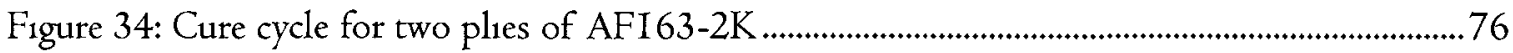

Figure 35: Core before (left) and after (right) nitrogen blast....................................................... 78

Figure 36: Picture frame fixture used during sandwich panel manufacturing.

Figure 37: Schematic of sandwich panel stacking order and specimen onentation with respect to the panel.

Figure 38: Left - SCB specimen with masked surface; Right - SCB with sealed edge and masking removed.

Figure 39: Schematic of heated salt water tank (shown upside-down)

Figure 40: Comparison of diffusion characteristics for 10-ply specimens in three different environments.

Figure 4I: Beaker filled with water that previously contained specimens. Visible particles are believed to be degradation products from the interaction of water and epoxy.

Figure 42: Close-up view through side of immersion tank. Orange heating element and particles in water are visible.

Figure 43: Specimens conditioned in the same environment appear to behave differently based on their thickness (Note: gap only indicates that no mass measurements were made at that specific time for some specimens)

Figure 44: Normalizing with respect to thickness results in superimposed curves

Figure 45: Comparison of Fick's theoretical diffusion curve and experimental curves for I0ply specimens.

Figure 46: Variation of diffusivity with temperature for BR/5505 laminate [83].

Figure 47: Prediction of diffusion behaviour for temperatures in range of $20-70^{\circ} \mathrm{C}$ for activation energies of 49 (solid) and 36 (dashed) $\mathrm{kJ} / \mathrm{mol}$.

Figure 48: Summary of preparation of DCB and SCB specimens leading to mechanical testing. 
Figure 49: Output from camera used to observe crack growth during DCB tests (short marks at every I $\mathrm{mm}$ and long ones every $5 \mathrm{~mm}$ )

Figure 50: DCB test set-up

Figure 5I: Typical output file (truncated) for DCB tests. Note that "Axial Strain" data were not used (nor properly configured) for this test.

Figure 52: Graphical determination of $\Delta$

Figure 53: The slope of the line obtaned by plotting a/h versus $C^{1 / 3}$ gives the value of $A_{I}$ to be used in the MCC method.

Figure 54: GIC vs. a for an unconditioned specimen

Figure 55: Gic vs. a for a specimen conditioned in $82^{\circ} \mathrm{C}$ water

Figure 56: Summary of initiation values. Dashed line shows slope of linear portion of $\mathrm{P}-\delta$ curve, $N L$ is the point where $\mathrm{P}-\delta$ deviates from linearity; $5 \%$ offset point is where the line having a $5 \%$ lower slope than the dashed line intersects $\mathrm{P}-\delta$ and VIS is at the first crack marker.

Figure 57: Initiation strain energy release rate based on NL point and CC calculation. Specimens are in order from SpI-Sp5

Figure 58: Propagation Gic of the five unconditioned specimens

Figure 59: Propagation Gic of the five IVWN specimens

Figure 60: Propagation Gic of the five HVWN specimens

Figure 6I: Propagation GIC of the five ITWN specimens

Figure 62: Propagation Gic of the five HIWN specimens

Figure 63: Propagation Gic of the five IISN specimens.

Figure 64: Propagation Gic of the five HISN specimens

Figure 65: Overall comparison of strain energy release rate of propagation for all conditions. Error bars represent $90 \% \mathrm{CI}$.

Figure 66: Overall comparison of strain energy release rate of propagation for all conditions, after removing data from outliers (CI: 90\%)

Figure 67: Areas of adhesive farlure (black on photo) resulted in lower Gic values. 
Figure 68: Some areas displayed a farlure surface that included visible fibres.

Figure 69: Most areas displayed a complex failure surface with visible laminate, adhesive and knit carrier.

Figure 70: The difference in colour and sharpness between these two photos is due only to a change in ISO setting.

Figure 7I: Example of a photograph of specimen C03-05 with ruler for scale.

Figure 72: Selection resulting from "Select by Colour" tool with a threshold of 30.

Figure 73: Composite image showing total areas of cohesive (pink) and adhesive (black) farlure for specimen $\mathrm{C} 03-05$

Figure 74: Close up of pixels on a picture edited as described in Section 5.2

Figure 75: Strain energy release rate and \% cohesive failure area versus crack length for specimen C04-08

Figure 76: Strain energy release rate and \% cohesive fa1lure area for specimen C04-02. In this case, the correlation is very poor.

Figure 77: Comparison of failure mode and strain energy release rate in an attempt to determine the necessary parameters for a linear correlation between them.

Figure 78: Typical sandwich farlure modes (modified from [8]).

Figure 79: Common terminology describing farlure of sandwich specimens, including separation of skin and core. [93]

Figure 80: SCB gripping fixture.

Figure 8I: Detalled view of gripping plate chamfer......

Figure 82: Typical load-displacement graph for SCB tests

Figure 83: During initiation, a new crack was formed in the core of the specimen rather than extending from the existing unbonded area.

Figure 84: Farlure of SCB specimens in this study was in the core, regardless of environmental exposure. For approximate scale, recall that fillets are $I / 8$ inch in diameter......

Figure 85: One area adjacent to a large vord sustained cohesive fallure of the fillet bond.

Figure 86: Initiation toughness data for 6 tested specimens using CC calculation method and VIS initiation criterion. 
Figure 87: Propagation Gic values for 6 tested specimens. CC calculation method used, and average calculated from all points after the first 0.5 inches as shown in Figure 88.

Figure 88: Curve of strain energy release rate with respect to crack length for specimen EOI-03.

Figure 89: Modified SCB gripping fixture with translatıng base. I86

\section{TABLES}

Table I: Parameters of interest in terms of effects on absorption of water and on resulting

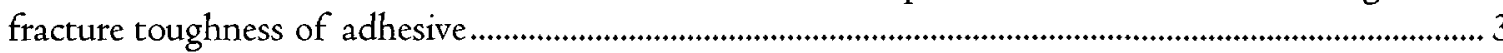

Table 2: Summary of polymers used as adhesives and their applications [36].................................. I7

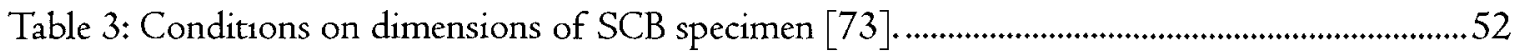

Table 4: Results of iterative analysis for SCB specimen dimensions................................................53

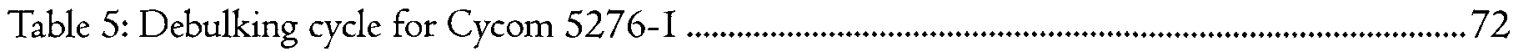

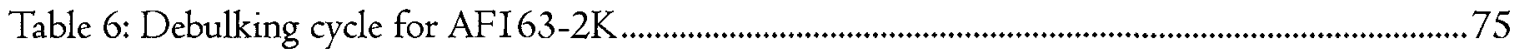

Table 7: Summary of selected environmental conditions for DCB specimens ......................................85

Table 8: Raw data of mass measurements. Italics indicate calculated value, thick border indicates $\mathrm{M}_{\infty}$, double border indicates points used for slope calculation and triple border is the calculated value of $\mathrm{D}_{z}$

Table 9: Test parameters of ASTM D5528 and the methods used in this study (deviations from the standard noted in bold)

Table I0: Reminder of the nomenclature for conditioning environment abbreviations.

Table I I: Allocation of specimens to environments.

Table 12: Initiation Gic,o values based on CC calculation and Non-Linear (NL) point.

Table I3: Mean Gic values and standard deviations for each unconditioned specimen.

Table I4: Mean Gic values and standard deviations for each IVWN specimen

Table I5: Mean Gic values and standard deviations for each HVWN specimen.

Table I6: Mean Gic values and standard deviations for each IIWN specimen 
Table I7: Mean Gic values and standard deviations for each HIWN specimen. .............................. I 33

Table I8: Mean Gic values and standard deviations for each IISN specimen. .................................... I 34

Table I9: Mean GIC values and standard deviations for each HISN specimen................................ I35

Table 20: Mean Gic and standard deviation for each specimen, as calculated using the CC method. Specimens I-5 can be identified from Table II. Outliers are highlighted and discussed in Section 4.5. 


\section{SYMBOLS AND ABBREVIATIONS}

\begin{tabular}{|c|c|}
\hline $\begin{array}{l}\text { Symbol or } \\
\text { Abbr. }\end{array}$ & Meaning \\
\hline$a$ & Crack length. \\
\hline$A_{1}$ & An empirical parameter used in the MCC method of calculating $G_{I C .}$ \\
\hline ASTM & $\begin{array}{l}\text { Formerly the American Society for Testing and Materials, now known as } \\
\text { "ASTM International". }\end{array}$ \\
\hline$b$ & Width of beam. \\
\hline$C$ & Compliance $(=\delta / P)$. \\
\hline $\mathrm{CI}$ & Confidence Interval \\
\hline $\mathrm{CC}$ & $\begin{array}{l}\text { Compliance Calibration. A method for calculating Grc. See also MBT and } \\
\text { MCC. }\end{array}$ \\
\hline CFRP & $\begin{array}{l}\text { Carbon Fibre Reinforced Plastic. Used mostly by Britrsh engineers and scientists } \\
\text { to refer to carbon fibre/polymer (usually epoxy) composites. }\end{array}$ \\
\hline CH-149 & $\begin{array}{l}\text { Canadian Forces SAR helicopter derived from the Agusta Westland EH-IOI. } \\
\text { Also known as the Cormorant. }\end{array}$ \\
\hline $\mathrm{CMH}-17$ & Composite Materials Handbook. \\
\hline$\delta$ & Displacement of loaded point (hinge pin). \\
\hline$\Delta$ & $\begin{array}{l}\text { Correction factor used in MBT calculation method of Gic to account for the } \\
\text { "cantilever beam" not being completely restricted from motion and rotation at } \\
\text { the crack tip (distance a from hinge). It is assumed to be completely constrained } \\
\text { at a distance of } a+\Delta \text {. }\end{array}$ \\
\hline DCB & Double Cantilever Beam. \\
\hline DDS & DiaminoDiphenyl Sulfone. A hardener used to crosslink epoxy chains. \\
\hline DGEBA & Diglycidyl Ether of Bisphenol A, an epoxy resin. \\
\hline FAA & Federal Aviation Administration. \\
\hline FEA & Finite Element Analysis. \\
\hline FEP & $\begin{array}{l}\text { Fluorinated Ethylene Propylene. Also known as Teflon FEP } \mathbb{B} \text { and other trade } \\
\text { names, it is used similarly to PTFE. }\end{array}$ \\
\hline$G_{I C}$ & Critical strain energy release rate in mode I. \\
\hline$G_{I C, O}$ & Critical strain energy release rate at initiation, in mode I. \\
\hline GIMP & $\begin{array}{l}\text { GNU Image Manipulation Program. Powerful freeware for manipulating and } \\
\text { editing images. Python scripts can be used to control GIMP programmatically } \\
\text { to automate tasks. }\end{array}$ \\
\hline$h$ & Beam thickness in DCB specimens. \\
\hline IAR & Institute for Aerospace Research. \\
\hline ISO & $\begin{array}{l}\text { On digital cameras, a setting of the sensitvity of the sensor to light. Higher } \\
\text { sensitivity helps in low light situations but results in noise in the picture. }\end{array}$ \\
\hline JPEG/JPG & A file format for compressing images, resulting in some loss of image quality. \\
\hline LVDT & $\begin{array}{l}\text { Linearly Variable Differential Transformer. A device used to measure } \\
\text { displacement precisely. }\end{array}$ \\
\hline MBT & Modified Beam Theory. A method for calculating Grc. See also CC and MCC. \\
\hline
\end{tabular}




\begin{tabular}{|c|c|}
\hline $\mathrm{MCC}$ & $\begin{array}{l}\text { Modified Compliance Calibration. A method for calculating } G_{K C} \text {. See also CC } \\
\text { and MBT. }\end{array}$ \\
\hline MEK & Methyl Ethyl Ketone. A degreasing solvent used to clean surfaces. \\
\hline MMB & $\begin{array}{l}\text { Mixed Mode Bending. A test in which the crack is exposed to a mix of mode I } \\
\text { and mode II loading, in proportions that can be controlled. }\end{array}$ \\
\hline MSDS & Material Safety Data Sheet. \\
\hline$n$ & An empirical parameter used in the CC method of calculating $G_{I C}$ \\
\hline NDI & $\begin{array}{l}\text { Non-Destructive Inspection. Also called NDT (Testing) and NDE } \\
\text { (Evaluation). }\end{array}$ \\
\hline $\mathrm{NL}$ & $\begin{array}{l}\text { One of the three indications of initiation of crack growth. "NL" is the point in } \\
\text { the load-displacement curve where deviation from linearity occurs. This method } \\
\text { was preferred because it was more conservative than the 5\% offset and less } \\
\text { dependent on the operator than VIS. See also "VIS". }\end{array}$ \\
\hline $\mathrm{NRC}$ & National Research Council. \\
\hline$P$ & Load. \\
\hline PEEK & $\begin{array}{l}\text { Poly Ether Ether Ketone: a modern thermoplastic polymer used as a matrix in } \\
\text { polymer matrix composites. }\end{array}$ \\
\hline PEKK & Poly Ether Ketone Ketone: another modern thermoplastic polymer. \\
\hline PID & Proportional-Integral-Derivative. A type of feedback control. \\
\hline PNG & Portable Network Graphics. A lossless image compression format. \\
\hline PTFE & $\begin{array}{l}\text { PolyTetraFluoroEthylene. Also known by its trade name Teflon } \AA \text {, it is known } \\
\text { for its inertness, which prevents most adhesives from bonding to it. }\end{array}$ \\
\hline RAW & $\begin{array}{l}\text { A file format containing all the "raw" image data from a digital photographic } \\
\text { sensor. It requires subsequent processing and conversion before being usable by } \\
\text { other applicatıons. }\end{array}$ \\
\hline RGB & $\begin{array}{l}\text { Red Green Blue. Indicates the colour of a pixel by the levels }(0-255) \text { of each } \\
\text { colour that it contains. E.g. }(255,0,0) \text { is pure red, }(0,0,0) \text { pure black. }\end{array}$ \\
\hline SAR & Search And Rescue. \\
\hline $\mathrm{SCB}$ & $\begin{array}{l}\text { Single Cantilever Beam: Test specimen for sandwich structures. Also known as } \\
\text { Cracked Sandwich Beam (CSB) and is a special case of the Tilted Sandwich } \\
\text { Debond (TSD) test. }\end{array}$ \\
\hline$T_{g}$ & $\begin{array}{l}\text { Glass transition Temperature. The temperature at which a polymer transitions } \\
\text { from a glass-like solid state to a rubber-like state. }\end{array}$ \\
\hline TGAP & TriGlycidyl p-Amıno Phenol, an epoxy resin. \\
\hline TGDDM & TetraGlycidyl DiamınoDiphenylMethane, an epoxy resin. \\
\hline VBA & $\begin{array}{l}\text { Visual Basic for Applications. A scripting language made available in all } \\
\text { Microsoft Office applications to automate repetitive tasks and perform more } \\
\text { advanced mathematical work. Used here to automate the data reduction } \\
\text { procedure for DCB and SCB tests, to format all summary sheets identically and } \\
\text { automatically, to create curves in diffusion analysis based on Fick's laws and } \\
\text { many other tasks. }\end{array}$ \\
\hline VIS & $\begin{array}{l}\text { One of the three indications of initiation of crack growth. "VIS" is the visual } \\
\text { or visible onset of crack growth and is thus dependent on the consistency and } \\
\text { skill of the operator. }\end{array}$ \\
\hline
\end{tabular}




\section{Chapter I: Literature Review}

In this Chapter, an introduction to and motivation for the research topic will be presented. The key research in the areas of composite materials, polymers, bonding, fracture, and the effects of the service environment (specifically moisture and high temperature) will be reviewed, to provide the necessary background information for the subsequent Chapters.

\footnotetext{
Chapter 1' " Literature Review"

Chapter 2 Manufacturing of DCB and SCB Specinens

Chapter 3 Fnvironmental Conditioning and Diffusion Data Analysis

Chapter 4 The Effects of the Environment on the Fracture Toughness of Bonded Laminates

Chapter 5 Preliminary Study of the Iffects of the Environment on the

Chapter 6 Disbond Fracture Toughness of Sandwich Structures Appendix $A$ Overview of Contribution and Recommendations for Future Work Appendix B Summary Shects for DCB Specimens Summary Shects for SC B Specimens
} 


\section{I.I. INTRODUCTION -}

Design optimization in the aerospace industry has led to an increase in the proportion of composite structures used in aircraft designs (e.g. $50 \%$ by weight for the Boeing 787 Dreamliner [I]). As the industry turns toward the new possibilities offered by composite materials-materials comprising two distinct phases, most often a toughened polymer matrix reinforced with continuous fibres for most aerospace applications-a new set of challenges is presenting itself. Whereas metals have been the subject of intense study for centuries, polymers and modern composites have a much shorter history of engineering applications, which can be considered to start (for composites) around 1942, when the first fibreglass boat was built [2]. The practical experience gained from the extensive use of metallic materials illustrates and reminds engineers in all disciplines that great care should be taken in implementing new materials and manufacturing methods that are not well understood and whose behaviour is not completely predictable with current analysis techniques. Meanwhile, however, the ever-increasing pressure for more energyefficient aircraft is pushing manufacturers to make aggressive use of the latest materials available. Consequently, research efforts are currently focussing on improving the prediction of failure in composites, for example in collaborative work such as the World-Wide Failure Exercises [3-5]. Additionally, a particular behaviour of polymers that is the focus of a project at the National Research Council's Institute for Aerospace Research (NRC-IAR) is their potential to absorb moisture from humid air or from water, which has been shown to adversely affect the material's mechanical properties [6]. The objective of this thesis, which is supported by the NRC-IAR project, is to analyse the effects of this absorption on a polymer adhesive's 
fracture toughness. Throughout this analysis, certain environmental parameters will be varied, as shown in Table I.

Table I: Parameters of interest in terms of effects on absorption of water and on resulting fracture toughness of adhesive

\begin{tabular}{|l|l|}
\hline \multicolumn{1}{|c|}{ Parameter Description } & \multicolumn{1}{c|}{ Conditions to be Applied } \\
\hline Water Salinity & Salt water $(24.5 \mathrm{~g} \mathrm{NaCl}$ per liter), fresh water. \\
\hline Physical Form of Water & $\begin{array}{l}\text { High humidity air (not applicable to salt water), } \\
\text { Immersion in liquid fresh water or salt water. }\end{array}$ \\
\hline Exposure Temperature & High temperature $\left(82^{\circ} \mathrm{C}\right)$ and Intermediate $\left(70^{\circ} \mathrm{C}\right)$. \\
\hline Specimen Type & $\begin{array}{l}\text { Bonded carbon fibre laminates, sandwich (carbon } \\
\text { fibre laminate bonded to honeycomb core) }\end{array}$ \\
\hline
\end{tabular}

In this Chapter, a brief overview and justification of the proposed objective will be presented first. Next, specific discussions on relevant related topics will be presented, including details on similar studies performed for both non-aerospace and aerospace applications; bonding of composite materials; the fracture analysis of engineering materials; the effects of high temperature, of moisture, and of their combination on polymers and composites; the kinetics of moisture diffusion; and the differences observed between the effects of exposure to salt water and fresh water.

The subsequent Chapters will present the specimen geometries, materials, and manufacturing (Chapter 2); the environmental conditioning process and accompanying equipment and procedures (Chapter 3); the testing procedure for the measurement of fracture toughness and results for DCB specimens (Chapter 4), and for SCB specimens (Chapter 5); and a discussion of the contribution brought by this work, the future directions and final conclusions (Chapter 6). A summary of the 
process that specimens go through, and how it is presented in this work in shown in Figure I.

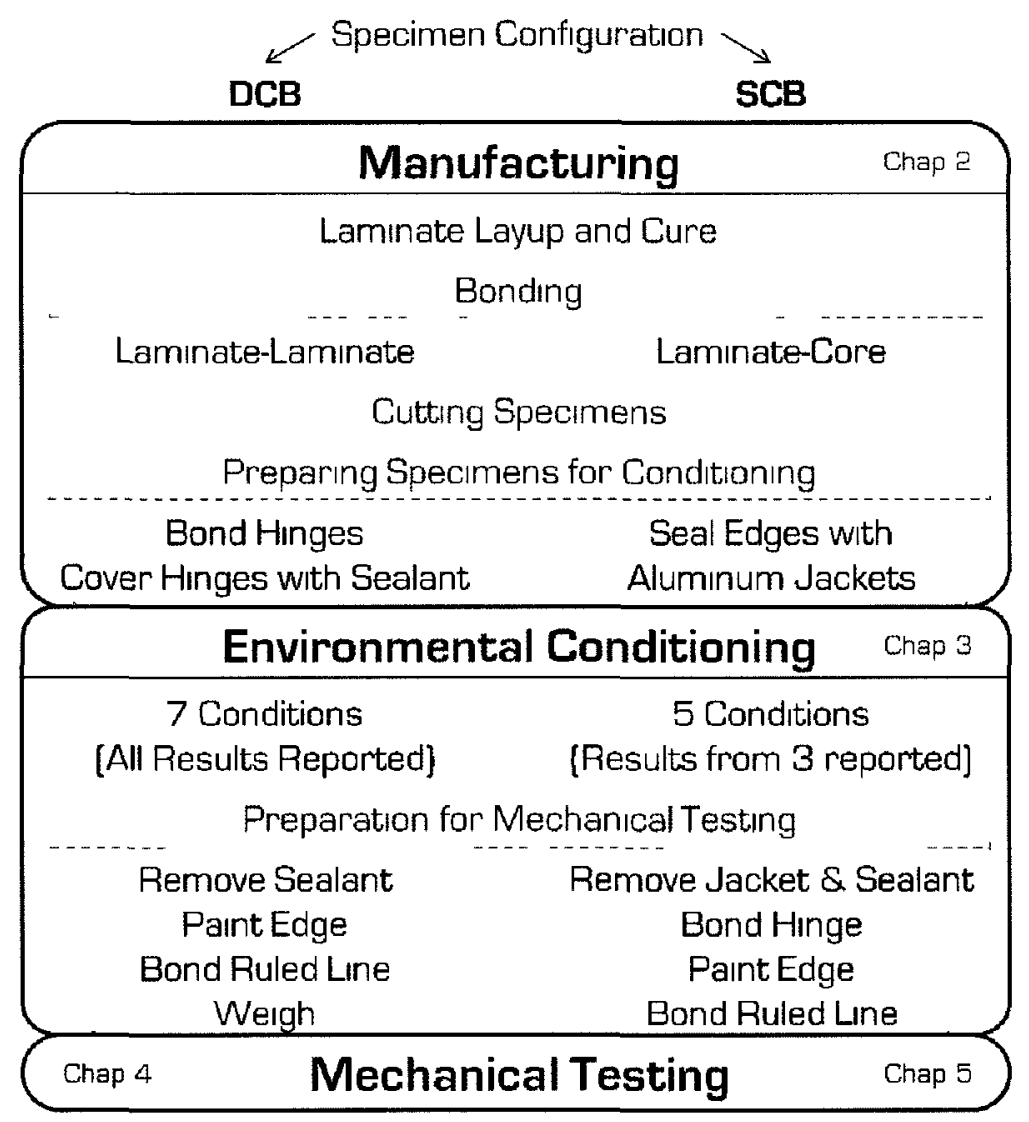

Figure I: Summary of specimen preparation procedure and outline of Chapters $I-5$.

\section{I.2. OVERVIEW OF AND MOTIVATION FOR SELECTED OBJECTIVE}

The reasons for studying the fracture toughness of an adhesive after exposing it to various environments may not be obviously important. This section will provide arguments for studying adhesives, then an explanation for the interest in exposing aerospace materials to salt water, and will briefly state the objective of the work presented here. 


\section{I.2.I. Importance of Adhesive Joints in Aerospace Structures}

The first point to rationalize is the interest of this study in adhesive joints. The reason for this interest is twofold: firstly, many practical aerospace composite structures require adhesives to be joined; and secondly, adhesives provide many advantages as a means of transferring stresses from one composite part to another.

An example illustrating structures that require adhesive joining is the sandwich structure, which is often used in structures that are subjected to bending and susceptible to buckling [7]. Like the I-beam introduced to many engineering students in solid mechanics, the principle of the sandwich structure is to contain highstrength and high-stiffness material far away from the neutral axis of bending; that is, where stresses are highest. Instead of using this material near the neutral axis, where the stresses induced by bending decrease as the distance from the neutral axis decreases, one can save weight by applying a lighter material which may have lower strength and stiffness. The increases in flexural rigidity (i.e., in bending) and strength resulting from increases in core thickness are depicted in Figure 2.

\begin{tabular}{|c|c|c|c|}
\hline & Solid Material & $\begin{array}{c}\text { Core Thickness } \\
\mathrm{t}\end{array}$ & 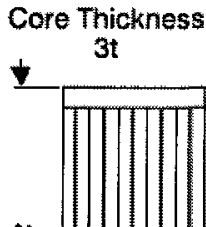 \\
\hline & 4 & $\frac{6}{4}$ & $\frac{71}{4}$ \\
\hline Stiffness & 1.0 & 7.0 & 37.0 \\
\hline $\begin{array}{l}\text { Flexural } \\
\text { Strength }\end{array}$ & 1.0 & 3.5 & 9.2 \\
\hline Weight & 1.0 & 1.03 & 1.06 \\
\hline
\end{tabular}

Figure 2: Illustration of improvements in strength and stiffness achieved by the introduction of a core material between laminates [8]. 
To transfer the stress from one material to the other, adhesive bonding is required. Figure 3 shows an example sandwich structure and its constituent materials.

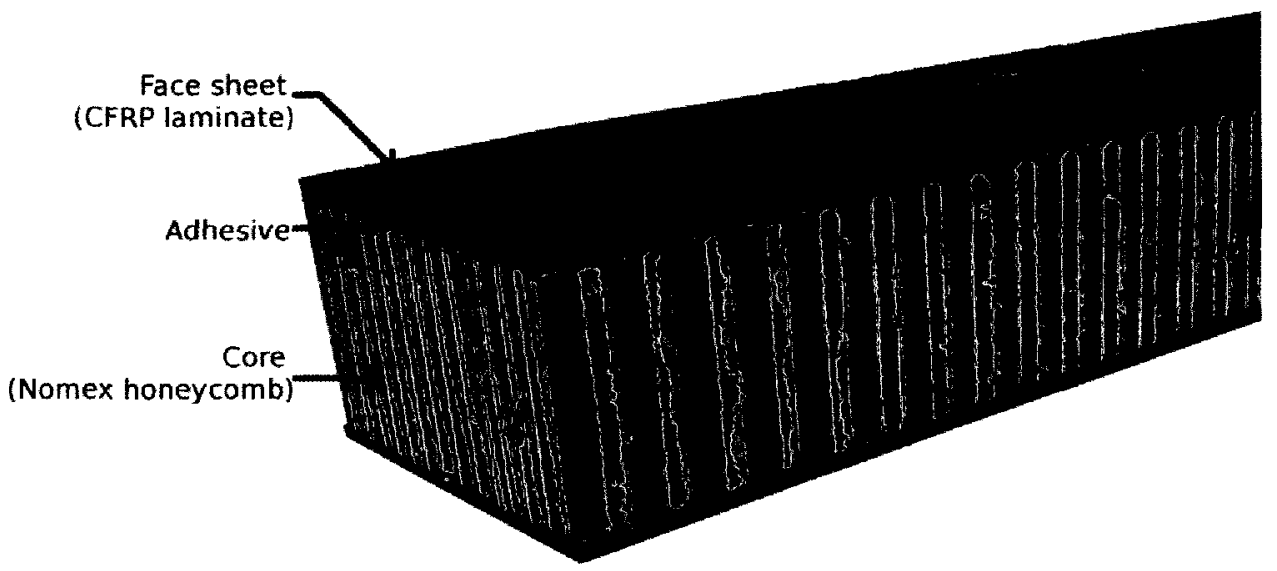

Figure 3: Example of a sandwich structure with carbon fibre-reinforced epoxy face sheets, adhesive and Nomex honeycomb core.

Examples of materials used in such structures are foam, balsa wood and honeycomb for the core (i.e. the volume surrounding the neutral axis, analogous to the web of the I-beam) and carbon fibre- or glass fibre-reinforced polymer laminates or aluminum sheets as the face sheets (flanges of the I-beam). The adhesive bonding may be provided by a separate adhesive system, typically in partially-cured sheet form, but recent work has focused on using resin-rich pre-pregs (pre-impregnated fibres) and allowing the excess resin to flow and form a bond with the core during cure [9]. In the present work, however, a separate adhesive layer is used.

The adhesive joint is also the preferred configuration for joining thin composite laminates. The well-established joint concepts for metal parts-the bolted joint, the rivet and the weld are likely the most familiar-have been thoroughly studied and are well standardized [I0], but they are not well suited for composite structures. For example, the need to insert holes to create riveted or bolted joints means that the 
continuous fibres that provide the best properties in laminated structures must be broken. One would therefore be causing a stress concentration (hole) in the precise area where fibres no longer provided as much support. Some techniques allow the fibres to be laid around such holes during manufacturing, but this remains a complex practice and might not always be feasible. Welding is being investigated for polymers but can only be applied to parts containing thermoplastic polymers, since thermosets cannot be melted and re-solidified [7]. By contrast, the application of adhesive to the surface of a composite laminate does not seriously affect the strength of the laminate, and a properly-designed joint can often be stronger than the joined substrates (this depends on the loading condition and materials involved)[7]. The situations in which joints usually fail most easily are under crack-opening (mode I) loads as shown in Figure 4. Furthermore, a known weakness of adhesive joints is the hot/wet environment (further described in Section I.6.3), which has been shown to affect the interface between the adhesive and substrate (references and more information in Sections I.4 and I.6). Hence, while the adhesive joint is at times the best method for joining composite parts, it does present at least this weakness, which is what the current study focused on. 

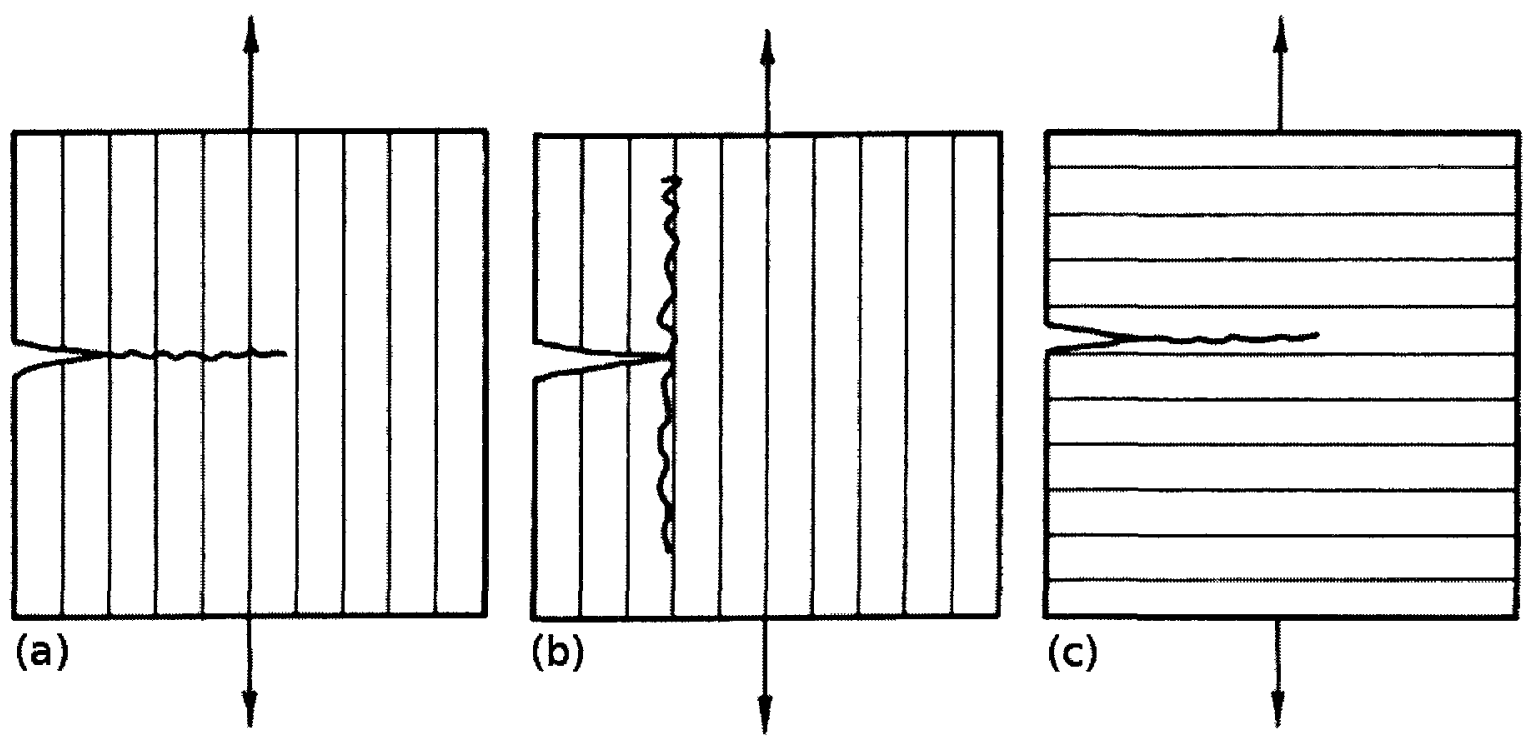

Figure 4: Different crack propagations are possible under loading in the crack-opening mode (mode I). Modified from [7].

The next point to be explained is the reason for studying the effects of salt water exposure on an aerospace composite material.

\subsubsection{Effect of Salt Water in Aerospace Applications}

There is little published research on the effect of salt water in materials and under loading conditions typically seen in aerospace structures. Researchers have typically focused on two other combinations, namely: the effect of humid air and high temperatures—the so-called "hot/wet" environment—on aerospace composite materials $[6, \mathrm{II}]$; and the effect of salt water immersion on marine composite materials [I2-I3]. Few studies have considered the case of the exposure to salt water of aerospace composite structures. Some previous work examined aerospace-type materials, namely carbon fibre/epoxy composites, under salt water exposure, but not under aerospace-type environments [I4-16]. The lack of data on the effect of salt water on aerospace composites is likely due to the rarity of aerospace applications that are consistently exposed to such an environment in service. Notable exceptions 
include military aircraft operating at low altitude in coastal regions (e.g. antisubmarine warfare and maritime patrol aircraft) and those operating from aircraft carriers (fighters, helicopters and others). Helicopters performing maritime Search and Rescue (SAR) operations or transporting workers to and from offshore oil platforms are also examples of aircraft subjected to such conditions. In Canada, an aircraft of particular interest in terms of this research topic is the Canadian Forces CH-I49 Cormorant SAR helicopter, which is modified from the Agusta-Westland EH-IOI medium-lift military transport helicopter to meet the requirements of Canadian Search and Rescue operations [17]. It has modern rotor blades that reduce vibrations, improve top speed and increase lift [I7]. It is claimed by the manufacturer to be capable of operations in conditions ranging from tropical (hot/wet) to arctic [18].

How the "hot/wet" environment compares to a salt water environment is not clear. "Hot/wet" refers to the high temperature and humidity atmospheric conditions in which aircraft are flown (e.g. $30^{\circ} \mathrm{C}$ and $80 \%$ relative humidity is considered hot/wet for aerospace composites [I9]). In the laboratory, extreme conditions (as high as $82^{\circ} \mathrm{C}$ and $95 \%$ humidity) are used to accelerate the process of diffusion while avoiding the introduction of unrealistic chemical changes (discussed in Section I.6 and Chapter 3). How materials that are most commonly used in the aerospace industry respond to this environment is well studied $[6,20-23]$ and discussed in more detail in Section I.6.2.

By contrast, the effects of salt water have not been as well characterized. Marine vessel designers have used composite materials since just after the Second World War and real-world evidence from those applications suggests a high level of material property stability over time [24]. However, marine and aerospace applications differ 
greatly, as will be discussed in Section I.3. The study proposed herein will address this lack of knowledge by applying salt water conditioning to aerospace materials and analyzing its effects on their fracture behaviour, as outlined in more detail in the next Section.

\subsubsection{Purpose of This Study}

The study presented here assesses the degradation of mode I fracture toughness of a typical modern aerospace epoxy adhesive after it is subjected to simulated environmental conditions-high temperatures combined with high humidity or liquid water. A comparison between the behaviour of specimens subjected to salt water with those exposed to freshwater will provide a means of assessing the contribution of salt to the degradation of the selected structural adhesive. The adhesive will be tested in two configurations: a simple joint between composite laminate adherends, and a sandwich structure with composite face sheets and Nomex honeycomb core.

The specimens are described in more detail in Chapter 2, and the selected environmental conditions in Chapter 3. The test method is described in Chapters 4 (for bonded laminates) and 5 (for sandwich specimens).

\subsection{APPLICATIONS OF COMPOSITES}

The referenced studies cover a number of combinations of materials, environments and load scenarios. In this Section, arguments will be presented to explain why existing information on the response of composites for marine applications to salt water is not sufficient to predict the response of aerospace 
materials (carbon fibre/epoxy) to salt water. The differences in design philosophies, materials and manufacturing methods between these applications will be explored.

\subsection{Design Philosophies}

In the aerospace industry, designers attempt to reduce weight as much as possible to derive a number of benefits. For example, it has been estimated that the value of reducing the weight of a military helicopter by I $\mathrm{kg}$ is US\$400, accounting for procurement and through-life support costs (estimates from the late I980's) [7]. This provides motivation for designers to consider more expensive and complex materials in order to save weight. Additionally, the civil aerospace industry designs structural components to a safety factor of I.5 [25]; this allows designs to be lighter, but also requires that the designers' understanding of the aircraft structural response to loads be thorough. For instance, the application of relatively complex fatigue loading spectra, such as the Fighter Aircraft Loading Standard for Fatigue Evaluation (Falstaff), is quite specific to aerospace applications [26].

By contrast, in marine applications higher weight is less of a hindrance to the success of a design. Indeed, safety factors of 4-6 are not uncommon for composite ships due to the complexity and novelty of the materials and designs [24]. For these applications, cost is a greater driver than weight, and this means that less expensive and simpler materials and manufacturing methods are often employed. It is likely that as costs reduce and predictability of material performance - and thus, safetyimprove, high-performance composites will gain favour outside the aerospace industry. For example, recent studies in civil engineering, which is similarly more concerned with cost rather than weight, have considered applying carbon fibrereinforced polymers to reinforce bridge columns and other concrete structures and 
how they react to freeze-thaw cycles $[28-30]$ and naval designers have considered the same materials for deep-sea exploration vehicles [24]. In terms of fatigue loading, marine applications also have standard spectra, such as the Wave Action Standard History (WASH), which are not suitable for aerospace uses [27].

Although fatigue loading is not being considered in this study, here it serves to illustrate the differences in the focus of studies undertaken from different points of view. More specific differences between the aerospace and marine industries' use of composites, namely the choice of material and manufacturing methods, will be explained in the next Sections.

\subsubsection{Material Selection}

Aerospace structures typically make use of thermoset resins, most commonly epoxy, reinforced with strong fibres such as S2-grade glass, carbon or graphite [7]. For optimum control of the ratio of matrix and fibre (50-70\% fibre by volume is the goal), partially-cured sheets of pre-impregnated carbon fibres (pre-pregs) are often used, in spite of certain limitations that they present [7-3I]. For instance, all uncured and partially-cured single part thermoset resins, have a finite shelf-life and must be kept in freezers. Thermosets have advantages in other respects, however, such as the very low resin viscosity achieved during cure, which helps wetting of the fibres [7]. Pre-pregs are also tacky, which helps to keep plies together during lamination and before curing. Thermoplastics, on the other hand, are far more viscous when melted and can be challenging to handle [7]. Nevertheless, thermoplastics that rival thermosets in terms of service temperature and chemical resistance, polyether ether keytone (PEEK) and polyether keytone keytone (PEKK), are being used [7]. Common core materials for aerospace structures are aluminum and Nomex 
honeycomb [7]. They are usually bonded to face sheets using toughened and moisture-resistant adhesives [7].

In marine applications, woven glass fabrics and chopped glass fibres reinforcing polyester or vinylester matrices are more common [32]. Fibre content is typically much lower than for aerospace materials at $20-40 \%$ by volume [32]. Cores of balsa wood and polyvinyl chloride (PVC) foam are common in marine applications, though racing yachts also make use of more expensive honeycomb cores [32].

Differences in materials mean that the mechanisms of bonding between fibre and matrix (within laminates), and between matrix and adhesive (between bonded laminates) can differ. This will be explored further in Section I.4, dedicated specifically to bonding, but serves here as an argument against the direct application of knowledge gained from marine applications to aerospace materials.

\subsubsection{Manufacturing Methods}

In the aerospace industry, pre-pregs are often laminated by hand and cured at high pressure and temperature in an autoclave, with high labour and energy costs [7]. This process ensures that a low void content and high fibre volume fraction are achieved in order to optimize the strength-to-weight ratio [7]. Other continuousfibre processes such as filament winding, braiding, tow/fibre placement and pultrusion are also used [7].

Marine manufacturing methods include manual wet lay-up and spray-up, which are well suited to woven and chopped glass fibres, and allow large areas to be covered more quickly [32]. Curing in an autoclave is uncommon; room-temperature or oven 
cures are lower in cost and produce higher void contents but are nonetheless used extensively in marine composite manufacturing [32].

Figure 5 produced by the U.S. Navy summarizes the differences between naval and aerospace materials and manufacturing methods, and the quality of the resulting parts.

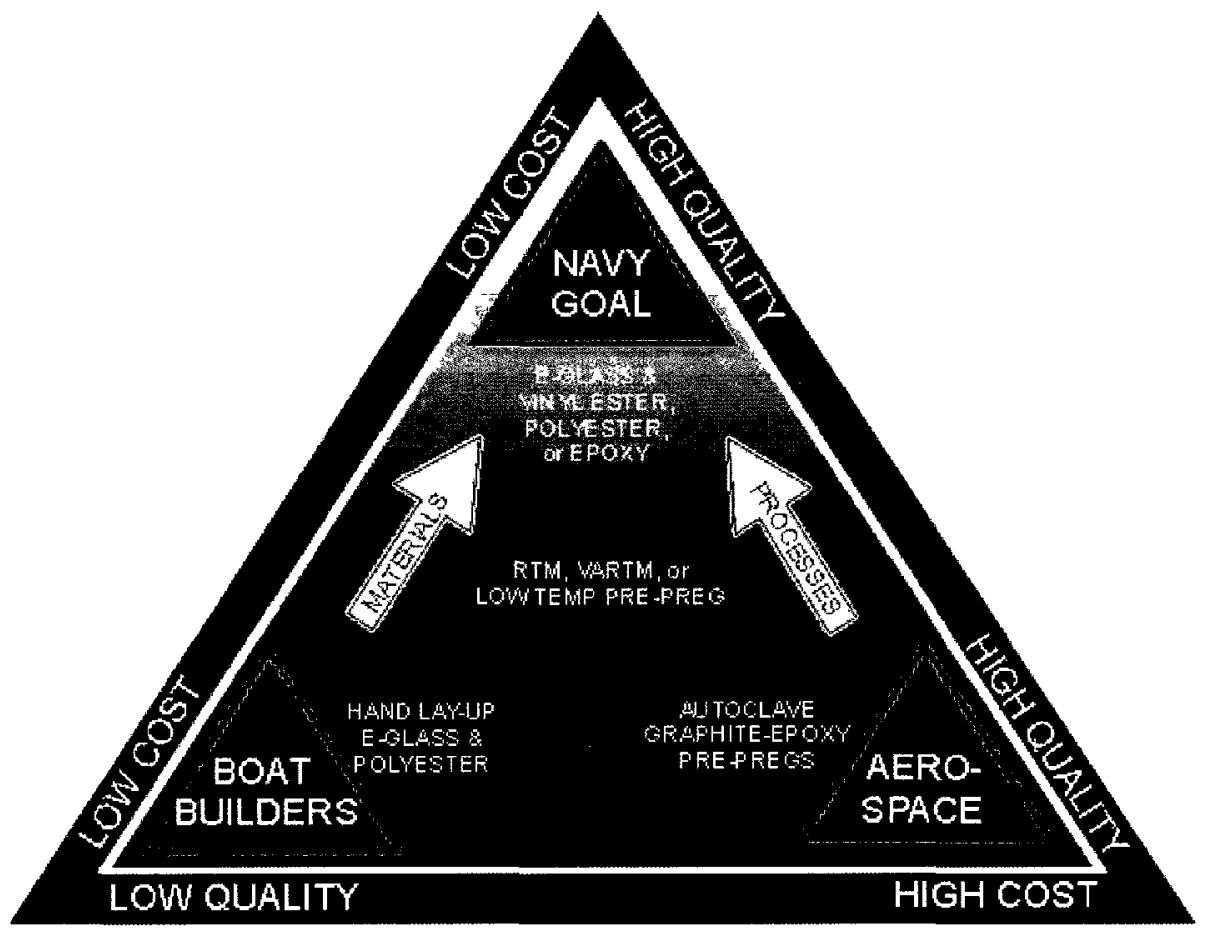

Figure 5: Schematic comparison of naval versus aerospace composite materials and manufacturing methods [33].

Because the manufacturing methods used in the marine and aerospace industries differ, the resulting parts have very different fibre volume and void volume fractions. Since matrix-dominated properties and fibre-matrix interfaces are most affected by moisture ingress (as discussed in Section I.6), the differences in materials and manufacturing methods make the direct application of results from tests on marine composites to aerospace composites difficult. 


\subsubsection{Applicability to Thesis Research}

While the differences between composite materials and manufacturing methods used by the marine and aerospace industries is illustrative of the need for more specific research in each field, the present study will focus on the durability of adhesive bonds between laminates of carbon fibre/epoxy. The diffusion of water in different matrix materials and its effects on different fibres and matrix-fibre interfaces varies, but these effects are unlikely to be probed by the fracture mechanics test that will be used here. That is, many studies of the interlaminar fracture of aerospace and marine composites are available, but not directly applicable to this research on bonded joints. As such, the next Section will focus on adhesive bonding and part of Section I.6 will focus on how the environment can affect their durability.

\section{I.4. BONDING}

The specimens to be studied here are bonded laminates of carbon fibre/epoxy. Exposure to moisture and subsequent mechanical testing will be revealing moisture and temperature effects on the laminates, the adhesive, and the interfaces between them, so that a discussion of bonding is necessary before covering fracture and moisture degradation, in Sections I.5 and I.6.

\section{I.4.I. Applications of Adhesive Joints in the Aerospace Industry}

For over 60 years, the aerospace industry has used adhesive bonding in primary aircraft structures, typically in place of rivetıng, on certain joints [34]. Indeed, many metallic aircraft have made use of adhesive bonding throughout history, from the DeHavilland Dove (first flown in 1945) to the Fokker I00 regional jet (I995) [34]. The main uses for adhesives are the bonding of stringers to fuselage and wing skins 
and the manufacturing of lightweight flight control surfaces out of honeycomb sandwich structures [34]. Many of these applications involved metallic structures, but the increased proportion of composites in aircraft will likely lead to an increase in adhesively-bonded joints, since these are much more compatible with fibrereinforced polymers than bolted or riveted joints [7].

The advantages of bonded joints, compared with mechanical ones, include: (i) the possibility of joining dissimilar materials without galvanic corrosion; (ii) reducing stress concentrations; (iii) the weight tends to be lower; and (iv) the joint is less sensitive to fatigue; among others $[7,35]$.

The disadvantages of bonded joints, again compared with traditional mechanical joints, include: (i) the joint cannot be disassembled; (ii) bonding requires a high level of quality control; (iii) they are prone to environmental degradation from absorbed moisture; and (iv) their service temperature is limited by the glass transition temperature of the adhesive; among others $[7,35]$.

In addition to the disadvantages noted above, the difficulty in predicting joint failure has been a major hurdle in the wider adoption of adhesive bonding in the aerospace industry, though new numerical methods are promising in this regard [36]. Certification is also challenging; FAA Advisory Circular AC20-107B provides guidance on the certification of composites and bonded joints and notes a few of the difficulties involved [37]. Paragraph 6.c and 8.a(I)(a) emphasise (i) the importance of controlling the entire bonding process, as explained in more detail in the subsections that follow; (ii) the current inability to reliably detect "weak bonds", i.e. joints that appear normal but where a strong chemical bond was not formed; (iii) the current limitations of NDI techniques that cannot be used to qualify bond quality 
and, perhaps the most challenging; (iv) the lack of industry standards for testing, forcing the applicant to take responsibility for the development of suitable tests before applying it to materials and structures [37].

Despite these challenges, adhesive joints in primary structures are still of interest (recall Section I.2.I on the importance of adhesives in aerospace) and the next Section will present the types of adhesive that are commonly used.

\subsubsection{Adhesives}

Modern adhesive bonding involves the use of polymers of many different types, which are cured between the parts to be bonded (typically called "substrates" or "adherends") [35]. Table 2 is a summary of the different polymers used and their applications.

Table 2: Summary of polymers used as adhesives and their applications [36].

\begin{tabular}{|l|l|}
\hline \multicolumn{1}{|c|}{ Polymer Class } & \multicolumn{1}{c|}{ Applications as Adhesives } \\
\hline Epoxies & High strength, high temperature applications \\
\hline Cyanoacrylates & Fast bonding to wide variety of materials \\
\hline Acrylics & Fast curing of less-prepared surfaces \\
\hline Polyurethanes & Flexible at low temperatures and fatigue resistant \\
\hline Silicones & $\begin{array}{l}\text { Flexible and effective sealant in low-stress applications } \\
\text { and at high temperatures }\end{array}$ \\
\hline $\begin{array}{l}\text { Phenolics, polyimides, } \\
\text { bismaleimides }\end{array}$ & $\begin{array}{l}\text { High temperature adhesives (typically higher than } \\
\text { epoxy) }\end{array}$ \\
\hline
\end{tabular}

The adhesive used in this study is a modern aerospace-grade toughened epoxy film. Epoxies are the oldest and most common form of synthetic adhesive and can be used with metal, glass, polymer and ceramic substrates [35]. They are available in one- and two-part liquid formulations ("paste"); the epoxy resin and hardener are separate in the latter [35]. In their film form, they are partially cured and stored at low temperatures (e.g., $-25^{\circ} \mathrm{C}$ at NRC) until ready to use; their shelf-life is thus 
limited because the cure reaction continues even at low temperature, albeit more slowly than at higher temperatures [35]. Epoxies include several types of resin and are cured using a number of hardeners to cross-link the chains. Figure 6 shows the chemical structure of three different epoxy resins.

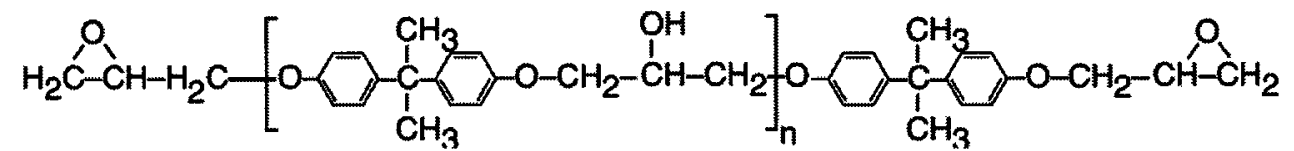

Diglycidyl Ether of Bisphenol-A (DGEBA)
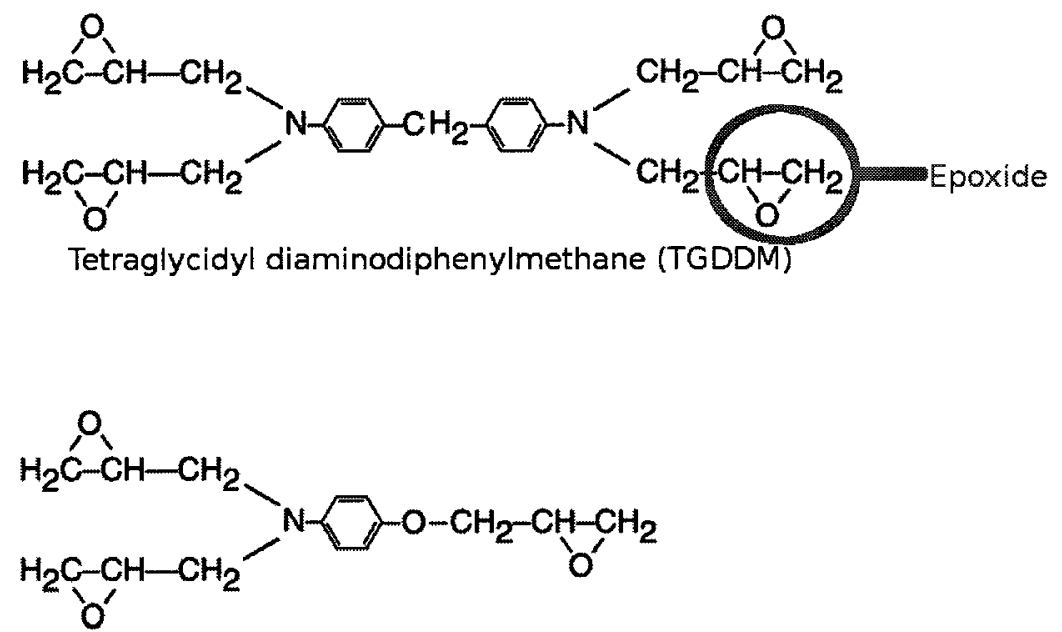

Triglycidyl derivative of $\mathrm{p}$-aminophenol (TGAP)

Figure 6: Chemical structure of DGEBA, TGDDM and TGAP epoxy resins. One epoxide group is highlighted. Modified from [7].

A number of hardeners can easily open the ring of the epoxide group due to the unfavourable angles of those bonds [7]. An example reaction is shown in Figure 7. The hardeners most used in aerospace applications are aromatic amines [7], which typically contain two $\mathrm{NH}_{2}$ groups, each capable of reacting with different epoxide groups, thus "cross-linking" two epoxy chains. 


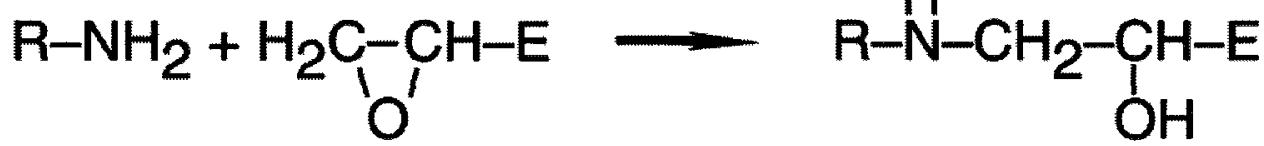

Figure 7: Example reaction between an amine hardener and epoxide group. $\mathrm{R}$ is a general amine backbone and E a general epoxy backbone [7].

The variety of resins and hardeners make epoxies a family of adhesives with wide-ranging properties [35]. Modern epoxy adhesives and composite matrices often combine different resins and hardeners, as well as thermoplastic particles, to optimize the combination of strength, toughness and moisture resistance as evidenced by the complex composition of AFI63-2 (latest MSDS with partial ingredient list available from 3M) and CYCOM 5276-I (see examples in [38]).

\section{I.4.3. The Nature of Adhesive Bonds}

The mechanisms that explain bonding are chemical, physical, diffusional/interdiffusional and mechanical in nature [35]. Figure 8 shows schematic representations of these bonding types, which are described in more detail in the subsections that follow.

\subsubsection{Chemical Bonding}

Chemical bonding refers to covalent, ionic and metallic bonds that are created between the adhesive and the substrate [35]. For this to occur, compatible chemical groups must be present between the adhesive and the adherend surface; these may be created by surface preparation techniques. For instance, coupling agents are used to improve the adherence of glass fibres to polymer matrices in glass fibre reinforced composites [35]. Chemical bonds require the most energy to break [35]. 
(a)

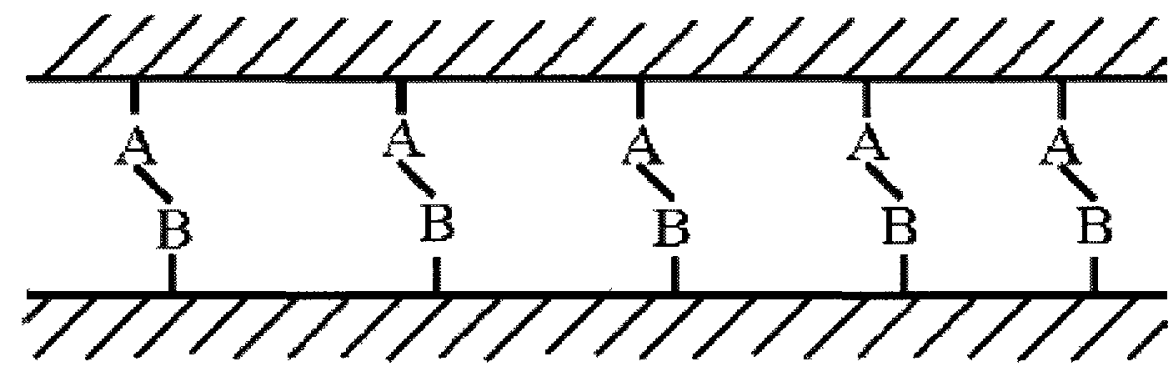

(b)

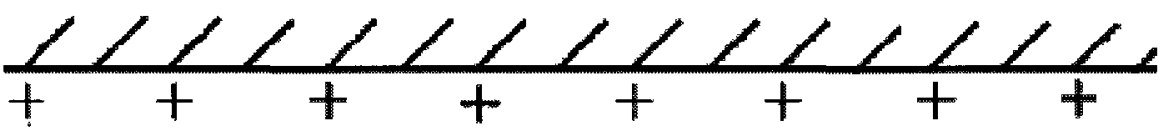

(c)
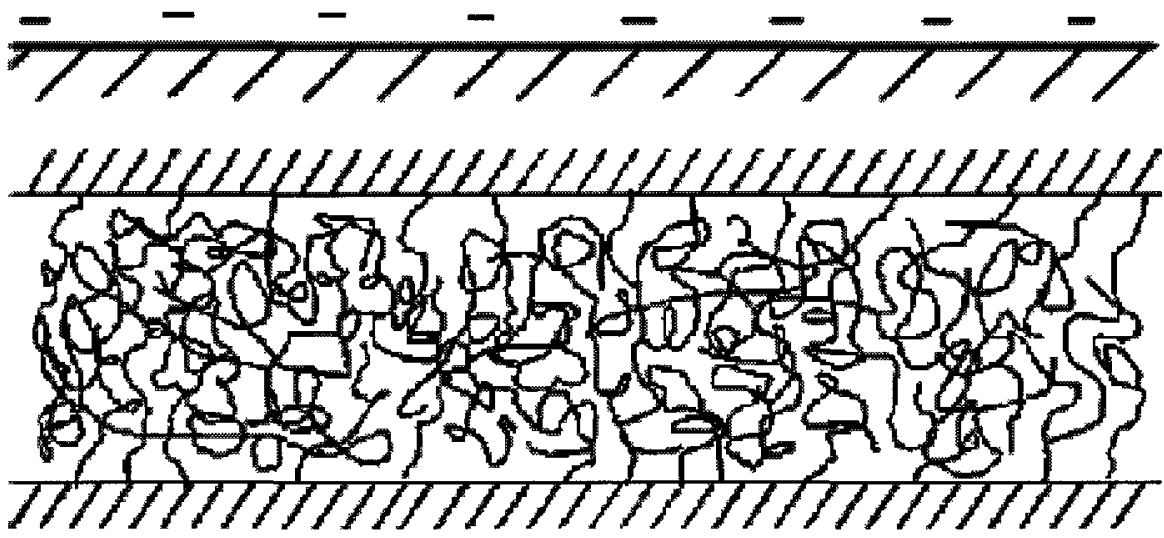

(d)

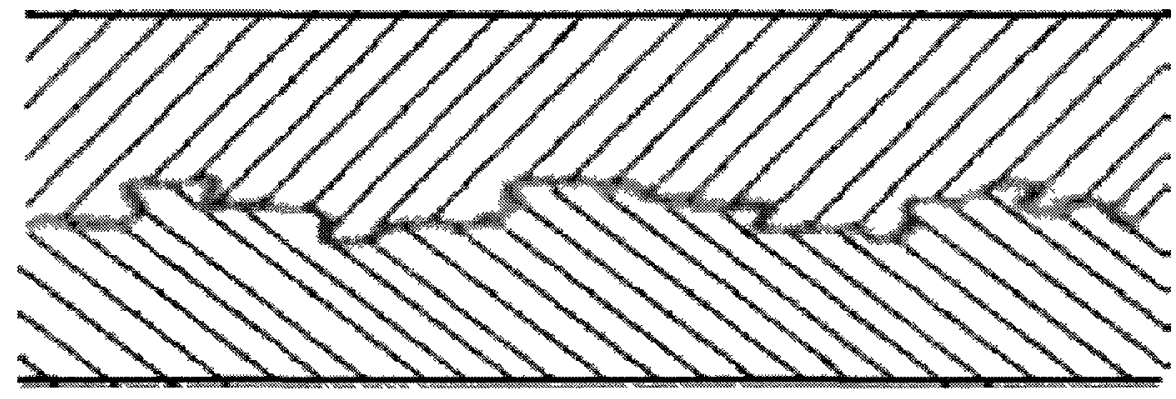

Figure 8: Schematic representations of (a) Chemical bonding; (b)

Physical bonding; (c) Interdiffusional bonding; and (d) Mechanical bonding (modified from [35])

\section{I.4.3.2. Physical Bonding}

This term encompasses a number of secondary (non-covalent) interactions at the molecular level such as van der Waals forces (relatively weak bonds between polar 
molecules) and hydrogen bonding (stronger bond between hydrogen in one molecule and an electronegative atom in another) [35]. These are the types of bonds that act between polymer chains, in addition to mechanical entanglement of the chains, while covalent bonding occurs between the atoms within a chain [35].

\subsubsection{Diffusional Bonding}

Diffusional bonding occurs when the adhesive contains a solvent of the adherend [35]. It requires that molecules pass across the interface and create a region with a different set of properties, where molecules from both materials are present. This can be promoted by the presence of solvents in the region and will depend on the ease of molecular motion and the nature and conformation of the chemical groups involved [35].

\subsubsection{Mechanical Bonding}

Mechanical bonding refers to the resistance to separation that is caused by the liquid adhesive conforming to the rough surface of the adherend [35]. It is generally a low-strength bond that can nevertheless contribute to improving the shear properties of a joint [35].

Though bonds may draw their strength from a combination of the above mechanisms, the best properties are achieved when a high degree of chemical bonding occurs, due to the high level of energy required to break them. To produce chemical bonds, surface preparation is often required, as described in the next Section. 


\section{I.4.4. Surface Preparation Procedures for Thermosetting Polymers}

Before discussing the pre-bonding procedure, some theoretical aspects of bonding that explain certain steps in the procedure will be discussed.

\section{I.4.4.I. Surface Tension and Wetting}

In order for a strong bond to form, it is required that the surface be wetted by the adhesive; that is, the liquid adhesive must completely cover and be in intimate contact with the surface prior to hardening [35]. The main obstacle to wetting is surface tension, which may cause a liquid to form beads on the adherend surface in order to minimize the tension of its surface exposed to air, rather than spread over the adherend [35]. The origin of surface tension is the unbalanced forces that act upon the atoms at the surface of a part [35]. Theoretically, the surface tension of the adhesive must be lower than that of the adherend to ensure complete wetting; therefore, means of increasing the surface tension of the adherend or decreasing that of the adhesive are advantageous [35].

\subsubsection{Pre-bond Moisture}

Moisture in a polymeric substrate prior to bonding has been found to cause voids in the adhesive layer due to evaporation of the water at high cure temperatures [36]. Even storing cured and dried panels in a sealed bag in a freezer was found to result in such voids, which was attributed to absorption that occurred during storage [36]. Prior drying of the adherend is therefore a crucial part of the bonding process $[36]$. 


\section{I.4.4.3. Surface Chemistry}

Various aspects of surface chemistry can play an important role in the durability of bonds. Firstly, a surface free from contaminants is crucial, as adhesives may not displace or dissolve contaminants to reach and bond to the adherend surface [35]. Some contaminants may in fact be transferred by the very materials meant to protect and prepare them. Much has been said of the contamination caused by release agents applied to nylon peel-plies, which are designed to be bonded to the surface of panels during their cure and then removed prior to secondary bonding to reveal a fresh, roughened surface [39]. Additionally, a chemically reactive surface is important for creating chemical bonds, as discussed in Section I.4.3; however, thermosetting-polymer-matrix composites bonded with thermosetting adhesives often do not require a specific procedure for modification of surface chemistry whereas metals and thermoplastics typically do [40]. Since this work focused on thermosetting polymers, surface chemistry modification will not be discussed in detail.

\subsubsection{Typical Pre-Bonding Procedure}

To ensure the durability of the bonded joint, a typical procedure includes three major steps: (I) cleaning/degreasing, (2) drying, (3) exposing a chemically active surface $[35-36,39-40]$. A joint that is strong in the short-term is easily achieved without performing all these steps, but long term joint durability is inevitably adversely affected [39-40].

The cleaning or degreasing step involves the removal of contamination deposited on the surface from the air, operators' hands, and other sources. They must 
be removed by using a solvent such as methyl ethyl ketone (MEK), acetone and ethylacetate [35].

Once the surface is cleaned, it may be dried by putting the parts in an oven for a few hours.

The clean and dry surface must then be abraded by sanding or, preferably, by grit-blasting. The former can more readily cause a microscopically folded surface where air, moisture and contaminants can be trapped in the folds and later cause voids [40]. Overly-aggressive grit-blasting can also create a folded surface, but minimal operator training and specific instructions regarding pressure and pass rate of the grit-blasting process reduce the risk of this occurrence [35].

This surface preparation procedure is followed by the actual application of the adhesive, which varies with the type (two-part paste, three-part paste, film) and class (epoxy, phenolic) of adhesive. In this work, an epoxy film adhesive was used and the specific procedure for its application is discussed in Chapter 2 on specimen manufacturing.

The next Section will outline the energy methods used to assess the fracture toughness or strain energy release rate of materials. This will provide the background information on the mechanical tests performed in this study.

\section{I.5. FRACTURE INPOLYMERS}

Fracture in metals has been the subject of much study since Griffith's initial work on the effects of surface treatments (e.g. polishing) on the strength of machined parts [4I]. However, fracture mechanics in polymers and to an even greater 
extent, in polymeric composites, is arguably more complex. A summary of the discussion provided in $[42]$ will be presented in this Section.

The method consists of accounting for energy that is input $\left(\delta U_{I}\right)$, dissipated $\left(\delta U_{2}\right)$, stored $\left(\delta U_{3}\right)$ or turned into kinetic energy $\left(\delta U_{4}\right)$ in a given system. Energy is generally input by mechanically loading a specimen. Dissipated energy describes the heat generated in a polymer due to plastic flow. Stored energy might be elastic or thermal. Kinetic energy would be of more importance in a fatigue study and will usually be considered null in the present (quasi-static) case. Given the above nomenclature, the equation for conservation of energy in an isothermal system would be [42]:

$$
\delta U_{1}-\delta U_{2}=\delta U_{3}+\delta U_{4}
$$

Or, if we consider increments in a given direction:

$$
\frac{\delta U_{1}}{\delta u}-\frac{\delta U_{2}}{\delta u}=\frac{\delta U_{3}}{\delta u}+\frac{\delta U_{4}}{\delta u}
$$

where $\delta u$ is the displacement. Now, considering the energy balance of a system in which a crack has increased in area by $d A$, we would start from [42]:

$$
\frac{d U_{1}}{d A}-\frac{d U_{2}}{d A}=\frac{d U_{3}}{d A}+\frac{d U_{4}}{d A}
$$

We could further define the energy dissipated by the extension of the crack as fracture resistance $R$, or [42]: 


$$
R=\frac{d U_{2}}{d A}
$$

The change in energy in the system due to fracture growth is further defined as $G$, or $[42]$ :

$$
G=\frac{d U_{1}}{d A}-\frac{d U_{3}}{d A}
$$

Which leads us to define fracture criteria based on [42]:

$$
G=\frac{d U_{1}}{d A}-\frac{d U_{3}}{d A}=R+\frac{d U_{4}}{d A}
$$

Before the onset of fracture, there is no notable motion in the system due to crack growth, so that $d U_{4} / d A=0$. The criterion for fracture to take place is thus [42]:

$$
G \geq R
$$

The behaviour after initiation of fracture will depend on the relationship between $G$ and $R$ at $A+d A$. This is defined as fracture stability, for which the criterion can be expressed as [42]:

$$
G+\frac{\delta G}{\delta A} \cdot \delta A \geq R+\frac{\delta R}{\delta A} \cdot \delta A
$$

Once the crack has initiated and continues to propagate, we can start to consider $U_{4}$ in the analysis, so that the criterion for fracture becomes [42]:

$$
G \geq R+\frac{d U_{4}}{d A}
$$

If $G=R$ at fracture, then the condition for crack instability given in equation (8) becomes [42]: 


$$
\frac{d G}{d A}=\frac{d R}{d A}
$$

Now that some theoretical relationships between various forms of energy and material properties have been presented, it is of interest to discuss how $G$ can be determined experimentally. Starting from the definition of $G$ given in Equation (5), we can consider the energy input when a force $P$ is applied to a boundary $S$ which is thus displaced by $d u$ due to the change in fracture area. The applied work would be [42]:

$$
\frac{d U_{1}}{d A}=P \frac{d u}{d A}
$$

The stored elastic energy due to the displacement up until the point of fracture would be [42]:

$$
U_{3}=\int_{0}^{u} \int_{0}^{u} P d u^{\prime \prime}
$$

The energy dissipation is assumed to be separate from the above and accounted for in $R$. Recalling Equation (6), we find that [42]:

$$
G=P \frac{d u}{d A}-\frac{d}{d A} \int_{0}^{u} \int_{0}^{u} P d u^{\prime \prime}
$$

Or, by observing that $P=\frac{\partial U_{3}}{\partial u}$ and that we can rewrite $\frac{d U_{3}}{d A}$ :

$$
\frac{d U_{3}}{d A}=\frac{\partial U_{3}}{\partial A}+\frac{\partial U_{3}}{\partial P} \frac{d P}{d A}+\frac{\partial U_{3}}{\partial u} \frac{d u}{d A}
$$

we can simplify Equation (I3) to [42]: 


$$
G=-\left[\frac{\partial U_{3}}{\partial A}+\frac{\partial U_{3}}{\partial P} \frac{d P}{d A}\right]=-\left[\frac{d U_{3}}{d A}\right]_{u=\text { const. }}=-\left[\frac{d}{d A} \int_{0}^{u} P d u^{\prime}\right]_{u=\text { const }}
$$

We therefore need only to determine $U_{3}$ (stored energy) in order to determine $G$. In general, this is done by first assuming that crack propagation is self-similar, that is, that $d A=B d a$, where $\mathrm{B}$ is specimen width and $a$ is crack length (e.g. a straightfronted through-crack remains a straight-fronted through crack after incremental crack extension $d a$ ). The resulting problem then becomes 2-dimensional and solvable by $[42]$ :

$$
G=\frac{1}{B}\left[P \frac{d u}{d a}-\frac{d}{d a} \int_{0}^{u} P d u^{\prime}\right]=-\frac{1}{B}\left[\frac{d U_{3}}{d a}\right]_{u=\text { const }}
$$

A simplifying case exists for linearly elastic materials, in which the relationship between displacement, applied load and energy is simple, as shown in Figure 9. 


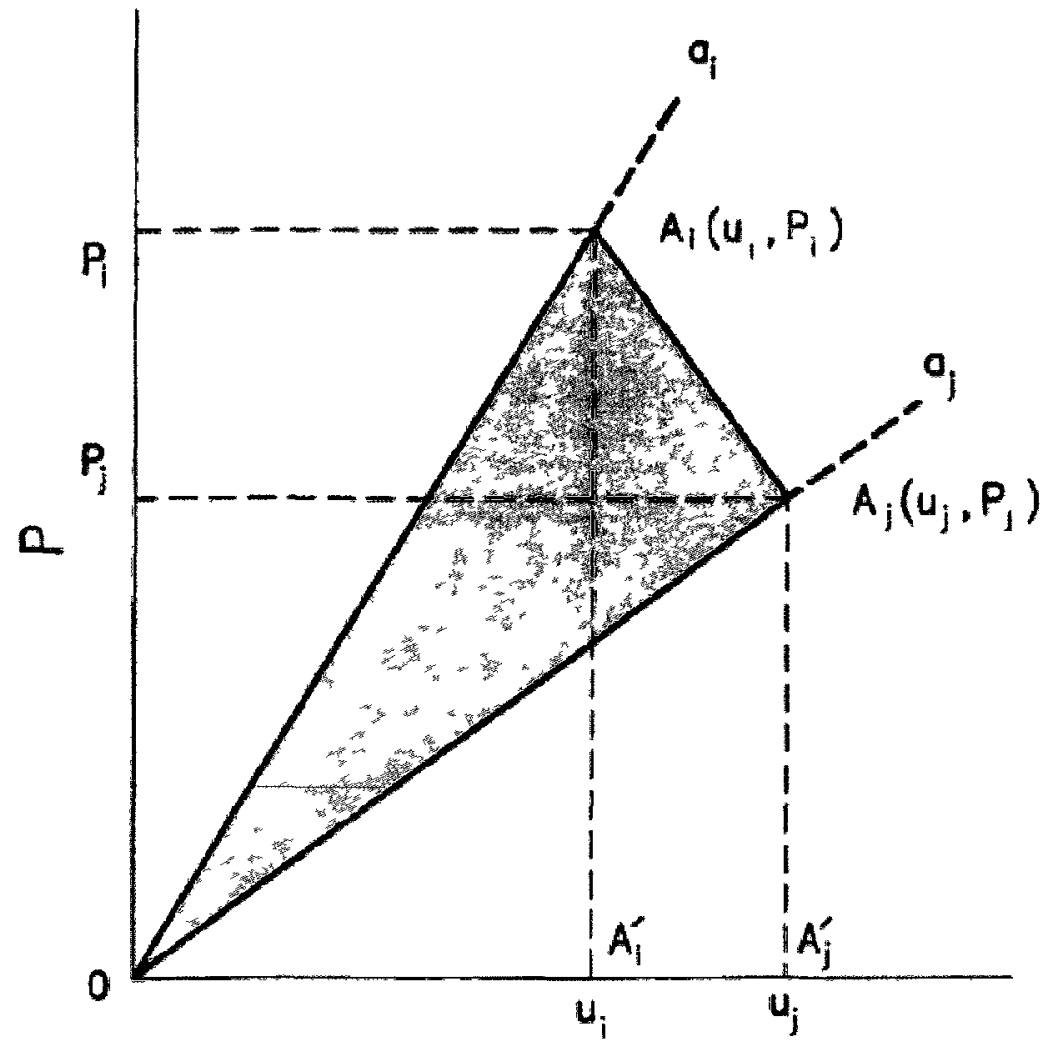

u

Frgure 9: Load-displacement $(\mathrm{P}-\mathrm{u})$ curve and resulting energy release (highlighted) for Innear-elastic materials [43]

Now, $U_{3}=\frac{1}{2} P u$ and $\frac{d U_{3}}{d A}=\frac{1}{2}\left[P \frac{d u}{d A}+u \frac{d P}{d A}\right]$ and Equation (I6) becomes [42]:

$$
G=P \frac{d u}{d A}-\left[\frac{1}{2} P \frac{d u}{d A}+\frac{1}{2} u \frac{d P}{d A}\right]=\frac{1}{2}\left[P \frac{d u}{d A}-u \frac{d P}{d A}\right]
$$

By substituting compliance $C=\frac{u}{P}$ into the relationship for $\frac{d u}{d A}$ we get [42]:

$$
\frac{d u}{d A}=P \frac{d C}{d A}+C \frac{d P}{d A}
$$

So that Equation (I7) can be written [42]: 


$$
G=\frac{1}{2} P^{2} \frac{d C}{d A}=\frac{1}{2} \frac{u^{2}}{C} \frac{d C}{d A}=U_{3} \frac{1}{C} \frac{d C}{d A}
$$

This can further be simplified, if we considered the planar case with self-similar propagation, to account for crack length rather than area [42]:

$$
G=\frac{P^{2}}{2 \mathrm{~B}} \frac{d C}{d a}=\frac{1}{2 \mathrm{~B}} \frac{u^{2}}{C} \frac{d C}{d a}=\frac{U_{3}}{B} \frac{1}{C} \frac{d C}{d a}
$$

In the case of the DCB test depicted in Figure I0, one could account for the specimen dimensions such as the thickness of one leg, $d$ and the specimen's width, $b$ (lowercase letters are used in ASTM D5528 and will be used hereafter [44]).

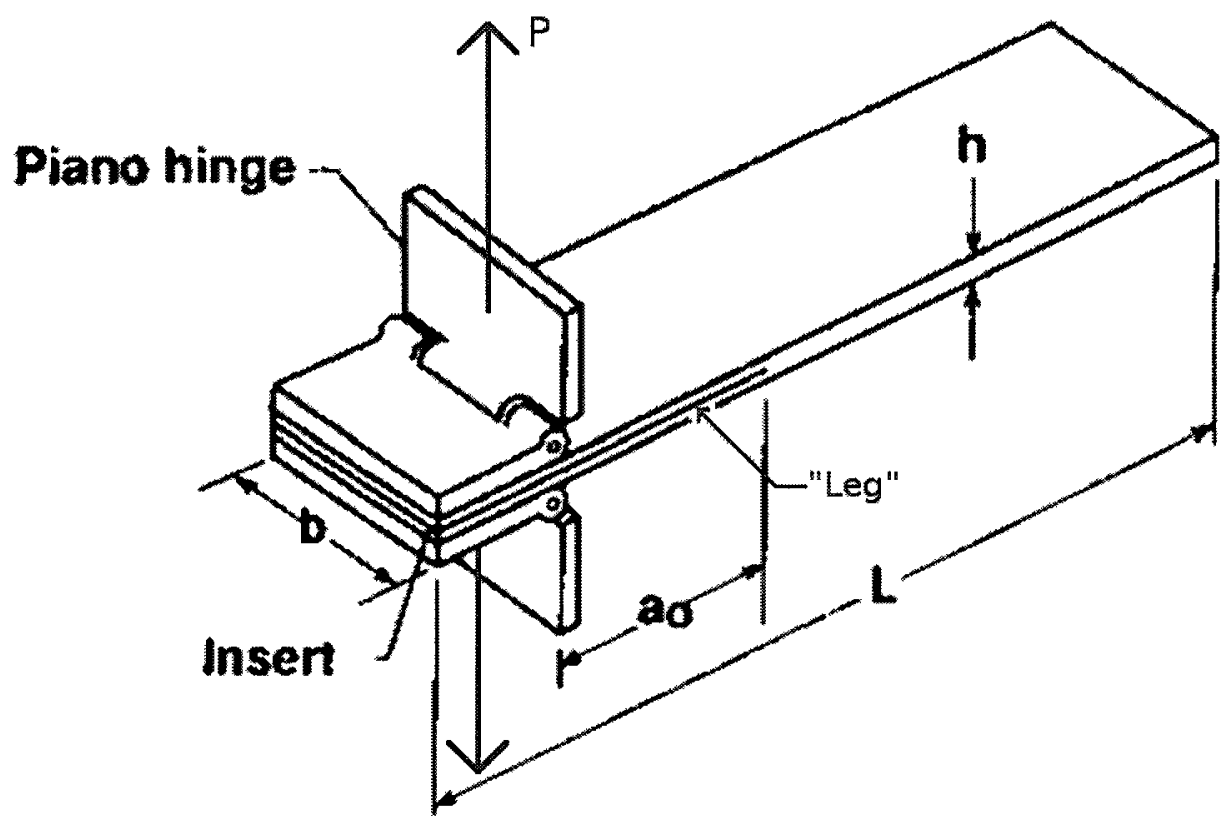

Figure IO: $D C B$ specimen configuration (modified from [44]).

In this case, considering linear-elastic deformation and $d=h / 2$, we get from beam bending equations, the displacement of each leg at the hinge loading point $[42]:$ 


$$
u=\frac{8 \mathrm{a}^{3}}{E b d^{3}} P
$$

Relating this to compliance using $C=\frac{u}{P}$ leads to:

$$
\frac{d C}{d a}=\frac{24 \mathrm{a}^{2}}{E b d^{3}}
$$

Which, using the first relationship in Equation (20) leads to [42]:

$$
G=\frac{12 P^{2} a^{2}}{E b^{2} d^{3}}
$$

The generalized discussion in this section will be elaborated upon in Chapter 4 to account for the specific analysis that will be performed using ASTM D5528 [44].

There are a number of models and techniques for studying the fracture of unidirectional laminates (e.g. [45], where various forms of energy dissipation such as fibre pull-out are accounted for), but because this work is focused on the adhesive bond between laminates, they will not be discussed here. This bond will be assumed to be isotropic, meaning that the fracture mechanics methods used on polymers and described in this Section will be applicable, while the effect of the fibres will be negligible.

The last item to cover in this review is the effects of the studied environment on composites, bonds and polymer fracture.

\subsection{EFFECTS OF HOT/HUMID ENVIRONMENTS}

Both high temperature and humidity have effects on the mechanical properties of polymers. In this Section, the effects of temperature, humidity, and their 
combination will be discussed, followed by a discussion on salt water and bonded joints.

\section{I.6.I. The Effects of High Temperature on Polymers}

For most polymers, service temperature can be considered "high" when it approaches its glass transition temperature, $T_{g}$. Epoxies can have a range of glass transition temperatures, with the cure temperature being a good indication of the $T_{g}$ that can be expected: epoxies cured at $120^{\circ} \mathrm{C}$ usually have a maximum service temperature around $100-130^{\circ} \mathrm{C}$, whereas curing at $180^{\circ} \mathrm{C}$ can yreld a maximum service temperature of $150^{\circ} \mathrm{C}[7]$. Long-term exposure to temperatures near these limits has an impact on the mechanical properties of epoxies. The main effects of high temperature on polymers are physical ageing, contınued cure (if the component was not completely cured) and thermo-oxidative reactions, as discussed in the subsections that follow.

\section{I.6.I.I. Physical Ageing of Polymers}

Polymers that are used below their $T_{g}$ (e.g. epoxies in aerospace applications) are inherently unstable. This stems from the rapid transition from a rubbery to a glassy state that typically occurs at the end of the cure cycle as the polymer cools to temperatures below its $T_{g}$, which prevents the polymer chains from arranging themselves in the most thermodynamically-stable configuration [46-47]. Over time, however, random molecular motions cause the polymer chans to achieve more stable configurations while changing physical properties. Physical ageing is the term used to describe this process, which is accelerated by high temperatures [46-47]. Physicallyaged polymers can be returned to their post-cure state by heating them above their $T_{g}$ and quenching them back to the glassy state $[46]$. 


\section{I.6.I.2. Continued Cure of Uncured Resin}

In addition to physical ageing, high temperature is known to provide the energy required for certain chemical reactions which might not occur or might be very slow at room temperature. For example, if a matrix is not completely cured, high service temperatures could lead to the continuation of cure reactions. This could be of particular concern in thick laminates or other cases where the temperature could vary through the thickness of the part during cure. In some cases, it is suspected that even the recommended cure cycle used for production results in an incompletely-cured matrix resin (e.g. see [48]). Such cases complicate analysis somewhat, since one would have to consider completion of cure in some parts of the structure and ageing of other parts simultaneously.

\subsubsection{Thermo-Oxidative and Other Chemical Reactions}

In the presence of oxygen and high temperatures, epoxies can be degraded through thermo-oxidative reactions. Studies using chemical identification techniques such as Fourier Transform InfraRed spectroscopy (FTIR) have shown evidence of a number of oxidation reactions occurring, even for an epoxy at temperatures as low as $70^{\circ} \mathrm{C}[48-49]$. By making measurements through the cross-section of specimens, it was found that these chemical changes were permanent and mostly affected the surface layers exposed to oxygen. Furthermore, it was suggested that correlation between chemical changes and mechanical properties of composites would be poor due to the great difference between the chemistry of the surface and centre of the material [48-49]. This provided important guidance regarding the use of extreme temperatures to simulate the use-environment: the authors noted that academic and material qualification studies often used temperatures as high as $200^{\circ} \mathrm{C}$, thereby inducing ageing mechanisms that would not have occurred in service and making 
observations based on tests that were not appropriate [48]. This is in line with recommendations made in the Composite Materials Handbook, CMH-I7, that the exposure temperatures of composite specimens not exceed $82^{\circ} \mathrm{C}$ [19]. A more thorough discussion of modelling and of chemical aspects of polymer degradation is provided in [50].

\section{I.6.1.4. Thermal Degradation}

Though the term "thermal degradation" might seem to describe all of the high-temperature mechanisms described previously, it is intended to refer to the change in material properties due to additional cross-linking and/or scission of polymer chains, as presented in [5I]. This type of degradation affects the $T_{g}$ of the polymer and is known to embrittle the polymer and lead to micro-cracking [47]. One would therefore expect fracture toughness to be negatively affected by thermal degradation.

\subsubsection{Effects of High Temperature on the Fracture of Epoxies}

Having discussed the various changes observed in thermoset polymers as a result of their exposure to high temperature, it is now appropriate to apply the discussion directly to the property of particular interest to this study, namely fracture resistance. This has been studied previously [22,52]. Results have shown a substantial decrease in strain energy release rate both after conditioning at high temperature and when testing at high temperature [52]. Interestingly, an initial increase was observed after 7 days of ageing, as seen in Figure II. The proposed justification was that there was a reduction in residual stresses that was competing with the ageing mechanisms until all residual stresses were removed. The ageing mechanisms subsequently dominated the evolution of total fracture energy and caused it to decline. 


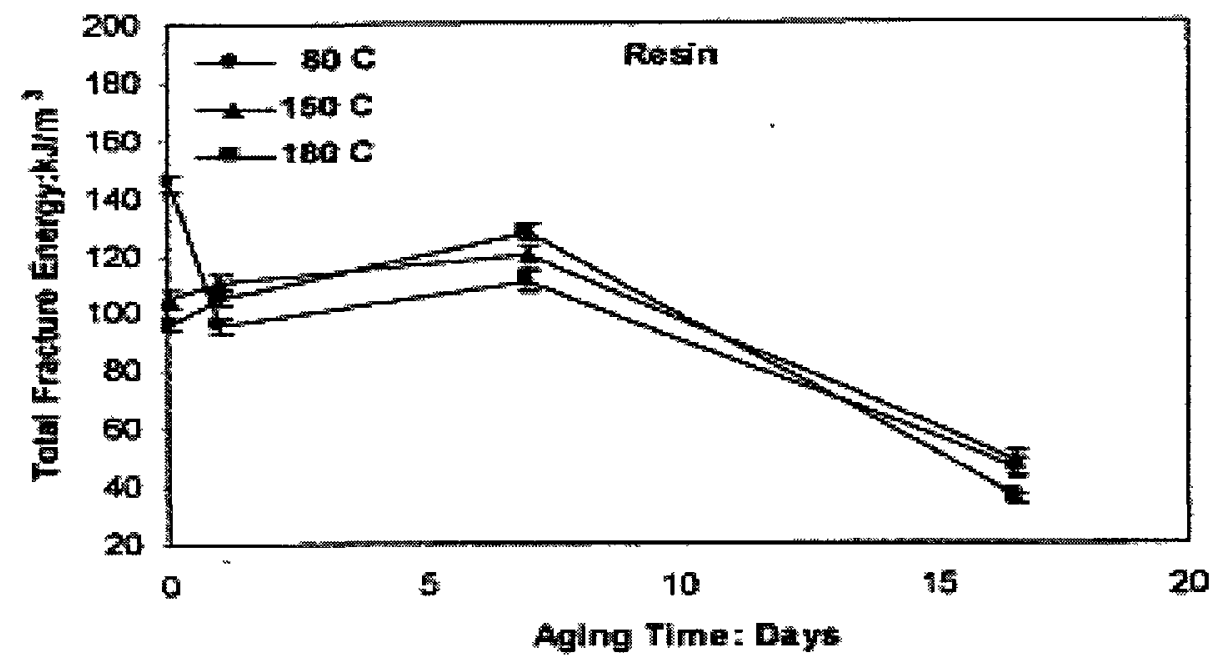

Figure II: Fracture energy versus Ageing Time for unreinforced epoxy resin [52]

The total fracture energy was found to decrease nearly linearly with testing temperature, as seen in Figure I2.

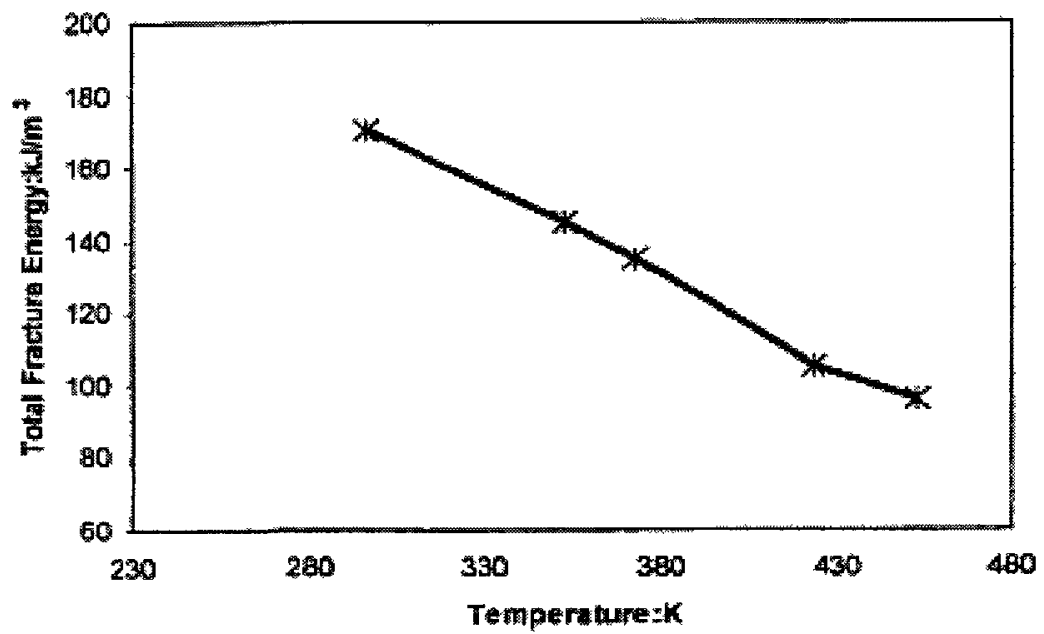

Figure I2: Total Fracture Energy versus Testing Temperature [52]

High temperature is not the only environmental variable that can degrade thermosets and change their properties; indeed, the effects of moisture on polymers and bonded joints cannot be ignored and will be discussed in the next Section. 


\section{I.6.2. The Effects of Moisture}

The effects of moisture can be understood to include a number of changes in material behaviour caused by the absorption of moisture or water into the polymer from the use-environment. These include chemical reactions of fibres and matrices with water, changes in physical properties caused by absorbed moisture and the introduction of damage by moisture. Before these specific effects are discussed, the nature and kinetics of moisture diffusion will be presented.

\section{I.6.2.I. The Nature of Moisture Diffusion and Its Effect on $T_{G}$}

Epoxies have been shown to absorb water when exposed to humid air and liquid water. The nature of the interaction between this absorbed water and the epoxy chain network is still debated, with two groups of theories currently being hypothesized. The two groups diverge mostly over one issue: whether the fact that absorbed water can be frozen means that it must not be bound to hydrophilic sites in the polymer network [53]. Arguments and observations have been made which suggest that water molecules do bind to polar, hydrophilic sites (such as $\mathrm{OH}$ ) in polymers and interfere with the interchain bonding network, as shown schematically in Figure I3 [54-56]. Others found that this effect is negligible and that treating the system as a polymerdiluent solution is sufficient to describe the effect of absorbed water on changes in mechanical properties (including the experimentally-observed decrease in $T_{g}$ ) [57$58]$. 


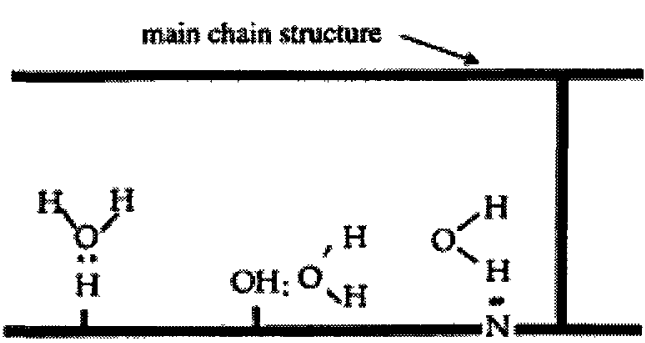

(a)

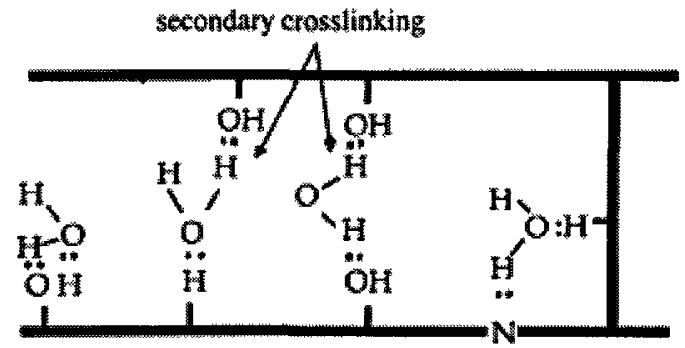

(b)

Figure 13: (a) Type I binding of water to epoxy main chain, which has a lower activation energy than (b) Type II binding, which occurs over longer times and at higher temperatures [55].

More thorough reviews of this subject are available in [53] and [59], but for this study, the fact that absorbed water plasticizes epoxies is sufficient. It should be noted that upon drying, plasticization is reversed and the initial $T_{g}$ can be recovered.

\subsubsection{The Kinetics of Moisture Diffusion}

Moisture may be absorbed by polymeric composites through a number of mechanisms, including:

- Diffusion of water molecules through the bulk polymer;

- Diffusion of moisture through the fibres;

- Diffusion of moisture through the fibre-matrix interface; and

- Penetration of moisture through cracks and voids in the laminate.

Diffusion of any molecule or contaminant into a polymer is possible if a "delta" parameter of the contaminant and that of the polymer are sufficiently similar. This parameter depends on the intermolecular cohesion of the two substances being considered: for the fluid, it is a function of the energy of vaporization while for the polymer, it depends on the chain characteristics [60]. Since the former cannot be controlled completely (e.g. it is implausible to avoid using aerospace structures in hot/wet environments), improvements in the polymers themselves are required if the 
problems associated with moisture diffusion are to be controlled. In order to assess the improvement of these properties in new systems over older ones, and attempt to predict diffusion given the conditions of the use-environment, a model for the diffusion is useful. Typically, the Fickian model is used as a starting point in modelling diffusion-such is the extent of this model's predominance that "Fickian" and "non-Fickian" are commonly-used terms to describe an observed diffusion trend.

\subsection{Fick's Diffusion Model}

Fick found that the trend observed in most diffusion problems could be described by two major equations which are commonly referred to as Fick's First and Second Laws. They will be presented in tensor notation (i.e. accounting for 3 dimensions) and the discussion will be applicable to carbon fibre/epoxy laminates. The discussion in this section is abridged and simplified from [II], which included a comprehensive review of the various findings and solutions made by Fick, Crank, Jost, and others.

Fick's first law relates the flux of matter (in this case, water) to the concentration gradient normal to a section being considered [II]:

$$
-F_{i}=D_{i j} \frac{\partial c}{\partial x_{j}}
$$

where: $F_{x} \quad$ Flux through plane with outward normal in " $i$ " direction.

$D_{\text {II }} \quad$ Diffusion tensor ( $3 \times 3$ matrix if 3 -dimensions being considered).

$c$ Concentration of water in "amount per volume" e.g. $\left[\mathrm{mol} / \mathrm{m}^{3}\right]$.

$x, \quad$ Position (traditional " $x$ ", " $y$ " and " $z$ " are replaced by $x I, x z$ and $x 3$ in this notation).

By assuming orthotropic properties, the diffusion tensor $D_{1 y}$ can be simplified to $[$ II $]$ : 


$$
D_{i j}=\left[\begin{array}{ccc}
D_{11} & 0 & 0 \\
0 & D_{22} & 0 \\
0 & 0 & D_{33}
\end{array}\right]
$$

In a unidirectional lamina where $x r$ is the fibre direction, one would expect the diffusion to be the same in the $x_{2}$ and $x_{3}$ directions since in both cases the water molecules must go around the circumference of the fibre. It is therefore often postulated that $D_{22}=D_{33}$. If the laminate is not unidirectional, consideration for the varying orientation of laminae must be made using approximate rules of mixtures. This discussion will not be shown here but is available in [I I].

The through-thickness diffusivity of a laminate (combination of laminae) with in-plane fibres that do not absorb water, such as carbon fibres, is [6]:

$$
\overline{D_{33}}=\mathrm{D}_{\mathrm{r}}\left(1-v_{f}\right)
$$

where: $D_{r} \quad$ Diffusivity of resin (matrix)

$v_{f} \quad$ Fibre volume fraction

While the in-plane diffusivities for multi-directional laminates are calculated from $[\mathrm{II}]$ :

$$
\overline{D_{11}}, \overline{D_{12}}, \overline{D_{22}}=\frac{1}{h} \sum_{i=1}^{N}\left(D_{11_{i}}, D_{12_{i}}, D_{22 i}\right) h_{i}
$$

where $h$ is the laminate thickness.

Fick's second law is a differential equation relating the concentration to time and position [II]: 


$$
\frac{\partial c}{\partial t}=\frac{\partial}{\partial x_{\imath}}\left[D_{\imath \jmath} \frac{\partial c}{\partial \mathrm{x}_{\mathrm{j}}}\right]
$$

where: $t \quad$ Time.

$x \quad$ Position in $x$-direction.

$D_{i j} \quad$ Diffusion coefficient.

\subsection{Numerical Solutions to Fick's Differential Equations}

Solving the differential equation for concentration with respect to position and time can be complex if no assumptions are made. A first approximation at a solution would be to assume that the diffusion is I-dimensional (as would apply through the faces of an infinite plate). In such a case, the boundary conditions are assumed to be $[\mathrm{II}]:$

$$
\begin{aligned}
& c=c o \text { at } t=0 \text { and all } x \\
& c=c \infty \text { at } t>0, x=0 \text { and } x=L \\
& c=c \infty \text { at } t=\infty \text { and all } x .
\end{aligned}
$$

where: co Initial concentration ( $=0$ ideally if specimen is dried initially)

$c_{\infty} \quad$ Concentration in the environment

$L \quad$ Thickness of laminate.

The differential equation can then be solved by a numerical approximation. The appropriate method to use depends on the length of the period of interest. If it is $10^{2}-10^{6}$ seconds, using a solution derived from the Laplace transformation is appropriate [II]:

$$
\frac{c_{t}-c_{0}}{c_{\infty}-c_{0}}=\sum_{n=1}^{\infty}(-1)^{n+1}\left[\operatorname{erfc} \frac{2 \mathrm{n}-1-x / L}{2 \sqrt{t^{*}}}+\operatorname{erfc} \frac{2 \mathrm{n}-1+x / L}{2 \sqrt{t^{*}}}\right]
$$

Where: $L \quad$ Thickness of laminate

$$
t^{*} \quad=\mathrm{Dt} / \mathrm{L}
$$


Another numerical solution (not involving the error function) was found to converge sufficiently quickly for durations greater than $10^{6}$ seconds:

$$
\frac{c_{t}-c_{0}}{c_{\infty}-c_{0}}=1-\frac{4}{\pi} \sum_{n=0}^{\infty}(2 \mathrm{n}+1)^{-1} \sin \left[\frac{(2 \mathrm{n}+1) \pi x}{L}\right] \exp \left[\frac{-D(2 \mathrm{n}+1)^{2} \pi^{2} t}{L^{2}}\right]
$$

In order to relate the total mass uptake to the concentration, we can use [II]:

$$
m=\int_{0}^{L} c(x, t) d x
$$

And substitute Equation (32) into (3I) to get [II]:

$$
\frac{m_{t}-m_{0}}{m_{\infty}-m_{0}}=1-\frac{8}{\pi^{2}} \sum_{n=0}^{\infty}(2 \mathrm{n}+1)^{-2} \exp \left[\frac{-D(2 \mathrm{n}+1)^{2} \pi^{2} t}{L^{2}}\right]
$$

The solution is most easily interpreted when plotted as $m_{t}$ versus $\sqrt{t}$. In this case, a graph such as Figure I4 would be obtained. 


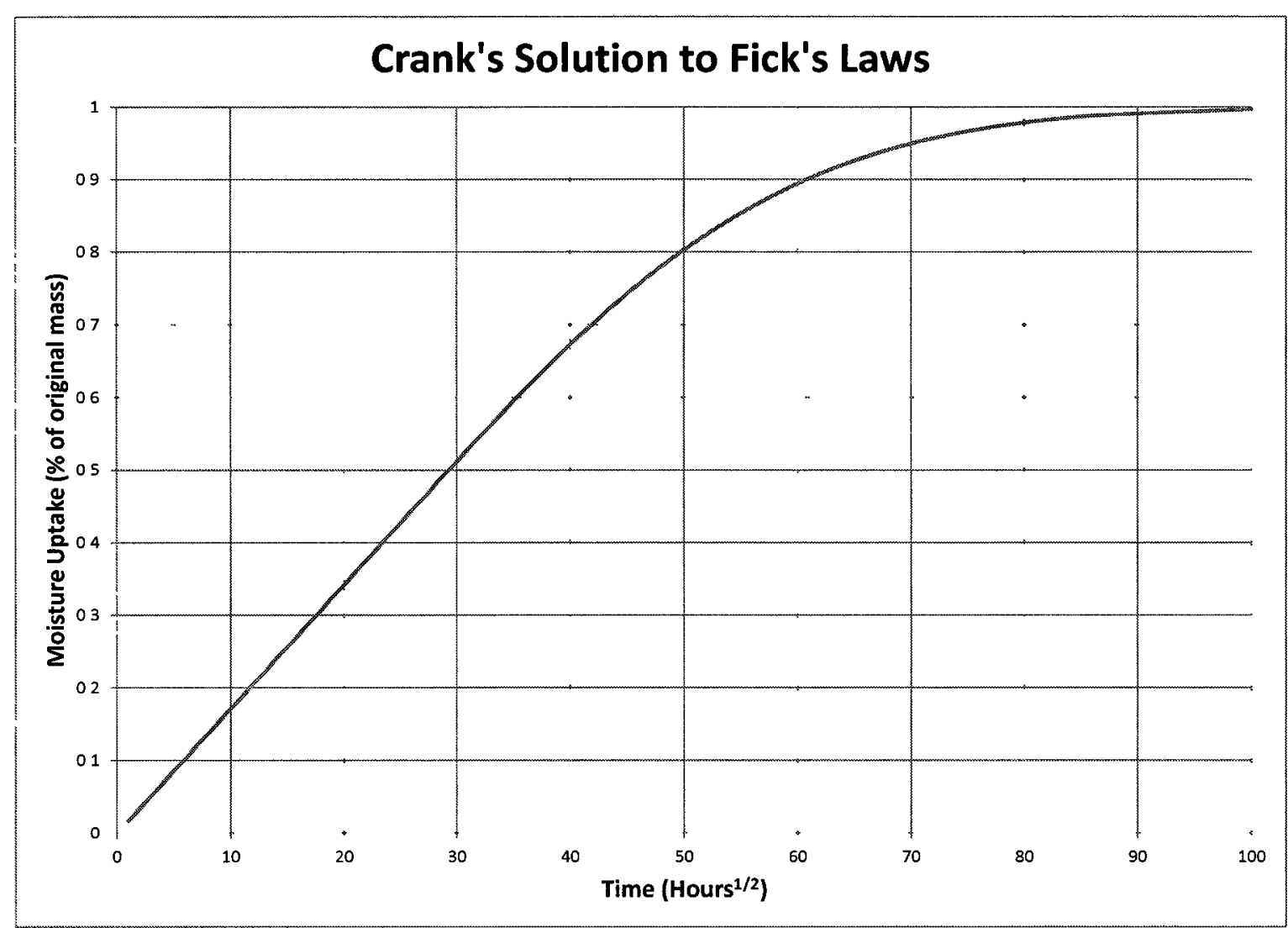

Figure I4: Example of Fickian diffusion trend for $\mathrm{D}=10^{-4} \mathrm{~mm}^{2} / \mathrm{hr}$,

$M_{\infty}=I$ and $L=I .3 \mathrm{~mm}$. Solution based on Equation (33).

\subsection{Non-Fickian Moisture Absorption}

There are a number of so-called "non-Fickian" mechanisms in which case the preceding model does not apply, or must be modified. An example of non-Fickian behaviour is observed after extensive micro-cracking occurs: this is a mechanism that serves to increase the amount of moisture absorbed and the speed at which it is absorbed beyond what would be predicted by Fick's model [I9]. Another example is complex polymer formulations, where resins with different diffusion parameters are mixed.

The nature and modelling of diffusion having now been presented, the effects of moisture on polymers will be discussed. 


\subsubsection{Hydrolysis and Chain Scission}

An important irreversible effect of moisture is the hydrolysis of epoxy chains. This reaction has been reported in [6I-62], both studies confirming the presence of leached substances in the immersion water used to condition the specimens. Fourier Transform InfraRed (FTIR) spectroscopy confirmed the presence of elements of the epoxy chain backbone structure in the degradation products from the water, as well as some evidence of the scission of cross-linking chains. This could be expected to have effects on the moisture absorption properties and strength of the polymer.

\subsubsection{Matrix Swelling}

The absorption of moisture by the matrix can cause it to swell [19]. Because glass and carbon fibres absorb virtually no moisture and do not swell, the strain difference between fibre and matrix can result in a residual stress in the composite [19]. The relationship between the amount of moisture that is absorbed and the strain that results is generally considered to be linear, as experimental data has shown [19]. This leads to the definition of a coefficient of moisture expansion which is used in a similar way as the coefficient of thermal expansion, with the exception that special consideration must be made for fibres that do not absorb moisture and do not expand.

\subsubsection{Effects of the Hot/Wet Environment on Bonded Joints}

Absorbed moisture has been found to change the failure mode of adhesive joints from cohesive to adhesive with an associated reduction of the energy release rate [63-65]. Most studies on the effect of moisture on the joint interface have employed metallic substrates; conclusions drawn from those experiments may not translate well to joints with polymer-matrix composite substrates. Among the studies 
that address bonding of composite substrates, whether moisture affects the failure mode (i.e. changes it from cohesive to adhesive) is unclear and may be system-specific $[66-68]$.

\subsubsection{Effects of Salt Water versus Fresh Water}

The effect of salt water on bonded joints has been studied for the case of aluminum substrates (e.g. [69] and [70]), for which corrosion at the interface is a great concern. Some data are also available for carbon fibre-epoxy laminates bonded to concrete, but this is of limited interest to this study. One notable effect of salt ions in water is the reduction of the rate of diffusion into a polymer when compared to distilled water [7I]. Conditioning in salt water actually slowed the degradation of the interlaminar shear strength of a laminate, but for a given mass of absorbed water, the shear strength results were the same $[7 \mathrm{I}]$.

\section{I.6.5. Synergistic Effects of Temperature and Moisture}

For most polymers, the diffusion of moisture would be extremely slow without high temperatures, which is why the hot/wet environment is of particular interest. In most cases, temperature is assumed to affect only the rate of diffusion, while the environmental moisture level is assumed to only affect the equilibrium moisture content [II,I9]. Some data have shown that an increase in temperature has the double effect of increasing the equilibrium moisture content and the rate of diffusion [52]. In the work presented in Chapter 3, the simpler case of temperature affecting only diffusion rate (diffusivity) will be assumed.

In terms of synergistic effects of these environmental factors on fracture properties of polymers, [52] reported that ageing time combined with moisture exposure led to fracture energies lower than that for specimens that were merely 
thermally aged, but higher than that for specimens that were only exposed to moisture, as shown in Figure I5.

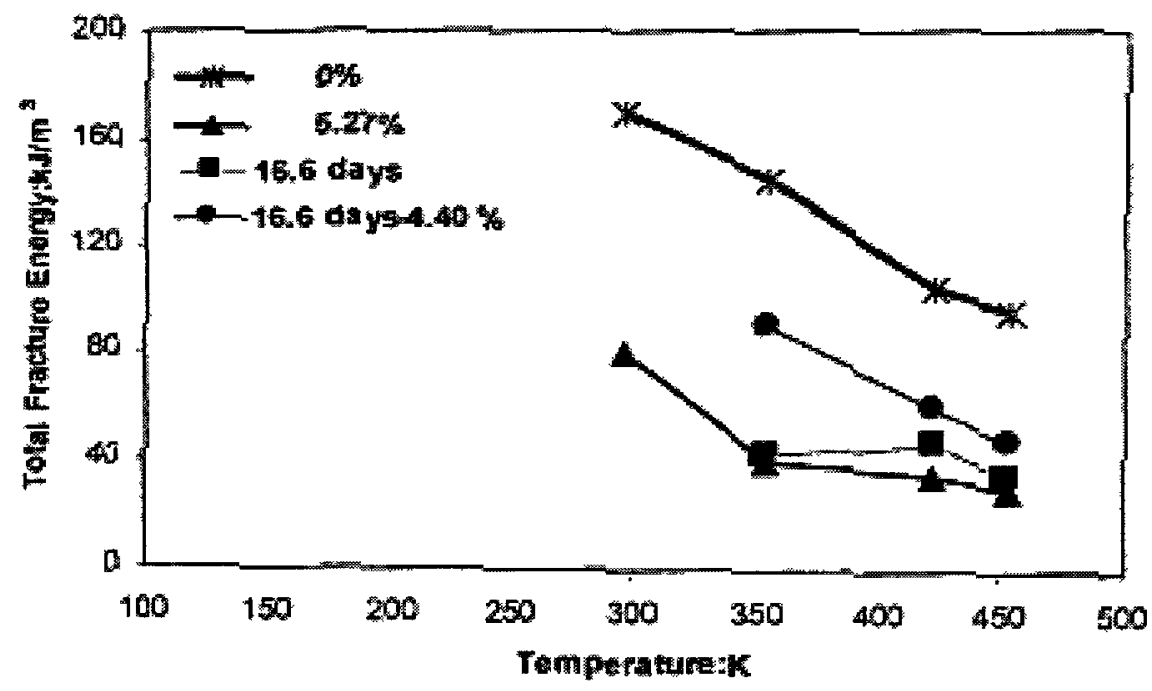

Figure 15: Synergistic effect on fracture energy of mossture (shown in key as mass \%), ageing time (shown in days) and testing temperature ( $x$ axis) [52].

This overview of the effects of the service environment on polymers, polymermatrix composites and bonded joints was the last topic to be covered in this literature review. In the Chapters that follow, more specific references that are directly applicable to the topics of interest will serve to enhance this general review.

\section{I.7. CONCLUSION}

In this Chapter, the literature related to composites, polymers, bonding, fracture and the effects of hot/wet environments on them has been reviewed. The major conclusions to be drawn are:

- The focus of the present study is on the effects of the hot/wet and salt water environments on the fracture toughness of bonded joints. 
- The literature has little information on mode I data for bonded composite substrates subjected to hot/wet or salt water environments.

- The data that do exist are often for different material types (e.g. marine composites), different environments (e.g. not considering salt) or different loading (e.g. shear instead of mode I). These differences preclude applying conclusions from the results of those studies to the aerospace materials considered in this thesis.

- Bonding requires specific knowledge and procedures to be performed appropriately, specifically in terms of creating a durable bond. Reliable and repeatable surface preparation plays a crucial role in ensuring the bond interface is strong and resistant to environmental attack over the life of the component in question.

- Fracture mechanics can be used to assess the strain energy release rate (a material property) of polymers.

- High temperature environments cause physical and chemical changes in thermoset polymers, which result in changes to their mechanical properties.

- Moisture is absorbed by polymers; the physics of the process is uncertain but the kinetics have been modelled successfully using Fick's laws. Moisture also causes physical and chemical changes in polymers and affects their mechanical properties: notably, polymer chains can be broken and the $T_{g}$ is decreased by the presence of moisture.

- Long-term exposure to high temperature and humidity has been shown to reduce the fracture energy of polymers.

The next Chapter will present the manufacturing methods and materials used to fabricate the specimens for this work. 


\section{Chapter 2: Manufacturing of DCB and SCB Specimens}

In this Chapter, the specimen configurations are first introduced. The materials and procedures used to manufacture laminates, and bond them to each other (for DCB specimens) or to Nomex honeycomb (for SCB specimens) are presented. This includes a description of the manufacturing equipment used at the NRC-IAR facilities.

Chapter I

Chapter 2

Chaper 3

Chapter 4

Chapter 5

Chapter 6

Appendix A

Appendu B
Literature Review

\section{Manufacturing of DCB and SCB Specimens}

Environmental Conditroning and Diffusion Data Analysis

The Effects of the Envmonment on the Fracture Toughness of Bonded Laminates

Preliminary Study of the Effects of the Environment on the

Disbond Fracture Joughness of Sandwich Siructures

Overview of Contribution and Recommendations for Futurc Work

Summary Sheets for DCB Specimens

Summary Sheets for SCB Specimens 


\subsection{INTRODUCTION}

This chapter will provide important information regarding the materials used, the manufacturing methods applied and the standards followed for specimen preparation. Step-by-step instructions will not be provided, but all key equipment and procedures will be described.

In order to simplify the subsequent discussion, the configuration of the two specimen types will precede the discussion of the materials used to manufacture them. Similarly, the specialized equipment required for manufacturing will be presented prior to the specimen manufacturing procedure. Some concluding remarks regarding important facts to remember from this Chapter will be given.

\subsection{SPECIMEN CONFIGURATIONS}

\subsubsection{The Double Cantilever Beam Specimen}

The Double Cantilever Beam (DCB) specimen is typically used to measure the mode I delamination fracture energy of laminates [44]. For this purpose, ASTM D5528 [44] addresses the configuration of the specimen, and the testing and data reduction methods used to obtain the (interlaminar) $G_{I c}$ value for the laminate. Because the objective of this study is to measure the $G_{I c}$ of an adhesive joint, and not of a laminate, slight modification of the configuration described in the ASTM standard was required. Figure I6 shows the ASTM D5528 specimen configuration, and Figure I7 shows how the specimens were modified for use in this study. 


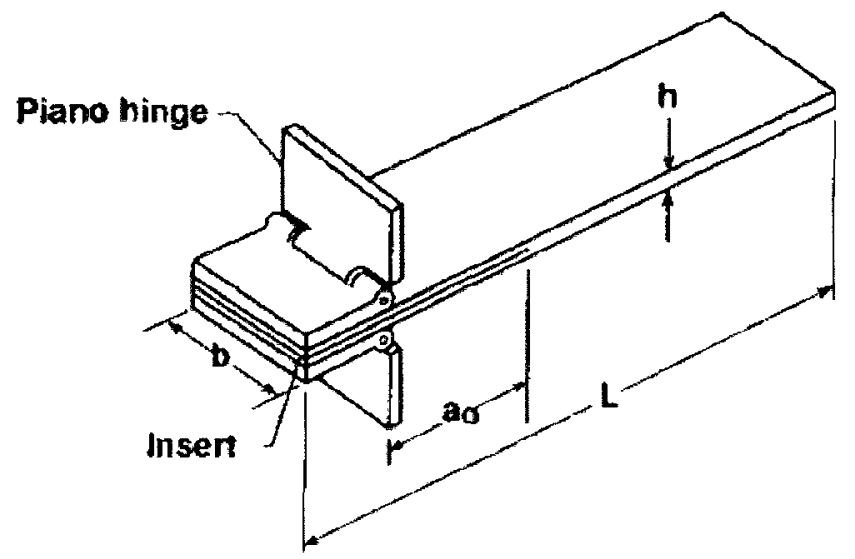

Figure I6: Configuration of DCB specimen in accordance with $A S T M D 5528[44]$

The dimensions provided in the standard were $b=20-25 \mathrm{~mm}, L=125 \mathrm{~mm}$, $h=3-5 \mathrm{~mm}$, ao $=50 \mathrm{~mm}$.

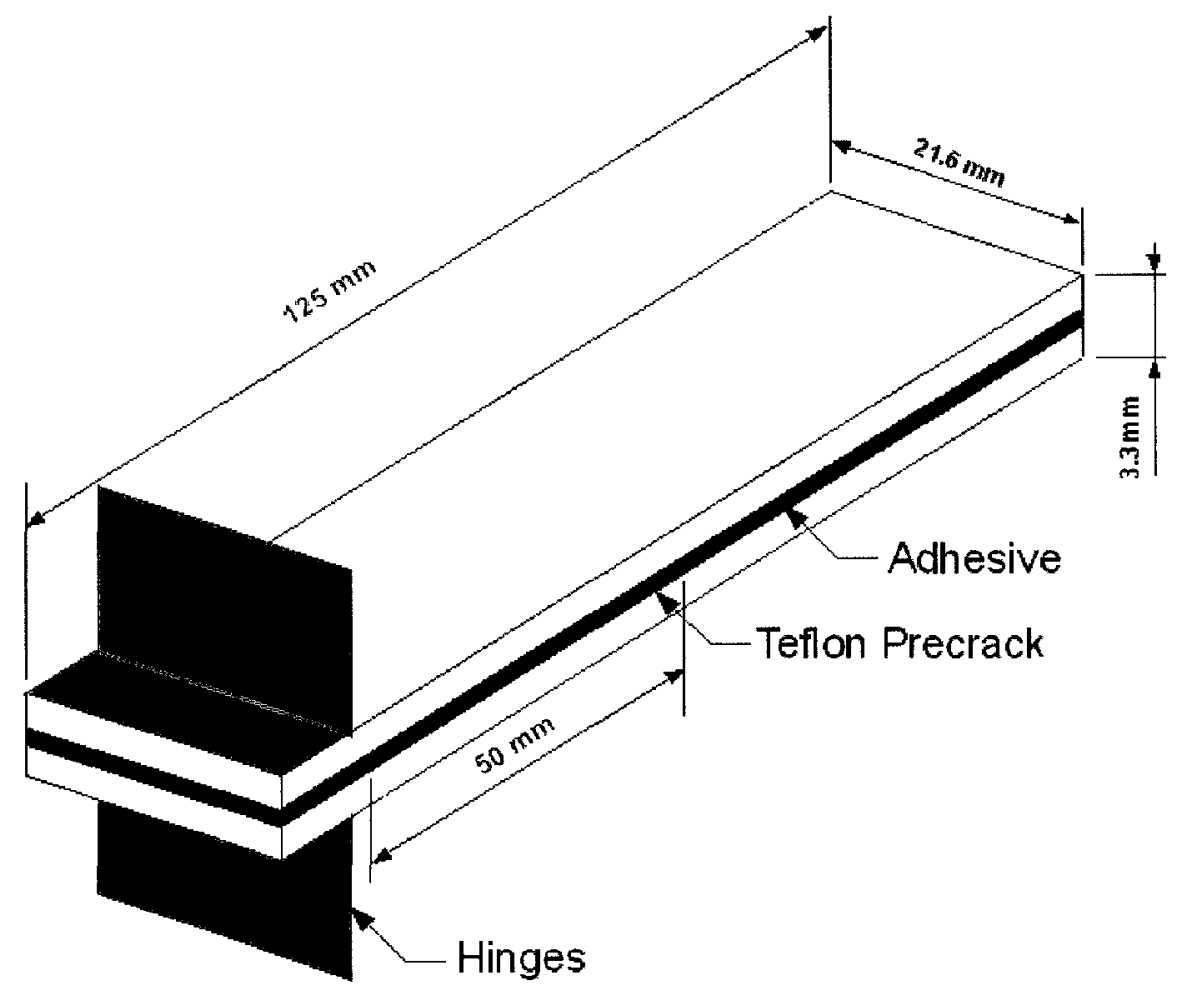

Figure 17: Bonded DCB specimen used in this study 
The standard specifies that a layer of PTFE (Teflon $\left.{ }^{\circledR}\right)$ be inserted within the laminate, between the two plies at the middle of the layup. This insert serves as an initiation site from which a delamination (crack between plies of the laminate) can start and subsequently advance through the matrix of the laminate. To adapt the test to a bonded joint, the PTFE strip was inserted between two plies of adhesive that bonded the laminates. Though typical joint designs would contain only one ply of adhesive, it was thought that starting the crack in the bulk of the adhesive might help avoid imposing an adhesive failure mode (i.e. a failure of the interface between adhesive and laminate) over a cohesive one (within the adhesive). Later work and literature review for the SCB specimen seemed to indicate that this was not necessarily true. Indeed, [63] showed that the stability of the direction of crack growth-an assessment of whether the crack will continue to grow in the current direction or change path (also known as "kinking")—-depended on the surface energies of the materials involved. The similar nature of the adhesive and laminate matrix (both epoxies) and previous experience indicated that crack growth in this configuration should be cohesive for the surface preparation methods used. Using one ply of adhesive and placing the PTFE insert at an interface was not attempted in this project to confirm this prediction.

\subsubsection{The Single Cantilever Beam (SCB) Sandwich Specimen}

The $\mathrm{CH}-\mathrm{I} 49$ contains many sandwich structures, which are composed of two laminates bonded to either side of a honeycomb core. This joint configuration cannot be tested using a standard test method because none exists for it yet. The recent literature in this area is still in the process of comparing various methods, with the objective of creating a standardized test [72-73]. A previous project at NRC attempted to use the Climbing Roller Peel test for sandwich specimens with 
composite laminate facings with little success [74]. It should be noted that this was partly due to the fact that the test is only meant as a tool to compare the strength of different materials or configurations in relative terms and cannot be used to quantitatively determine the $G_{l c}$ of the adhesive joint or its constituent materials $[74]$.

The Single Cantilever Beam (SCB) was identified in [72] and [74] as the most promising candidate for testing the fracture toughness of sandwich structures. At the time of writing, no standard SCB test existed, but communication with Dr. Ratcliffe (author of [73] and many other papers on the assessment of fracture properties of sandwich structures) confirmed that the progress to date would likely lead to a structure-level evaluation rather than a test of a material property (e.g. $G_{l c}$ of adhesive). One of the reasons for this is that the failure may occur in the laminate, adhesive or core, or at any of their interfaces, depending on both the loading case and the properties of each of these materials and interfaces. Further exploration of the SCB test method was nonetheless of interest to the project and was undertaken with the goal of observing the environmental effects, if any, on the results-whether or not the observed effect was on the adhesive, which was originally hoped in order to make a comparison with the DCB test results.

This test method required that specimens meet a number of criteria in order for the data reduction tools to be effective. This was presented in [73] and is shown in Table 3. 
Table 3: Conditions on dimensions of SCB specimen [73].

\begin{tabular}{|c|c|c|}
\hline I & Specimen width. & $b \geq 25 \mathrm{~mm}$ or six honeycomb cell sizes \\
\hline 2 & $\begin{array}{l}\text { Minimum intact length to ensure } \\
\text { FI, F2, and F3 remain at unity. }\end{array}$ & $L_{b, \min } \geq 2.7\left[\frac{t_{c} t_{f}^{3} E_{f}}{3 E_{c}}\right]^{\frac{1}{4}}$ \\
\hline 3 & $\begin{array}{l}\text { Initial debond length to ensure } \\
\text { bending is dominant deformation } \\
\text { mode of facesheet. }\end{array}$ & $a_{0} \geq a_{\min }^{\text {bending }}=\sqrt{\left(\frac{30 E_{f} T_{f}^{2}}{G_{x z, f}}\right)}-0.59 L_{b, \min }$ \\
\hline 4 & $\begin{array}{l}\text { Initial debond length to ensure } \\
\text { compliance adopts the form of } \\
\text { Eq. } 2 \text { in }[73] .\end{array}$ & $a_{0} \geq a_{\min }^{\text {compliance }}=L_{b, \min }$ \\
\hline 5 & $\begin{array}{l}\text { Final debond length to ensure a } \\
\text { required amount of debond } \\
\text { growth, } a_{\text {prop. }}\end{array}$ & $\begin{array}{l}a_{\max } \geq a_{0}+a_{\text {prop }} \text { where } a_{\text {prop }}= \\
50 \text { or } 80 \mathrm{~mm}\end{array}$ \\
\hline & \multirow{2}{*}{$\begin{array}{l}\text { Minimum face sheet thickness to } \\
\text { assume small deformation in } \\
\text { linear analysis. }\end{array}$} & $t_{f} \geq t_{f}^{\text {small disp }}=\frac{a_{\max }}{1}$ \\
\hline 6 & & $t_{f} \geq t_{f} \quad=\left[\overline{\left(\frac{3 a_{\max }^{2} E_{f}}{200 G_{c}}\right)^{\frac{1}{4}}-\left(\frac{t_{c} E_{f}}{3 E_{c}}\right)^{\frac{1}{4}}}\right\rfloor$ \\
\hline 7 & $\begin{array}{l}\text { Minimum face sheet thickness to } \\
\text { prevent flexural failure of face } \\
\text { sheet. }\end{array}$ & $\begin{aligned} t_{f} \geq t_{f}^{\text {strength }} & =\frac{6 E_{f} G_{c} a_{\max }^{2}}{\sigma_{c}^{2}}\left[a_{\max }\right. \\
& \left.+\left(\frac{t_{c}\left(t_{f}^{\text {smalldisp }}\right)^{3} E_{f}}{3 E_{c}}\right)^{\frac{1}{4}}\right]^{2}\end{aligned}$ \\
\hline 8 & Minimum specimen length. & $L_{\min } \geq L_{\text {hinge }}+a_{\max }+L_{b, \min }$ \\
\hline 9 & $\begin{array}{l}\text { Minimum load application offset } \\
\text { to ensure vertical load application. }\end{array}$ & $h_{p, \min }=1.062 a_{\max }$ \\
\hline
\end{tabular}

To solve for the required thickness, an iterative approach was necessary and was presented in [73]. The results of this process are presented next. 


\subsubsection{Dimensions of SCB Specimens Used in this Study}

The publication of [73] and the project's first contact with Dr. Ratcliffe occurred after the bulk of SCB specimen manufacturing had taken place, such that the face sheet thickness and layup orientation did not meet the requirements of [73]. Performing the calculations in this paper yielded the results shown in Table 4.

Table 4: Results of iterative analysis for $S C B$ specimen dimensions

\begin{tabular}{|c|c|c|c|}
\hline Outputs & Description & Result & Units \\
\hline$b$ & Specimen width & 19.0 & $\mathrm{~mm}$ \\
\hline$L_{b, \text { mun }}$ & Min. intact length & 34.2 & $\mathrm{~mm}$ \\
\hline aoguess $I$ & Initial debond length & 36.3 & $\mathrm{~mm}$ \\
\hline ao.guess2 & Initial debond length & 34.2 & $\mathrm{~mm}$ \\
\hline ao & Initial debond length & 36.3 & $\mathrm{~mm}$ \\
\hline$a_{\max }$ & Max debond length & 86.3 & $\mathrm{~mm}$ \\
\hline$t_{\text {finumgruess } I}$ & Min. facesheet thk (value no.I) & $\mathrm{I} .84$ & $\mathrm{~mm}$ \\
\hline$t_{\text {tmmnguess } 2}$ & Min. facesheet thk (value no. 2) & 0.110 & $\mathrm{~mm}$ \\
\hline$t_{t, m m n}$ & $\begin{array}{l}\text { Min. facesheet thk (thicker of value } \\
\text { no.I or no.2) }\end{array}$ & $\mathrm{I} .84$ & $\mathrm{~mm}$ \\
\hline
\end{tabular}

Based on information available from another NRC project which also employed the SCB test, the specimens had been manufactured with 8-ply facesheets in the $[0 / 45 / 90 /-45]$ s layup. In order to meet the criteria of [73], a unidirectional layup with approximately $\mathrm{I} 3$ plies would have been required. This non-conformity of the specimens to the requirements of [73] represented a significant stiffness difference and is discussed in Chapter 5 in more detail.

The configuration of the specimens now being familiar, the next Section will deal with the specific materials used to manufacture them. 


\subsection{MATERIALS USED FOR SPECIMENS}

As presented in Chapter I, the objective of this research is to obtain materialand structural-level data to aid in assessing how long-term exposure to hot, wet and high salinity environments might affect the integrity of the composite and bonded components in the CH-I49 Cormorant helicopter. However, the materials and processes used in the study were not necessarily those used by Agusta Westland in manufacturing the helicopter, but were instead selected to represent generic aerospace structures. As such, high-strength carbon fibres pre-impregnated in a toughened epoxy matrix (known as a pre-preg) were used to manufacture the laminates used in the specimens. These laminates were cured under a tightly-controlled pressure and temperature cycle in an autoclave. An epoxy adhesive in film form was used to create the joints presented in Section 2.2 with these laminates. This section contains descriptions of the materials used for laminate, adhesive and core.

\subsection{Laminates}

As discussed in Chapter I, parts with low void content and high fibre volume fraction are the norm in aerospace composite materials. The best results are obtained by laying up pre-impregnated plies of carbon fibre/epoxy material, then curing the resulting laminate under carefully-controlled temperature and pressure [7]. This process is used for civil and military aerospace structures, as discussed in Chapter I. Therefore, an autoclave process was selected for manufacturing the specimens used in this project.

The material used for laminates was CYCOM 5276-I, a toughened epoxy, reinforced with unidirectional G40-800-24K carbon fibres, supplied by Cytec Industries Inc. The pre-preg was kept in a freezer at $-25^{\circ} \mathrm{C}$ (actual setting: $-\mathrm{I} 4^{\circ} \mathrm{F}$ ) as 
recommended by the manufacturer. Though most of the laminates were made within the manufacturer's recommended period of 6 months from delivery, some were layed up afterward. The raw material was received in December 2009, meaning that any cure that took place after May 2010 was technically done with time-expired material. Consequences of this might include absorption of too high a quantity of moisture by the raw material, having potential effects on the cured properties of the laminates (similar issues to those discussed in Section 4, on bonding, of Chapter I). Partial curing of the material could also be expected, as preventing this reaction is the reason that the material must be kept at very low temperature and has an expiry date.

Throughout manufacturing, the material's handling characteristics such as tack (how well plies could be stuck together during layup) and drape (how flexible the material was) remained very good. Based on this and the characteristics claimed by the manufacturer and presented below, the author and experienced researchers involved with this project were confident that the results obtained from panels made with time-expired pre-preg would nonetheless be representative of the material response.

Key features for the CYCOM 5276-I polymer are [75]:

- Uncured characteristics:

- Excellent tack and drape

O Shelf life $>6$ months if stored at $-18^{\circ} \mathrm{C}$

- I0 days handling life (length of time it can be out of the freezer when laying up)

O No change in mechanical performance when used after storing at room temperature for 1000 hours ( 42 days). 
- Cured pre-preg characteristics, unidirectional G40-800 fibres:

- Service temperature: $-59^{\circ} \mathrm{C}\left(-74^{\circ} \mathrm{F}\right)$ to $121^{\circ} \mathrm{C}\left(250^{\circ} \mathrm{F}\right)$

- $0^{\circ}$ Tensile strength and modulus (room temperature): 3.0I GPa (437 ksi) and I55.I GPa (22.5 Msi)

- $90^{\circ}$ Tensile strength (room temperature): $90.3 \mathrm{MPa}$ (I3.I ksi)

- In-plane shear strength and modulus (room temperature): I39 MPa (20.2 ksi) and 4.83 MPa (0.70 Msi)

○ $G_{l c}$ (room temperature): $0.385 \mathrm{~kJ} / \mathrm{m}^{2}\left(2.2 \mathrm{in} \cdot \mathrm{lb} / \mathrm{in}^{2}\right)$

○ $T_{g}($ dry $)$ and $T_{g}$ (wet): $188^{\circ} \mathrm{C}\left(370^{\circ} \mathrm{F}\right)$ and $154^{\circ} \mathrm{C}\left(310^{\circ} \mathrm{F}\right)$

In the current study, the cured laminates made from this pre-preg were bonded using an adhesive, which will be described next.

\subsubsection{Adhesive}

The adhesive used was AFI63-2K by 3M, a modified epoxy adhesive supplied in film form supported by a knit nylon carrier (as indicated by the " $\mathrm{K}$ " suffix). The carrier's purpose is twofold: (i) it allows the otherwise fragile film to be handled when uncured, (ii) it helps control the thickness of the bond line by controlling/limiting flow of the adhesive during cure [34]. Properties of AFI63-2K that are of interest to the aerospace industry and to this study include its high bond strength, peel strength and fracture toughness and excellent resistance to high moisture environments [76].

The following lists some of the characteristics highlighted by the manufacturer [76]:

- High strength maintained over temperature range of: $-55^{\circ} \mathrm{C}\left(-67^{\circ} \mathrm{F}\right)$ to $121^{\circ} \mathrm{C}\left(250^{\circ} \mathrm{F}\right)$ 
- Dry $T_{g}$ and Wet $T_{g:}: 108^{\circ} \mathrm{C}\left(226^{\circ} \mathrm{F}\right)$ and $82^{\circ} \mathrm{C}\left(180^{\circ} \mathrm{F}\right)$

- Tensile strength at $24^{\circ} \mathrm{C}$ and $82^{\circ} \mathrm{C}: 48.3 \mathrm{MPa}$ (7000 psi) and $20.6 \mathrm{MPa}(3000 \mathrm{psi})$

- Tensile modulus at $24^{\circ} \mathrm{C}$ and $82^{\circ} \mathrm{C}:$ I.I0 GPa (I60 ksi) and 0.4 I4 GPa (60 ksi)

- Bond fracture toughness $\left(24^{\circ} \mathrm{C}\right): 4.378 \mathrm{~kJ} / \mathrm{m}^{2}\left(25 \mathrm{in} \cdot 1 \mathrm{~b} / \mathrm{in}^{2}\right)$

- Shear strength on Epoxy FRP at $24^{\circ} \mathrm{C}$ and $82^{\circ} \mathrm{C}: 29.6 \mathrm{MPa}$ (4300 psi) and $15.9 \mathrm{MPa}(2300 \mathrm{psi})$

A core material was required to manufacture SCB specimens and will be discussed next.

\subsubsection{Core}

The sandwich specimens in this study contained an Aerospace-grade Aramid fibre $\left(\right.$ Nomex $($ ) $)$ honeycomb core with a density of $6 \mathrm{lb} / \mathrm{ft}^{3}\left(96 \mathrm{~kg} / \mathrm{m}^{3}\right)$ and I/ 8 inch ( $3 \mathrm{~mm})$ cell diameter, supplied by Plascore, Inc. This core was selected after a previous study found that a core of lower density failed before the bond did. It was hoped that a bondline failure could be produced since such a failure mode had been observed in two previous projects at NRC. As will be discussed in Chapter 5, however, this failure mode was not necessarily achievable, nor was it a requirement for the validity of the test. However, it did mean that if the test produced a core failure, the adhesive's fracture toughness (or its variation due to conditioning) could not be measured in this configuration.

Key properties of this core material are [77]:

- Bare compressive strength: 6.4I MPa (930 psi) typical, $4.83 \mathrm{MPa}$ (700 psi) minimum 
- Plate shear strength (L direction): $2.48 \mathrm{MPa}$ (360 psi) typical, 2.2I MPa (320 psi) minimum

- Plate shear strength (W direction): I.69 MPa (245 psi) typical, I.03 $\mathrm{MPa}$ (I50 psi) minimum

The $\mathrm{L}$ and $\mathrm{W}$ directions are two orientations in the plane of the core material in which the mechanical properties are quite different. This is due to the way honeycomb core materials are manufactured: in one direction (W), the cells are held together by adhesive, while in the other $(\mathrm{L})$, the sheets of aramid fibre are continuous. Note that the $\mathrm{L}$ direction is also known as the ribbon direction. See Figure 18 for a schematic description. 

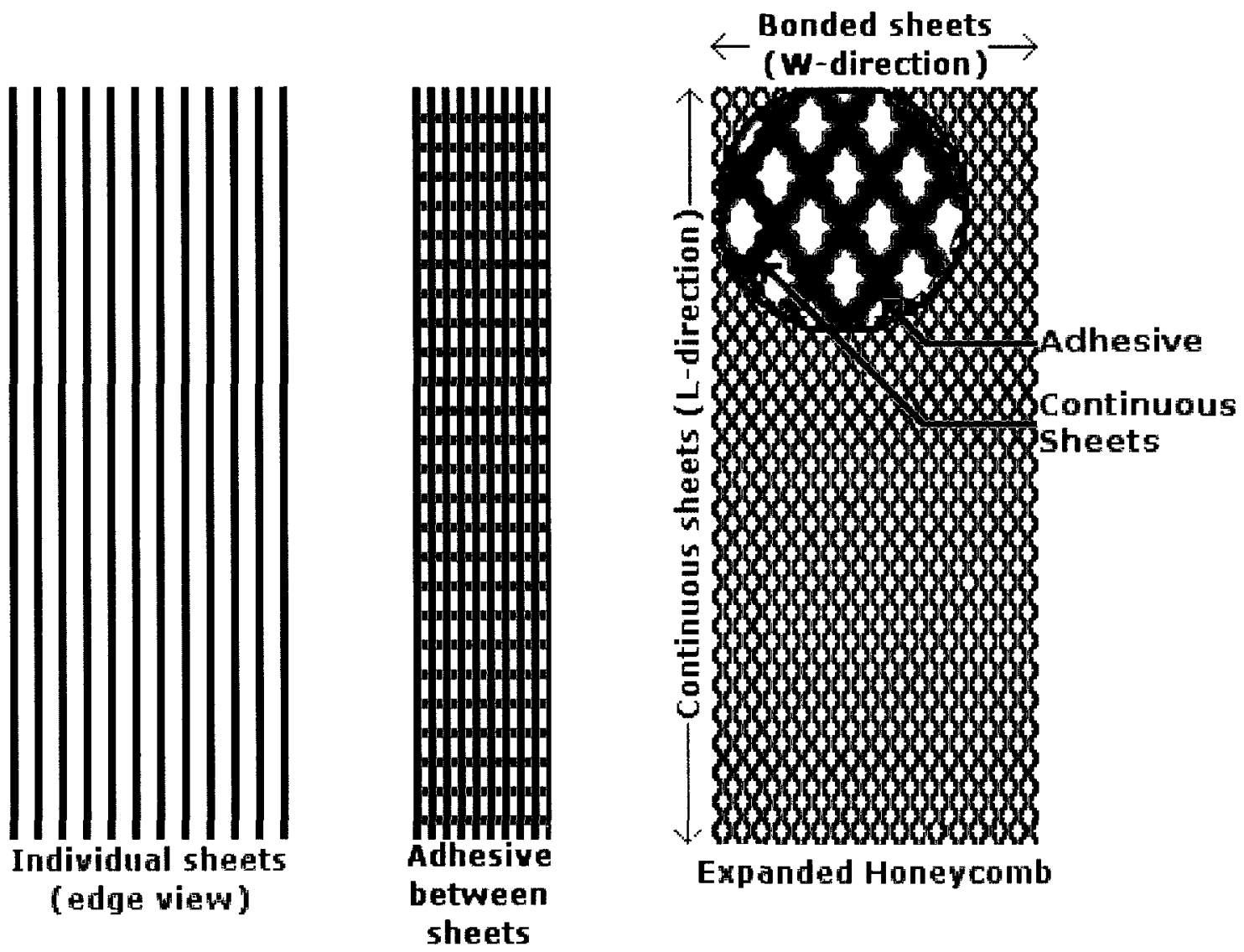

Figure I8: Honeycomb is manufactured from sheets that are bonded together. This results in different properties in the two in-plane directions.

In addition to the materials used in the specimens that have been discussed in this Section, some specialized equipment and consumable materials were required to manufacture them. Section 2.4 will briefly present the key equipment and consumables that were used.

\subsection{OTHER MATERIALS AND EQUIPMENT}

\subsection{Manufacturing Equipment}

A number of pieces of equipment were required to manufacture the two types of specimens presented in Section 2.2, and these were all available at the NRC. The 
major equipment that was used will be listed and described here, in the approximate order in which it was used, while other commonly-available equipment and tools (e.g. rulers, squares, knives, and clamps) will be mentioned in the manufacturing procedure without prior introduction.

\subsection{I.I. Debulking (Vacuum) Table}

Debulking is part of the lay-up procedure that removes trapped air from between the plies-beyond what is achieved by applying manual pressure through simple hands rollers - thereby improving consolidation of the plies prior to curing the laminate [7]. At the NRC, debulking of flat panels is performed on a table that applies vacuum pressure to the layed-up plies. The debulking table was supplied by Torr Technlologies, Inc, has a working area of $36.5 \times 47.5$ inch $^{2}$ and is connected to a pump capable of supplying -28 inch $\mathrm{Hg}$ vacuum pressure. To debulk a panel, it is simply placed on the table, the lid is closed and a cycle of vacuum pressures is applied on the controls. The seals around the edges of the lid and the high strength silicone rubber lid itself ensure that this pressure is applied to flatten the panel and extract entrapped air through its edges. Figure 19 is a picture of NRC's debulking table. 


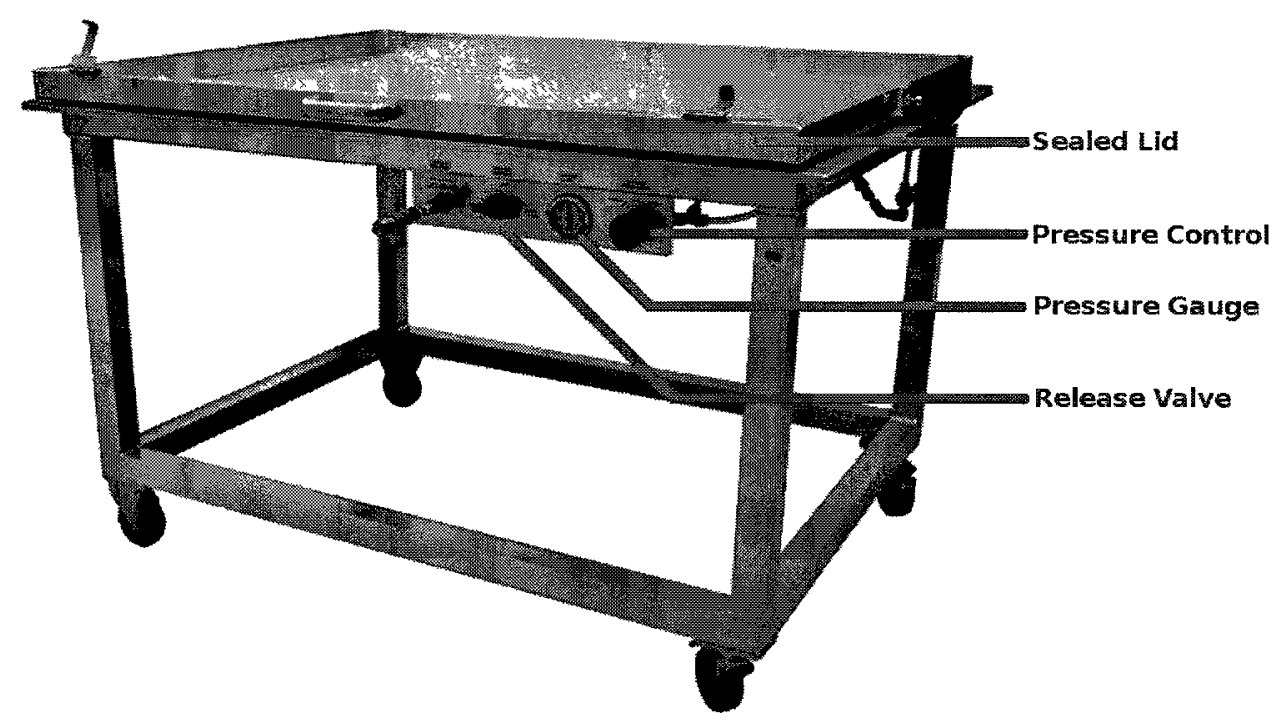

Figure 19: Custom-made de-bulking table by Torr Technologies, Inc.

\subsection{I.2. Tool Plates, Pressure Plates and Shims}

Providing a very flat surface for the matrix to flow against and conform to while curing results in a flat, smooth surface on the cured laminate. "Tool plates" generally refers to the lower plate onto which multiple panels may be cured. "Pressure plate" or "caul plate" refers to a plate having sides that are approximately I in. $(25.4 \mathrm{~mm})$ longer than the sides of the panel. This plate rests on shims that are of the expected thickness of the cured panel and placed around the laminate during cure. It ensures that the other surface of the panel is flat and smooth. Both types of plate must be separated from the curing panel by release film since epoxy adheres well to aluminum.

The tool plate and pressure plate are both $3 / 4$ inch-thick ( $19 \mathrm{~mm}$ ), dimensionally-stable aluminum plates. The KIO0 S plates are supplied by Alpase. Rolled aluminum plates are not used due to the introduction of anisotropic residual stresses through cold working, which may cause the plates to warp when heated. 
Shims can be made of aluminum or steel and should be of the thickness expected from the cured panel (the manufacturer of the pre-preg would typically provide such information). If required, multiple shims can be stacked to achieve the correct thickness. Shims should be protected with a generous amount of release agent (e.g. Frekote by Henkel, Inc.) to avoid having the matrix material bond to the shims, making them almost impossible to clean and re-use. Figure 20 shows two shims with de-burred edges; this is to avoid having the shims cut through the release film.

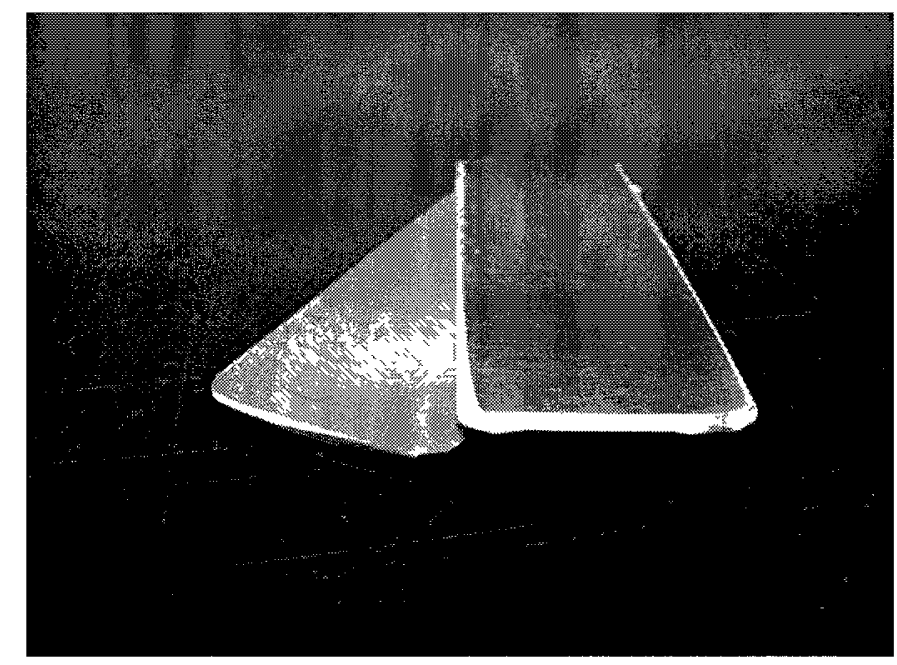

Figure 20: Shims with de-burred edges.

\subsection{I.3. Consumables for Curing}

Every cure requires a number of single-use consumable materials. The curing process that follows layup and debulking requires that a tool plate be prepared in the configuration shown in Figure 2I and Figure 22. 


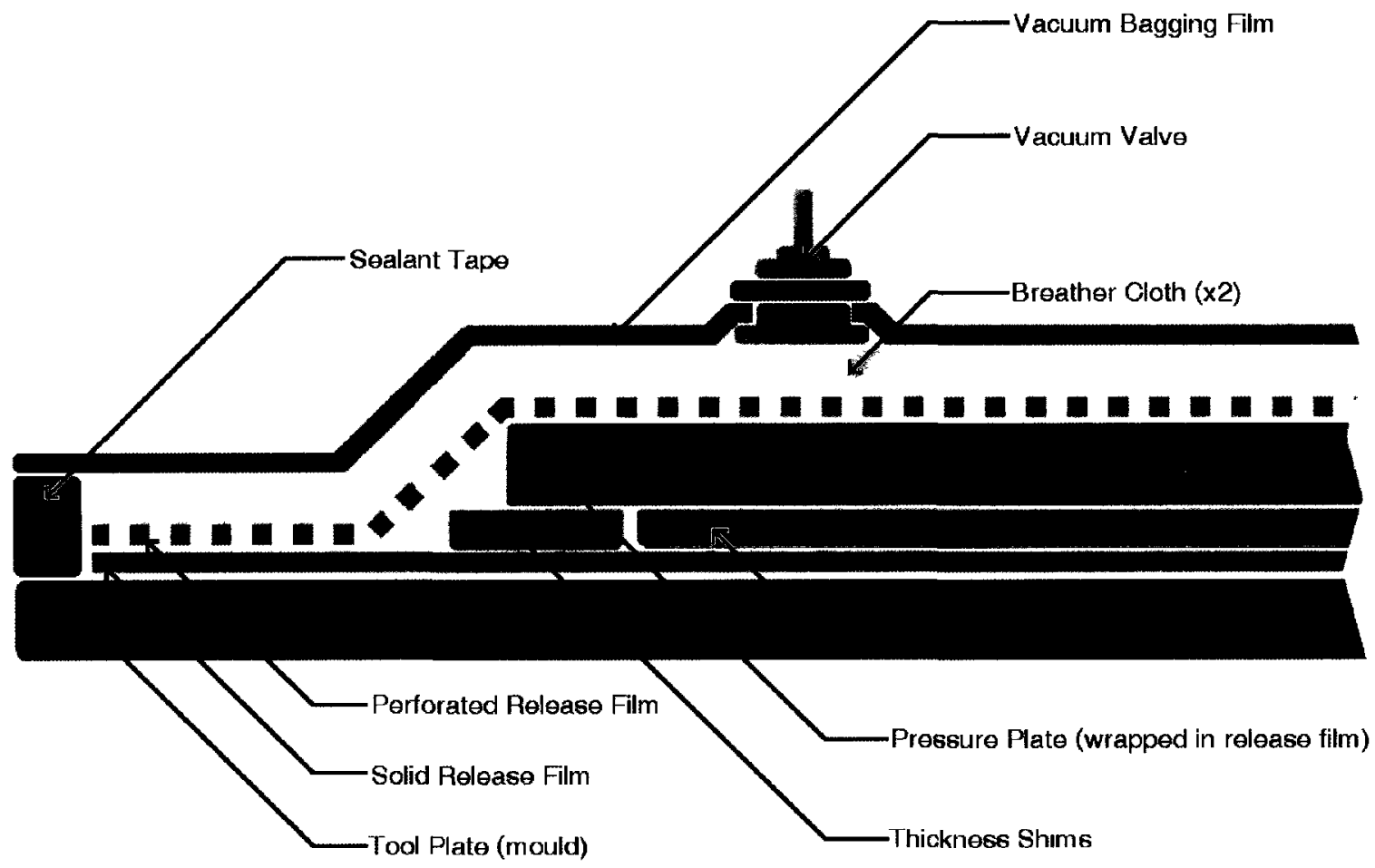

Figute 2I: Schematic of NRC tool plate bagging practice

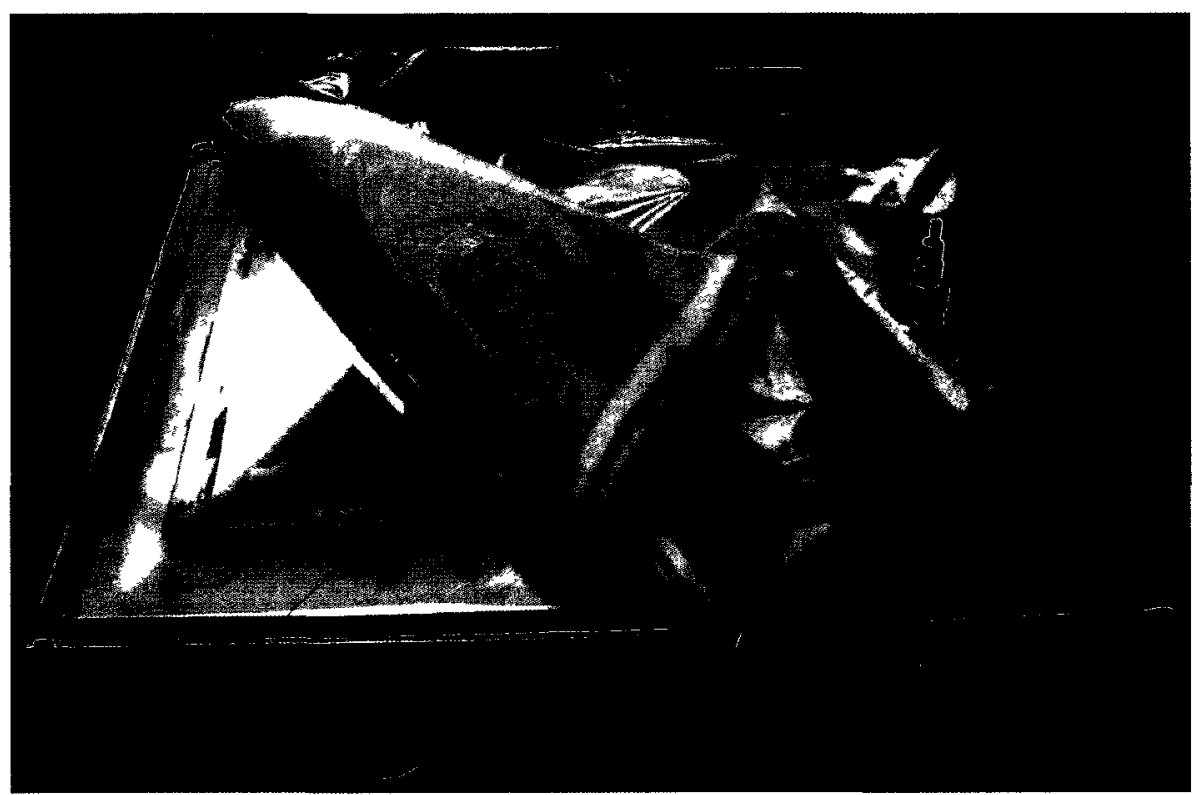

Figure 22: Picture of tool plate setup prior to sealing the vacuum bag. I: Perforated release film, 2: Breather cloth, 3: Vacuum bag, 4: Solid release film, 5: Sealing tape, 6: Shims, 7: Wrapped pressure plate (covering the part), 8: Vacuum valve. 
This setup is designed to create parts that: (i) conform to the shape of the mould (here, a flat tool plate); (ii) have a smooth surface finish on both sides; (iii) have a low void content and high fibre volume fraction; and (iv) are easily removable from the mould after curing.

The release film prevents the curing resin from bonding to the metal plates (see Figure 23). For this purpose, $A-5000$ FEP release film supplied by Richmond Aerovac was used. This 0.002 inch-thick film may be used for cure temperatures as high as $260^{\circ} \mathrm{C}\left(500^{\circ} \mathrm{F}\right)$.

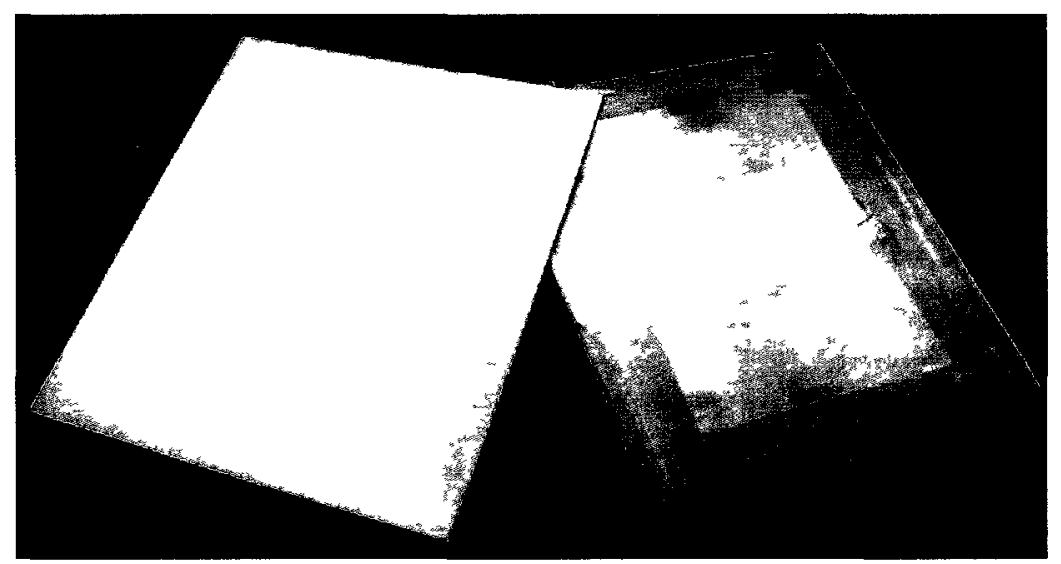

Figure 23: FEP-covered pressure plates

The breather cloth serves two main purposes: it prevents the vacuum bag from being perforated by any sharp corners on the plates, and it absorbs excess resin that might flow out of the shim perimeter when the curing polymer reaches low viscosity. It performs these tasks while allowing air to flow freely out of the vacuum bag.

The vacuum bag and sealant tape (Figure 24) together form an airtight barrier which allows vacuum to be applied to the volume contained within their boundaries. When a high enough pressure-usually $\mathrm{I} 03 \mathrm{kPa}(\mathrm{g})$ (I5 psig)—is reached within the autoclave, the volume under the vacuum bag is vented to atmosphere. The pressure on 
the outside of the barrier and opening to atmosphere on the inside are necessary to maintain a low void content in the curing resin, as discussed in Section 2.4.I.4.

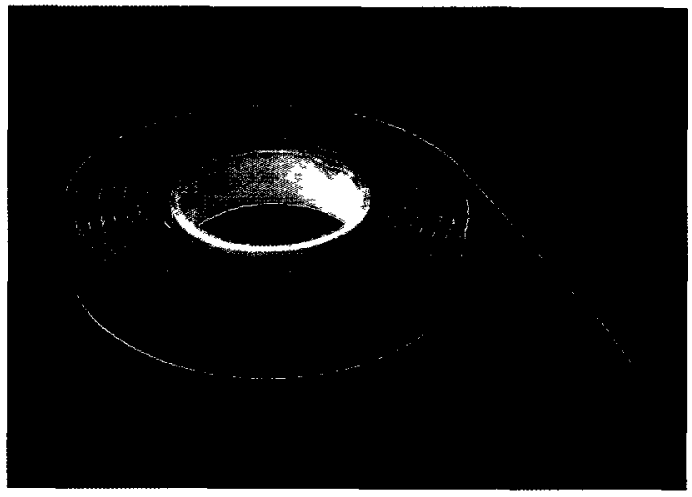

Figure 24: Roll of sealant tape.

Though not a consumable, the vacuum valve is required equipment designed to seal around the hole required for its insertion into the vacuum bag. See Figure 25 .

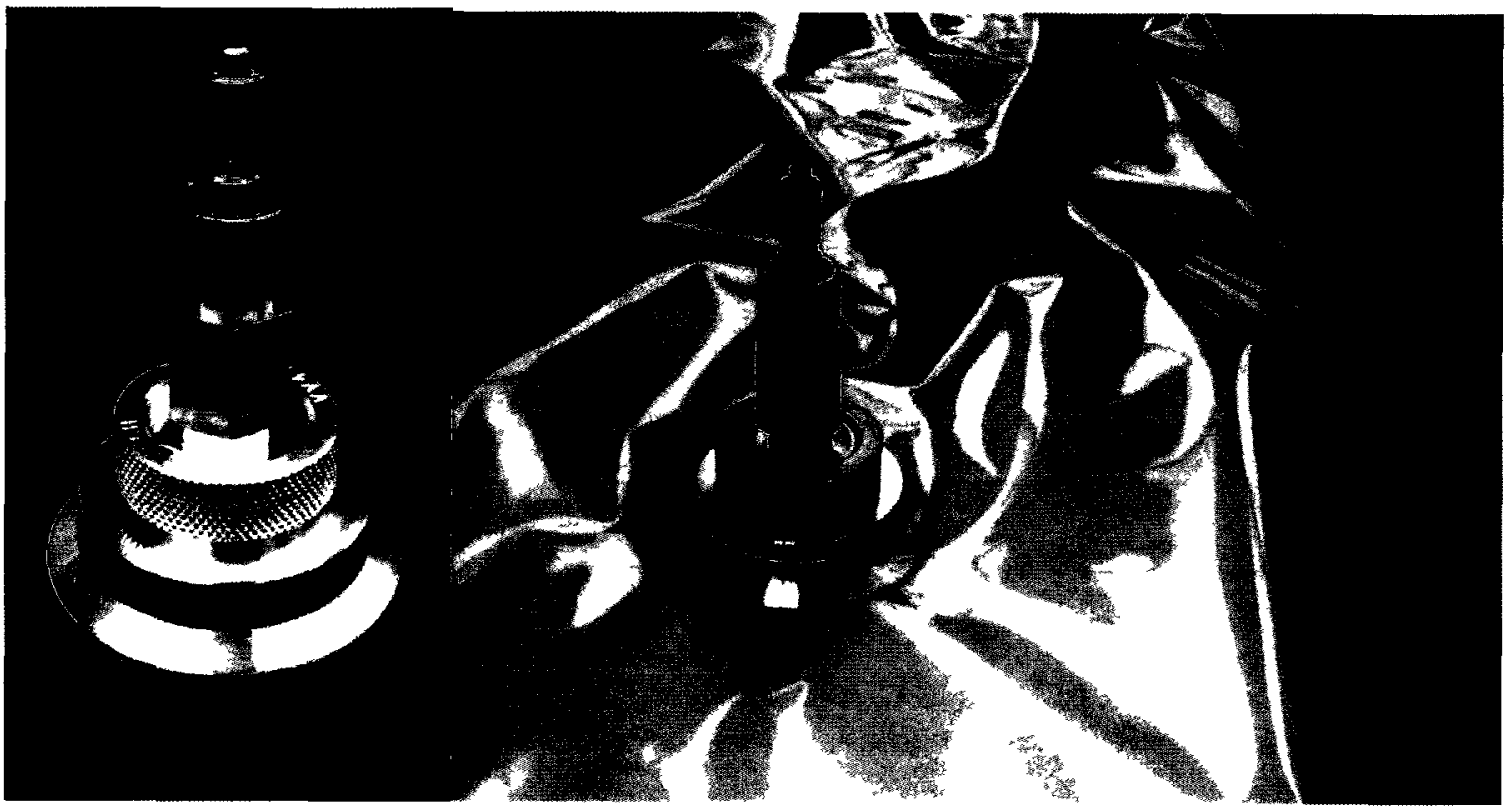

Figure 25: Vacuum valve. Picture at nght shows vacuum bagging between the elastomeric and metallic nungs of the valve. 


\subsection{I.4. Autoclave}

An autoclave is essentially an internally-heated pressure vessel. Aerospace components containing thermosets are generally cured in autoclaves to help remove air and volatiles during cure and to ensure a high service temperature of the resulting part [7]. Moreover, the application of pressure during the low-viscosity phase of the resin's curing process helps remove excess resin and entrapped gases [7]. This results in parts with low void contents (voids are cause by trapped gases forming bubbles in the resin) and high fibre volume fraction (by removing excess resin). The autoclave at NRC is a Baron Blakeslee BAC-46 (see Figure 26), which is electrically-heated, has a working diameter of $4 \mathrm{ft}(\mathrm{I} .22 \mathrm{~m})$, a maximum pressure of $200 \mathrm{psig}$ (I380 kPa) and a maximum temperature of $700^{\circ} \mathrm{F}\left(370^{\circ} \mathrm{C}\right)$.

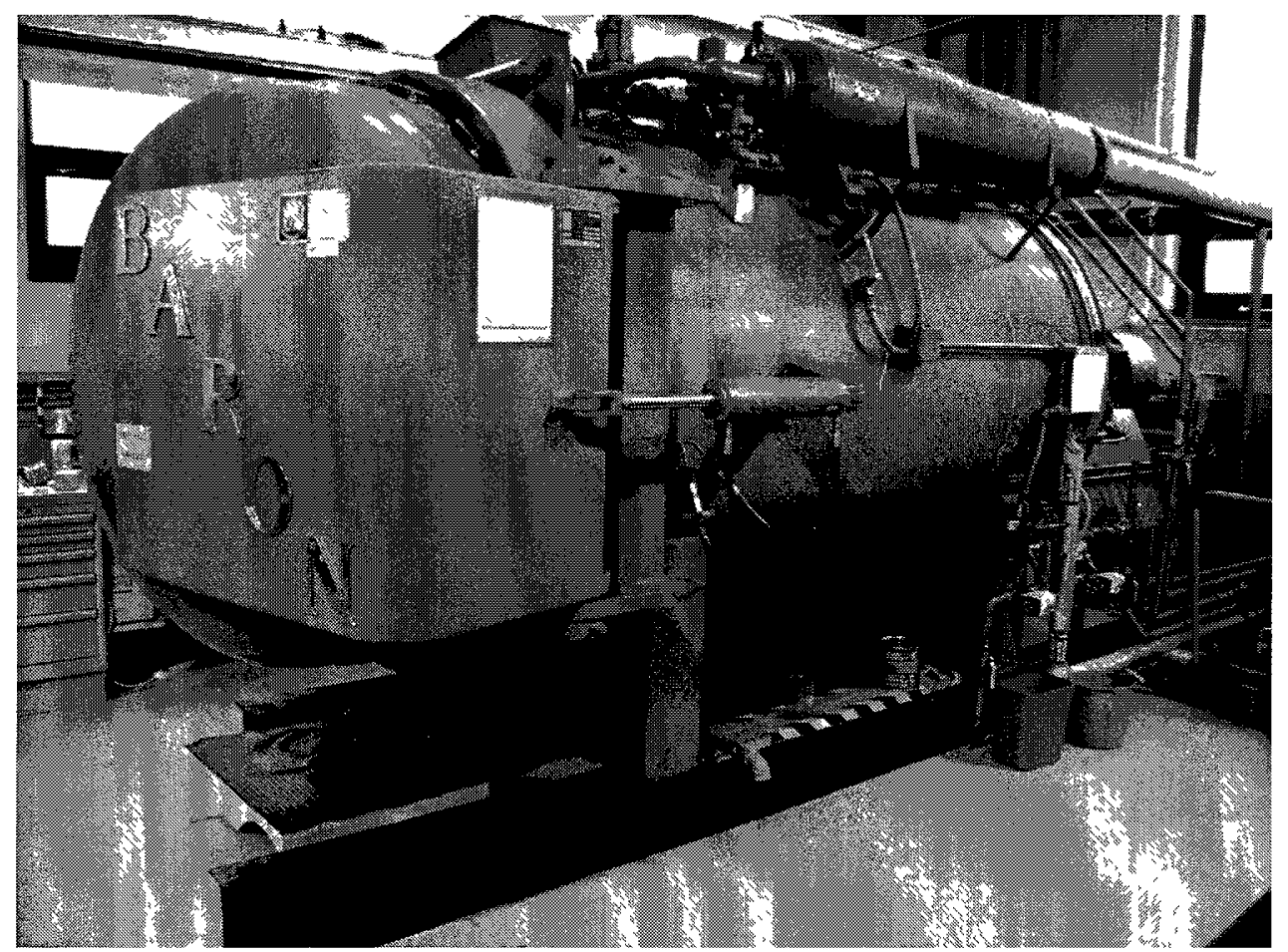

Figure 26: NRC's autoclave. 


\subsubsection{Saw}

The saw used for cutting carbon fibre/epoxy panels and sandwich panels was a custom-made table saw (see Figure 27) with a diamond blade (see Figure 28). For reasons of operator health and safety, strong vacuum sources were maintaned near the blade in order to reduce the amount of dust produced by this operation. The operator also wore approprate personal protective equipment.

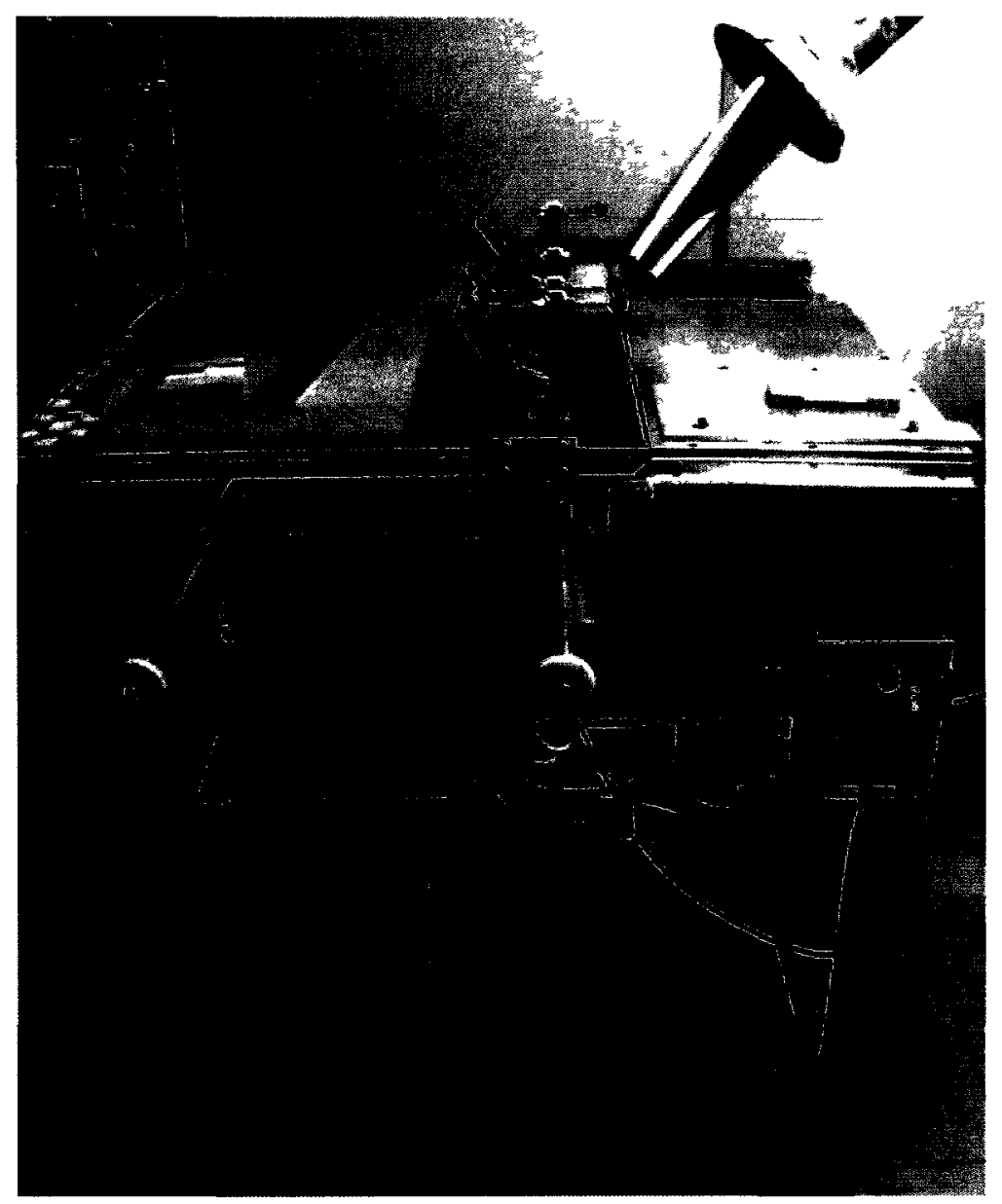

Figure 27: Table saw used to cut specimens from carbon fibre/epoxy and sandwich panels. 


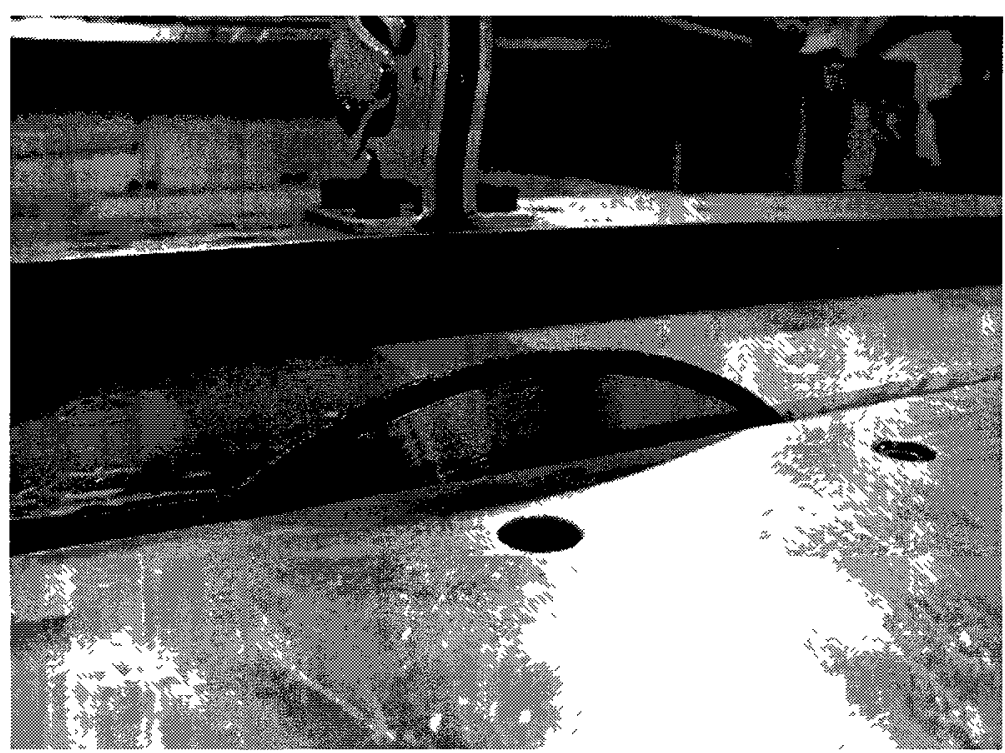

Figure 28: The diamond blade consists of a metal disk coated with synthetic diamond along the cutting edge.

The blade speed and feed rate were operator-controlled and not specified in advance. The operator used cues such as sounds and vibrations from the cutting disk and the resulting edges of the cut part to adjust settings.

\subsubsection{Equipment for Preparation of Specimens for Conditioning and Mechanical Testing}

Once the specimens were cut from the bonded panels, hinges were bonded to them in order to apply the load from the load frame to the specimen. In the case of the DCB specimens, this required that a hinge be bonded to both faces of the specimen, whereas only the top face of the SCB specimens required a hinge. The materials and equipment used for this procedure are discussed first. In the case of the DCB specimens, the hinge was bonded prior to conditioning, so that protection of the hinge bond from the conditioning environment was necessary, as discussed next. Finally, protection from the conditioning environment for the core material of the SCB specimens will be described. 


\subsubsection{Hinge Bonding Materials and Equipment}

Standard aerospace aluminum hinges known as MS-2000I continuous hinges were bonded to the specimens. They were purchased because of their high quality and because of an existing bonding fixture which allowed 6 specimens to be bonded to hinges at once, with the hinge "knuckle" centred on each of the specimens, as shown on Figure 29.

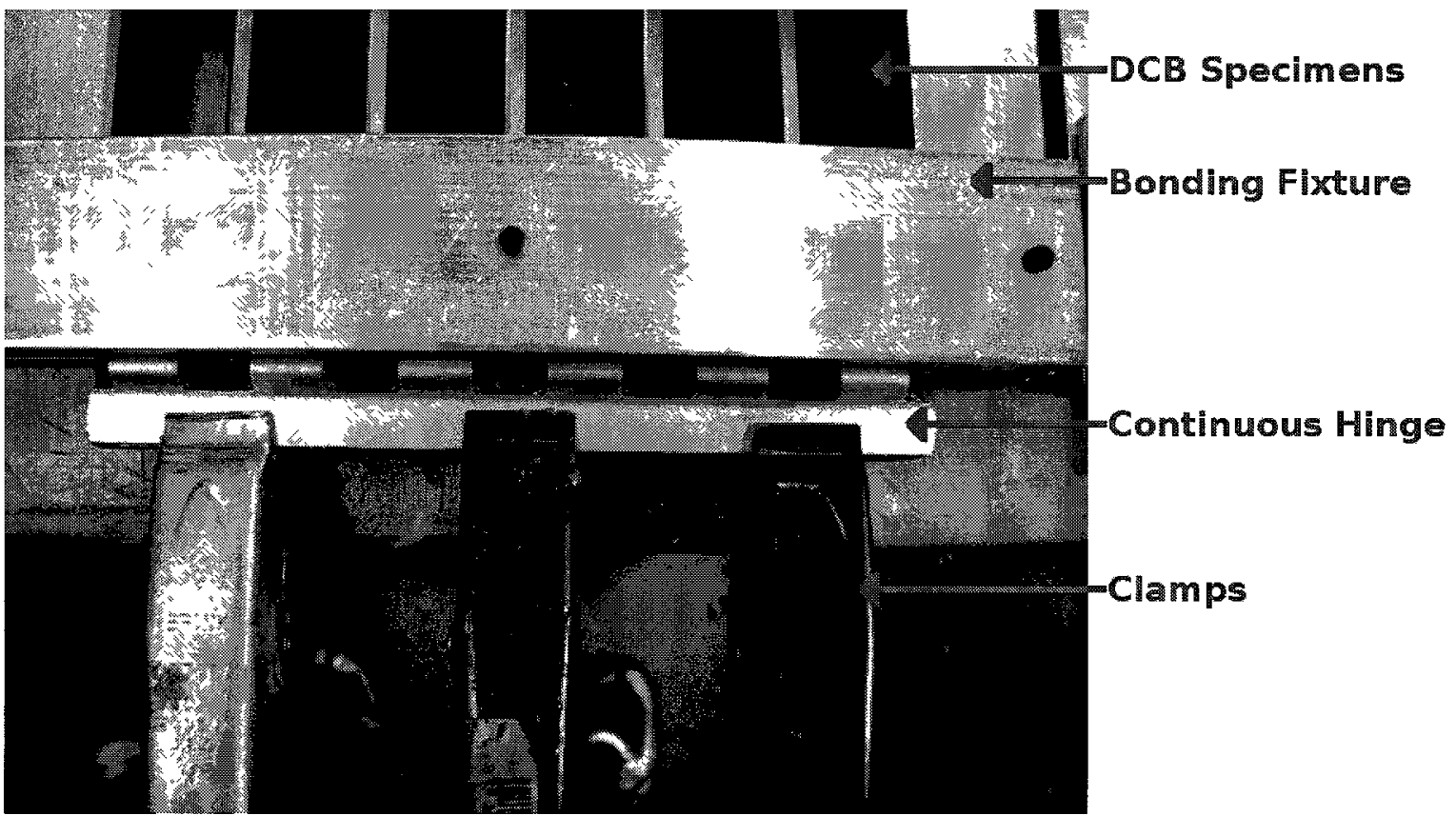

Figure 29: The hinge bonding fixture was designed to bond a length of hinge to 6 specimens at once while maintaining a $90^{\circ}$ angle between the hinge and specimens.

The adhesive used to bond the hinges to the specimens was EA9360, supplied by Henkel Corp. It was selected, on the recommendation of the manufacturer, for its retention of shear and peel strength after moisture conditioning. This two-part paste adhesive was mixed by a Thinky mixer (see Figure 30). To control the bondline thickness (nominal value and uniformity), $\mathrm{I} 25 \mu \mathrm{m}$ (0.005 inch) glass beads were used. 


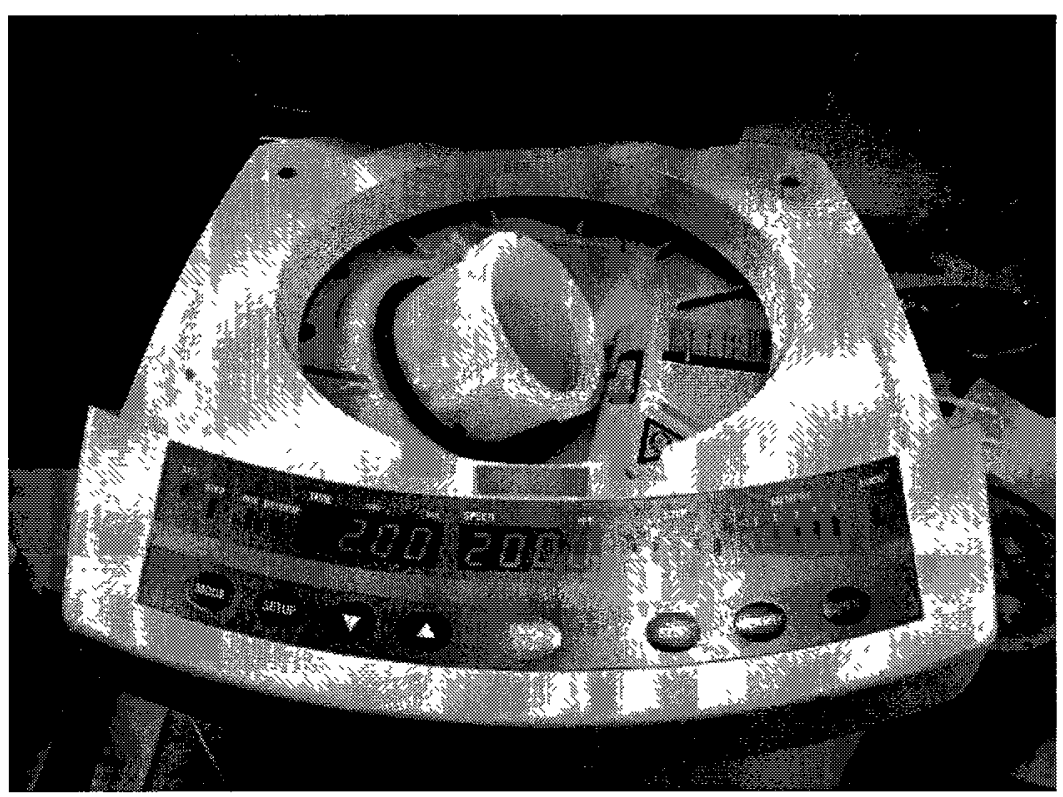

Figure 30: Thinky brand mixer.

\subsubsection{SCB Edge Sealing Materials}

The exposed core at the edges of the SCB sandwich coupons was protected during environmental conditioning so that the moisture diffusion would occur only through the laminated face sheets. In the past, two techniques had been used for this purpose: (i) completely covering the exposed core with silicone sealant, applied in successive thin layers to allow the sealant to cure; and (ii) aluminum and stainless steel tape covering the edges. Method (i) proved to be extremely time-consuming both in application of sealant prior to conditioning and removal prior to testing. Moreover, mass gain data for the specimens was of no value because it was not possible to distinguish between the mass gained by the large volume of sealant versus that gained by the face sheets and bondline. On the other hand, method (ii) proved ineffective, with water being found behind the tape after its removal. A new method was devised by technical staff at NRC. Taking inspiration from methods (i) and (ii), 
a 0.020 inch-thick 3000-series alummum sheet was bonded to the specimens using RTV-I62 silicone sealant. The procedure will be described in Section 2.5.3.3.

\subsection{SPECIMEN MANUFACTURING PROCEDURES}

\subsection{Laminate Manufacturing}

\subsection{I.I. Cutting Raw Material}

The raw pre-preg material was supplied in the form of 38 inch-wide rolls. Cutting plies from these rolls usually involved two people, one on each side of the cutting table. The roll was generally allowed to thaw over a few hours under forced air convection from two fans. Prior to cutting, the table was cleaned using a LabClean spray and lint-free wipes. The roll was then removed from the vacuum-sealed bag and unrolled onto the clean table. Using a clean square and straight edge, plies were cut using the edge of the roll as a reference for the direction of the fibres. When $45^{\circ}$ plies were required, the square was replaced by a triangle designed for that purpose. The cut plies were then stacked and placed in a vacuum-sealed bag and put in the freezer if layup was not done the same day.

\subsection{I.2. Layup and Debulking}

The layup procedure involved stacking the previously-cut plies and debulking them. In order to maintain a close control over the ply orientation, they were butted up against a straight edge during layup. The side against the straight edge therefore became the reference edge and was marked as such throughout the rest of the process, since it was the best avallable indication of the $0^{\circ}$ direction. 
Debulking was performed on stacks of fewer than 4 plies. This was to ensure that the debulking process would be able to remove as much of the entrapped air as possible- the larger the stack, the more difficult the debulking because of the increase in the number of possible entrapment sites. The debulked stacks were then combined, as necessary, to make the desired layup. For example, the I3-ply laminates used for DCB specimens included two 4-ply stacks and one each of 3- and 2-ply stacks. The debulking procedure developed at NRC for G40-800-24K/CYCOM 5276-I pre-preg is given in Table 5.

Table 5: Debulking cycle for Cycom 5276-I

\begin{tabular}{|c|c|}
\hline $\begin{array}{l}\text { Vacuum Pressure } \\
\text { Inches } \mathrm{Hg}(\mathrm{kPa})\end{array}$ & $\begin{array}{l}\text { Time } \\
\text { Minutes }\end{array}$ \\
\hline$-5(-17)$ & 5 \\
\hline$-\mathrm{IO}(-34)$ & 5 \\
\hline$-\mathrm{I} 5(-5 \mathrm{I})$ & 5 \\
\hline$-20(-68)$ & 5 \\
\hline$-28(-95)$ & I0 \\
\hline Total: & 30 \\
\hline
\end{tabular}

The curing procedure that followed layup and debulking will be described next.

\subsection{I.3. Cure}

In order to cure the ply stacks, tool plates were used as described in Sections 2.4.I.2 and 2.4.1.3. After sealing the bagging film, full vacuum pressure was applied to the part until it was ready to be placed in the autoclave. If necessary, the plate was maintained in this way overnight to start the cure the next morning. The working life of the pre-preg material easily allowed for this delay at room temperature.

The cure cycle applied by the autoclave is shown in Figure 3I. 
Autoclave Cure Cycle CYCOM 5276-1 CF Unidirectional Pre-preg.

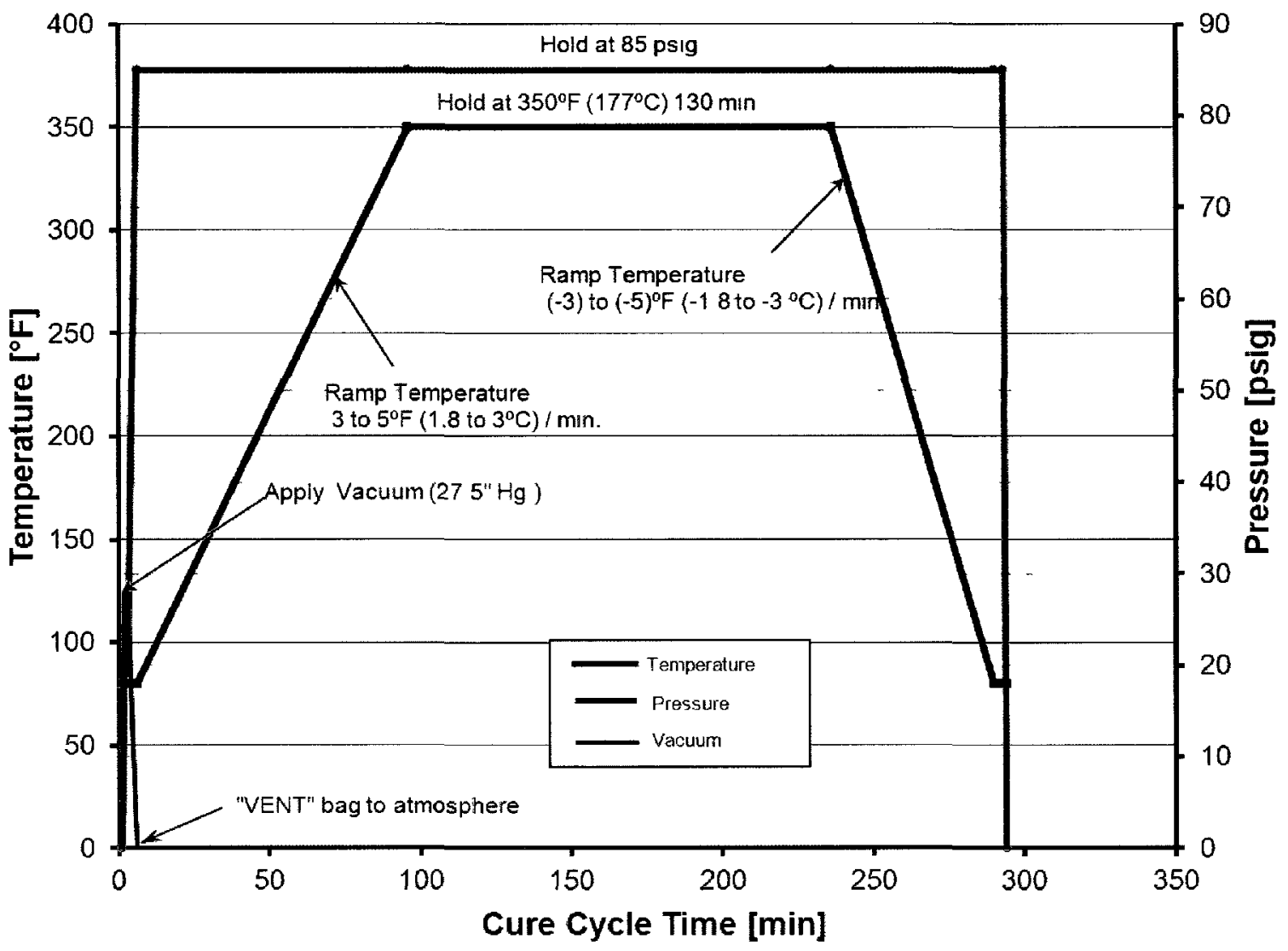

Figure 31: Cure cycle for CYCOM5276-I

The cured panels could be removed from the autoclave approximately 5 hours after the start of the cure cycle. The vacuum bag was removed and discarded, as well as the breather cloth, FEP film and sealant tape. The panels were carefully removed and the original reference edge marked using metallic-finish or paint-type markers. This edge was then used as a reference of the $0^{\circ}$ direction for the cutting operations that would follow. The resulting panels were then ready for bonding to either a core or another laminate, depending on the specimen type that they were intended for. DCB panel bonding will be described first. 


\subsubsection{DCB Specimen Manufacturing}

\subsubsection{Bonding Laminates}

Two plies of AFI63-2K adhesive were required per panel and were cut from rolls in the same way as the pre-preg plies (see Section 2.5.I.I). The bonding procedure then started by cleaning the trimmed face sheets (cured panels) with a solvent such as Isopropyl Alcohol or MEK. The panels were then dried in an oven at $80^{\circ} \mathrm{C}\left(176^{\circ} \mathrm{F}\right)$ for two hours. One surface of each panel was subsequently activated by grit-blasting it in a cross-hatch pattern. The nozzle was aimed at an angle of approximately $45^{\circ}$ with respect to the surface to avoid embedding any of the grit media in the panel. This process is shown in Figure 32.

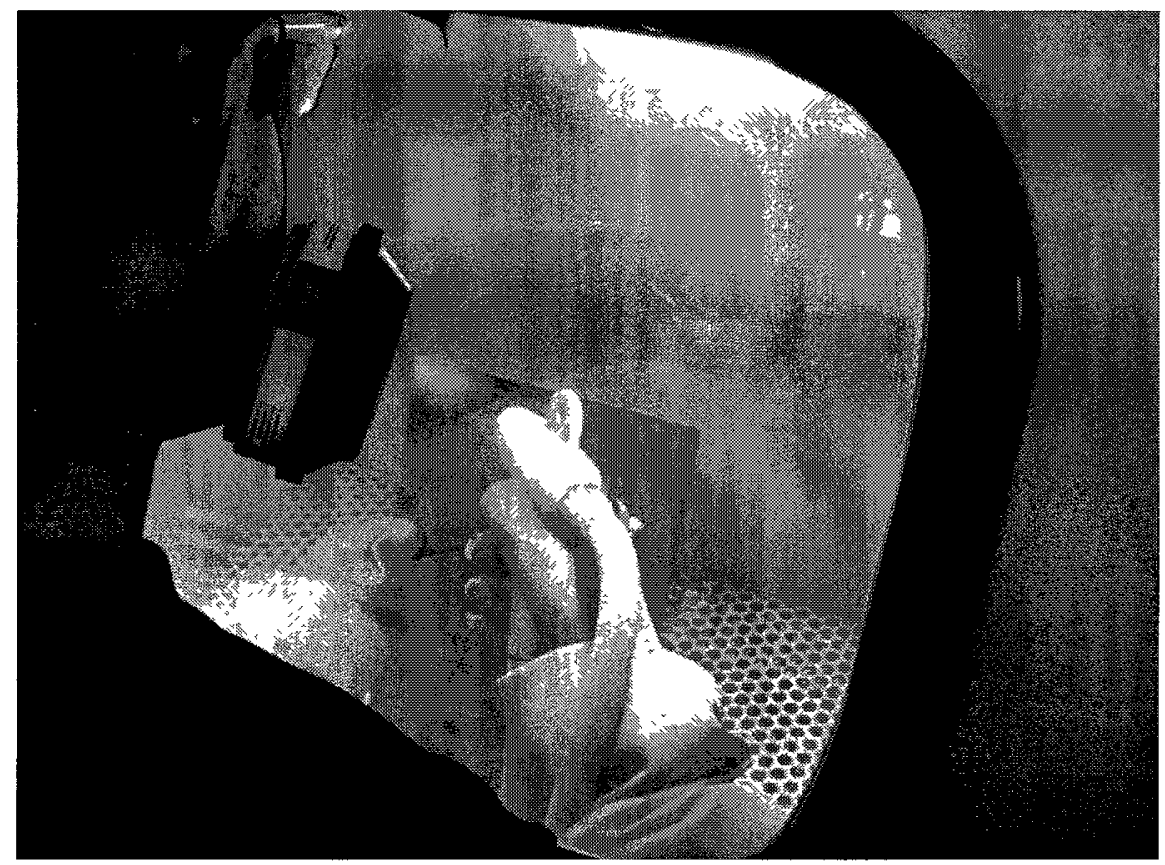

Figure 32: Grit blasting a panel before bonding activates its surface and increases its roughness as described in Chapter 1 .

A ply of film adhesive was applied to each of the activated surfaces of the face sheets and debulked according to the cycle described in Table 6 . 
Table 6: Debulking cycle for AFI63-2K

\begin{tabular}{|c|c|}
\hline $\begin{array}{l}\text { Vacuum Pressure } \\
\text { Inches } \mathrm{Hg}(\mathrm{kPa})\end{array}$ & $\begin{array}{l}\text { Time } \\
\text { Minutes }\end{array}$ \\
\hline$-5(-17)$ & IO \\
\hline$-10(-34)$ & I0 \\
\hline$-20(-68)$ & I0 \\
\hline$-28(-95)$ & 30 \\
\hline Total: & 60 \\
\hline
\end{tabular}

The debulked laminate/adhesive stacks were then stacked two-by-two with a layer of 0.0005 inch-thick PTFE release film over the desired crack area. See Figure 33 for the cutting plan that was devised and the location of the PTFE insert.

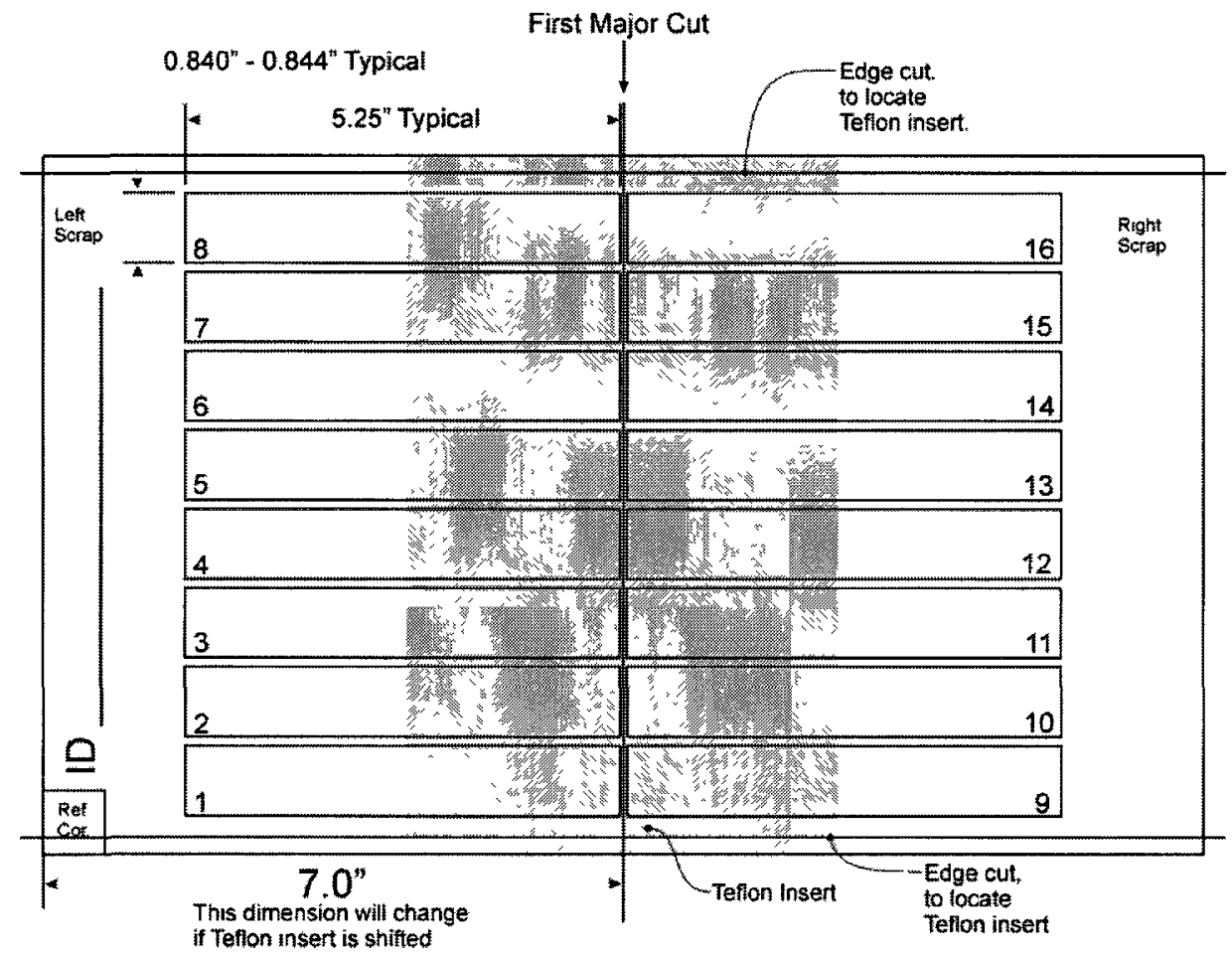

Figure 33: DCB panel cutting plan

The assembly was debulked again using the cycle shown in Table 6 and then cured using the cycle shown in Figure 34. 


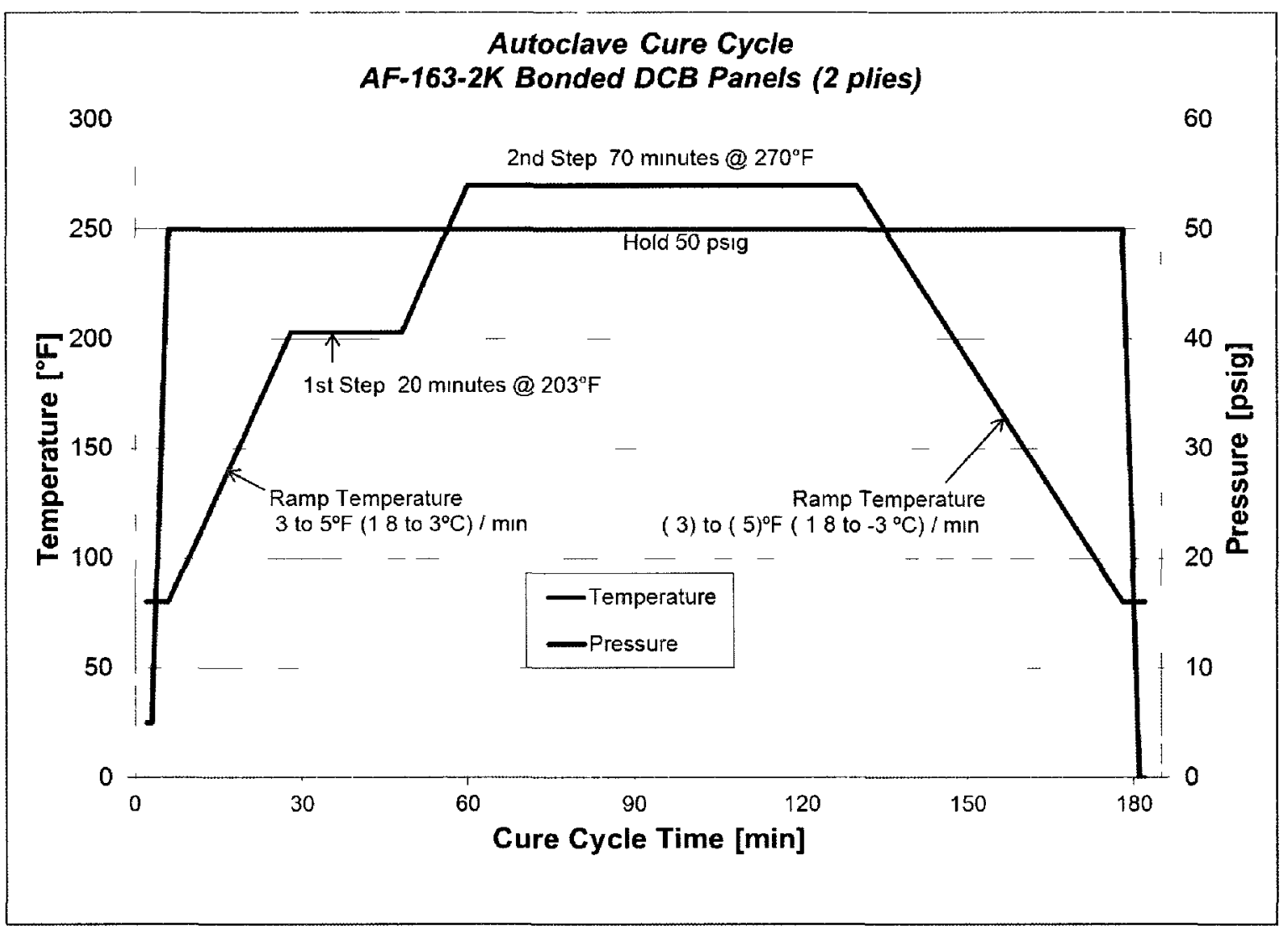

Figure 34: Cure cycle for two plies of AFI63-2K

This two-step cure cycle allowed a relatively large volume of adhesive to flow out thanks to the first hold around the temperature where the lowest viscosity was achieved. This was specified after some panels exhibited large variations in thickness between the middle and the edges, which indicated that the excess adhesive did not have time to flow out before hardening. In addition to a two-step cure, short shims1.e. a series of short shims with gaps between them rather than continuous shims that covered the length of the sides of the panels-ensured that the excess adhesive was able to flow out as needed. The bondlines of the resulting panels had a $0.152 \mathrm{~mm}$ (0.006 inch) thickness variation on average. The variation of bondline thickness along a given specimen from the panel rarely exceeded $0.076 \mathrm{~mm}(0.003 \mathrm{inch})$. 


\subsubsection{Cutting Panels}

The cured panels were first trimmed to remove the adhesive flash; the shims were easily removed from the flash because they had been coated with release agent. Once a rectangular panel with edges aligned with the $0^{\circ}$ and $90^{\circ}$ orientations (with respect to the fibre direction) were obtained, the cutting pattern shown in Figure 33 was followed using the table saw. The specimens that were cut out were then tested for fit in the hinge bonding fixture, whose use will be described next.

\subsubsection{Bonding Hinges}

The hinge bonding procedure had been developed in previous DCB studies and was replicated for this one. It involved cleaning and grit-blasting the end of the specimens, then placing them in the specially-designed fixture. They were then aligned such that the hinge would be bonded to the very end of the specimens as shown in Figure 29. The adhesive was mixed using the Thinky mixer and was applied to the top of the specimens. The hinge was placed on the adhesive and centered on the specimens. It was then clamped and allowed to sit at room temperature for approximately 6 hours. The entire setup-bonding fixture, specimens, and clampedon hinge-was then placed in an oven at $80^{\circ} \mathrm{C}\left(176^{\circ} \mathrm{F}\right)$ for 2 hours to achieve a full cure of the adhesive. The specimens were then flipped over and the procedure repeated for the hinge on the opposite face.

\subsubsection{SCB Specimen Manufacturing}

\subsubsection{Bonding}

The procedure to prepare the laminates and initially tack the adhesive plies to them was as described in Section 2.5.2.I, with the exception of the top face receiving two plies of adhesive, separated by a Teflon film in the position shown in Figure 37. 
The core was cut by hand using a sharp knife and a square. It was then cleaned by a blast of Nitrogen, the results of which can be seen in Figure 35.

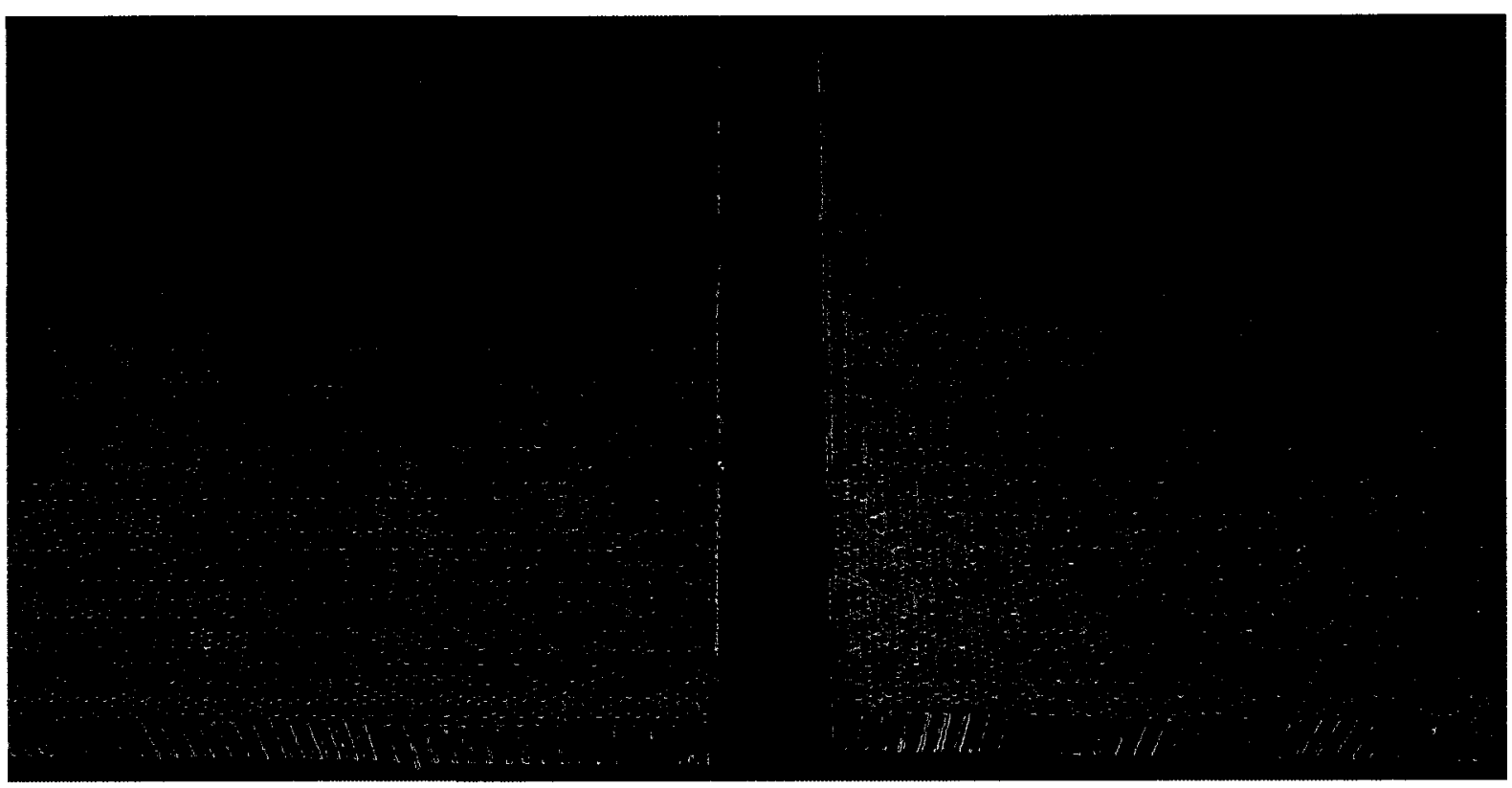

Figure 35: Core before (left) and after (right) nitrogen blast.

The tool plate was set up as in Figure 22, except that the panel was supported by a "picture frame" fixture, as shown in Figure 36. This supported the edges of the panel when autoclave pressure was applied, thereby protecting them from problems such as core crushing. The panel stacking sequence is shown in Figure 37. The height of the vertical parts of the picture frame exceeded the height of the panel, such that these parts formed a dam that prevented the top laminate from moving when the adhesive reached low viscosity. 


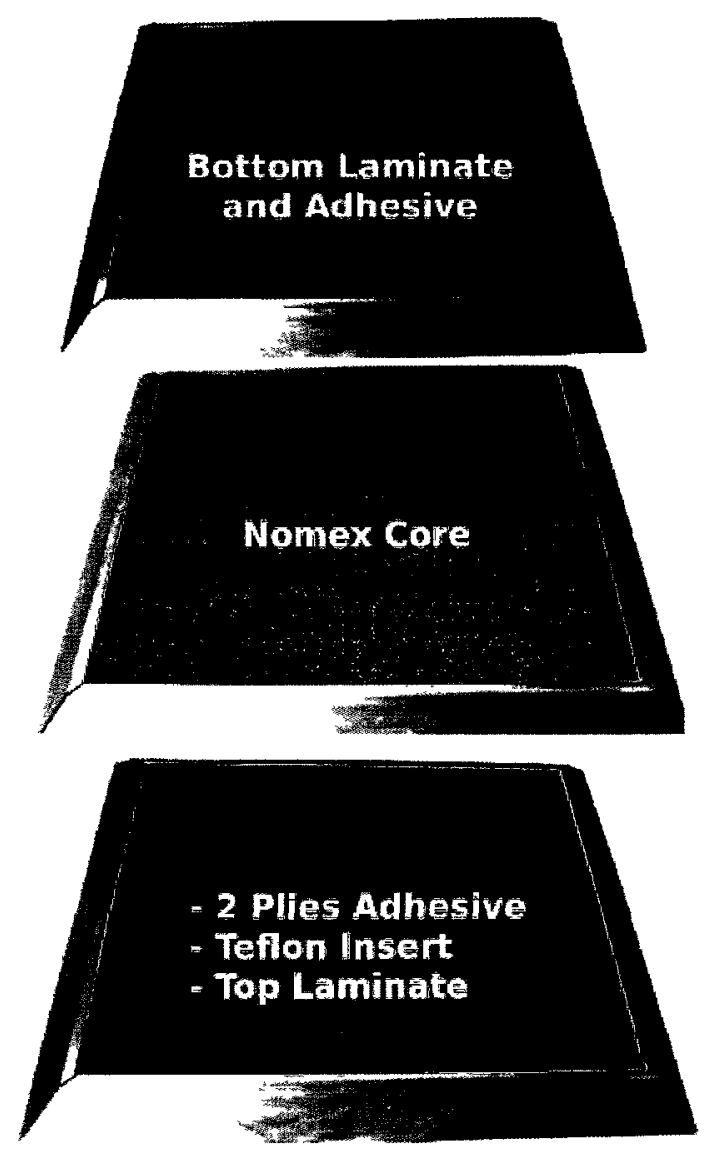

Figure 36: Picture frame fixture used during sandwich panel manufacturing.

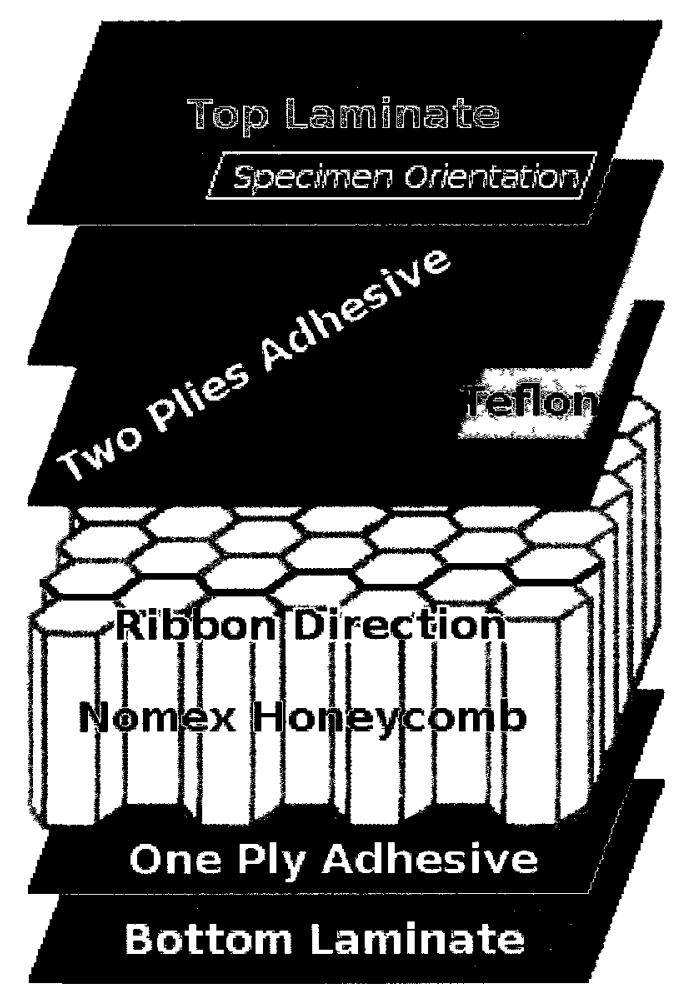

Figure 37: Schematic of sandwich panel stacking order and specimen orientation with respect to the panel.

\subsubsection{Cutting}

The sandwich panels were cut using a procedure similar to that described in Section 2.5.2.2. Because of their greater thickness, however, an 8- or I0-inch diameter diamond blade was used.

\subsubsection{Edge Protection}

Since the original objective of testing the sandwich structure was to study the effects of environmental exposure on the adhesive bond between the face sheets and core, it was necessary to protect the core from direct exposure to the environment. 
This was also required to ensure that the boundary conditions on the $47 \mathrm{~mm}$ (I.85 inch)-wide specimens were representative of a part of a large panel. The new sealing procedure introduced in Section 2.4.2.2 involved a thin aluminum "jacket" bonded to the specimens with sealant. To bend it to the correct shape, a solid metallic male mould was machined to dimensions slightly larger than those of a typical specimen. Using clamps and a small hammer, the edges of the metallic jackets were bent around the mould. The angles thus formed were then filled with RTV I62 sealant prior to inserting the specimen and closing the jacket around it. The sealant was allowed to cure while pressure was maintained on the jacket by clamps to ensure a snug fit. To ensure that a maximum surface area of the face sheets remained unsealed for diffusion, they were masked using tape, which was removed after the sealant cured. The resulting specimens are shown in Figure 38.

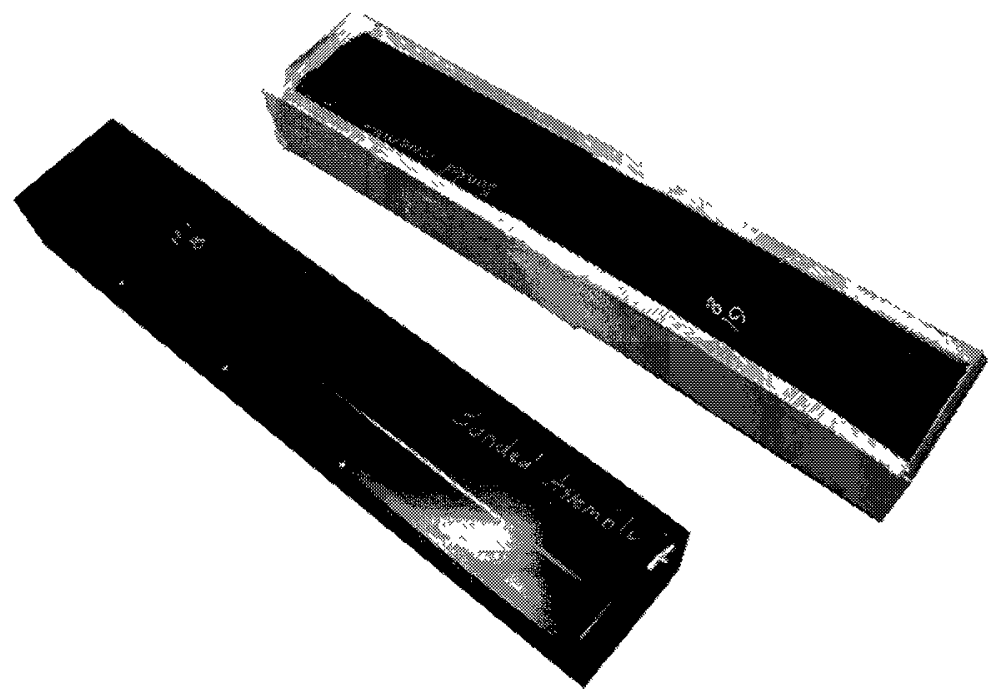

Figure 38: Left - SCB specimen with masked surface; Right - SCB with sealed edge and masking removed. 


\subsection{CONCLUSIONS}

This Chapter presented the procedures that were used to manufacture and prepare the DCB and SCB specimens that would form the basis of the subsequentlypresented experiments. A few key facts discussed in this Chapter are:

- ASTM D5528 is a standardized test for assessing the interlaminar fracture energy in unidirectional laminates.

- The specimens studied here could be described as "DCB joints" in that they are composed of two laminates adhesively bonded together. The fracture that will be studied is therefore within the adhesive rather than interlaminar.

- The recommendations and data reduction methods presented in ASTM D5528 were nonetheless applicable to these specimens.

- There is no standardized test for SCB specimens.

- The field of sandwich fracture mechanics is still somewhat new.

- Recommendations on SCB dimensions were published after the specimens for this study had been manufactured, so that the face sheets of the specimens studied here are not as stiff as required. This is corrected as discussed in Chapter 5.

- The materials, equipment and procedures described in this Chapter were the result of the researcher's access to composite manufacturing facilities and staff at the National Research Council's Institute for Aerospace Research.

- Of particular importance to the project were the alreadyestablished procedures for lay up, debulking, tooling, curing, cutting, and preparation for conditioning. Many procedures were presented here very briefly and without justification of the details (e.g. debulking cycles and cure cycles) because previous work by the NRC staff had already established the best course of action. 
- As such, only "newly-gained" experience was thoroughly discussed here, for example the details surrounding the SCB specimen sizing as well as the procedure for sealing their exposed edges.

Since the purpose of the work presented here was to assess the effect of exposure to different environments on the fracture toughness of these two joint configurations, the step that followed the completion of manufacturing was, for most specimens, environmental conditioning. This process is described in the next Chapter. 


\section{Chapter 3: Environmental Conditioning and Diffusion Analysis}

In this Chapter, the selected environmental conditions and the equipment used to maintain them will be described first. Next, the mass measurement procedure, used to assess the progress of moisture absorption, as well as the analysis of moisture diffusion for the pre-preg material used in manufacturing all specimens will follow. It was found that the pre-preg does not follow the Fickian trend exactly, and that the surface of the epoxy in the laminates was degraded by water causing chain scission. Using the Fickian model as a tool, comparisons are made between the artificial environment and lower, probably more realistic temperatures to find how the 3-4 months of conditioning at $70^{\circ} \mathrm{C}$ would compare to temperatures in the range of 20 $60^{\circ} \mathrm{C}$.

Chapter I Literature Review

Chapter 2 Manufacturny of $D$ C CB and SC B Specimens

Chapter 3 anvironmental Conditioning and Diffusion Data Analysis

Chapter 4 The Effects of the Environment on the Fracture loughness of Bonded Lammates

Chapter 5 Preliminary Study of the Eiffects of the Fnyronment on the Disbond Fracture Toughness of Sandwich Structures

Chapter 6 Overview of Contribution and Recommendations for Future Work Appendix A Summary Sheets for DCB Specumens

Appondix B Stummary Shects for SCB Specmens 


\section{I. INTRODUCTION}

The intent of this study was to assess the effects of moisture and salt water on the fracture toughness of bonded composite specimens-either bonded laminates or sandwich composites - using an aerospace adhesive. To study the effect of each factor and its combination with others, 7 different environmental conditions were selected. These conditions will be presented first. Next, the equipment required to maintain the environments will be described. Finally, the procedure for determining moisture uptake by mass measurements, which is the typical method used in similar work, will be followed by analysis of the mass data that was obtained for the materials in this study.

\subsection{SELECTED CONDITIONS}

Given the nature of SAR helicopter missions, conditioning involving salt water was added to the test matrix for the NRC project preceding this one. One major issue that was encountered in that project was the difficulty in achieving high moisture content in the specimens in a reasonably short time, due to the low maximum temperature of the salt-spray chambers. The solution to this problem was to build custom immersion tanks as described in Section 3.3.2.

To see whether environmental conditioning at a temperature approaching the wet glass transition temperature of the adhesive system $\left(82^{\circ} \mathrm{C}\right.$ or $\left.180^{\circ} \mathrm{F}[76]\right)$ would significantly change the fracture toughness of the bonded specimens, two temperatures were selected. The first, $70^{\circ} \mathrm{C}\left(158^{\circ} \mathrm{F}\right)$, was the limit stated in ASTM D5229 for $121^{\circ} \mathrm{C}\left(250^{\circ} \mathrm{F}\right)$-curing epoxy, while the second, at $82^{\circ} \mathrm{C}$ $\left(180^{\circ} \mathrm{F}\right)$, was the limit set for $177^{\circ} \mathrm{C}\left(350^{\circ} \mathrm{F}\right)$-curing epoxy [78]. Recall from 
Chapter 2 that the laminates were cured at $350^{\circ} \mathrm{F}$ while the adhesive was cured at $250^{\circ} \mathrm{F}$.

Finally, to see how conditioning by liquid immersion differed from conditioning in humid air, both of these environments were included for DCB specimens.

In an attempt to study synergistic effects while isolating certain factors, 7 different conditions were considered to be of interest, as shown in Table 7.

Table 7: Summary of selected environmental conditions for DCB specimens

\begin{tabular}{|l|l|}
\hline Name & Condition Description \\
\hline RTA & Room Temperature, Ambient humidity \\
\hline HVWN & $\begin{array}{l}\text { High temperature }\left(82^{\circ} \mathrm{C}\right) \text {, Vapour }(95 \% \text { r.h. }) \text {, Fresh Water, No freeze- } \\
\text { thaw cycles }\end{array}$ \\
\hline HIWN & $\begin{array}{l}\text { High temperature }\left(82^{\circ} \mathrm{C}\right) \text {, Immersion, Fresh Water, No freeze-thaw } \\
\text { cycles }\end{array}$ \\
\hline IVWN & $\begin{array}{l}\text { Intermediate temperature }\left(70^{\circ} \mathrm{C}\right) \text {, Vapour }(95 \% \text { r.h. }) \text {, Fresh Water, No } \\
\text { freeze-thaw }\end{array}$ \\
\hline IIWN & $\begin{array}{l}\text { Intermediate temperature }\left(70^{\circ} \mathrm{C}\right), \text { Immersion, Fresh Water, No freeze- } \\
\text { thaw cycles }\end{array}$ \\
\hline HISN & High temperature $\left(82^{\circ} \mathrm{C}\right)$, Immersion, Salt water, No freeze-thaw cycles \\
\hline IISN & $\begin{array}{l}\text { Intermediate temperature }\left(70^{\circ} \mathrm{C}\right), \text { Immersion, Salt water, No freeze-thaw } \\
\text { cycles }\end{array}$ \\
\hline
\end{tabular}

SCB specimens were part of a preliminary study and were only subjected to five conditions: fresh water immersion was excluded.

All conditions other than RTA required specialized equipment, as described in the next Section. 


\subsection{SPECIMEN CONDITIONING EQUIPMENT}

Environmental chambers were used to condition most of the specimens.

However, in order to condition in salt water without damaging the metallic chambers, separate equipment containing salt water was required. The environmental chambers and custom-made salt water chambers will be described in this Section.

\subsection{Conditioning Chambers}

Two chambers were used to condition the DCB and SCB specimens. Both were capable of wide temperature ranges and could be programmed to achieve complex cycles, but for this experiment, they were only set to hold a given temperature and humidity over a long period of time. The first chamber, an ESPEC Model ESX$3 \mathrm{CA}$, had interior dimensions of $600 \times 800 \times 850 \mathrm{~mm}^{3}\left(23.6 \times 31.5 \times 33.5\right.$ inch $\left.^{3}\right)$ and held a temperature of $70^{\circ} \mathrm{C}$ and a humidity of $95 \%$ for $4-5$ months of conditioning. An upper bound for relative humidity of $85 \%$ is given in $\mathrm{CMH}-17$ [79], but in this study, maximising moisture content was desired. The second chamber was a similar but older model ESPEC that was set to $82^{\circ} \mathrm{C}\left(180^{\circ} \mathrm{F}\right)$ and $95 \%$ R.H. The simultaneous availability of the two chambers for this project was difficult to achieve at times and this particularly affected the SCB specimens, which were not all available for testing at the time of writing.

\subsubsection{Custom-made Salt Water Immersion Tanks}

The Institute for Aerospace Research at the NRC (NRC-IAR) had performed numerous corrosion studies prior to this project and therefore had a number of salt spray and immersion tanks available. However, the main limitation with the existing systems was the low maximum temperature of around $38^{\circ} \mathrm{C}$. As explored in Chapter $\mathrm{I}$, the diffusion of moisture into polymers is strongly related to the temperature of 
the process. Often, in order to minimize the time taken for moisture to diffuse in lab environments, a high temperature that remains below the (wet) $T_{g}$ of the polymer being studied is used. In the case of the epoxy polymers used in the matrix of the laminates, temperatures as high as $80^{\circ} \mathrm{C}$ were acceptable, though the lowertemperature curing of the adhesive would suggest a maximum temperature of $70^{\circ} \mathrm{C}$. In order to achieve these high temperatures, a new system was manufactured for this project. The design process, materials and manufacturing of the system will be briefly described.

\subsubsection{Design Requirements}

The system was expected to be able to hold salt water at $82^{\circ} \mathrm{C}$ over long periods of time. Heat-up time was not important, but quick enough reaction to changes in temperature and uniformity of temperature throughout the tank were desired (a requirement of roughly $\pm 3^{\circ} \mathrm{C}$ was the goal). The tank was required to contain $25 \mathrm{SCB}$ specimens ( $\mathrm{I} x \mathrm{I} .85 \times \mathrm{IO}$ inch $^{3}$ ) with gaps between them of roughly I inch all around. Finally, it was required that the immersion system be safe: this meant keeping electric wires and connectors away from potential water leaks, and preventing damage to other equipment or property if the tank should fail.

\subsubsection{Materials}

The main concern for this system was the exposure of parts to the corrosive salt environment. As such, all materials coming into contact with the water were nonmetallic.

$610 \times 305 \times 305 \mathrm{~mm}^{3}\left(24 \times 12 \times 12\right.$ in $\left.^{3}\right)$ glass aquariums became the leading candidate for the tanks once confirmation was received from the manufacturer regarding the adhesive used to fabricate them. The silicon-based adhesive used to join 
the five panes of glass (similar to that used in kitchens and bathrooms) was found to be capable of withstanding temperatures up to $204^{\circ} \mathrm{C}\left(400^{\circ} \mathrm{F}\right)$ once cured and was designed to withstand moisture. Since there was no difference between commercially available salt water and fresh water fish tanks, it was assumed that the fact that the tank would hold salt water should be of no concern.

$610 \times 25.4 \mathrm{~mm}^{2}\left(24 \mathrm{xI} \mathrm{in}^{2}\right)$ wire-wound rubber heaters that could produce $5 \mathrm{~W} /$ inch $^{2}$ were available at the NRC. A small number of such elements could easily provide sufficient power to maintain the required temperatures. These were supplied by Minco. They were bonded to the outside of the aquarium surfaces using twosided tape capable of withstanding the design temperatures. Three heaters were bonded to the bottom of the tank, and three per long side, approximately covering the bottom half of those sides as shown in Section 3.3.2.3.

Four small PID temperature controllers were also available at the NRC and were already set up to run ovens. In running an immersion system consisting of two tanks, two controllers could be used to measure water temperature, and two could be used to limit the heater temperature (to avoid very high temperature gradients across the glass during heat up). The PID controllers were supplied by Omega.

K-type thermocouples with polymeric insulation over their entire section were purchased to measure the salt water temperature for the controller. These were supplied by Omega as well.

In order to maintain a constant temperature and reduce water loss through evaporation, a piece of fibreglass insulation, well covered with FEP film, was used to cover each tank. 
The salt used to raise the water's salt concentration to the average of the ocean (24.5 g/L, as defined by ASTM DI I4I [80]) was lab-grade $\mathrm{NaCl}$, supplied by Canadawide Scientific.

\subsubsection{Fabrication}

The tanks were fabricated as shown schematically in Figure 39 with electrical and control system wiring work performed by an experienced technician at NRC.

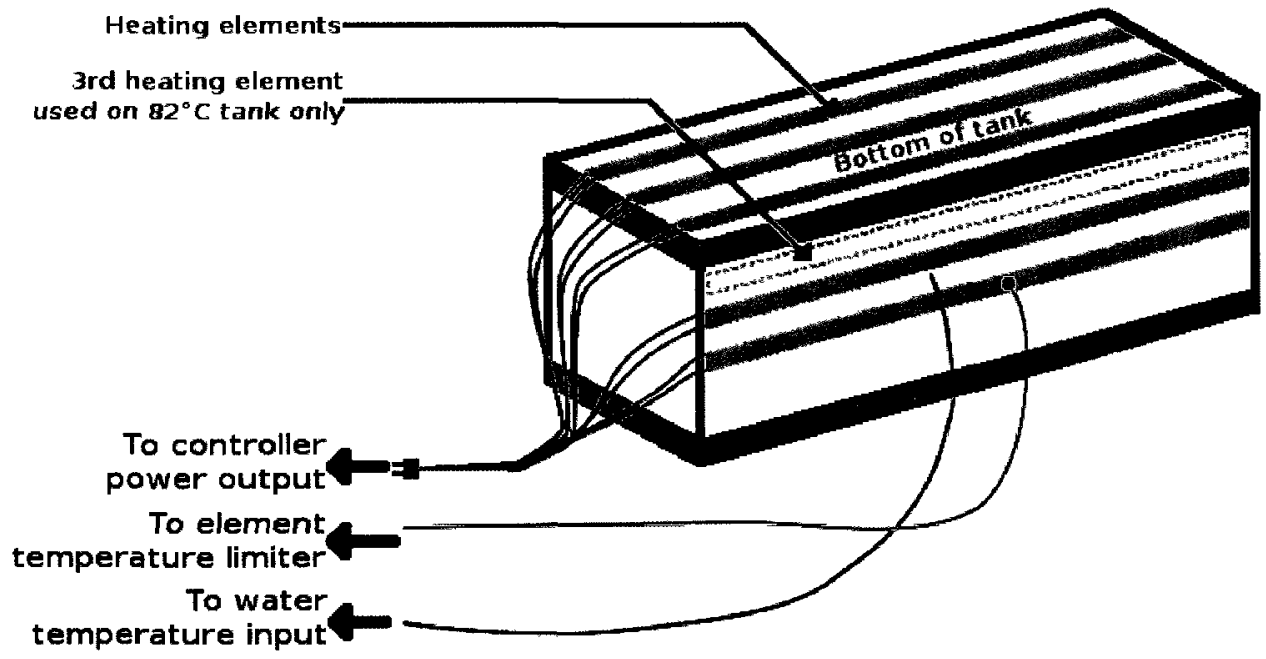

Figure 39: Schematic of heated salt water tank (shown upside-down)

\subsubsection{Testing}

A long period of testing and troubleshooting followed the fabrication of the immersion tanks. Firstly, the control system was changed from its initial setup to allow for easier programming of temperature limits on the heating elements. Next, issues with water cleanliness were spotted after approximately I week of continuous use. It was discovered that the tap from which the water was obtained contained a high amount of rust, so that de-ionized water (produced at NRC) was subsequently specified. 
The temperature uniformity throughout the tank and accuracy of the control thermocouple measurement were tested. Uniformity at a given time was found to be, at worst, $\pm 2^{\circ} \mathrm{C}\left(3.6^{\circ} \mathrm{F}\right)$. A calibrated thermocouple reader with separate thermocouple was used to measure temperature at different points in the tank and at different depths. The accuracy of the control input temperature, however, was not as good. It was found that, most times, the control measurement of temperature was as much as $3^{\circ} \mathrm{C}\left(5.4^{\circ} \mathrm{F}\right)$ below the set point and was never seen to go over it. This situation was considered acceptable since $[79]$ sets $70^{\circ} \mathrm{C}\left(158^{\circ} \mathrm{F}\right)$ and $82^{\circ} \mathrm{C}\left(\mathrm{I} 80^{\circ} \mathrm{F}\right)$ as upper limits of artificial conditioning temperatures.

Once the tanks had been successfully run for 2 continuous weeks at temperature, it was decided that the system was safe and the temperature stable enough for specimen conditioning.

The DCB specimens were hung, using string, such that the entire uncracked bonded area, as well as the tip of the crack, was completely submerged. Despite being kept out of the salt water, many hinges corroded over the months of conditioning and needed replacing prior to testing. Other specimens for the same project were immersed in the salt water and had a relatively thick layer of silicone sealant covering the hinges. Whether this method was superior is unknown at the time of writing.

The SCB specimens were allowed to float, Teflon-side-down, on the salt water surface. This did not allow a very large number of specimens to be conditioned, but only 6 per tank were required for this project (there was enough space for I0). A method of keeping the specimens below the water would be required to simultaneously condition 25 specimens, as originally intended and stated in Section

\subsubsection{I}




\subsection{MASS MEASUREMENT PROCEDURE}

During specimen conditioning, mass gain data was obtained for the laminates of the DCB and SCB specimens. This section describes the mass measurement procedure, which was used to measure the amount of water that was absorbed by the specimens.

\subsection{ASTM D5229 Procedures}

Procedures A and B of ASTM D5229 were used in this project. Procedure A, used to determine diffusion parameters of a material, required square specimens with a (side length) to (thickness) ratio of I00 or more to be manufactured [78]. Unidirectional 6-, 10- and 13-ply specimens were manufactured and cut to dimensions of $76.2 \times 76.2 \mathrm{~mm}^{2}\left(3 \times 3 \mathrm{inch}^{2}\right)$, I27 $\times$ I $27 \mathrm{~mm}^{2}\left(5 \times 5 \mathrm{inch}^{2}\right)$ and $165 \times 165 \mathrm{~mm}^{2}\left(6.5 \times 6.5\right.$ inch $\left.^{2}\right)$, respectively. This was required for the diffusion characteristics to be considered one-dimensional (almost I00\% through the thickness). These specimens were placed in $70^{\circ} \mathrm{C}\left(158^{\circ} \mathrm{F}\right)$ fresh water, salt water, and vapour, to observe any differences in diffusion behaviour caused by the type of conditioning environment.

Procedure $B$ was used to condition the $\mathrm{DCB}$ specimens to equilibrium. It states that specimens can be weighed weekly and defines "effective moisture equilibrium" as the state of the specimen when two consecutive measurements are less than $0.01 \%$ apart $[78]$. SCB specimens were not weighed during conditioning because of the large amount of extra mass added to them by the aluminum jackets (which might lose mass through corrosion) and silicone sealant (which gained mass during its moisture-activated cure). It was estimated that 3-4 months of conditioning should suffice for the SCBs, based on the fact that 26-ply DCBs (recall that two I3-ply 
laminates were bonded together) took about that long and the SCBs had 8-ply facesheets exposed to the environment only on one side.

\subsubsection{Mass Measurement Requirements}

All specimen masses were measured using a calibrated and shielded (from air currents and small vibrations) 0.I mg-precision scale. Both types of specimens (i.e. diffusion and $\mathrm{DCB}$ ) were weighed at frequent intervals at the beginning of exposure and less frequently as the diffusion period progressed. The mass gain data (Section 3.5) show that the weighing schedule that was adopted was sufficient to obtain a good characterisation of the diffusion process.

ASTM D5229 provides a time interval to use for assessing whether specimens have "sufficiently" approached equilibrium, defined in the standard as "when the average moisture content of the material changes by less than $0.01 \%$ within the span of the reference time period" [78]. For specimens with unknown diffusion characteristics, the reference time period is 7 days. Hence, once two mass measurements separated by 7 days are within $0.01 \%$ of each other, the specimen is considered to be in equilibrium and may be tested. Although some knowledge of diffusion characteristics for epoxy was available, the more conservative reference time period of 7 days was adopted.

\subsection{RESULTS OF DIFFUSION STUDY}

\subsection{Comparison of Conditioning Environments}

In the literature review presented in Chapter I, it was found that some researchers observed a difference in the diffusion rate for fresh water versus salt water [7I-8I], and others reporting none $[13,82]$. Furthermore, differences between 
immersion and vapour were noted. In order to observe what effect the environment had on the diffusion process with the material used in this study, six I0-ply specimens were used, i.e. two per environmental condition. The results are summarized in Figure 40.

It is quite clear from Figure 40 that, for the material studied and the salt concentration considered, there was no observable change in diffusion behaviour between salt water and fresh water immersion.

The second observation is that immersion led to a nearly $20 \%$ higher moisture content than vapour after 1600 hours. A note in [79] (Section 6.3.3.I) confirms that even conditioning coupons at I00\% R.H. does not necessarily yield the same results as immersing them. A brief explanation that matrix components can dissolve into water is given, but it is not stated whether this causes specimens to gain more or less mass when immersed [79]. One might expect a mass loss from the dissolution of matrix components, but the available volume to be occupied by water is increased so no simple conclusion can be drawn. To add to the complexity, an apparent degradation of the polymer structure from water was observed, as described next. 


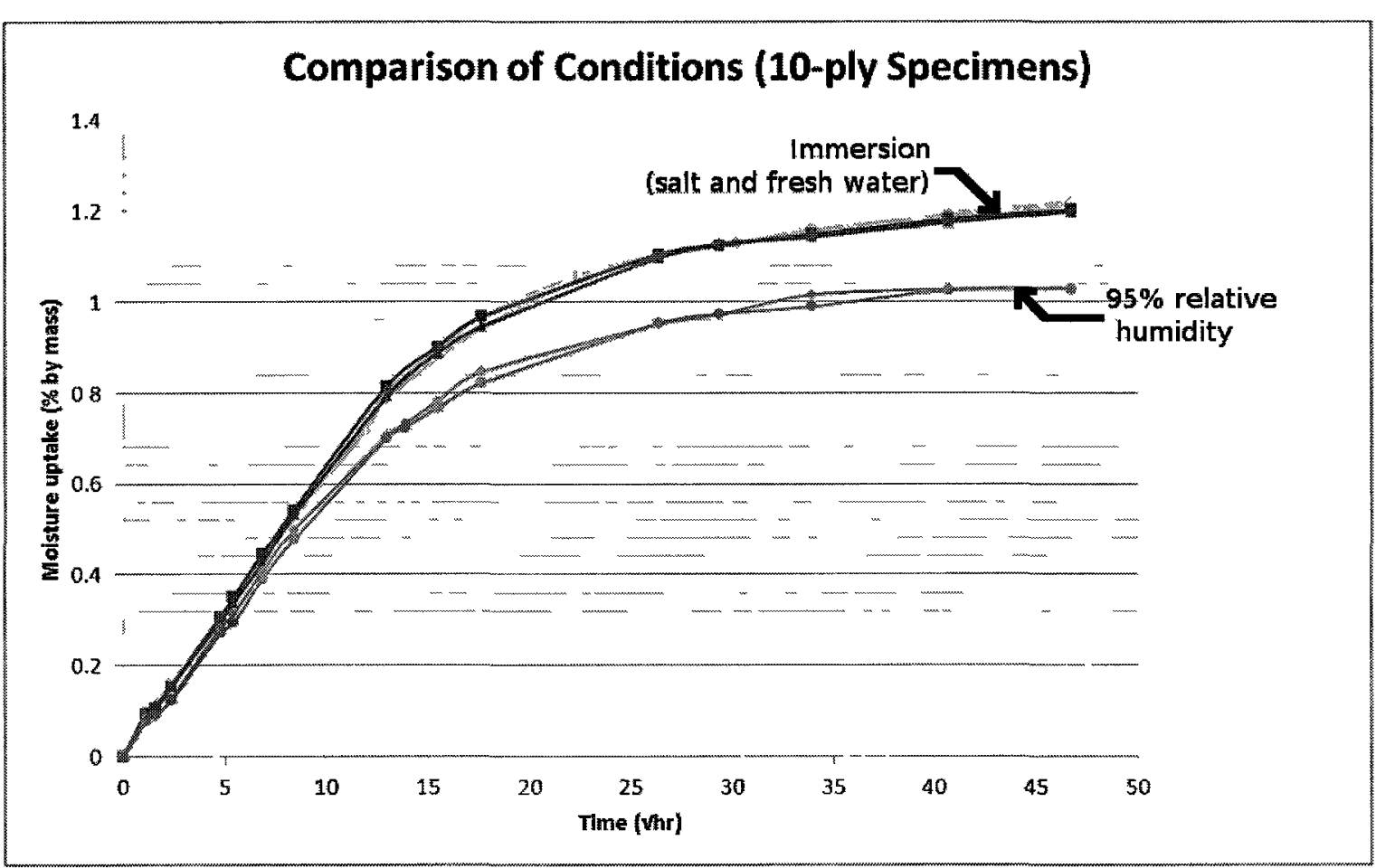

Figure 40: Comparison of diffusion characteristics for IO-ply specimens in three different environments

\subsection{I.I. Visual Observation of Polymer Degradation in Water}

In the literature, a chain scission phenomenon of water on epoxy was described and analysed [6I-62]. However, no information on the exact effects of chain scission and dissolution of matrix components on the subsequent diffusion characteristics of the material could be found, making it difficult to explain the difference in diffusion behaviour between the two conditions.

The photographs in Figure 4I and Figure 42 show that polymer degradation did lead to visible products in the immersion water. This was assumed to be the result of a similar process to that described in [83] but was not investigated further, due in part to the complexity of the chemical identification methods typically used in such analyses. 


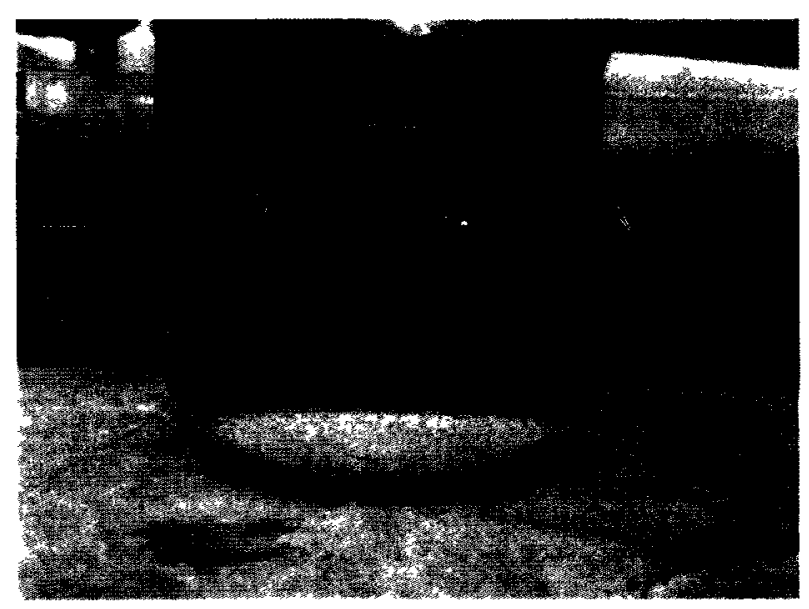

Figure 4I: Beaker filled with water that previously contained specimens. Visible particles are believed to be degradation products from the interaction of water and epoxy.

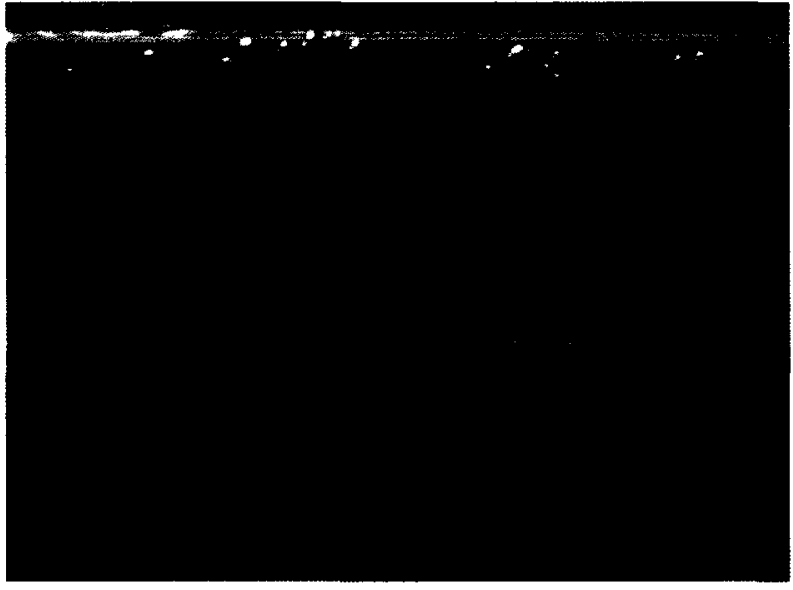

Figure 42: Close-up view through side of immetsion tank. Orange heating element and particles in water ate visible.

The chemical nature of the particles is likely to be a combination of molecules containing $-\mathrm{OH},-\mathrm{NH},-\mathrm{C}=\mathrm{O}$, and perhaps unreacted hardener, as explained in $[83]$ and $[62]$.

The difference between conditioning in humid air and immersing in water might therefore be that the liquid water provides a medium in which degradation products can be transported out. Degradation products in the vapour-conditioned specimens may remain within the polymer, thereby occupying the sites that water molecules might otherwise take.

\subsubsection{Thickness Effect}

The thickness of specimens appears to affect the diffusion behaviour, as seen on Figure 43. However, these curves can be superimposed by normalizing the data with respect to thickness, as shown in Figure 44. One notable conclusion to be drawn from this is that thinner specimens can be used to assess equilibrium moisture 
content more quickly, and thicker specimens can be used to obtain the initial diffusion data with less noise in the data.

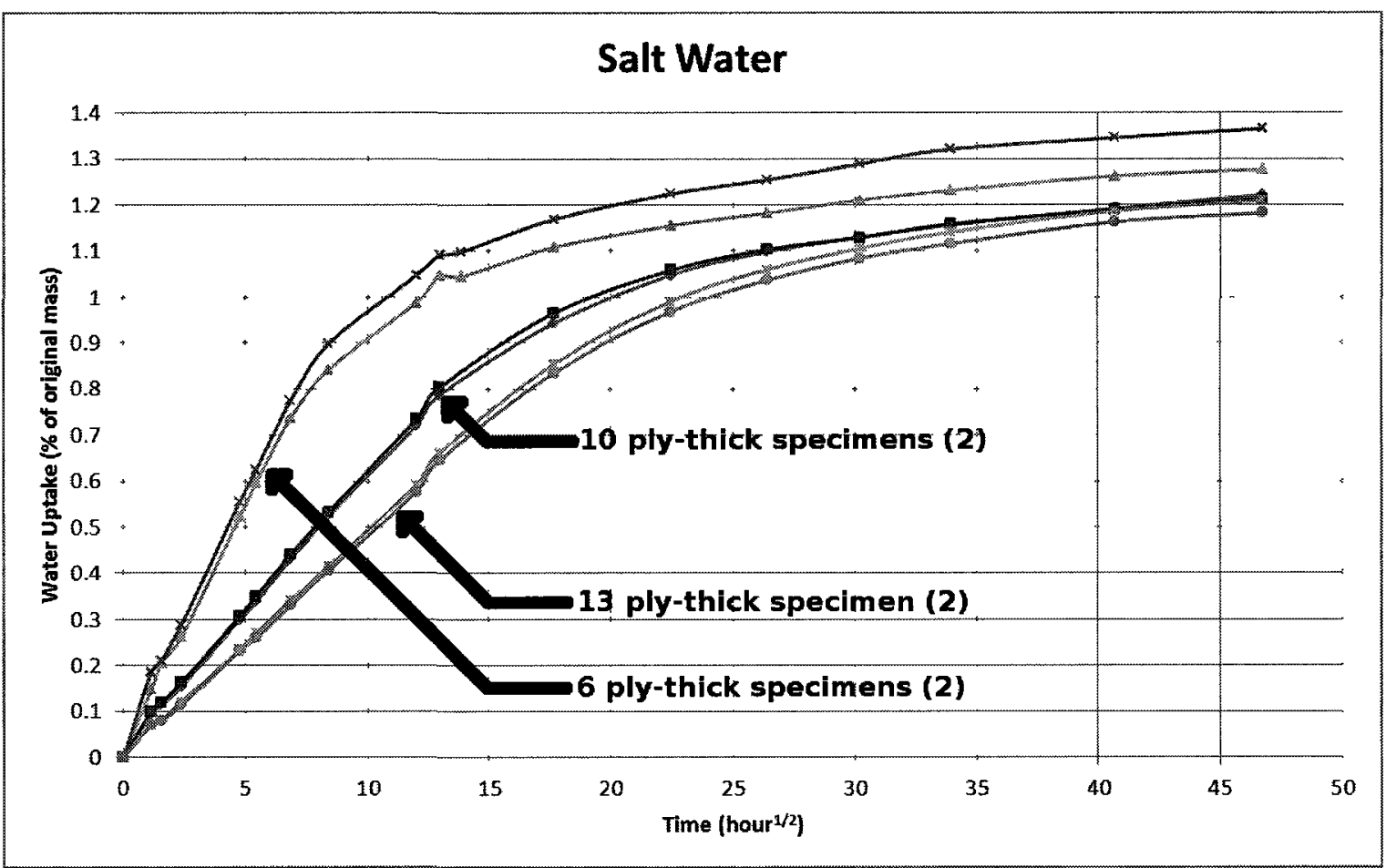

Figure 43: Specimens conditioned in the same environment appear to behave differently based on their thickness (Note: gap only indicates that no mass measurements were made at that specific time for some specimens) 


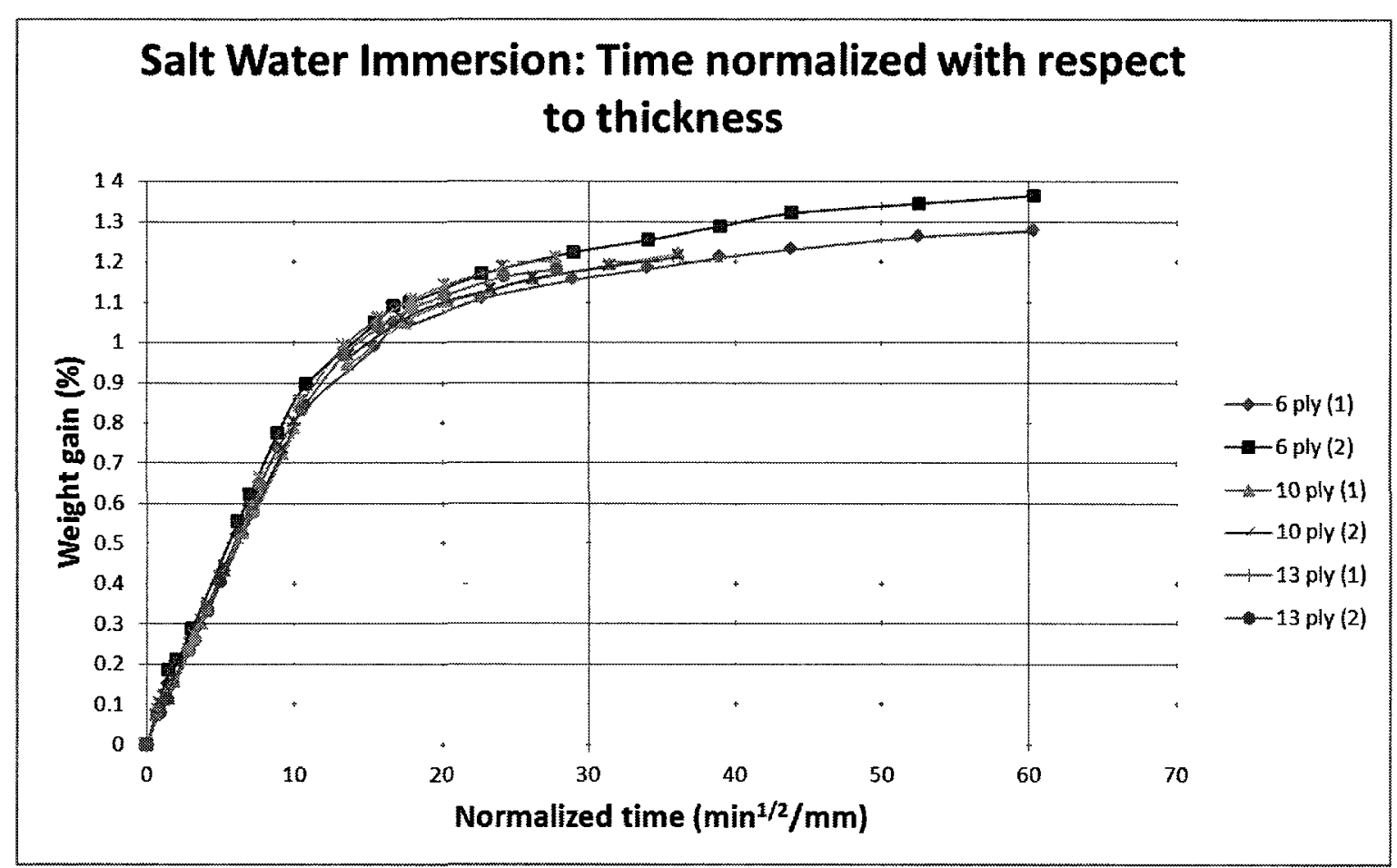

Figure 44: Normalizing with respect to thickness results in superimposed curves

\subsubsection{Modelling Diffusion: Fickian or Non-Fickian?}

When the diffusion parameters $D$ and $m_{\infty}$ are calculated, there is an underlying assumption that the diffusion process can be accurately described by the Fickian model described in Chapter I. However, this may not be true of the material system being considered here, especially because the laminate prepreg is a multi-phase system containing thermoplastic particles [38]. The behaviour of the diffusion specimens were therefore checked against the theoretical Fickian trend.

The through-thickness diffusivity, $D_{z}$, was calculated by [78]:

$$
D_{z}=\pi\left(\frac{h}{4 M_{\infty}}\right)^{2}\left(\frac{M_{2}-M_{1}}{\sqrt{t_{2}}-\sqrt{t_{1}}}\right)^{2}
$$


where $h$ is the specimen thickness, $M_{\infty}$ is the equilibrium moisture content and $\left(M_{2}-M_{1}\right) \div\left(\sqrt{t_{2}}-\sqrt{t_{1}}\right)$ is the slope of the initial linear part of the curve. $M_{\infty}$ is read directly from the graph.

An example calculation for specimen Diff-IOp-OI using the raw data shown in Table 8 would yield:

$$
D_{z}=\pi\left(\frac{1.32}{4(1.22)}\right)^{2}\left(\frac{.787-0}{13.0-0}\right)^{2}=.0008 \mathrm{~mm}^{2} / \mathrm{hr}
$$

Note that in Excel, the "slope(known_y's, known_x's)" function was used, which calculates the slope of a least-squares fit of the data rather than using only two points as shown above. 
Table 8: Raw data of mass measurements. Italics indicate calculated value, thick border indicates $\mathrm{M}_{\infty}$, double border indicates points used for slope calculation and triple border is the calculated value of $\mathrm{D}_{z}$.

\begin{tabular}{|c|c|c|c|c|}
\hline \multicolumn{2}{|c|}{ Specimen|Diffusivity $\rightarrow$} & \multicolumn{2}{|c|}{ Diff-IOp-0I } & \multirow{2}{*}{$\frac{8.13 E-04}{\text { \%Total }}$} \\
\hline Date & Hours $^{1 / 2}$ & $\begin{array}{c}\text { Mass } \\
{[\mathrm{g}]}\end{array}$ & $\% \mathrm{D}$ & \\
\hline $0 \mathrm{I} / \mathrm{II} / 20 \mathrm{II}$ & 0 & 36.1130 & $W_{b}$ & $O$ \\
\hline$+\mathrm{I}: 20$ & I.I & 36.1475 & 0.0955 & 0.0955 \\
\hline$+2: 30$ & 1.6 & 36.1544 & 0.0191 & 0.115 \\
\hline$+5: 35$ & 2.4 & 36.1686 & 0.0393 & 0.154 \\
\hline $01 / 12 / 2011$ & 4.8 & 36.221 & 0.145 & 0.299 \\
\hline$+29: 35$ & 5.4 & 36.2353 & 0.0395 & 0.339 \\
\hline $01 / 13 / 2011$ & 6.9 & 36.2686 & 0.0919 & $0.43 I$ \\
\hline $01 / 14 / 2011$ & 8.4 & 36.3022 & 0.0926 & 0.524 \\
\hline $01 / 17 / 2011$ & $\mathrm{I} 2.0$ & 36.3734 & 0.196 & $0.72 I$ \\
\hline $01 / 18 / 2011$ & 13.0 & 36.3972 & 0.0654 & 0.787 \\
\hline $01 / 19 / 2011$ & 13.9 & & & \\
\hline $0 I / 24 / 201 \mathrm{I}$ & I7.7 & 36.4535 & 0.155 & 0.943 \\
\hline $02 / 01 / 2011$ & 22.5 & $36.49 \mathrm{I} 4$ & 0.104 & 1.05 \\
\hline $02 / 09 / 2011$ & 26.4 & 36.5097 & 0.0502 & 1.10 \\
\hline $02 / 18 / 2011$ & 30.2 & 36.5211 & 0.0312 & I.I3 \\
\hline $02 / 28 / 20 \mathrm{II}$ & 33.9 & 36.5305 & 0.0257 & $I .16$ \\
\hline $03 / 2 \mathrm{I} / 20 \mathrm{II}$ & 40.7 & 36.5434 & 0.0353 & $I .19$ \\
\hline $04 / \mathrm{I} 2 / 2011$ & 46.7 & 36.5540 & 0.0290 & 1.22 \\
\hline
\end{tabular}

With this diffusivity value, it was then possible to plot the Fickian diffusion curve and compare it to the experimental curves. For example, Figure 45 shows this comparison for I0-ply specimens conditioned in salt water.

As can be seen, Fick's diffusion model does not accurately represent the later part of the diffusion process. Indeed, none of the data gathered in this study seems to suggest that the moisture absorption will reach the "plateau" that Fick's diffusion theory predicts. Whether the continuing increase in mass is indicating a continuing damage of the structure by chemical interaction with the water, which in turn is allowing more water to be absorbed, or whether there are parts of the resin that 
absorb moisture at a much slower rate and over a longer period cannot be ascertained from the present study. The specimens will be left in their conditioning environments for others to continue studying this diffusion behaviour.

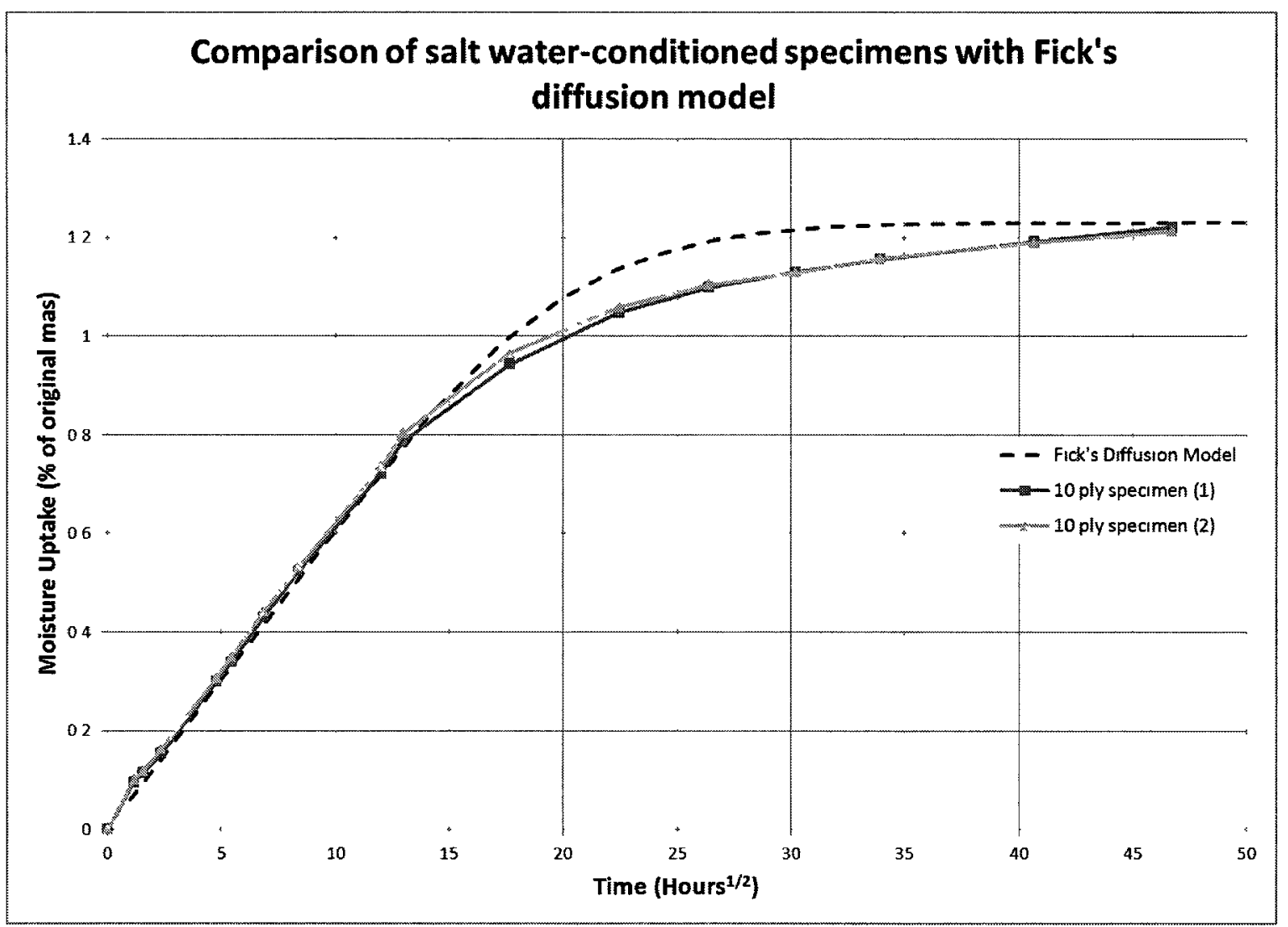

Figure 45: Comparison of Fick's theoretical diffusion curve and experimental curves for 10-ply specimens

Despite the Fickian model being somewhat inaccurate, it will be used in the next section to illustrate the effect of temperature on diffusion using data available in the literature. 


\subsubsection{Temperature Effect: How the Artificial Environment Compares to the Service Environment}

The relationship between conditioning temperature and diffusion parameters cannot be obtained from the data gathered in this study. Such information would be of great value, especially to establish how the conditioning time at $82^{\circ} \mathrm{C}$ and $95 \%$ relative humidity compares to the expected service conditions of the structures of interest. A lack of ava1lable specimens, time (e.g. it might take years to reach equilibrium when conditioning at $35^{\circ} \mathrm{C}$ ) and chambers to maintain a multitude of conditions made this unrealistic for the present study. Nevertheless, a brief discussion of the applicable method is presented.

A simple model of the temperature dependence of diffusivity is [II]:

$$
D=D_{0} \exp \left[-\frac{E_{d}}{R T}\right]
$$

where $D_{o}$ is the permeability index $\left[\mathrm{m}^{2} / \mathrm{s}\right], E_{d}$ is the energy of activation for diffusion $[\mathrm{J} / \mathrm{mol}], R$ is the universal gas constant $[\mathrm{J} /(\mathrm{mol} \cdot \mathrm{K})]$ and $T$ is the temperature $[\mathrm{K}]$. An example of this relationship is 1llustrated in Figure 46, which applies to BR/5505 (a Boron fibre/epoxy pre-preg). A calculation based on this graph yrelds an activation energy of approximately $28 \mathrm{~kJ} / \mathrm{mol}$. Similar data could not be found for CYCOM 5276-I. The difference between the chemistry of the 5505 matrix material studied in [83] and CYCOM 5276-I is difficult to establish due to the proprietary nature of that information. However, another analysis presented values of $E_{d}$ from the literature to be in the range of $8.8-I I .8 \mathrm{kcal} / \mathrm{mol}(36-49 \mathrm{~kJ} / \mathrm{mol})$ for DDS-hardened epoxies; note that the hardener was said to be the most determinant factor in the value of $E_{d}[83]$. 


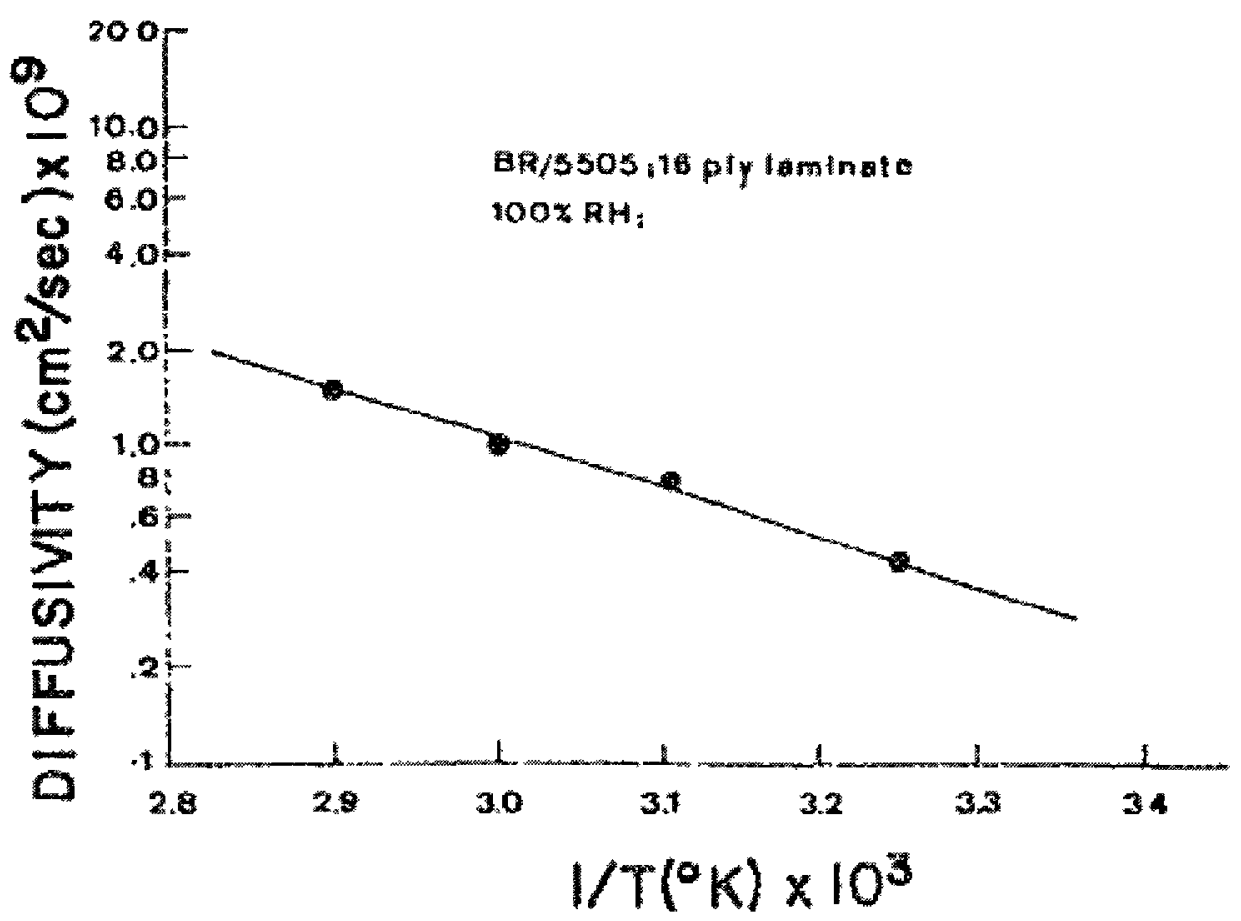

Figure 46: Variation of diffusivity with temperature for $B R / 5505$ laminate [83].

Given that CYCOM 5276-I is a DDS-hardened epoxy (of TGDDM and TGAP resins) [38], we will perform an estimation of equivalent ageing time with the $E_{d}$ values from the literature. If we assume an activation energy of $49 \mathrm{~kJ} / \mathrm{mol}$ (higher activation energy is more conservative), we know the slope of the graph of $D$ versus $I / T$. Then we can use the point $(I / T ; D)=\left(0.0029 ; 3.55 \times 10^{-9}\right)$, which comes from actual data for a $\mathrm{IO}$-ply laminate at $70^{\circ} \mathrm{C}$, to recreate an approximate exponential relationship for CYCOM 5276-I similar to Figure 46. Performing this calculation yields a value of $D_{0}=24 \times I 0^{3} \mathrm{~mm}^{2} / \mathrm{hr}$, such that, for $20^{\circ} \mathrm{C}$ :

$$
D\left(20^{\circ} \mathrm{C}\right)=24000 \exp \left(-\frac{49000}{8.31 * 293.15}\right)=4.43 * 10^{-5} \frac{\mathrm{mm}^{2}}{\mathrm{hr}}
$$

Now, performing this calculation for temperatures in the range of $20-70^{\circ} \mathrm{C}$ and using Fick's diffusion model yields Figure 47. 


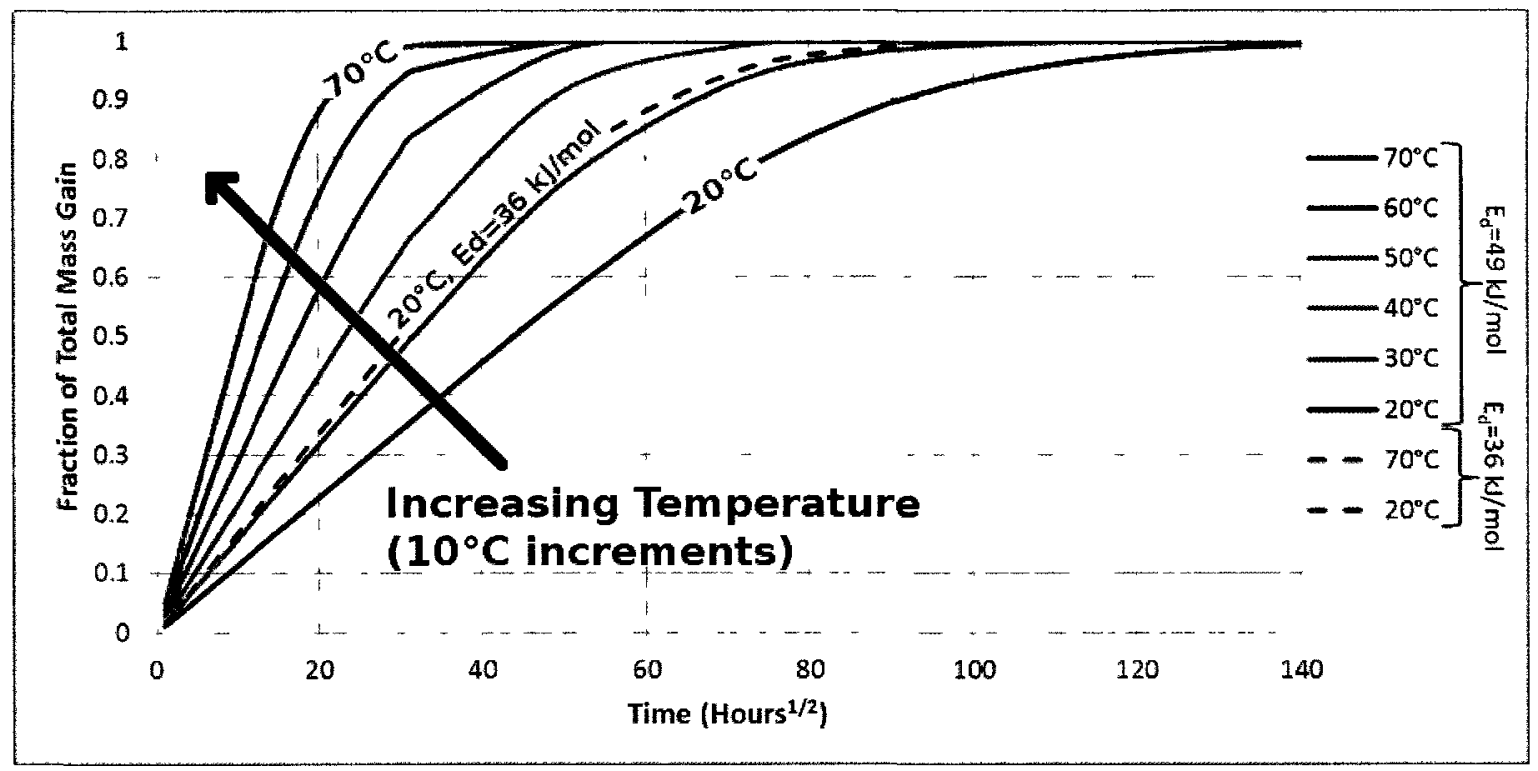

Figure 47: Prediction of diffusion behaviour for temperatures in range of $20-70^{\circ} \mathrm{C}$ for activation energies of 49 (solid) and 36 (dashed) $\mathrm{kJ} / \mathrm{mol}$.

To achieve the level of moisture of the DCB specimens at the time of the test, a diffusion period greater than 20,000 hours ( 833 days or $I 40$ hours $\left.^{1 / 2}\right)$ can be expected in an environment at $20^{\circ} \mathrm{C}$ and $95 \%$ relative humidity.

Important caveats in this assessment are that (i) no aircraft is exposed to such a constant environment; (ii) how the previously-noted deviation from Fick's law is affected by temperature is unknown; (iii) the activation energy used was not specific to this material; (iv) how the variation of humidity affects diffusion was not at all accounted for, and $95 \%$ is above the maximum value to be used for design according to $\mathrm{CMH}-\mathrm{I} 7$ [79]; and (v) it is unknown whether conditioning at $70^{\circ} \mathrm{C}$ is more damaging to the material than temperatures further below its wet $T_{g}$. This exercise still illustrated how additional data could be gathered (e.g. by performing tests at different humidity levels and with more temperatures) and used to more accurately predict the time it would take for structures made of this material to reach moisture equilibrium. 
After moisture conditioning, the specimens were prepared for mechanical testing. DCB specimens will be discussed in Chapter 4, next, and SCB specimens in Chapter 5.

\subsection{CONCLUSIONS}

The most important conclusions to be drawn from the diffusion analysis presented here are:

- No effect of salinity of the immersion water on the diffusion of moisture into carbon fibre-reinforced epoxy specimens was observed.

- Immersion was observed to result in a greater equilibrium moisture content than $95 \%$ relative humidity.

- The Fickian diffusion laws did not accurately reflect the behaviour of the materials used here.

- Scission of epoxy chains during conditioning was likely observed, but further analysis (chemical identification by a technique such as FTIR) is required for confirmation.

- The moisture content achieved in a $70^{\circ} \mathrm{C} / 95 \%$ R.H. environment in 85 days is believed to be equivalent to what would be achieved in more than two years at $20^{\circ} \mathrm{C}$ and $95 \%$ R.H. 


\section{Chapter 4: The Effects of the Environment on the Fracture Toughness of Bonded Laminates}

In this Chapter, the testing procedure, data reduction, and results of the Double Cantilever Beam testing are presented. Two aspects of the results are covered: the calculated GIC values for specimens from 7 different conditions, and the observed failure mode. Obtaining a correlation between failure mode and resulting GIC is attempted, but an example shows that the GIC does not vary only with failure mode.

Chapter I Literature Review

Chapter 2 Manufacturing of DCB and SCB Specimens

Chapter 3 Iinvironmental Conditioning and Diffusion Data Analysis

Chapter 4

Chapter 5 The Effects of the Environment on the Fracture Toughness of Bonded Laminates

Preliminary Sudy of the Effects of the Environment on the

Chapter 6 Overview of Contribution and Recommendations for Future Work

Appendix A Summary Sheets for DCB Specimens

Appendix B Summaty Sheecs for SCB Specimens 


\section{I. INTRODUCTION}

The DCB and SCB specimens have until now been discussed in parallel and their manufacturing and conditioning have been described. Figure 48 provides a brief summary of the discussion thus far and highlights some of the differences between how the two specimen types were handled prior to mechanical testing.

\begin{tabular}{|c|c|}
\hline \multicolumn{2}{|c|}{$\swarrow$ Specimen Configuration $\searrow$} \\
\hline \multicolumn{2}{|c|}{ Manufacturing } \\
\hline \multirow{2}{*}{\multicolumn{2}{|c|}{$\begin{array}{c}\text { Lamınate Layup and Cure } \\
\text { Bondıng }\end{array}$}} \\
\hline & \\
\hline Laminate-Lamınate & Lamınate-Core \\
\hline \multicolumn{2}{|c|}{ Cutting Specimens } \\
\hline \multicolumn{2}{|c|}{ Preparing Specimens for Conditioning } \\
\hline $\begin{array}{l}\text { Band Hinges } \\
\text { Cover Hinges with Sealant }\end{array}$ & $\begin{array}{c}\text { Seal Edges with } \\
\text { Aluminum Jackets }\end{array}$ \\
\hline \multicolumn{2}{|c|}{ Environmental Conditioning tha } \\
\hline $\begin{array}{l}7 \text { Conditions } \\
\text { [All Results Reported] }\end{array}$ & $\begin{array}{l}5 \text { Conditions } \\
\text { [Results from } 3 \text { reported] }\end{array}$ \\
\hline \multicolumn{2}{|c|}{ Preparation for Mechanical Testing } \\
\hline $\begin{array}{l}\text { Remove Sealant } \\
\text { Paint Edge } \\
\text { Bond Ruled Line } \\
\text { Weigh }\end{array}$ & $\begin{array}{c}\text { Remove Jacket } \& \text { Sealant } \\
\text { Bond Hinge } \\
\text { Pant Edge } \\
\text { Bond Ruled Line } \\
\end{array}$ \\
\hline Mechan & Testing Chap 5 \\
\hline
\end{tabular}

Figute 48: Summaty of preparation of $D C B$ and SCB specimens leading to mechanical testing.

In this Chapter, the mechanical testing of Double Cantilever Beam specimens will be discussed. This test is designed to measure the mode I interlaminar fracture toughness of composite laminates and was adapted to be applied to the bonded 
laminates in this study [44]. A mode I test is the most conservative: it yields the lowest values of strain energy release rate. While this may be of great interest to designers as a worst-case criterion, it may not always be representative of typical loading seen by parts-in fact, because of the low strain energy release rate, it is recommended to avoid intentionally loading parts in pure mode I when possible. Therefore, the more realistic mixed-mode fracture test of bonded joints subjected to environmental exposure has also been included in the NRC project to which this thesis is contributing, but will not be discussed here. Also of interest is the effect of fatigue loading on the results. A study of the environmental effects on mode I failure of bonded composite joints under fatigue was also included in the NRC project, but again, was beyond the scope of this thesis. Together, the data produced by all three tests (static DCB, static Mixed-Mode Bending or MMB, and fatigue DCB) will give a nearly complete picture of the behaviour of this joint configuration and how it changes with exposure to the service environment.

The static DCB tests were performed before any of the other tests and with the most varied range of conditioning environments with the purpose of assessing the effects of the studied environmental conditions on mode I fracture toughness of bonded joints. The results of these tests, presented in this Chapter, will be used to select which environments are of greatest interest and limit the environmental conditioning matrix accordingly for fatigue and MMB tests to reduce costs. An additional purpose of these tests was to serve as a basis for comparison with the Single Cantilever Beam (SCB) tests on sandwich panels that will be presented in the next Chapter.

The mechanical testing procedure will be presented first. After an overview of the data reduction procedure, the results of the tests will be presented and discussed 
in terms of the calculated strain energy release rate and the observed failure modes. A method for measuring the percentage of adhesive and cohesive failure will also be presented, followed by conclusions.

\subsection{Mechanical TeStiNg PROCEDURE}

The standardized ASTM D5528 procedure was adopted for these tests. Its major requirements and any deviations are summarized in Table 9.

Spraying the entire edge of each specimen with matte white paint allowed for easier tracking of crack progress throughout the test. Rather than manually marking every I mm initially and $5 \mathrm{~mm}$ afterward, a ruled line was printed on a strip of paper and glued to the face of specimens such that the edge of the paper, which contained the printed tick marks, could be folded over and be visible to the camera as seen in Figure 49.

The standard recommended using a slower displacement rate at the beginning of the test. For simplicity, a displacement rate of $2.03 \mathrm{~mm} / \mathrm{min}$ was used throughout, but did prove to be a challenge in terms of a single operator marking the crack lengths accurately once the crack started propagating. As will be explained in Section 4.4.I.3, the data at the very beginning of the test were ignored when presenting a propagation value for this reason. 
Chapter 4: The Effects of the Environment on the Fracture Toughness of Bonded Lammates I09

Table 9: Test parameters of ASTM D5528 and the methods used in this study (deviations from the standard noted in bold)

\begin{tabular}{|c|c|c|}
\hline Test Parameter & Requirement & Used \\
\hline Sample size & Minimum of 5 specimens & 5 specimens \\
\hline \multirow[t]{4}{*}{ Specimen dimensions } & Width between 20 and $25 \mathrm{~mm}$ & $21.6 \mathrm{~mm}$ \\
\hline & Length at least $125 \mathrm{~mm}$ & $127 \mathrm{~mm}$ \\
\hline & $\begin{array}{l}\text { Initial crack length approximately } \\
50 \mathrm{~mm}\end{array}$ & $50 \mathrm{~mm}$ \\
\hline & Thickness 3 to $5 \mathrm{~mm}$ & $3.57 \mathrm{~mm}$ \\
\hline $\begin{array}{l}\text { Non-adhesive film } \\
\text { thickness }\end{array}$ & Maximum I3 $\mu \mathrm{m}$ & $\mathrm{I} 3 \mu \mathrm{m}$ \\
\hline Load introduction & $\begin{array}{l}\text { Bonded piano hinge or loading } \\
\text { blocks }\end{array}$ & Bonded piano hinge \\
\hline $\begin{array}{l}\text { Coating of specimen } \\
\text { edge }\end{array}$ & $\begin{array}{l}\text { Correction fluid or similar to } \\
\text { improve crack visibility }\end{array}$ & Matte white spray paint \\
\hline $\begin{array}{l}\text { Marking for crack } \\
\text { measurements }\end{array}$ & $\begin{array}{l}\text { Thin mark every I mm initially, } \\
\text { then every } 5 \mathrm{~mm}\end{array}$ & Bonded ruled line \\
\hline Crack observation & Travelling microscope & $\begin{array}{l}\text { Travelling magnifying } \\
\text { camera }\end{array}$ \\
\hline $\begin{array}{l}\text { Pre-cracking } \\
\text { (cracking, unloading, } \\
\text { then running test) to } \\
\text { obtain sharp crack tip }\end{array}$ & $\begin{array}{l}\text { Not recommended for } \\
\text { interlaminar tests due to possible } \\
\text { fibre bridging changing initiation } \\
\text { results when re-loading }\end{array}$ & $\begin{array}{l}3 \mathrm{~mm} \text { (not interlaminar } \\
\text { so no fibre bridging) }\end{array}$ \\
\hline $\begin{array}{l}\text { Crosshead } \\
\text { displacement rate }\end{array}$ & $\begin{array}{l}0.5 \mathrm{~mm} / \mathrm{min} \text { for first } 5 \mathrm{~mm} \text { of } \\
\text { crack extension, then increased if } \\
\text { necessary }\end{array}$ & $\begin{array}{l}2.03 \mathrm{~mm} / \mathrm{min} \\
\text { throughout }\end{array}$ \\
\hline Unloading & $\begin{array}{l}\text { After } 25 \mathrm{~mm} \text { of crack extension } \\
\text { data }\end{array}$ & $\begin{array}{l}\text { Never (completely } \\
\text { cracked specimens) }\end{array}$ \\
\hline Mass measurements & (none) & $\begin{array}{l}\text { Weighed after applying } \\
\text { paint and ruled line, } \\
\text { and again after test }\end{array}$ \\
\hline
\end{tabular}

In order to observe the fracture surface, specimens were not unloaded after $25 \mathrm{~mm}$, as recommended by ASTM D5528. Instead, data were gathered over $50 \mathrm{~mm}$ of crack extension to check for any effects of crack length on the results. The specimens were subsequently loaded to failure. A photograph of the two halves could 
then be taken in order to measure the percentage of the failure mode that was adhesive versus cohesive.

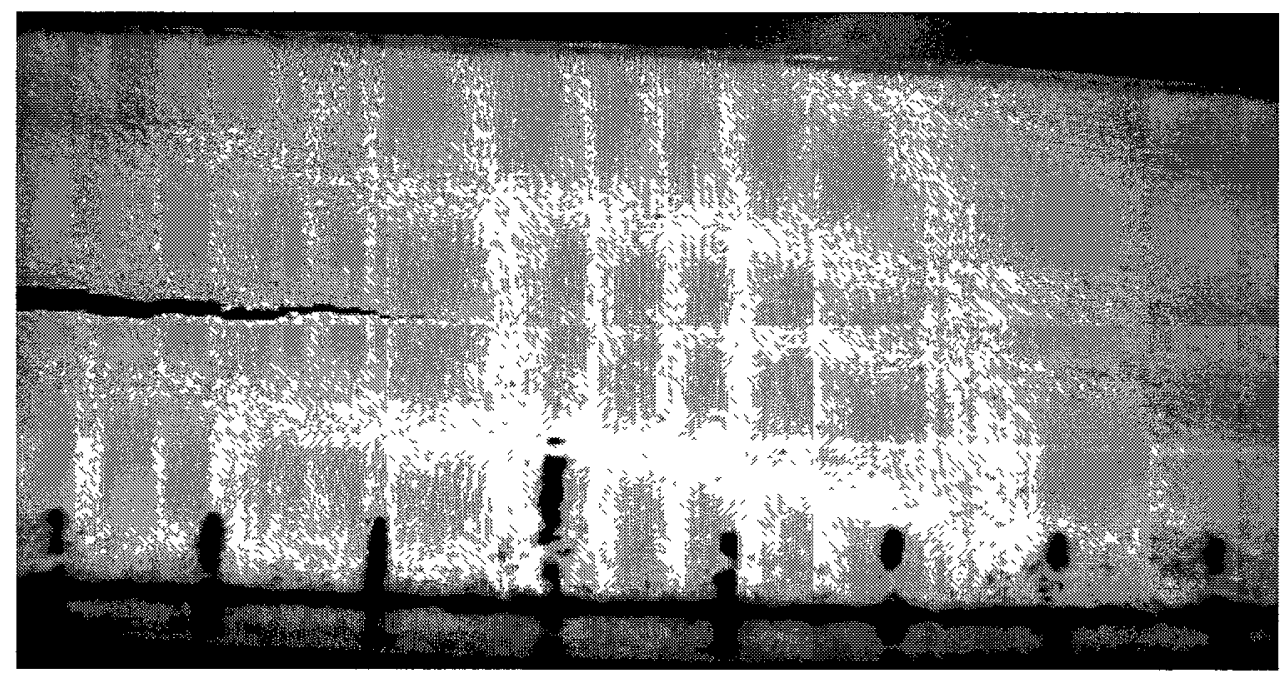

Figure 49: Output from camera used to observe crack growth during $D C B$ tests (short matks at every $I \mathrm{~mm}$ and long ones every $5 \mathrm{~mm}$ )

Weighing steps of coupons that had been conditioned in a hot and wet environment were added to the procedure in order to have some record of the mass loss incurred by testing the specimens in the lab environment. This will be discussed in more detail in Section 4.4.4.4.

A view of the test set-up is provided in Figure 50. To summarize the procedure, the specimens were first taken out of the conditioning environment. Water that tended to be trapped in the pre-crack area was removed by pressing the specimens with pliers and thick layers of paper towel to avoid causing damage. The specimens were then spray-painted and a ruled line was bonded to the bottom surface of the coupon and folded over. While allowing the paint to dry for approximately IO minutes (wet paint was not brittle enough and made viewing the crack tip difficult), the specimen was weighed, then loaded into the frame. A hinge was left in the 
bottom grip of the frame throughout testing; the specimen was therefore attached to that hinge with a pin prior to lowering the top grip and gripping the top hinge. After gripping, the displacement reading of the frame was zeroed (load reading was only zeroed once before all the tests to account for specimen weight and not re-zeroed subsequently) and the test was initiated. A pre-cracking phase of approximately $3 \mathrm{~mm}$ was followed by unloading and restarting the test. This was done to ensure a sharp crack tip and remove the effect of the edge of the Teflon insert, if any. Upon reloading, a new "initiation" reading was recorded, and readings were made for every I $\mathrm{mm}$ for at least the first $5 \mathrm{~mm}$. Subsequently, recordings were made every $5 \mathrm{~mm}$ until the last $5 \mathrm{~mm}$ of the test, where readings were again made every I mm. A "reading" consisted in pressing a button on the load-frame software Graphic User Interface, which placed a marker in the data file. In order to later relate that marker (which contained load, displacement and time information) to a crack length, the displacement and crack length at the time the button was pressed were recorded in a table by hand. 


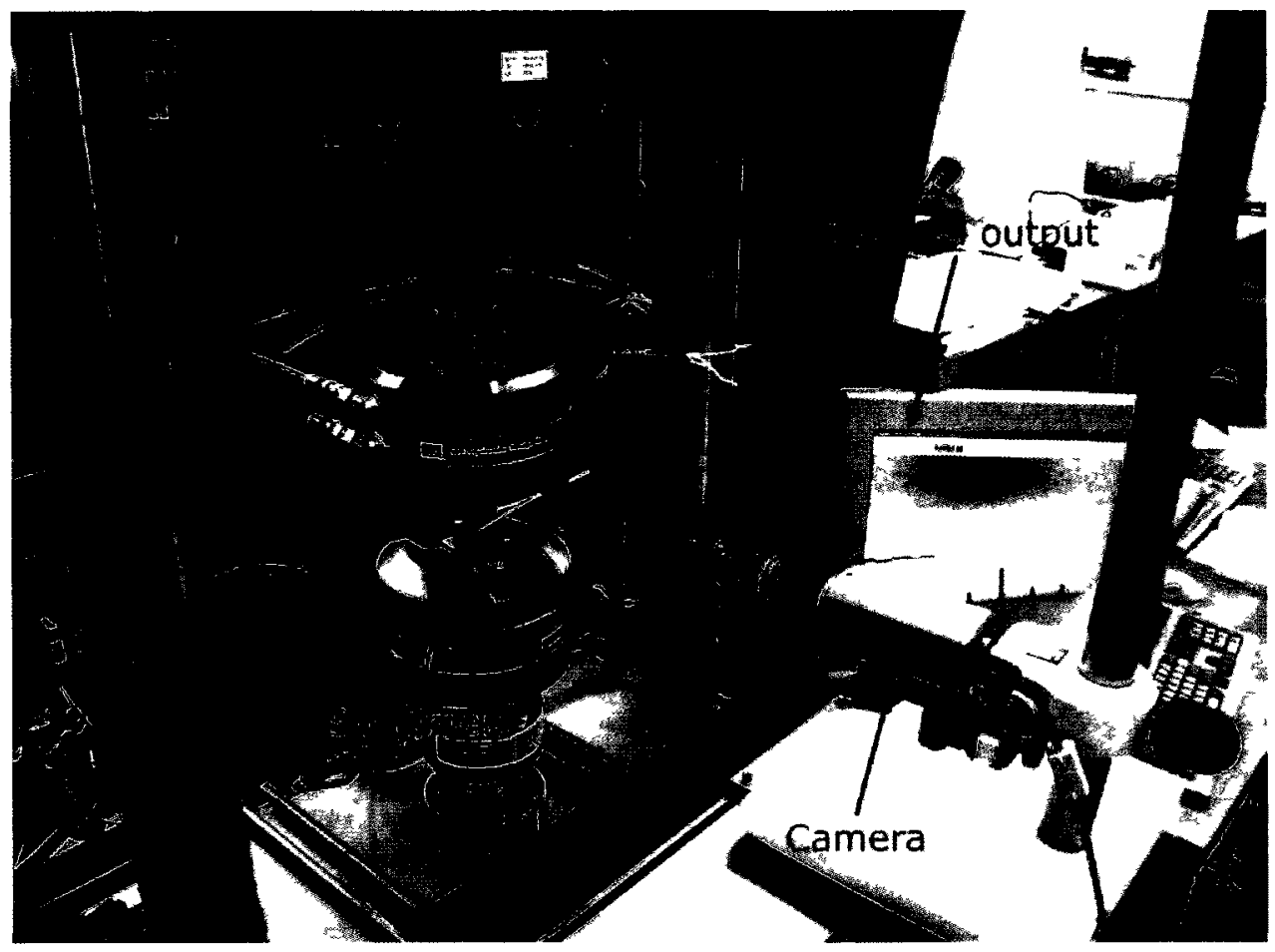

Figure 50: DCB test set-up

The resulting data file typically appeared as shown in Figure 5I.

The precision of load measurements was $\pm 1 \%$ and the displacements were measured by an Linearly Variable Differential Transformer (LVDT) and also within $\pm 1 \%$.

With the data for instantaneous crack length, load and displacement, it was then possible to perform the calculations outlined in ASTM D5528 for the Modified Beam Theory (MBT), Compliance Calibration (CC) and Modified Compliance Calibration (MCC) methods, as described next. 


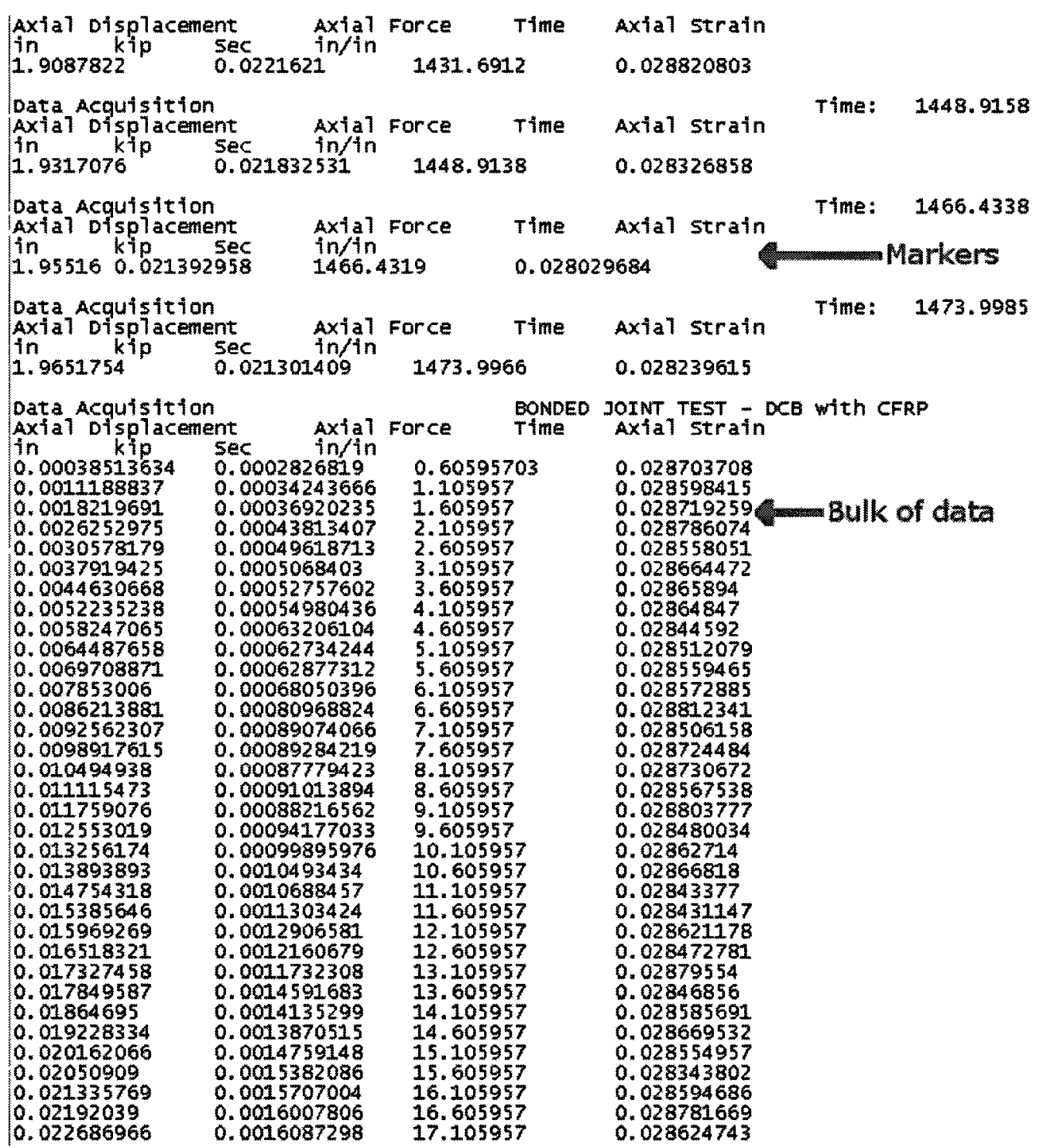

Figure 51: Typical output file (truncated) for DCB tests. Note that "Axial Strain" data were not used (nor properly configured) for this test

\subsection{DATA REDUCTION PROCEDURE}

ASTM D5528 provides three different methods of calculating the strain energy release rate, and correction factors that account for inaccuracies that occur when displacements are large and when loading blocks are used (only the former was necessary since hinges were used in these tests). All three calculation methods were 
used and compared, since the standard did not specifically endorse any one of them. Each method will be described in this Section.

\subsection{The Modified Beam Theory (MBT) Method}

In Section 5 of Chapter I, a general relationship for strain energy release rate, Gc, was given as Equation 23:

$$
G_{c}=\frac{12 P^{2} a^{2}}{E b^{2} h^{3}}
$$

where $P$ is the applied load, $a$ is the instantaneous crack length, $E$ is the Young's modulus, $b$ is the specimen width and $h$ is the specimen thickness. For DCB specimens, this may be further simplified to eliminate the need to separately measure the modulus $E$. This involves applying beam theory to find that the compliance, $C$, can be expressed as $[85]$ :

$$
C=\frac{\delta}{P}=\frac{8 a^{3}}{b h^{3} E_{11}}
$$

where $\delta$ is the displacement of the loaded point and $E_{I I}$ is the modulus in the direction of the fibres. From this we can deduce an expression for $E_{I r}$ :

$$
E_{11}=\frac{8 P a^{3}}{b \delta h^{3}}
$$

which can be substituted into Equation (34) to give us the beam theory solution to calculate GIC from DCB data: 


$$
G_{I C}=\frac{3 P \delta}{2 a b}
$$

This equation assumes that at the crack tip (which is the root of the beams in question), the boundary condition is zero rotation and displacement. In fact, neither degree of freedom is completely constrained, so that the above equation requires correction. It has been shown that adding a product, $\chi h$, to the crack length used in the above calculation corrects for this inaccuracy [85]. The value of $\chi$ is dependent on material properties and can be calculated from these, but it is also easily calculated from the data gathered during the DCB test. Because of the relationship:

$$
C^{\frac{1}{3}}=\left(\frac{8}{b h^{3} E_{11}}\right)^{\frac{1}{3}}(a+\chi h)
$$

a plot of $\mathrm{C}^{1 / 3}$ versus a will display the $\chi h$ as the $\mathrm{x}$-intercept of the curve [85], as shown in Figure 52 for a DCB specimen from this study. In ASTM D5528, this constant is called $\Delta$, so that the MBT calculation of GrC is:

$$
G_{I C}=\frac{3 P \delta}{2 b(a+|\Delta|)}
$$




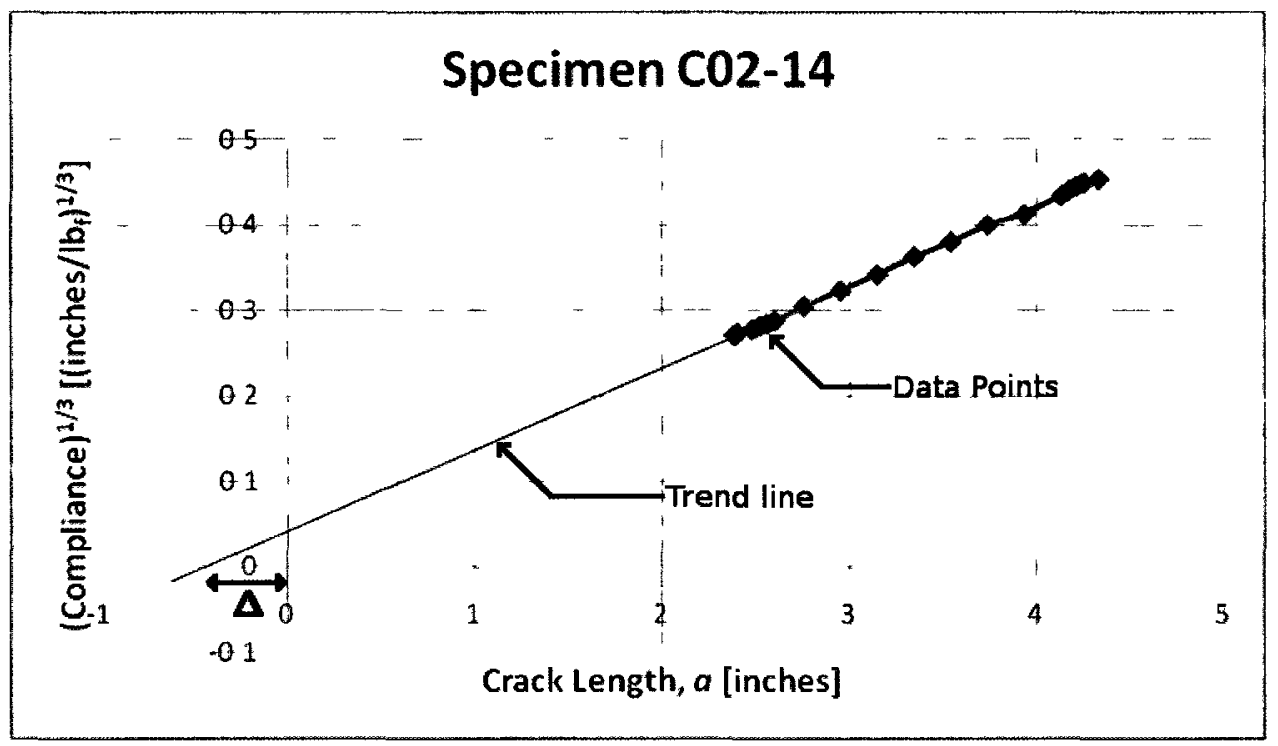

Figure 52: Graphical determination of $\Delta$

\subsubsection{The Compliance Calibration (CC) Method}

This technique simply assumes that the relationship between force and displacement is of the general form [86]:

$$
P=\left(c a^{-n}\right) \delta
$$

which is a generalized version of the relationship from beam theory:

$$
P=\left(\frac{3}{2} E I a^{-3}\right) \delta
$$

By taking the logarithm of the generalized relationship with $m=P / \delta$ :

$$
\log (m)=\log (c)-n \log (a)
$$

one can see that plotting $\log (m)$ versus $\log (a)$ will yield a linear relationship if the initially-assumed generalized form was correct. From this plot, the constants $c$ and $n$ could be determined. Griffith's criterion for crack propagation is given by [4I]: 


$$
\frac{\partial S}{\partial a}+\frac{\partial U}{\partial a}=0
$$

where $S$ is the free surface energy and $U$ is the the strain energy. $\frac{\partial U}{\partial a}$ can be expressed conveniently by substituting Equation (40) where needed:

$$
\begin{aligned}
U & =\frac{1}{2} P \delta \\
& =\frac{1}{2} c \delta^{2} a^{-n} \\
\frac{\partial U}{\partial a} & =-\frac{n c \delta^{2} a^{-n-1}}{2} \\
& =-\frac{n\left(c a^{-n}\right) \delta^{2}}{2 a} \\
& =-\frac{n P \delta}{2 a}
\end{aligned}
$$

The change in free surface energy per increment crack length is:

$$
\frac{\partial S}{\partial a}=2 \gamma b
$$

so that Griffith's criterion can be expressed, without requiring the value of the constant $c$, as $[86]$ :

$$
\begin{aligned}
2 \gamma b-\frac{n P \delta}{2 a} & =0 \\
G=2 \gamma & =\frac{n P \delta}{2 b a} .
\end{aligned}
$$

This expression reduces to the MBT equation if $n=3$. The advantage of this method is its validity in situations where the "ideal" beam theory may be inaccurate, e.g., if the crack is nonplanar or the specimen is not perfectly symmetrical. This is the main reason why this method was preferred for SCB specimens, which will be discussed in the next Chapter. 


\subsubsection{The Modified Compliance Calibration (MCC) Method}

The third and final method provided in ASTM D5528 is called the modified compliance calibration method. It is based on a previous solution that required numerical analysis (FEA) to establish the value of four constants $C_{0}, C_{1}, C_{2}$ and $C_{3}$, which were used to express the relationship between the non-dimensional ratio $a / h$ (crack length to thickness ratio) and compliance $C$ as [87]:

$$
\frac{a}{h}=C_{0}+C_{1} \gamma+C_{2} \gamma^{2}+C_{3} \gamma^{3}
$$

where $\gamma=\left(b E_{L} C\right)^{\frac{1}{3}}$ is the normalized compliance, and $E_{L}$ is the modulus in the longitudinal direction ( $=E_{I I}$ for unidirectional DCB specimens). With this relationship, the strain energy release rate was calculated to be [87]:

$$
G_{I}=\frac{3}{2 E_{L} h}\left(\frac{P}{b}\right)^{2}\left(\frac{\gamma^{2}}{C_{1}+2 C_{2} \gamma+3 C_{3} \gamma^{2}}\right) .
$$

Simplifying the relationship between $a / h$ and $C$ to another empirical equation [88]:

$$
\frac{a}{h}=A_{0}+A_{1} C^{\frac{1}{3}}
$$

then differentiating yields:

$$
\begin{aligned}
\frac{1}{h} & =\frac{1}{3} A_{1}\left(\frac{\partial C}{\partial a}\right)\left(C^{-\frac{2}{3}}\right) \\
\frac{\partial C}{\partial a} & =\frac{3 C^{\frac{2}{3}}}{A_{1} h}
\end{aligned}
$$

Inserting this into the GIC relationship given in Chapter I for general DCBs, yields: 


$$
G_{I C}=\frac{P^{2}}{2 b}\left(\frac{\partial C}{\partial a}\right)=\frac{3 P^{2} C^{\frac{2}{3}}}{2 b h A_{1}}
$$

In this relationship, $A_{I}$ can be obtained by finding the slope of the line obtained when plotting $(a / h)$ versus $C^{1 / 3}$, as shown in Figure 53. The advantage of this method is stated as the ability to calculate $G_{I C}$ values for a specimen configuration without having to measure the crack length once the $A_{I}$ value is known. For the specimens in this study, the amount of degradation observed for specimens from the same condition was inconsistent, meaning that the $A_{r}$ values were not always close to each other. The method used for crack measurement was also not as difficult to implement as the suggested method of ASTM D5528, so that avoiding crack measurements was not particularly advantageous. Furthermore, the ASTM D5528 procedure is to find $A_{I}$ for every specimen, meaning that the main advantage stated in $[88]$ is essentially lost.

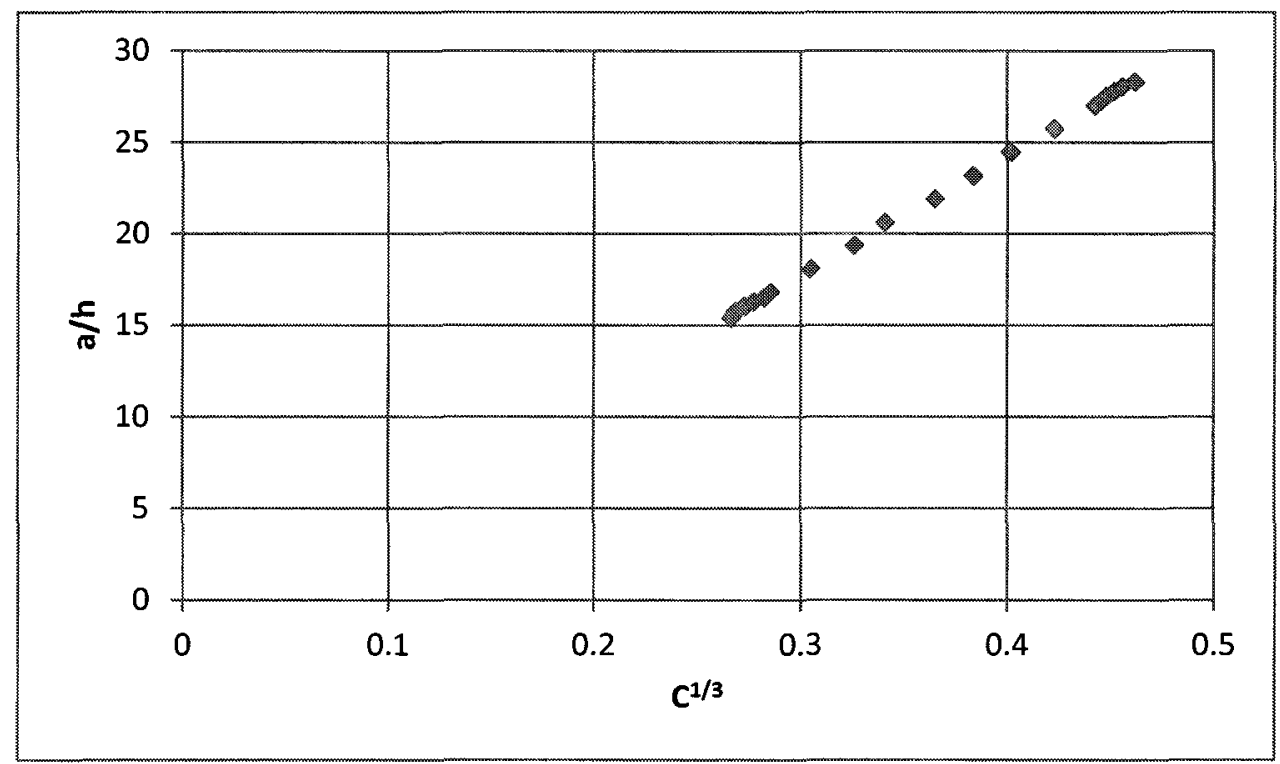

Figure 53: The slope of the line obtained by plotting a/h versus $\mathrm{C}^{1 / 3}$ gives the value of $\mathrm{A}_{1}$ to be used in the MCC method. 
The results from each of the three methods, as well as observations of the fracture surface will be presented in Sections 4.4 and 4.5.

\subsection{TEST RESULTS: STRAIN ENERGY RELEASE RATES}

\subsection{Foreword on Presentation of Strain Energy Release Rate Results}

\subsection{I.I. Summary Data Sheets}

Appendix A contains summary data sheets for every DCB specimen tested. These sheets include:

- Environmental conditioning information,

- Average GIC values, calculated using the three methods, and therr standard deviation,

- Initiation values (as discussed in Section 4.4.I.4),

- The various parameters required for GIC calculations $\left(n, \Delta, A_{1}\right)$,

- The $P-\delta$ (load versus displacement) and GIc-a (strain energy release rate versus crack length) graphs, and

- A scaled composite photograph of the fracture surface, created by the method described in Section 4.5.

While the detailed results are available in these summary data sheets, they will not all be discussed here. The focus of the presentation of a summary of the results in this Chapter will be explained in Sections 4.4.I.2-4.4.I.5. 


\subsection{I.2. Selection of Most Suitable Method of GIC Calculation}

Typical Grc-a graphs are shown in Figure 54 (unconditioned specimen) and Figure 55 (conditioned specimen). As can be seen in both Figures, the three calculation methods produced very similar results.

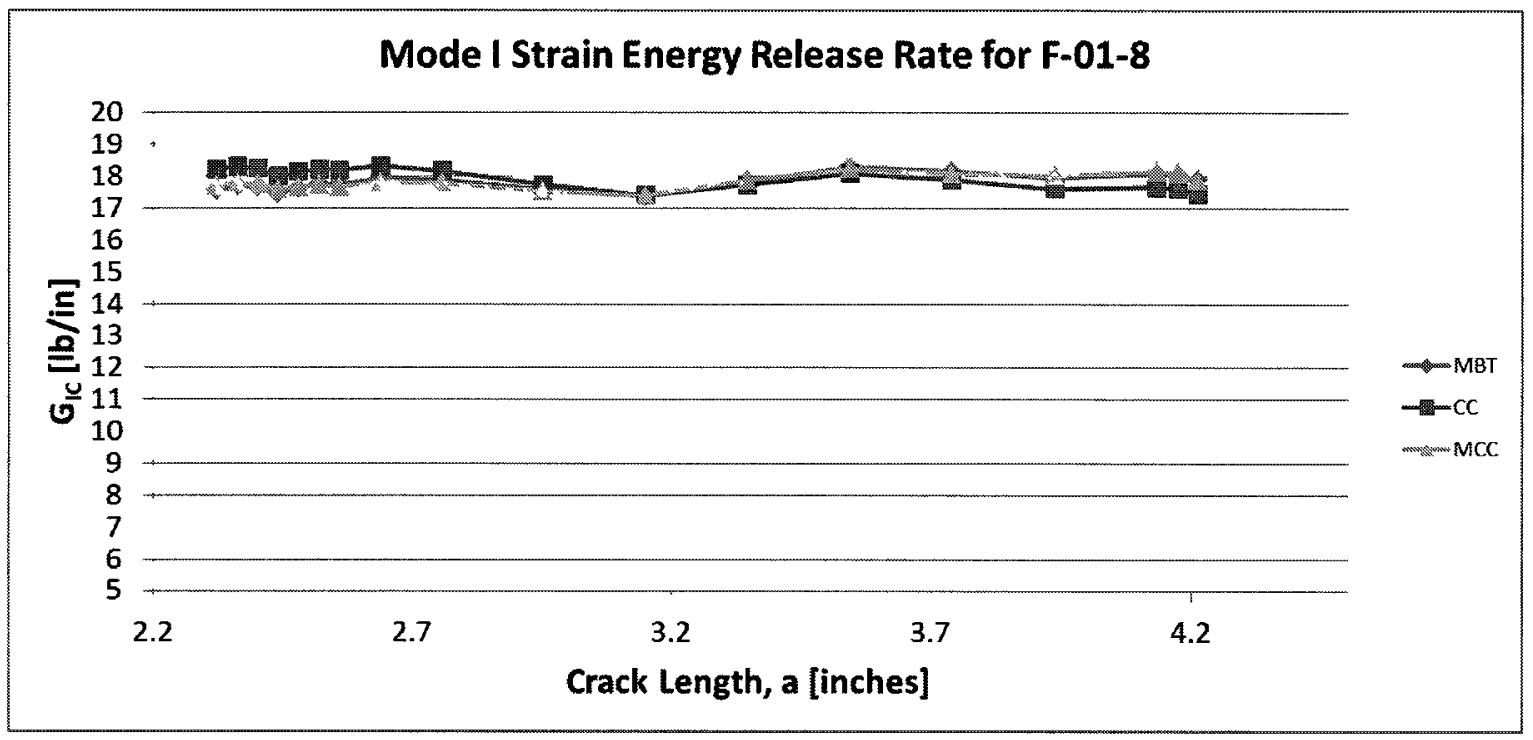

Figure 54: Gic vs. a for an unconditioned specimen.

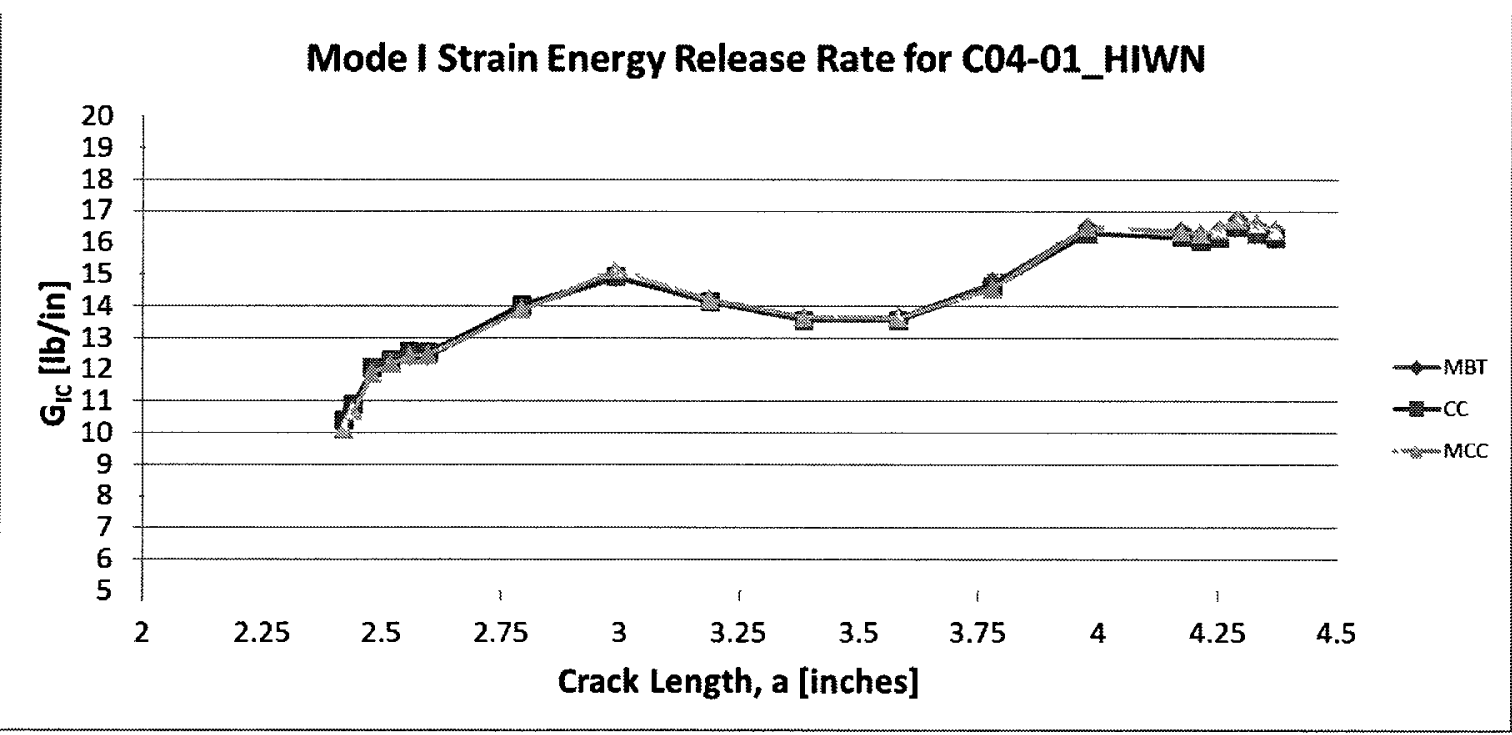

Figure 55: Gic vs. a for a specimen conditioned in $82^{\circ} \mathrm{C}$ water. 
Whereas the recommendation in ASTM D5528 is to use the Modified Beam Theory (MBT) result because it was the most conservative in $80 \%$ of round-robin tests, the Compliance Calibration (CC) results were consistently more conservative in the present study. However, the difference between the results of each of the three calculations was negligible (at most $1.5 \%$ difference). In the presentation of results, when only one GIC value is specified, it should be assumed that it is the CC result; the Figure and Table captions will nonetheless provide a reminder.

\subsection{I.3. The Presentation of Means and Standard Deviations}

The mean and standard deviation values presented in subsequent Sections are different based on the situation.

When data are presented for a single specimen, the mean and standard deviation value is calculated from only the 8 or 9 measurements made every $5 \mathrm{~mm}$ (in Figure 54 and Figure 55, these points are visibly spaced further apart along the $\mathrm{x}-$ axis). This eliminated the areas of highest variation and experimental uncertainty, when the crack measurements are made in quick succession by the operator (recall that a slower displacement rate was not used at the beginning of the test, as recommended in the standard). It also eliminated the initiation area, which is treated separately, as discussed in the next Section.

When data are presented for a given environmental conditioning case (i.e. encompassing 5 specimens), the standard deviation is calculated from all the values used to calculate the mean for each specimen. That is, the true distribution of data points across all specimens is presented. This made the most difference for the unconditioned specimens, for which GIC did not vary considerably with crack length 
(for individual specimens), but which had a wide distribution of $G_{I C}$ results across the 5 specimens.

\subsection{I.4. The Presentation of Initiation Strain Energy Release Rates}

In addition to the three methods of calculating GIC at any data point (discussed in Section 4.3), ASTM D5528 provides three options for determining at what point during the test initiation of crack propagation has occurred-i.e., what the load and displacement values were that first caused the crack to grow. It is therefore possible to report nine different initiation values. Although all values were calculated in this work and are available in Appendix A, the results will not all be presented in detail here.

The three methods for identifying the load and displacement that caused initiation to occur are the visual onset of crack growth (abbreviated "VIS"), the beginning of non-linearity of the $P-\delta$ curve ("NL") and the intersection of a line with a $5 \%$ offset slope from the linear portion of the $P-\delta$ curve with this curve. These are summarized in Figure 56. 


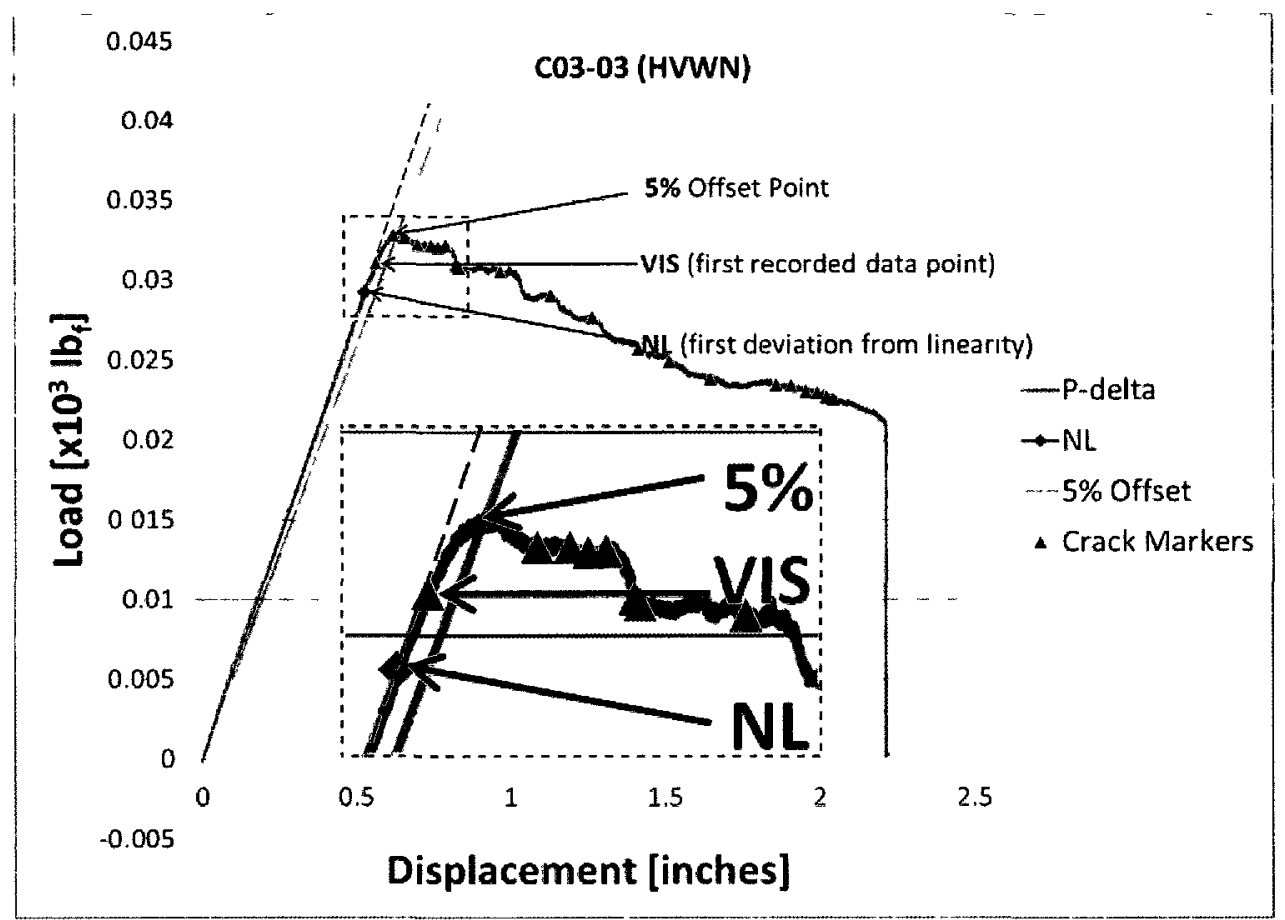

Figure 56: Summary of initiation values. Dashed line shows slope of linear portion of $\mathrm{P}-\delta$ curve, $N L$ is the point where $\mathrm{P}-\delta$ deviates from linearity; $5 \%$ offset point is where the line having a $5 \%$ lower slope than the dashed line intersects $\mathrm{P}-\delta$ and VIS is at the first crack marker.

The calculation of the NL point was performed by a VBA script in Excel during the data reduction procedure. It is selected as the first point at which the slope of the line of best fit through the 10 preceding and subsequent points is always lower than the overall slope of the curve up to that point. The ASTM-recommended method of drawing on a paper graph was not applicable to the system used here, nor would it have provided the same level of consistency as the numerical method.

In ASTM D5528 the NL value is said to consistently be the most conservative value. Since it is also not dependent on the operator's ability to observe the crack growth (the main limitation of the "VIS" value) and can be justified in physical terms unlike the $5 \%$ offset method, it was the preferred value for this work. In the discussion, GIC,o will be used to indicate initiation $G_{I C .}$ 


\subsection{I.5. Allocation of Specimens to Environmental Conditions}

As a reminder, Table I0 shows what the conditioning environment abbreviations are, since they are used extensively in the subsequent Sections. Furthermore, to help with the presentation of data in later tables, Table II shows the allocation of specimens to the different conditions and provides a specimen number Sp.I-Sp.5 for each specimen of each condition.

Table IO: Reminder of the nomenclature for conditioning environment abbreviations.

\begin{tabular}{|c|c|c|c|}
\hline $\mathrm{I}^{\text {st }}$ Letter & $2^{\text {nd }}$ Letter & $3^{\text {rd }}$ Letter & $4^{\text {th }}$ Letter \\
\hline Temperature & Water state & $\begin{array}{c}\text { Salinity }[g / L \\
N a C I]\end{array}$ & $\begin{array}{c}\text { Freeze- } \\
\text { Thaw } \\
\text { Cycling }\end{array}$ \\
\hline $\mathrm{H}=$ High $\left(82^{\circ} \mathrm{C}\right)$ & $\mathrm{I}=$ Immersion & $\begin{array}{c}\mathrm{S}=\text { Salt water } \\
{[24.5]}\end{array}$ & $\mathrm{N}=$ No \\
\hline $\begin{array}{c}\mathrm{I}=\text { Intermediate } \\
\left(70^{\circ} \mathrm{C}\right)\end{array}$ & $\begin{array}{c}\mathrm{V}=\text { Vapour }(95 \% \\
\text { R.H. })\end{array}$ & $\mathrm{W}=$ Water $[0.0]$ & $\mathrm{Y}=$ Yes \\
\hline
\end{tabular}

Table II: Allocation of specimens to environments.

\begin{tabular}{|l|c|c|c|c|c|}
\hline Environment & Sp. I & Sp. 2 & Sp. 3 & Sp. 4 & Sp. 5 \\
\hline HISN & C03-08 & C03-I0 & C04-I4 & E04-07 & N/A \\
\hline IISN & C02-02 & C02-I4 & C03-06 & C03-I2 & E04-03 \\
\hline HIWN & C02-07 & C03-05 & C04-0I & E04-04 & E04-I6 \\
\hline IIWN & C02-04 & C02-I6 & C03-I6 & C04-03 & E04-08 \\
\hline HVWN & C02-I0 & C03-03 & C03-I4 & C04-09 & E04-09 \\
\hline IVWN & C03-02 & C03-07 & C04-02 & C04-08 & E04-I3 \\
\hline RTA & F0I-04 & F0I-08 & FOI-I0 & F0I-I2 & F0I-I6 \\
\hline
\end{tabular}

For the HISN condition, the hinges disbonded from two specimens (out of a total of 6) during testing: the aluminum-adhesive interface was severely degraded by exposure to salt water. The time taken to thaw the adhesive and rebond the hinges would have led to significant losses in absorbed moisture regardless of whether a 
multi-day cure at room temperature or a one-hour cure at $70^{\circ} \mathrm{C}$ was used for the rebonding. As such, the results would not have been comparable to those of the other specimens.

\subsubsection{Results: Strain Energy Release Rate During Initiation}

\section{Table I2 and}

Figure 57 summarize the initiation strain energy release rates. Specimen 3 in the IVWN condition is a clear outlier, but problems during the beginning of the test are at fault. Comments on the data sheet indicate that the specimen was not pre-cracked in the same way as the others due to a mistake that was made in zeroing displacement at the beginning of the test. As such, this datum was discarded. 
Chapter 4:The Effects of the Environment on the Fracture Toughness of Bonded Laminates 127

Table 12: Initiation GIC,o values based on CC calculation and Non-Linear (NL) point.

\begin{tabular}{|c|c|c|c|c|c|c|c|c|}
\hline \multicolumn{2}{|c|}{ ENVIRONMENT } & \multicolumn{5}{|c|}{ INITIATION $G_{I C, o \text { BASED ON NL POINT }}$} & \multirow[b]{2}{*}{ Mean } & \multirow[b]{2}{*}{$\boldsymbol{\sigma}$} \\
\hline & & Sp. I & Sp. 2 & Sp. 3 & Sp. 4 & Sp. 5 & & \\
\hline \multirow{2}{*}{ HISN } & {$\left[\right.$ in $-1 b_{f} /$ in $\left.^{2}\right]$} & 7.66 & 7.62 & 5.89 & 6.68 & $\mathrm{~N} / \mathrm{A}$ & 6.96 & 0.85 \\
\hline & {$\left[\mathrm{kJ} / \mathrm{m}^{2}\right]$} & 1.34 & 1.33 & 1.03 & 1.17 & $\mathrm{~N} / \mathrm{A}$ & 1.22 & 0.15 \\
\hline \multirow{2}{*}{ IISN } & {$\left[\right.$ in $-1 b_{f} /$ in $\left.^{2}\right]$} & 9.23 & 8.70 & 10.29 & 7.85 & 7.58 & 8.73 & I.I \\
\hline & {$\left[\mathrm{kJ} / \mathrm{m}^{2}\right]$} & I.62 & I.52 & $\mathrm{I} .80$ & 1.37 & 1.33 & $\mathrm{I} .53$ & 0.19 \\
\hline \multirow{2}{*}{ HIWN } & {$\left[\right.$ in $-1 b_{f} /$ in $\left.^{2}\right]$} & 8.27 & 9.09 & 9.72 & 8.27 & $\mathrm{I} 0.3 \mathrm{I}$ & 9.13 & 0.90 \\
\hline & {$\left[\mathrm{kJ} / \mathrm{m}^{2}\right]$} & $\mathrm{I} .45$ & 1.59 & 1.70 & $\mathrm{I} .45$ & $\mathrm{I} .80$ & 1.60 & 0.16 \\
\hline \multirow{2}{*}{ IIWN } & {$\left[\mathrm{in} \cdot \mathrm{lb}_{\mathrm{f}} / \mathrm{in}^{2}\right]$} & 8.76 & 9.75 & $8.8 \mathrm{I}$ & 8.22 & 9.75 & 9.06 & 0.67 \\
\hline & {$\left[\mathrm{kJ} / \mathrm{m}^{2}\right]$} & 1.53 & $\mathrm{I} .7 \mathrm{I}$ & 1.54 & 1.44 & $\mathrm{I} .7 \mathrm{I}$ & 1.59 & 0.12 \\
\hline \multirow{2}{*}{ HVWN } & 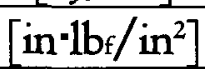 & 9.92 & II.04 & 10.59 & II.68 & 10.38 & 10.72 & 0.67 \\
\hline & {$\left[\mathrm{kJ} / \mathrm{m}^{2}\right]$} & $\mathrm{I} .74$ & 1.93 & $\mathrm{I} .85$ & 2.04 & 1.82 & 1.88 & 0.12 \\
\hline \multirow{2}{*}{ IVWN } & {$\left[\mathrm{in}^{\left.-1 \mathrm{~b}_{\mathrm{f}} / \mathrm{in}^{2}\right]}\right.$} & 9.24 & 9.58 & 3.32 & II.02 & 8.80 & 8.39 & 2.95 \\
\hline & {$\left[\mathrm{kJ} / \mathrm{m}^{2}\right]$} & 1.62 & 1.68 & 0.58 & 1.93 & 1.54 & $\mathrm{I} .47$ & 0.52 \\
\hline \multirow{2}{*}{ RTA } & {$\left[\mathrm{in} \cdot \mathrm{lb}_{\mathrm{f}} / \mathrm{in}^{2}\right]$} & $\mathrm{I} 4.56$ & 12.96 & 13.25 & $\mathrm{I} 4.59$ & 13.56 & 13.78 & 0.75 \\
\hline & {$\left[\mathrm{kJ} / \mathrm{m}^{2}\right]$} & 2.55 & 2.27 & 2.32 & 2.55 & 2.37 & $2.4 \mathrm{I}$ & 0.13 \\
\hline
\end{tabular}

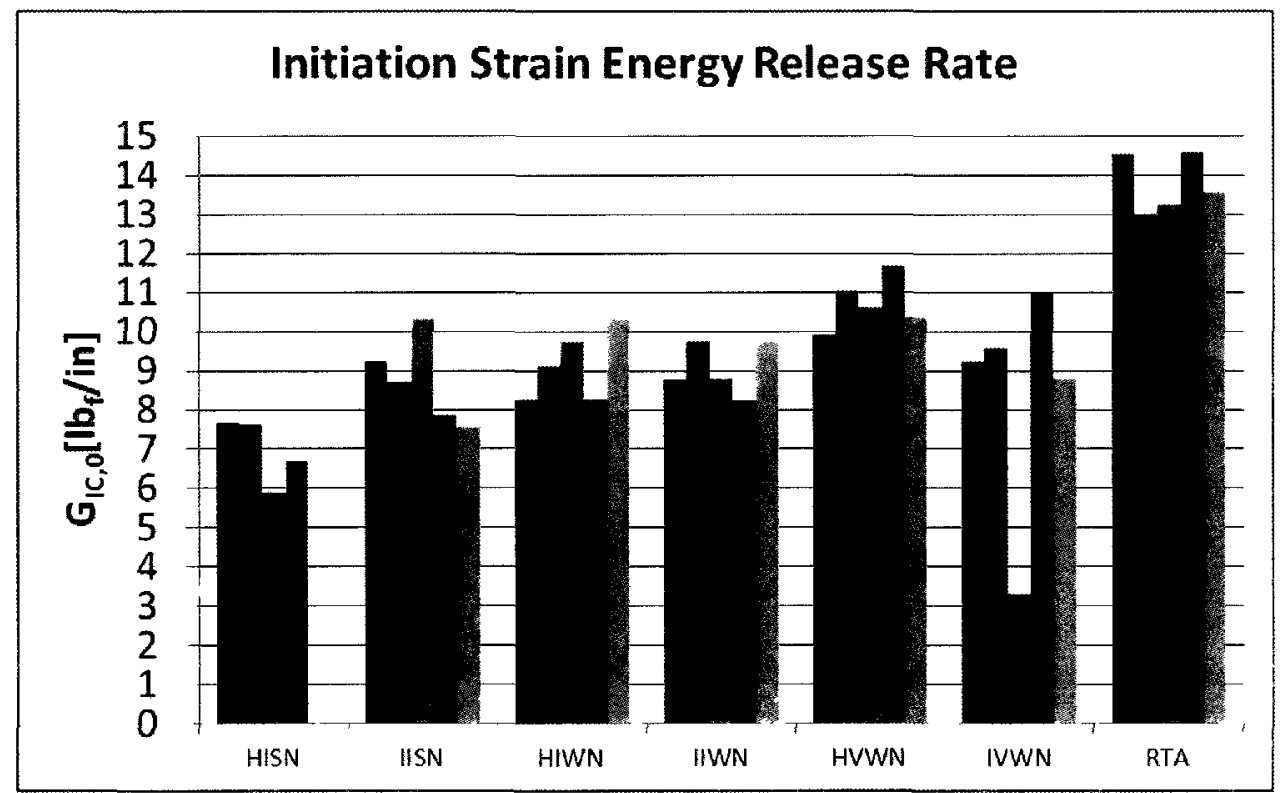

Figure 57: Initiation strain energy release rate based on $N L$ point and $C C$ calculation. Specimens are in order from $S p I-S p 5$ 


\subsubsection{Results: Strain Energy Release Rates During Crack Propagation}

In this Section, the propagation GIC results will be presented, with each conditioning environment forming a sub-section. For each environment, a graph and a table will provide two means of visualizing the data, with the table also including standard deviation values. Any interesting features observed in the results will be shown and references to the appropriate discussion Section will be provided. The last sub-sections will provide a summary of all the data, so that comparisons between conditioning environments can be made.

\subsubsection{Unconditioned Specimens (RTA)}

Some specimens were not exposed to any high-temperature environments and were to serve as a baseline to which other results would be compared. Even with the RTA specimens, however, the strain energy release rate value proved to be difficult to establish, given that with the five specimens tested, the population standard deviation was large at $\mathrm{I} .3 \mathrm{lb} /$ inch $\left(0.23 \mathrm{~kJ} / \mathrm{m}^{2}\right)$. All conditioned specimens also resulted in high values of standard deviation, making comparisons difficult. Figure 58 and Table I 3 both provide the results for the five RTA specimens. 


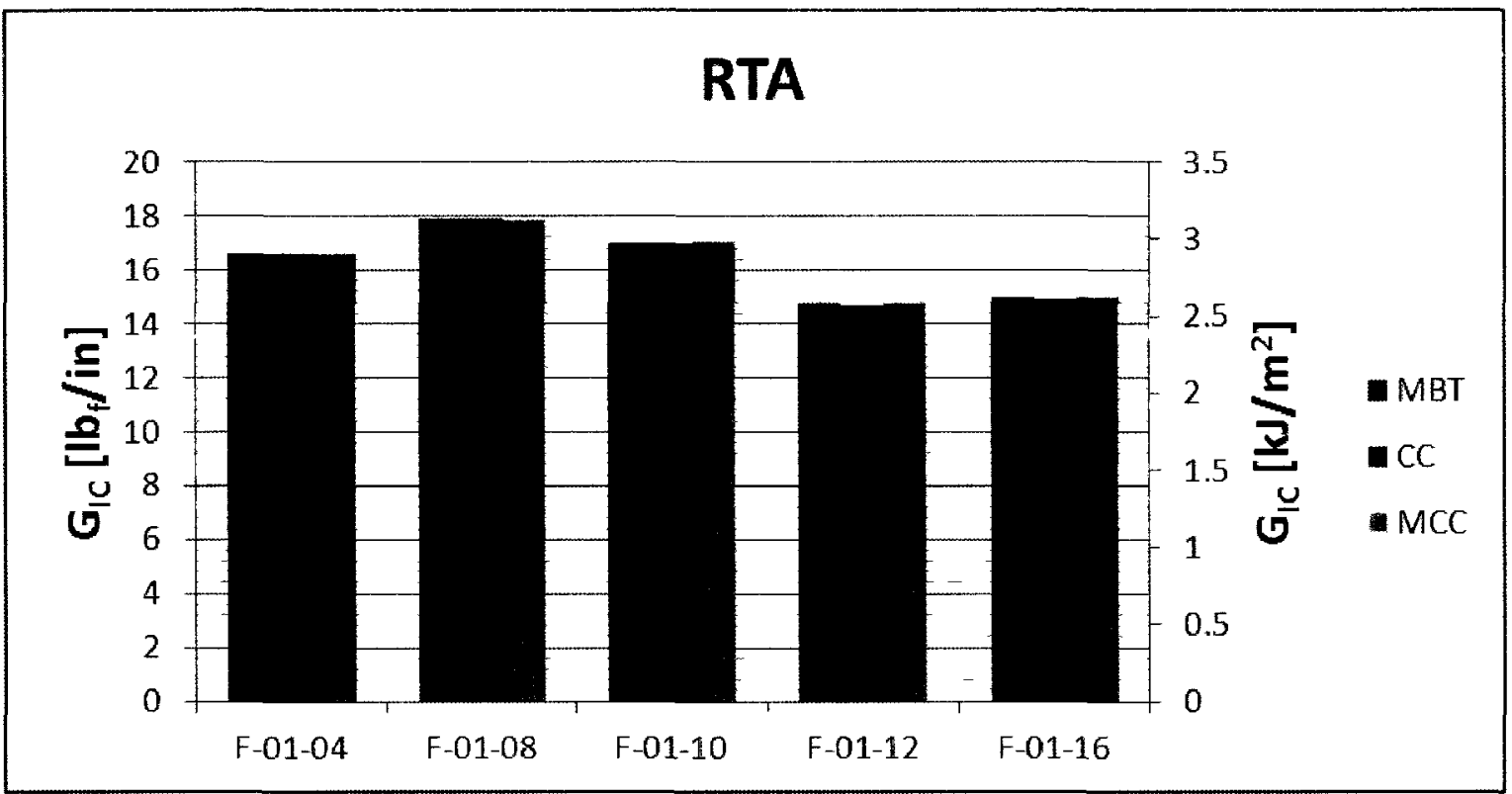

Figure 58: Propagation Gic of the five unconditioned specimens

Table 13: Mean Gic values and standard deviations for each unconditioned specimen.

\begin{tabular}{|c|c|c|c|c|c|c|c|}
\hline \multirow{2}{*}{\multicolumn{2}{|c|}{ Specimen Number }} & \multicolumn{6}{|c|}{ Strain energy release rate, Gic } \\
\hline & & \multirow{2}{*}{$\frac{\mathrm{MBT}}{\mathrm{I} 6.65}$} & \multirow{2}{*}{$\begin{array}{c}\boldsymbol{\sigma} \\
0.34\end{array}$} & \multirow{2}{*}{$\frac{\mathrm{CC}}{16.62}$} & \multirow{2}{*}{$\frac{\boldsymbol{\sigma}}{0.14}$} & \multirow{2}{*}{$\begin{array}{r}\text { MCC } \\
16.64 \\
\end{array}$} & \multirow{2}{*}{$\frac{\boldsymbol{\sigma}}{0.35}$} \\
\hline$F_{n} \cap \cap A$ & {$\left[\right.$ in $\left.\cdot \mathrm{lb}_{\mathrm{f}} / \mathrm{in}^{2}\right]$} & & & & & & \\
\hline F-01-04 & {$\left[\mathrm{kJ} / \mathrm{m}^{2}\right]$} & $2.9 \mathrm{I}$ & 0.06 & $2.9 \mathrm{I}$ & 0.02 & $2.9 \mathrm{I}$ & 0.06 \\
\hline \multirow{2}{*}{ F-0I-08 } & {$\left[\right.$ in $-1 b_{f} /$ in $\left.^{2}\right]$} & 17.89 & 0.26 & I7.88 & 0.30 & 17.86 & 0.27 \\
\hline & {$\left[\mathrm{kJ} / \mathrm{m}^{2}\right]$} & 3.13 & 0.05 & 3.13 & 0.05 & 3.13 & 0.05 \\
\hline \multirow{2}{*}{ F-OI-IO } & {$\left[\mathrm{in} \cdot \mathrm{lb}_{\mathrm{f}} / \mathrm{in}^{2}\right]$} & 17.00 & $0.2 \mathrm{I}$ & I6.97 & 0.38 & 17.04 & 0.21 \\
\hline & $\left.[\mathrm{k}] / \mathrm{m}^{2}\right]$ & 2.98 & 0.04 & 2.97 & 0.07 & 2.98 & 0.04 \\
\hline \multirow{2}{*}{ F-0I-I2 } & {$\left[\right.$ in $-1 b_{f} /$ in $\left.^{2}\right]$} & $\mathrm{I} 4.77$ & 0.32 & $\mathrm{I} 4.65$ & 0.34 & $\mathrm{I} 4.77$ & 0.33 \\
\hline & {$\left[\mathrm{k} J / \mathrm{m}^{2}\right]$} & 2.58 & 0.06 & 2.56 & 0.06 & 2.58 & 0.06 \\
\hline \multirow{2}{*}{ F-OI-I 6} & {$\left[\right.$ in-lbf $/$ in $\left.^{2}\right]$} & 15.03 & 0.23 & $\mathrm{I} 4.93$ & 0.52 & 15.03 & 0.24 \\
\hline & {$\left[\mathrm{kJ} / \mathrm{m}^{2}\right]$} & 2.63 & 0.04 & $2.6 \mathrm{I}$ & 0.09 & 2.63 & 0.04 \\
\hline
\end{tabular}


Chapter 4: The Effects of the Environment on the Fracture Toughness of Bonded Laminates I30

\subsubsection{IVWN Specimens (Conditioned at $70^{\circ} \mathrm{C}, 95 \%$ R.H.)}

Figure 59 and Table I4 provide the results from the five IVWN specimens.

Specimen C04-08 appears to be an outlier and will be discussed in Section 4.4.4.4.

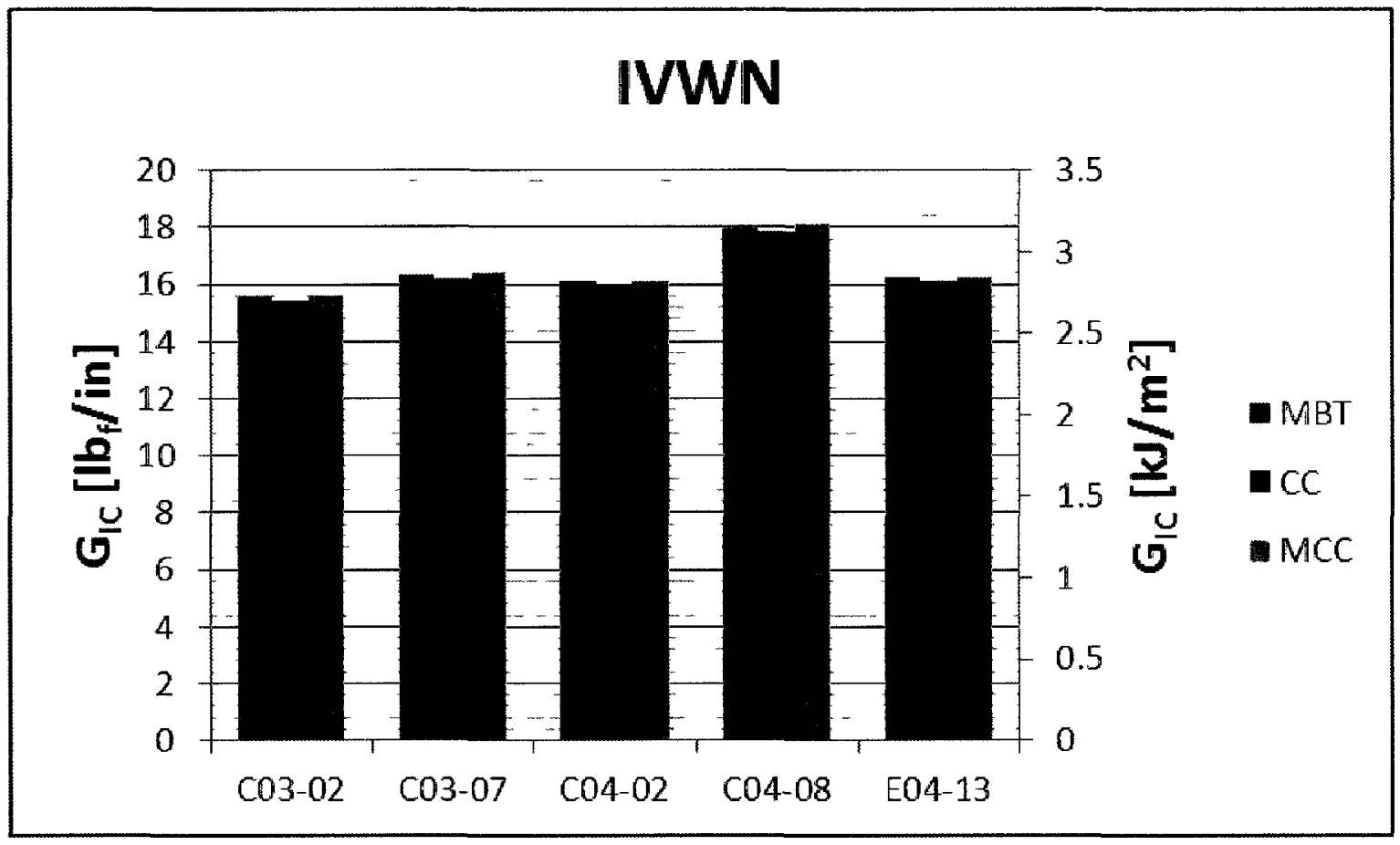

Figure 59: Propagation Gic of the five IVWN specimens

Table I4: Mean Gic values and standard deviations for each IVWN specimen.

\begin{tabular}{|c|c|c|c|c|c|c|c|}
\hline \multirow{2}{*}{\multicolumn{2}{|c|}{ Specimen Number }} & \multicolumn{6}{|c|}{ Strain energy release rate, Gic } \\
\hline & & \multirow{2}{*}{$\frac{\mathrm{MBT}}{\mathrm{I} 5.56}$} & \multirow{2}{*}{$\frac{\boldsymbol{\sigma}}{1.35}$} & \multirow{2}{*}{$\frac{\mathrm{CC}}{\mathrm{I} 5.45}$} & \multirow{2}{*}{$\frac{\sigma}{1.13}$} & \multirow{2}{*}{$\begin{array}{c}\text { MCC } \\
15.63\end{array}$} & \multirow{2}{*}{$\frac{\boldsymbol{\sigma}}{1.37}$} \\
\hline $\mathrm{CO3}-02$ & {$\left[\right.$ in $\cdot 1 b_{f} /$ in $\left.^{2}\right]$} & & & & & & \\
\hline & {$\left[\mathrm{kJ} / \mathrm{m}^{2}\right]$} & 2.723 & 0.23625 & 2.70375 & 0.19775 & 2.73525 & 0.23975 \\
\hline \multirow[t]{2}{*}{ C03-07 } & {$\left[\right.$ in $\cdot 1 \mathrm{bf} /$ in $\left.^{2}\right]$} & I 6.3 & 0.45 & 16.2 & 0.34 & $\mathrm{I} 6.38$ & 0.39 \\
\hline & {$\left[\mathrm{kJ} / \mathrm{m}^{2}\right]$} & 2.8525 & 0.07875 & 2.835 & 0.0595 & 2.8665 & 0.06825 \\
\hline \multirow[t]{2}{*}{ C04-02 } & {$\left[\mathrm{in} \cdot \mathrm{lb}_{\mathrm{f}} / \mathrm{in}^{2}\right]$} & I6.I & $\mathrm{I} .47$ & 16.02 & 1.28 & 16.12 & $\mathrm{I} .49$ \\
\hline & {$\left[\mathrm{kJ} / \mathrm{m}^{2}\right]$} & 2.8175 & 0.25725 & 2.8035 & 0.224 & $2.82 \mathrm{I}$ & 0.26075 \\
\hline \multirow[t]{2}{*}{ C04-08 } & {$\left[\mathrm{in} \cdot 1 \mathrm{lb}_{\mathrm{f}} / \mathrm{in}^{2}\right]$} & 17.99 & I.OI & $\mathrm{I} 7.85$ & 1.05 & I8.I I & $\mathrm{I} . \mathrm{I} 2$ \\
\hline & {$\left[\mathrm{kJ} / \mathrm{m}^{2}\right]$} & 3.14825 & 0.17675 & 3.12375 & 0.18375 & 3.16925 & 0.196 \\
\hline \multirow[t]{2}{*}{ E04-I3 } & {$\left[\right.$ in $\left./ l_{\mathrm{f}} / \mathrm{in}^{2}\right]$} & $\mathrm{I} 6.25$ & $\mathrm{I}$ & $\mathrm{I} 6.15$ & 0.88 & 16.25 & 0.98 \\
\hline & {$\left[\mathrm{kJ} / \mathrm{m}^{2}\right]$} & 2.84375 & 0.175 & 2.82625 & 0.154 & 2.84375 & 0.1715 \\
\hline
\end{tabular}




\subsubsection{HVWN Specimens (Conditioned at $82^{\circ} \mathrm{C}, 95 \%$ R.H.)}

Figure 60 and Table I5 provide the results for the HVWN specimens.

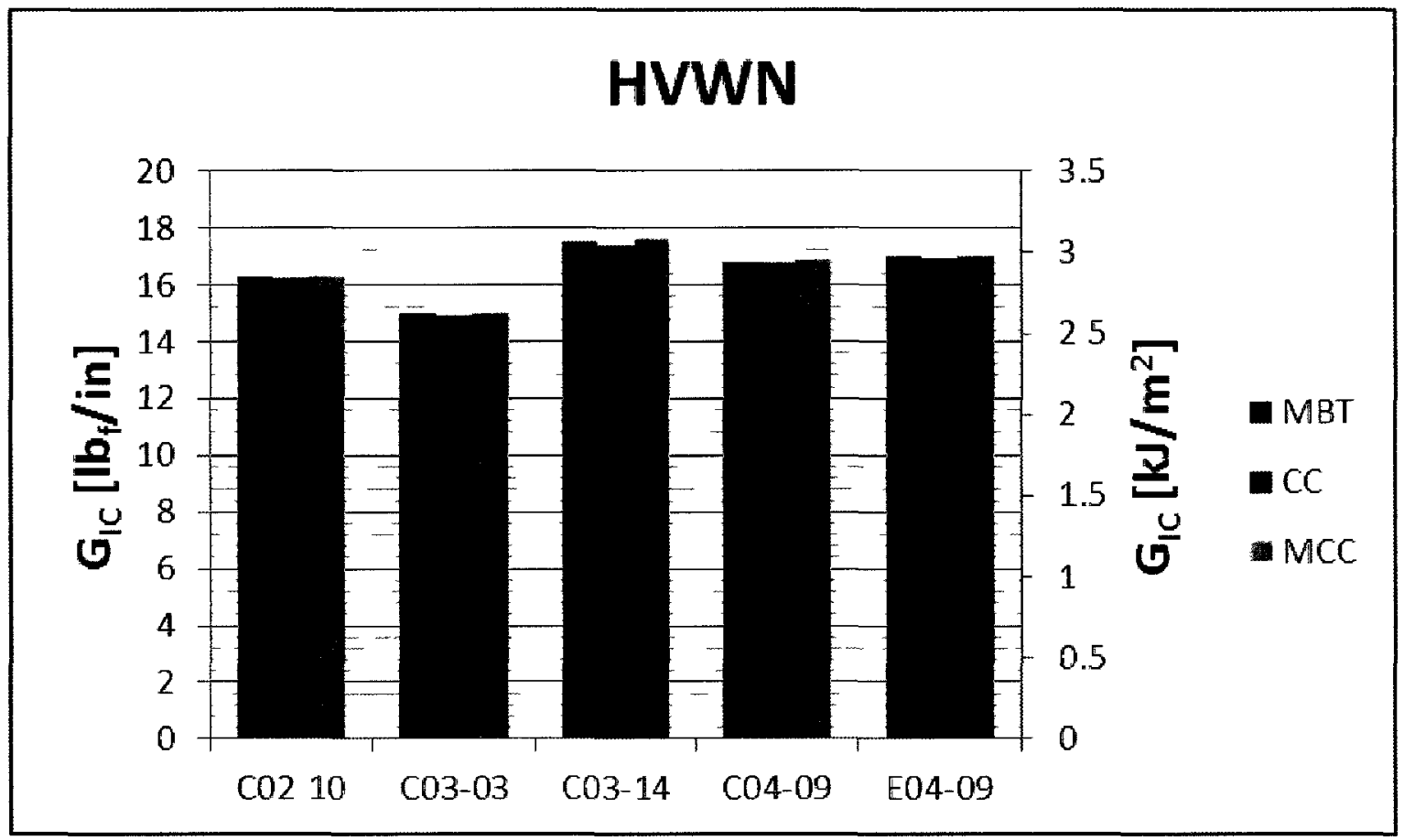

Figure 60. Propagation Gic of the five HVWN specimens

Table 15: Mean Gic values and standard deviations for each HVWN specumen.

\begin{tabular}{|c|c|c|c|c|c|c|c|}
\hline \multirow{2}{*}{\multicolumn{2}{|c|}{ Specimen Number }} & \multicolumn{6}{|c|}{ Strain energy release rate, GI } \\
\hline & & \multirow{2}{*}{$\frac{\text { MBT }}{16.30}$} & \multirow{2}{*}{$\begin{array}{c}\boldsymbol{\sigma} \\
0.27\end{array}$} & \multirow{2}{*}{$\frac{\mathrm{CC}}{\mathrm{I} 6.22}$} & \multirow{2}{*}{$\begin{array}{c}\boldsymbol{\sigma} \\
0.52\end{array}$} & \multirow{2}{*}{$\frac{\mathrm{MCC}}{16.27}$} & \multirow{2}{*}{$\begin{array}{c}\boldsymbol{\sigma} \\
0.30\end{array}$} \\
\hline & {$\left[\right.$ in $\left.\cdot \mathrm{lb}_{\mathrm{f}} / \mathrm{in}^{2}\right]$} & & & & & & \\
\hline COL-10 & {$\left[\mathrm{kJ} / \mathrm{m}^{2}\right]$} & 2.85 & 0.05 & 2.84 & 0.09 & 2.85 & 0.05 \\
\hline \multirow{2}{*}{$\mathrm{CO3-03}$} & in $\cdot \mathrm{lb}_{\mathrm{f}} / \mathrm{in}^{2}$ & 15.00 & 0.59 & $\mathrm{I} 4.95$ & 0.47 & 14.99 & 0.59 \\
\hline & {$\left[\mathrm{kJ} / \mathrm{m}^{2}\right]$} & 2.63 & 0.10 & 2.62 & 0.08 & 2.62 & 0.10 \\
\hline \multirow{2}{*}{ CO3-I4 } & {$\left[\right.$ in $-1 b_{f} /$ in $\left.^{2}\right]$} & 17.50 & 0.74 & I7.4I & 0.70 & 17.56 & 0.79 \\
\hline & {$\left[\mathrm{kJ} / \mathrm{m}^{2}\right]$} & 3.06 & 0.13 & 3.05 & 0.12 & 3.07 & 0.14 \\
\hline \multirow{2}{*}{ C04-09 } & {$\left[\right.$ in $\cdot 1 b_{f} /$ in $\left.^{2}\right]$} & I6.8I & $\mathrm{I} .08$ & 16.72 & 0.93 & $\mathrm{I} 6.87$ & 1.05 \\
\hline & {$\left[\mathrm{kJ} / \mathrm{m}^{2}\right]$} & 2.94 & 0.19 & 2.93 & 0.16 & 2.95 & 0.18 \\
\hline \multirow{2}{*}{ E04-09 } & {$\left[\right.$ in $-1 b_{f} /$ in $\left.^{2}\right]$} & 17.03 & 0.74 & 16.95 & 0.66 & 17.03 & $0.7 \mathrm{I}$ \\
\hline & {$\left[\mathrm{kJ} / \mathrm{m}^{2}\right]$} & 2.98 & 0.13 & 2.97 & 0.12 & 2.98 & 0.12 \\
\hline
\end{tabular}




\subsubsection{IIWN Specimens (Conditioned at $70^{\circ} \mathrm{C}$, Immersed in Water)}

Figure $6 I$ and Table I6 provide the results for the IIWN specimens. C03-I6 appears to have a high $G_{I}$, but unlike others, no explanation could be found for this behaviour.

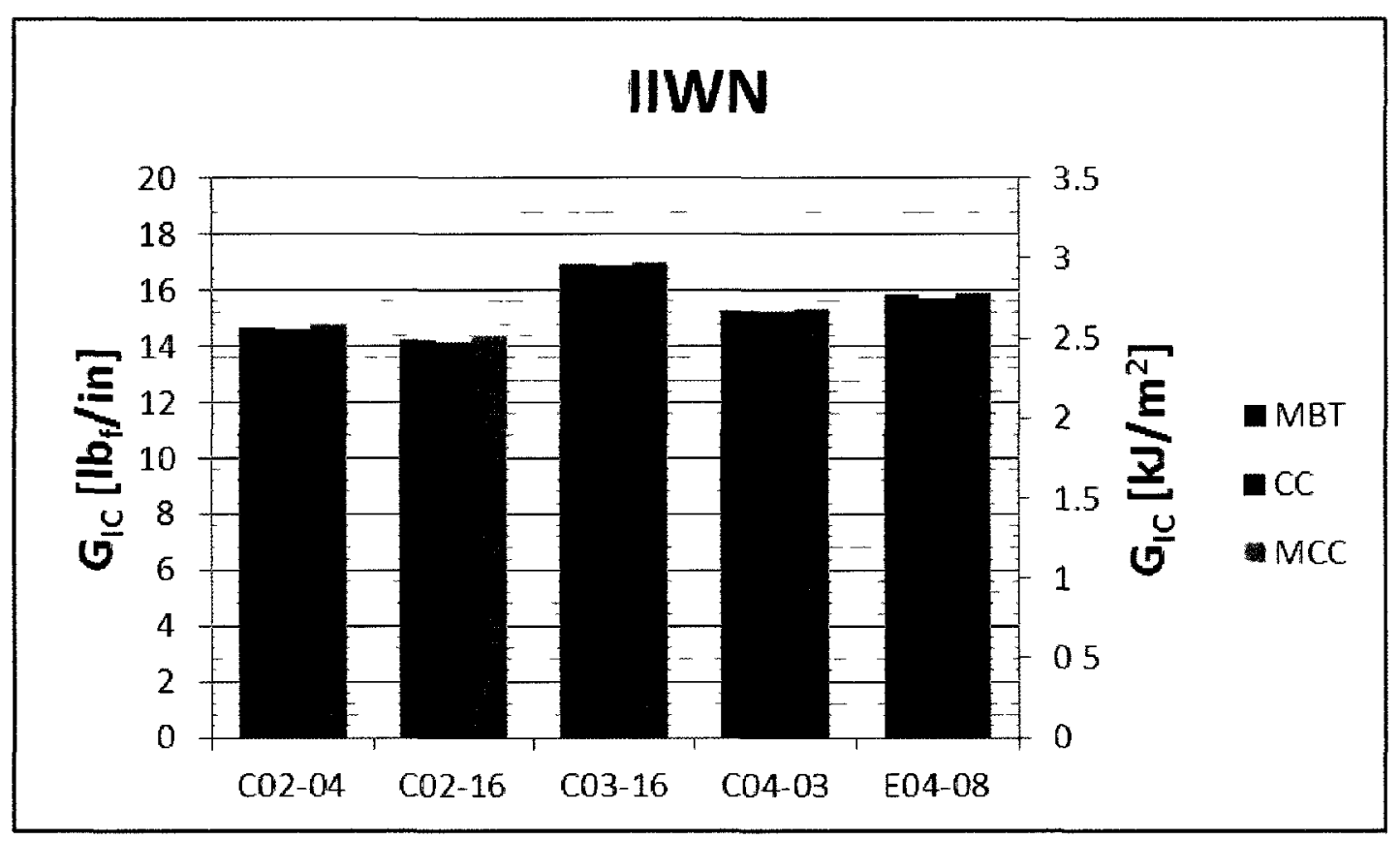

Figute 61: Propagation Gic of the five IIWN specimens

Table I6: Mean Gic values and standard deviations for each IIWN specimen.

\begin{tabular}{|c|c|c|c|c|c|c|c|}
\hline \multirow{2}{*}{\multicolumn{2}{|c|}{ Specimen Number }} & \multicolumn{6}{|c|}{ Strain energy release rate, Gic } \\
\hline & & \multirow{2}{*}{$\frac{\mathrm{MBT}}{\mathrm{I} 4.67}$} & \multirow{2}{*}{$\begin{array}{c}\boldsymbol{\sigma} \\
0.87\end{array}$} & \multirow{2}{*}{$\frac{\mathrm{CC}}{\mathrm{I} 4.60}$} & \multirow{2}{*}{$\begin{array}{c}\boldsymbol{\sigma} \\
0.8 \mathrm{I}\end{array}$} & \multirow{2}{*}{$\frac{\mathrm{MCC}}{\mathrm{I} 4.7 \mathrm{I}}$} & \multirow{2}{*}{$\frac{\boldsymbol{\sigma}}{0.85}$} \\
\hline \multirow{2}{*}{ C02-04 } & {$\left[\right.$ in $-1 b_{f} /$ in $\left.^{2}\right]$} & & & & & & \\
\hline & {$\left[\mathrm{kJ} / \mathrm{m}^{2}\right]$} & 2.57 & 0.15 & 2.56 & 0.14 & 2.57 & 0.15 \\
\hline \multirow{2}{*}{ C02-I6 } & {$\left[\right.$ in $\left.\cdot \mathrm{lb}_{\mathrm{f}} / \mathrm{in}^{2}\right]$} & I4.24 & 0.60 & I4.15 & 0.56 & I4.35 & 0.66 \\
\hline & {$\left[\mathrm{kJ} / \mathrm{m}^{2}\right]$} & 2.49 & 0.11 & 2.48 & 0.10 & $2.5 \mathrm{I}$ & 0.12 \\
\hline \multirow{2}{*}{$\mathrm{CO3}-\mathrm{I} 6$} & {$\left[\right.$ in $\left.\cdot \mathrm{lb}_{\mathrm{f}} / \mathrm{in}^{2}\right]$} & 16.96 & 1.49 & I6.89 & 1.37 & 16.99 & I.47 \\
\hline & {$\left[\mathrm{kJ} / \mathrm{m}^{2}\right]$} & 2.97 & 0.26 & 2.96 & 0.24 & 2.97 & 0.26 \\
\hline \multirow{2}{*}{ CO4-03 } & {$\left[\mathrm{in}^{\circ} \mathrm{lb}_{\mathrm{f}} / \mathrm{in}^{2}\right]$} & 15.28 & 1.64 & I5.2I & 1.52 & 15.32 & 1.61 \\
\hline & {$\left[\mathrm{kJ} / \mathrm{m}^{2}\right]$} & 2.67 & 0.29 & 2.66 & 0.27 & 2.68 & 0.28 \\
\hline \multirow{2}{*}{ E04-08 } & {$\left[\mathrm{in}^{\left.-1 \mathrm{~b}_{\mathrm{f}} / \mathrm{in}^{2}\right]}\right.$} & 15.85 & 0.90 & 15.74 & 0.83 & 15.92 & 0.89 \\
\hline & {$\left[\mathrm{kJ} / \mathrm{m}^{2}\right]$} & 2.77 & 0.16 & 2.75 & 0.15 & 2.79 & 0.16 \\
\hline
\end{tabular}




\subsubsection{HWN Specimens (Conditioned at $82^{\circ} \mathrm{C}$, Immersed in Water)}

Figure 62 and Table 17 provide the results for HIWN specimens. The outlier C02-07 is discussed in Section 4.4.4.4.

\section{HIWN}

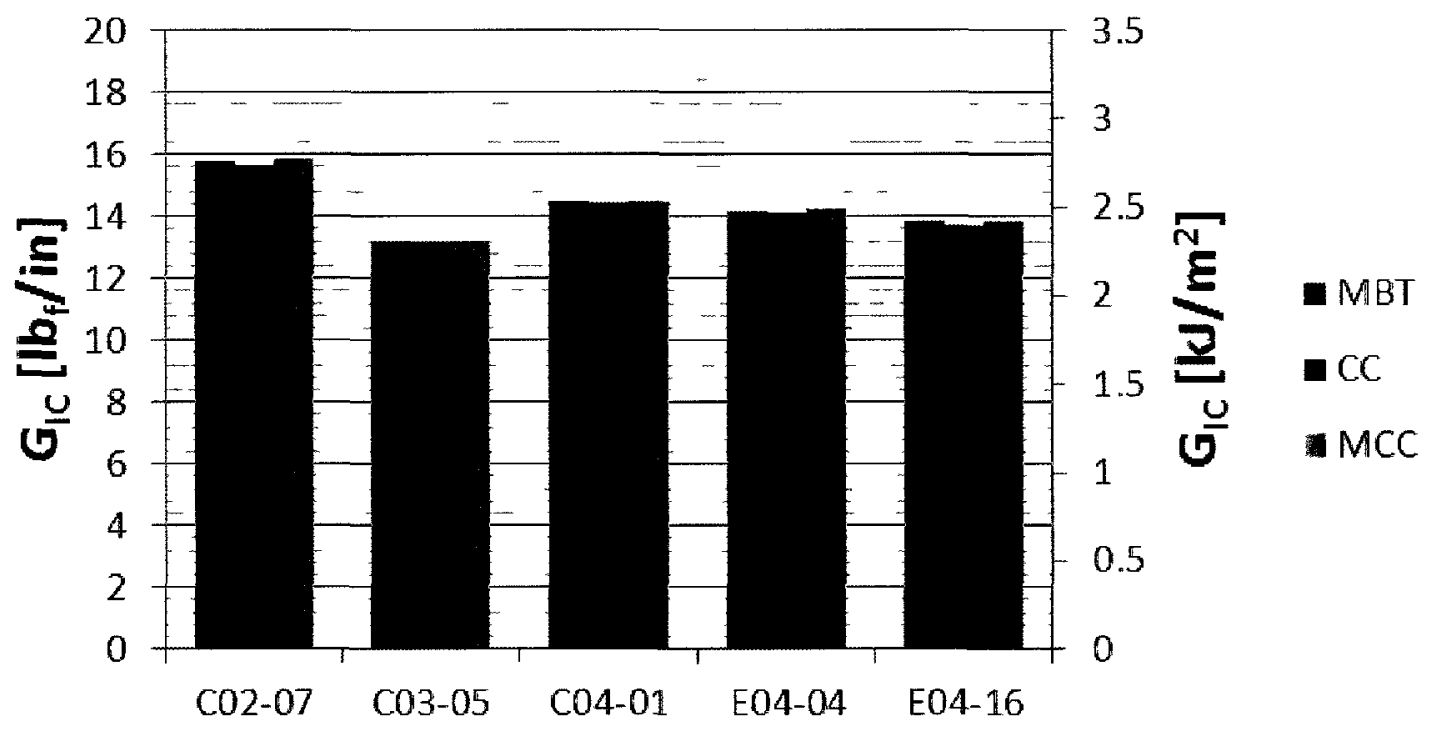

Figute 62: Propagation Gic of the five HIWN specimens

Table I7: Mean Gic values and standard devations for each HIWN specimen.

\begin{tabular}{|c|c|c|c|c|c|c|c|}
\hline \multirow{2}{*}{\multicolumn{2}{|c|}{ Specimen Number }} & \multicolumn{6}{|c|}{ Strain energy release rate, GC } \\
\hline & & \multirow{2}{*}{$\begin{array}{l}\text { MBT } \\
15.78\end{array}$} & \multirow{2}{*}{$\begin{array}{c}\boldsymbol{\sigma} \\
0.63\end{array}$} & \multirow{2}{*}{$\frac{\mathrm{CC}}{15.67}$} & \multirow{2}{*}{$\frac{\boldsymbol{\sigma}}{0.60}$} & \multirow{2}{*}{$\frac{\text { MCC }}{15.84}$} & \multirow{2}{*}{$\begin{array}{c}\boldsymbol{\sigma} \\
0.59 \\
\end{array}$} \\
\hline $\mathrm{CO2-}$ & {$\left[\mathrm{in} \cdot 1 \mathrm{~b}_{\mathrm{f}} / \mathrm{in}^{2}\right]$} & & & & & & \\
\hline 07 & & 2.76 & 0.11 & 2.74 & 0.11 & 2.77 & 0.10 \\
\hline \multirow{2}{*}{$\begin{array}{c}\mathrm{C} 03- \\
05\end{array}$} & {$\left[\mathrm{in}^{-1} \mathrm{lb}_{\mathrm{f}} / \mathrm{in}^{2}\right]$} & I3.2I & I.I2 & 13.15 & 1.0 & I3.2I & $\mathrm{I.I4}$ \\
\hline & & $2.3 \mathrm{I}$ & 0.20 & 2.30 & 0.1 & $2.3 \mathrm{I}$ & 0.20 \\
\hline \multirow{2}{*}{$\begin{array}{c}\mathrm{CO} 4- \\
\text { OI }\end{array}$} & {$\left[\right.$ in $-1 b_{f} /$ in $\left.^{2}\right]$} & $\mathrm{I} 4.47$ & 1.33 & I4.43 & 1.23 & 14.49 & 1.32 \\
\hline & & 2.53 & 0.23 & 2.53 & 0.2 & 2.54 & 0.23 \\
\hline \multirow{2}{*}{$\begin{array}{c}\text { E04- } \\
04\end{array}$} & rin.lhding & I4.I8 & 0.62 & I4.I4 & 0.57 & I 4.22 & 0.62 \\
\hline & & 2.48 & 0.11 & 2.47 & 0.1 & 2.49 & $0 . I \mathrm{I}$ \\
\hline \multirow{2}{*}{$\begin{array}{c}\text { E04- } \\
\text { I6 }\end{array}$} & $\Gamma \cdot 1 \mathrm{~h} / \mathrm{i} 2 \mathrm{z}$ & 13.83 & 1.33 & I3.74 & 0.95 & 13.83 & 1.28 \\
\hline & {$\left[\mathrm{kJ} / \mathrm{m}^{2}\right]$} & 2.42 & 0.23 & 2.40 & 0.17 & 2.42 & 0.22 \\
\hline
\end{tabular}




\subsubsection{IISN Specimens (Conditioned at $70^{\circ} \mathrm{C}$, Immersed in Salt Water)}

Figure 63 and Table I8 provide the results for the IISN specimens.

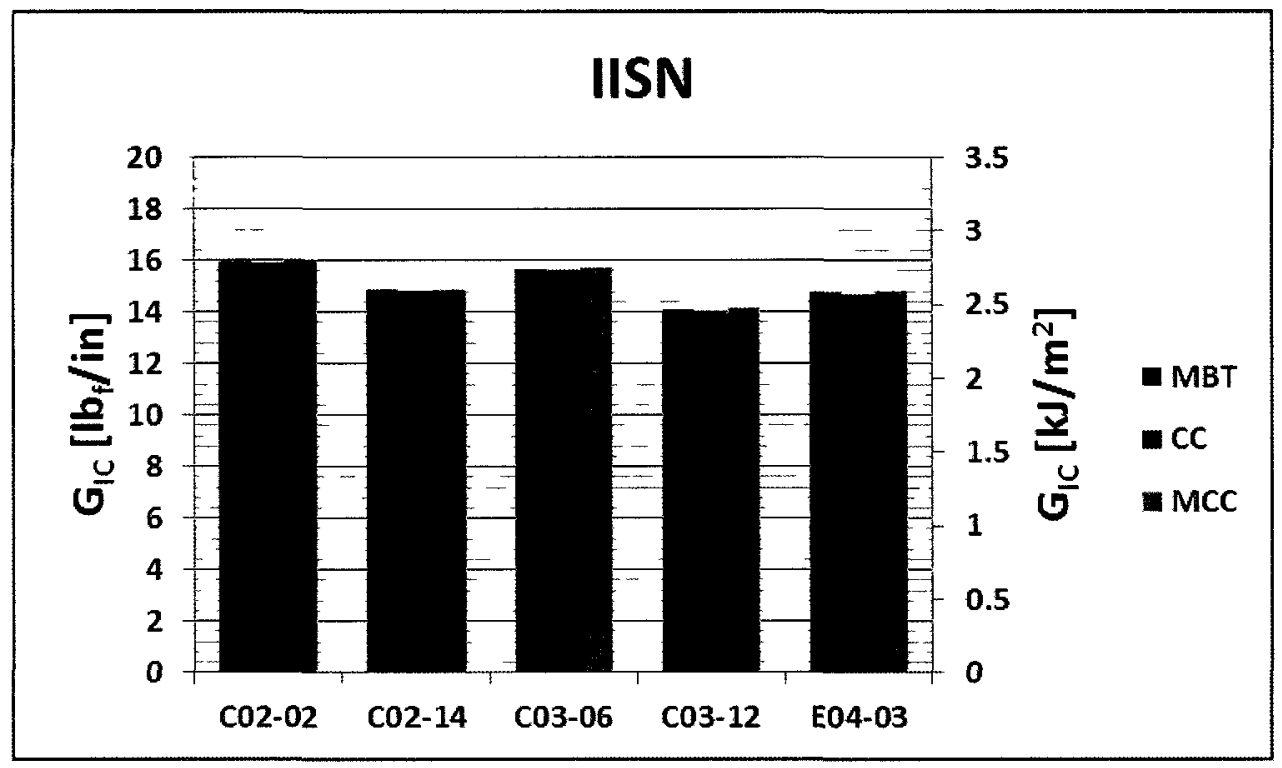

Figure 63: Propagation Gic of the five IISN specimens

Table I8: Mean GIC values and standard deviations for each IISN specumen.

\begin{tabular}{|c|c|c|c|c|c|c|c|}
\hline \multirow{2}{*}{\multicolumn{2}{|c|}{ Specimen Number }} & \multicolumn{6}{|c|}{ Strain energy release rate, $\mathrm{G}_{\mathrm{C}}$} \\
\hline & & \multirow{2}{*}{$\frac{\text { MBT }}{16.00}$} & \multirow{2}{*}{$\begin{array}{c}\boldsymbol{\sigma} \\
1.43\end{array}$} & \multirow{2}{*}{$\begin{array}{c}\mathrm{CC} \\
\mathrm{I} 5.9 \mathrm{I}\end{array}$} & \multirow{2}{*}{$\frac{\boldsymbol{\sigma}}{\mathrm{I} .3 \mathrm{I}}$} & \multirow{2}{*}{$\frac{\text { MCC }}{16.03}$} & \multirow{2}{*}{$\frac{\boldsymbol{\sigma}}{1.37}$} \\
\hline \multirow{2}{*}{$\mathrm{C} 02-02$} & {$\left[\right.$ in $\left.1 \mathrm{lb}_{\mathrm{f}} / \mathrm{in}^{2}\right]$} & & & & & & \\
\hline & {$\left[\mathrm{kJ} / \mathrm{m}^{2}\right]$} & 2.80 & 0.25 & 2.78 & 0.23 & $2.8 \mathrm{I}$ & 0.24 \\
\hline \multirow{2}{*}{$\mathrm{CO2-I4}$} & {$\left[\mathrm{in} \cdot \mathrm{lbf} / \mathrm{in}^{2}\right]$} & I 4.86 & 1.24 & 14.85 & 1.05 & $\mathrm{I} 4.88$ & 1.24 \\
\hline & {$\left[\mathrm{kJ} / \mathrm{m}^{2}\right]$} & 2.60 & 0.22 & 2.60 & 0.18 & 2.60 & 0.22 \\
\hline \multirow{2}{*}{ C03-06 } & {$\left[\mathrm{in} \cdot 1 \mathrm{bf} / \mathrm{in}^{2}\right]$} & 15.67 & 0.78 & 15.58 & 0.76 & 15.73 & 0.81 \\
\hline & {$\left[\mathrm{kJ} / \mathrm{m}^{2}\right]$} & 2.74 & 0.14 & 2.73 & 0.13 & 2.75 & 0.14 \\
\hline \multirow{2}{*}{$\mathrm{CO3}-\mathrm{I} 2$} & {$\left[\mathrm{in} \cdot 1 \mathrm{~b}_{\mathrm{f}} / \mathrm{in}^{2}\right]$} & I4.IO & 1.13 & 14.00 & 0.98 & I4.I7 & 1.13 \\
\hline & {$\left[\mathrm{kJ} / \mathrm{m}^{2}\right]$} & 2.47 & 0.20 & 2.45 & 0.17 & 2.48 & 0.20 \\
\hline \multirow{2}{*}{ E04-03 } & {$\left[\mathrm{in} \cdot 1 \mathrm{~b}_{\mathrm{f}} / \mathrm{in}^{2}\right]$} & 14.76 & 1.79 & $\mathrm{I} 4.70$ & 1.66 & $\mathrm{I} 4.80$ & $\mathrm{I} .74$ \\
\hline & {$\left[\mathrm{kJ} / \mathrm{m}^{2}\right]$} & 2.58 & 0.31 & 2.57 & 0.29 & 2.59 & 0.30 \\
\hline
\end{tabular}




\subsubsection{HISN Specimens (Conditioned at $82^{\circ} \mathrm{C}$, Immersed in Salt Water)}

Figure 64 and Table 19 provide the results for the HISN specimens. The outlier C03-08 is discussed in Section 4.4.4.4.

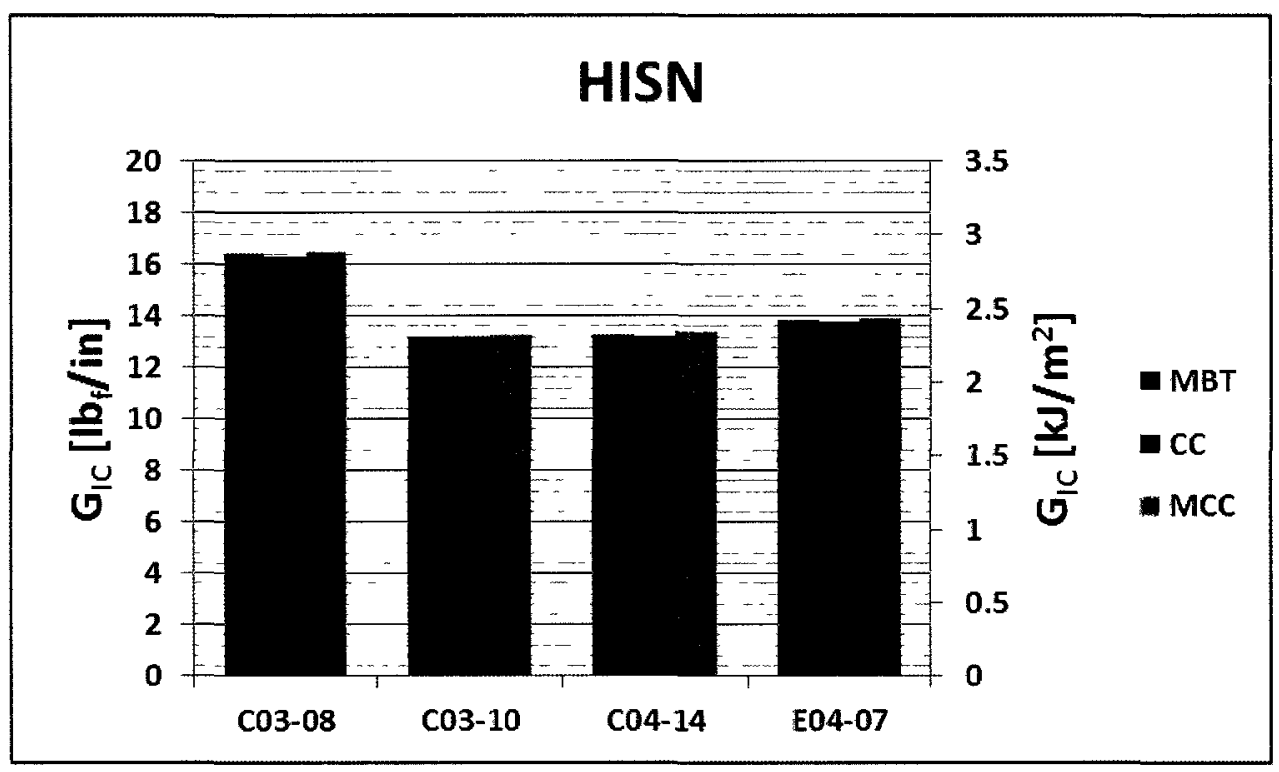

Figute 64: Propagation Gic of the five HISN specimens

Table 19: Mean GIC values and standard deviations for each HISN specimen.

\begin{tabular}{|c|c|c|c|c|c|c|c|}
\hline \multirow{2}{*}{\multicolumn{2}{|c|}{ Specimen Number }} & \multicolumn{6}{|c|}{ Strain energy release rate, $\mathrm{G}_{\mathrm{C}}$} \\
\hline & & \multirow{2}{*}{$\begin{array}{r}\mathrm{MBT} \\
16.42 \\
\end{array}$} & \multirow{2}{*}{$\begin{array}{c}\boldsymbol{\sigma} \\
\mathrm{I} .18\end{array}$} & \multirow{2}{*}{ CC } & \multirow{2}{*}{$\begin{array}{c}\boldsymbol{\sigma} \\
1.10 \\
\end{array}$} & \multirow{2}{*}{$\frac{\mathrm{MCC}}{\mathrm{I} 6.48}$} & \multirow{2}{*}{$\frac{\boldsymbol{\sigma}}{1.20}$} \\
\hline \multirow{2}{*}{ C03-08 } & $\Gamma^{\circ} \cdot 11$ & & & & & & \\
\hline & & 2.87 & & 2.86 & 0.19 & 2.88 & \\
\hline \multirow{2}{*}{ CO3-IO } & rin.the & 13.24 & & 13.24 & & 13.25 & 63 \\
\hline & & 32 & & 32 & & 2.32 & \\
\hline \multirow{2}{*}{ C04-I4 } & & I3.29 & & 13.19 & & 13.37 & \\
\hline & & 2.33 & & $2.3 \mathrm{I}$ & $00_{-}$ & 2.34 & 0.09 \\
\hline \multirow{2}{*}{ E04-07 } & in 1 & I3.84 & & 13.79 & & I3.9I & 0.96 \\
\hline & {$\left[\mathrm{kJ} / \mathrm{m}^{2}\right]$} & 2.42 & 0.16 & $2.4 \mathrm{I}$ & 0.14 & 2.43 & 0.17 \\
\hline
\end{tabular}




\subsubsection{Comparison of Conditions}

Figure 65 shows the mean and standard error ( $90 \%$ confidence interval, CI) for propagation $G_{I C}$ values from all 7 environmental conditions. It can be seen that the error is quite large and approximately on the same order as the difference between the means of different conditions. Removing the outliers highlighted in Table 20 helped reduce the standard error on those three conditions (IVWN, HIWN, HISN), as seen in Figure 66.

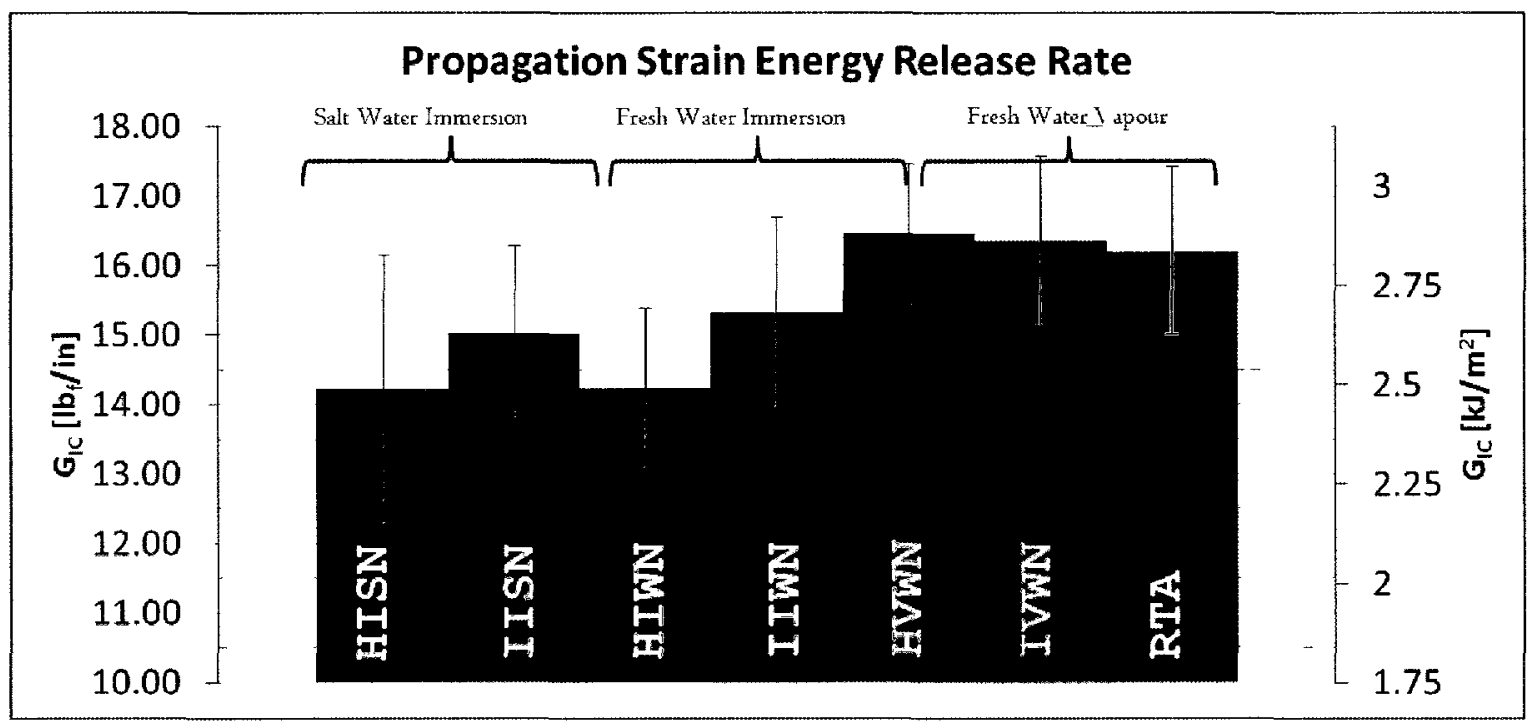

Figure 65: Overall comparison of strain energy release rate of propagation for all conditions. Error bars represent $90 \% \mathrm{CI}$.

Table 20 is a summary of the GIC values obtained from the CC method and includes the standard deviation for each specimen. 
Table 20: Mean GIC and standard deviation for each specimen, as calculated using the CC method. Specimens I-5 can be identified from Table II. Outliers are highlighted and discussed in Section 4.4.5.

\begin{tabular}{|c|c|c|c|c|c|c|c|c|c|c|c|}
\hline \multirow{2}{*}{\multicolumn{2}{|c|}{ CONDITION }} & \multicolumn{2}{|c|}{ SP. I } & \multicolumn{2}{|c|}{ SP. 2} & \multicolumn{2}{|c|}{ SP. 3} & \multicolumn{2}{|c|}{ SP. 4} & \multicolumn{2}{|c|}{$\mathrm{SP} .5$} \\
\hline & & $G_{I C}$ & $\sigma$ & $G_{C}$ & $\sigma$ & $G_{I C}$ & $\sigma$ & $G_{C}$ & $\sigma$ & $G_{I C}$ & $\sigma$ \\
\hline \multirow{2}{*}{ HISN } & {$\left[\mathrm{in} \cdot \mathrm{lb} f / \mathrm{in}^{2}\right]$} & I6.33 & 1.09 & $\mathrm{I} 3.24$ & $\mathrm{I} .48$ & 13.19 & 0.47 & 13.79 & 0.79 & N/A & $N / A$ \\
\hline & {$\left[\mathrm{kJ} / \mathrm{m}^{2}\right]$} & 2.86 & 0.19 & 2.32 & 0.26 & $2.3 \mathrm{I}$ & 0.08 & $2.4 \mathrm{I}$ & 0.14 & N/A & $\mathrm{N} / \mathrm{A}$ \\
\hline \multirow{2}{*}{ IISN } & in $1 b_{f} /$ in $^{2}$ & I5.9I & I.3I & $\mathrm{I} 4.85$ & 1.05 & I5.58 & 0.76 & I 4.00 & 0.98 & I4.70 & I.66 \\
\hline & {$\left[\mathrm{kJ} / \mathrm{m}^{2}\right]$} & 2.78 & 0.23 & 2.60 & 0.18 & 2.73 & 0.13 & 2.45 & 0.17 & 2.57 & 0.29 \\
\hline \multirow{2}{*}{ HIWN } & {$\left[\mathrm{in} \cdot \mathrm{lb}_{\mathrm{f}} / \mathrm{in}^{2}\right]$} & I5.67 & 0.60 & I3.I5 & 1.00 & 14.43 & $\mathrm{I} .23$ & I4.I4 & 0.57 & I3.74 & 0.95 \\
\hline & {$\left[\mathrm{kJ} / \mathrm{m}^{2}\right]$} & 2.74 & $0.1 \mathrm{I}$ & 2.30 & 0.18 & 2.53 & 0.22 & 2.47 & 0.10 & 2.40 & 0.17 \\
\hline \multirow{2}{*}{ IIWN } & {$\left[\right.$ in $\left.\cdot \mathrm{lb}_{\mathrm{f}} / \mathrm{in}^{2}\right]$} & $\mathrm{I} 4.60$ & $0.8 \mathrm{I}$ & 14.15 & 0.56 & I6.89 & $\mathrm{I} .37$ & $\mathrm{I} 5.2 \mathrm{I}$ & $\mathrm{I} .52$ & $\mathrm{I} 5.74$ & 0.83 \\
\hline & {$\left[\mathrm{kJ} / \mathrm{m}^{2}\right]$} & 2.56 & 0.14 & 2.48 & 0.10 & 2.96 & 0.24 & 2.66 & 0.27 & 2.75 & 0.15 \\
\hline \multirow{2}{*}{ HVWN } & in $1 b_{f} /$ in $^{2}$ & I6.22 & 0.52 & $\mathrm{I} 4.95$ & 0.47 & I7.4I & 0.70 & 16.72 & 0.93 & I6.95 & 0.66 \\
\hline & {$\left[\mathrm{kJ} / \mathrm{m}^{2}\right]$} & 2.84 & 000 & 2.62 & 0.08 & 3.05 & 0.12 & 2.93 & 0.16 & 2.97 & 0.12 \\
\hline \multirow{2}{*}{ IVWN } & {$\left[\mathrm{in} \cdot \mathrm{lb} \mathrm{b}_{\mathrm{f}} / \mathrm{in}^{2}\right]$} & $\mathrm{I} 5.45$ & I.I3 & 16.20 & 0.34 & 16.02 & I. 28 & 17.85 & 1.05 & I6.I5 & 0.88 \\
\hline & {$\left[\mathrm{kJ} / \mathrm{m}^{2}\right]$} & 2.70 & 0.20 & 2.84 & 0.06 & 2.80 & 0.22 & 3.12 & 0.18 & 2.83 & 0.15 \\
\hline \multirow{2}{*}{ RTA } & {$\left[\mathrm{in}^{-} / \mathrm{b}_{\mathrm{f}} / \mathrm{in}^{2}\right]$} & I 6.62 & 0.14 & I7.88 & 0.30 & I6.97 & 0.38 & 14.65 & 0.34 & I4.93 & 0.52 \\
\hline & {$\left[\mathrm{kJ} / \mathrm{m}^{2}\right]$} & 2.91 & 0.02 & 3.13 & 0.05 & 2.97 & 0.07 & 2.56 & 0.06 & $2.6 \mathrm{I}$ & 0.09 \\
\hline
\end{tabular}

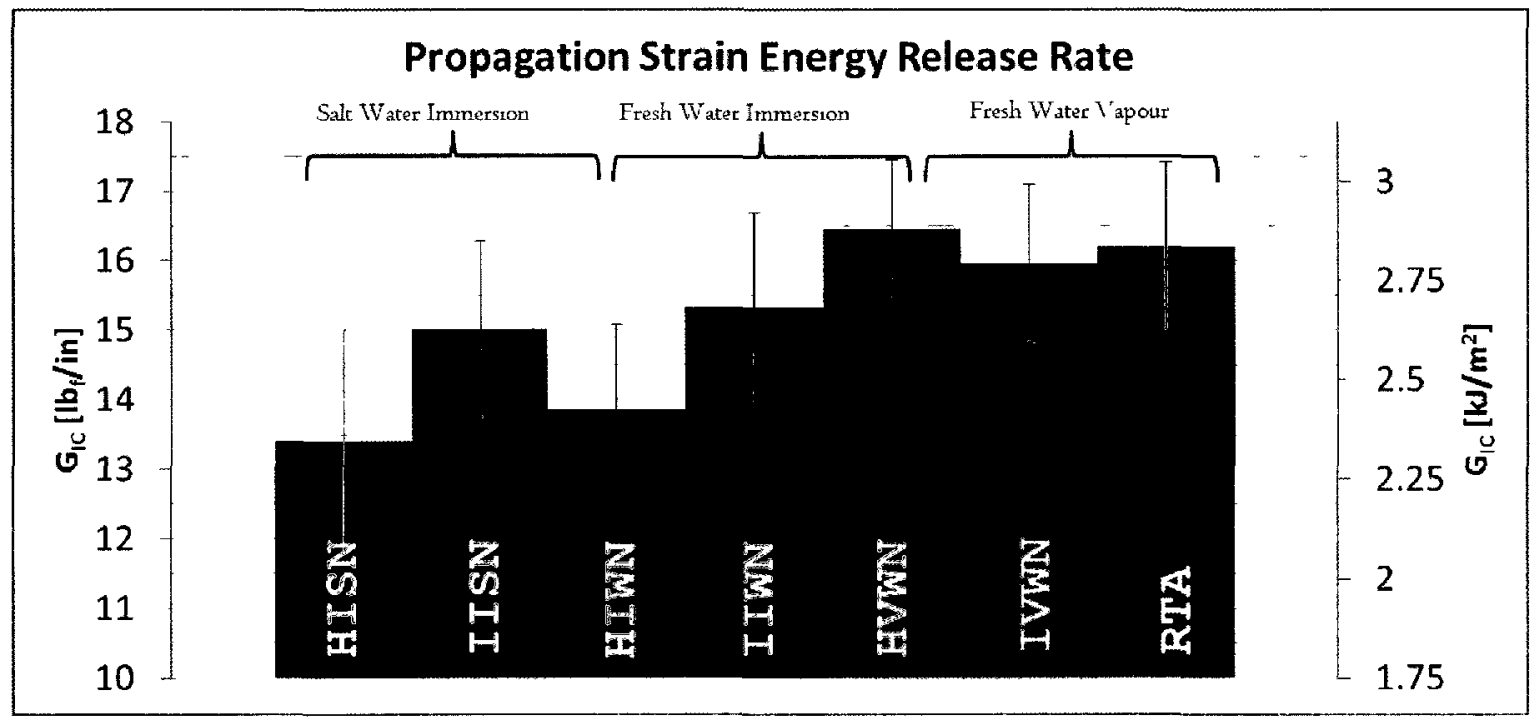

Figure 66: Ovetall comparison of strain energy release rate of propagation for all conditions, after removing data from outliers (CI: 
A more detailed discussion on the sources of observed variations and the interesting points to be taken from these results will follow, in Sections 4.4.4 and 4.4.5 respectively.

\subsubsection{Possible Sources of Observed Variations}

The strain energy release rate results were difficult to interpret due to wide error bars on the results. In each condition, GIC varied greatly from specimen to specimen. Moreover, for many specimens, it varied with crack length. Figure 54 and Figure 55 show, respectively, examples of a specimen with relatively consistent and widely-varying energy release rates versus crack length. The former was representative of conditioned specimens, while the latter, of unconditioned ones. All environmentally-conditioned specimens also had very low initiation values compared with the propagation value, which was not the case for the unconditioned specimens. Some of the potential reasons for this observation will be discussed in this Section.

\subsubsection{Panel of Origin and Position of Specimen within Panel}

At first glance, the two most probable sources for the great differences that were observed among specimens that were exposed to the same condition were differences in the panel of origin and in the original position of the specimen within that panel. Trends that would suggest the former might indicate inconsistencies in the surface preparation of the laminates or cure of the adhesive, while the latter could indicate problems with the panel design. For example, if the panel were too large, it might cause a difference in the properties at the middle of the panel (where the bond line may, for example, be thicker) when compared with the edges. No noteworthy trend could be found to suggest that either of these hypotheses held true. For instance, while C02-02 had the highest fracture toughness in the IISN condition, C02-04 and 
C02-I6 had the lowest in the IIWN condition. Similarly, specimens from the edges of the different panels did not consistently perform better or worse than those from the middle. Additionally, the date of the test (with the related differences in the testing temperature and humidity) did not seem to influence the observed variations.

\subsubsection{Variability in Bonding Operations}

Two more possible explanations for the variability of the data were the moisture content of the laminates prior to the bonding operation, and inconsistencies arising from the manual grit-blasting operation. The standard practice by specimen manufacturers at NRC-IAR is to surface-dry the specimens by putting them in an oven at $80^{\circ} \mathrm{C}$ for at least 2 hours prior to wiping with MEK and grit-blasting (then wiping again). This practice was followed for the DCB panels. The panels were bonded between 20 and 36 days after curing the laminates and were kept in a controlled environment, limiting the relative humidity to $50 \%$ and maintaining a temperature around $2 \mathrm{I}^{\circ} \mathrm{C}$. In the months that bonding was performed, February and March, the relative humidity is much lower than $50 \%$ due to the air being dried by heating of the facilities, so that over a 36-day period, a negligible amount of moisture absorption would be expected (recall from Chapter 3 that an estimate unfortunately cannot be calculated for this temperature and humidity from the data obtained in the present experiments). In addition to this argument, it could be added that a difference in moisture content would result in variability between panels (which was not observed, as discussed in Section 4.4.4.I), but would not explain variability of the fracture toughness of a specimen with respect to crack length. An inconsistent grit-blasting operation could, however, explain both inter- and intrapanel variations. Unfortunately, the consistency of grit-blasting is very difficult to 
measure and cannot be commented upon further, except to say that the same experienced operator performed the grit-blasting for all panels.

Additionally, inconsistent bondline thickness would affect the results. The first panels that were manufactured had thicker centres than edges. Three actions were taken to improve the consistency of bondline thickness. Recall from Chapter 2 that short shims were used, so that any excess adhesive was not contained and the panels could be compressed to the shims thickness. Also previously mentioned, the 2-step cure cycle, with a temperature dwell at the point where the adhesive reached its lowest viscosity, helped improve flow of excess adhesive out from the centre of the panel. Finally, the panel dimensions used to produce DCB specimens were reduced by half. By making smaller panels, the distance that excess adhesive had to cover to flow out of the panels was reduced. The resulting overall variation of bondline thickness over a panel was approximately $0.152 \mathrm{~mm}(0.006 \mathrm{inch})$ and over a specimen, $0.076 \mathrm{~mm}$ $(0.003$ inch).

\subsubsection{Variability of Failure Mode}

As will be discussed in more detail in Section 4.5, the observed failure mode for the conditioned specimens did provide some insight into the reasons for variation of GIC with crack length, as shown in Figure 67. While the reasons for certain areas failing adhesively are not easily explained, this does appear to be a source of the variability of $G C$ with $a$. Where a greater proportion of failure area was adhesive, as evidenced by the visibility of the black laminate, a drop in GIC was typically observed. 


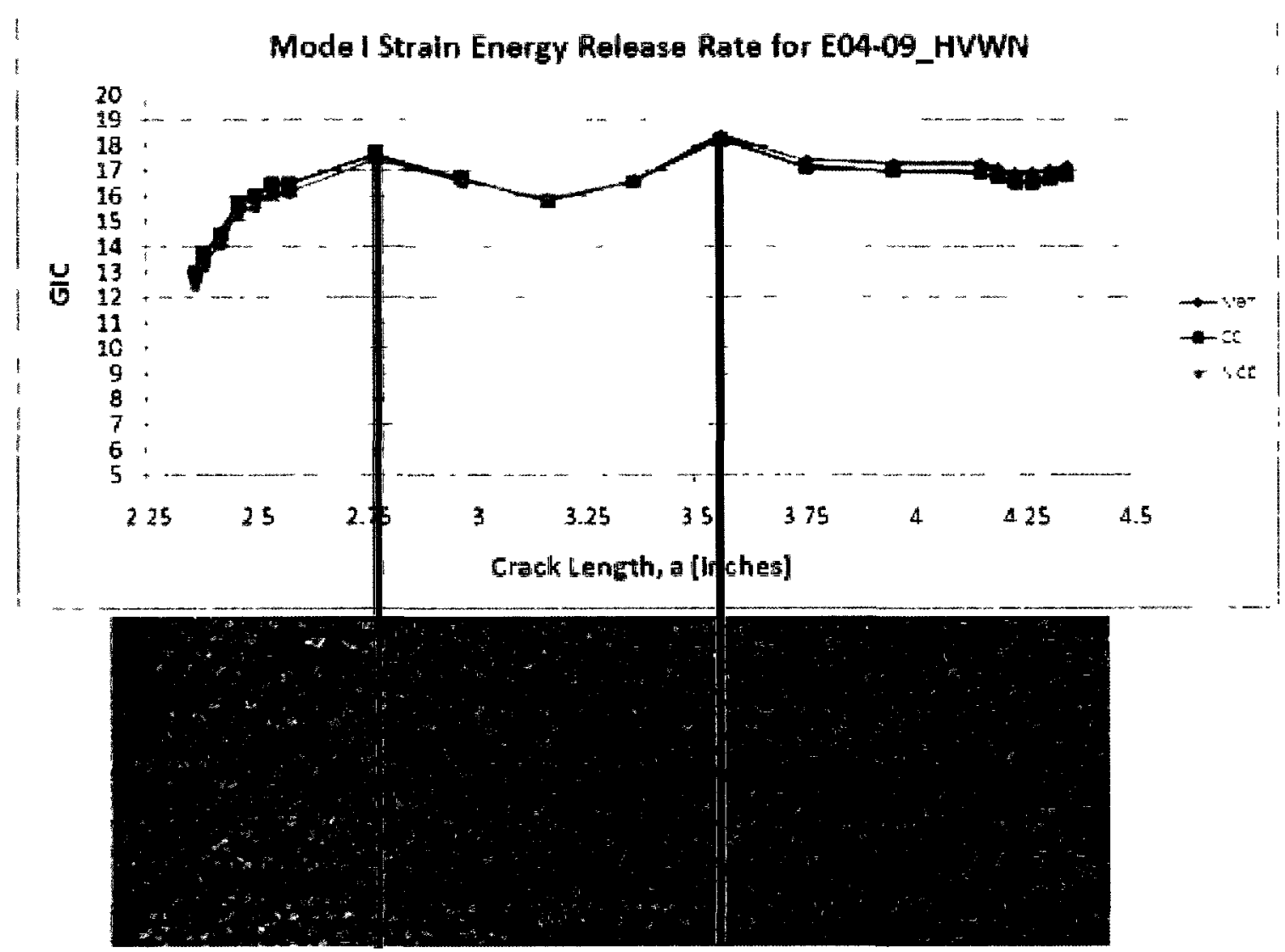

Figure 67: Areas of adhesive fallute (black on photo) resulted in lower Gic values

\subsubsection{Specimen Drying During Test (Outlier Analysis)}

Throughout the mechanical testing described in this Chapter, the specimens were weighed before and after the test to account for the drying that occurred while exposed to the lab environment. On average, the specimens lost $0.15 \%$ of their mass (with the mass of hinge and adhesive removed) over the approximately I-hour long preparation and testing period.

Based on mass gain measurements for DCB specimens, the average loss of moisture of $0.15 \%$ represents approximately 3 days of conditioning in water at $70^{\circ} \mathrm{C}$, during the very beginning of the "linear" segment of the diffusion curve. This 
is unexpectedly high for I hour at room temperature. The mass loss should be slower than the mass gain at $70^{\circ} \mathrm{C}$, since the same diffusion characteristics govern both processes, but the temperature of the drying process is lower. However, cracking the specimen in half during the test is exposing the centre-most region to dry air, thereby allowing the volume that took longest to absorb moisture to dry nearly instantly. Furthermore, at the end of the test, the laminate is turned into two laminates that are half as thick as the original, with both faces of each exposed to air. This important change in the boundary conditions of the diffusion problem is believed to be the major contributor to the much faster drying of the specimens during testing.

Three outliers in terms of moisture loss were specimens $\mathrm{C} 02-07$ (0.51\% mass loss from drying), C03-08 (0.33\%) and C04-08 (0.40\%)—each from a different panel and conditioning environment. They matched the specimens identified in Table 20 as outliers in terms of GIC values: it appears that drying during testing has a direct impact on fracture toughness. It is therefore important to maintain the moisture levels in the DCB specimens during testing. Factors which affect moisture levels include the amount of time the specimen spends outside the chamber before testing and the duration of the test. The conditions in the $1 \mathrm{ab}$ (relative humidity and temperature) also have an influence.

For C02-07, a comment regarding a software crash that occurred during specimen set-up indicates a delay in testing. Although no comment was written for C03-08, the record shows the specimen was taken out of the chamber at 9:45, but only tested at $13: 25$. This specimen was carried from the building in which it was being conditioned to the one with the test frame and prepared, but was not tested immediately (probably due to the camera being unavailable) and put back in the conditioning chamber prior to testing. This deviation from the usual procedure 
would explain the extra drying observed for that specimen. No clear indication of the cause of drying of specimen C04-08 could be found.

It would appear that the source of variability between specimens can at least be partly explained by differences in moisture loss during testing. By contrast, the variability over the crack length for each specimen is due to differences in the failure mode (discussed in Section 4.5), which might be caused by manufacturing inconsistencies. More fundamental research on the moisture sensitivity of the interface between epoxy adhesive and epoxy matrix laminates was not found (information abounds for epoxy-metal interfaces, e.g. [69] and [70], but is not applicable here) but could help explain this phenomenon.

A new system to maintain a hot and humid environment around the specimen during mechanical testing is being designed at NRC, and it is hoped that this will improve the consistency of results by preventing drying of the specimens, though outliers also existed in dry specimens.

\subsubsection{Discussion of Mode I Fracture Toughness Results for Bonded $\underline{\mathrm{DCBs}}$}

Despite the wide error bars on Figure 66, a few general observations can be drawn regarding the effects of various conditioning environments on the mode I strain energy release rate of the bonded DCB specimens. Note that no easily comparable data were found (i.e. GIC data for moisture-conditioned, bonded composite laminates) to assess whether the large error was unusual.

Firstly, there is a notable difference between conditioning in high humidity air and liquid water. In fact, no notable change in GIC was observed for vapourconditioned specimens compared with unconditioned ones, while immersed 
specimens displayed a decrease in GIC. This is difficult to explain; both conditioning environments led to moisture absorption, but the absorbed water did not appear to have the same effect on the GIC of the specimens. This is interesting for aerospace applications, since immersion in water is not a long-term service environment that can be expected, and GICappears unaffected by high humidity environments. However, the failure mode did change for vapour-conditioned specimens in the same way as for all conditioned specimens, as will be discussed in Section 4.5. The change in failure mode without a change in GIC is very difficult to explain based on currently-available data and comparisons with the immersion conditions; further study is certainly required. Interestingly, GIC,o (i.e. at initiation) was affected by vapour conditioning, but to a lesser degree than it was by immersion conditioning.

Secondly, there was an effect of temperature when conditioning by immersion: the HISN and HIWN specimens displayed a $17 \%$ and $14 \%$ decrease in mean GIC, respectively, whereas the IISN and IIWN had a $7 \%$ and $5 \%$ lower mean GIC, respectively (all comparisons are against the mean GIC of RTA specimens). Assuming normally-distributed populations and performing a t-test to 0.1 to verify the significance of these differences shows that the HISN and HIWN conditions result in significant reductions in mean GIC whereas the reduction observed for IISN and IIWN conditions is not statistically significant.

Thirdly, immersion in salt water or fresh water did not appear to produce different results. This seems to suggest that there is no need for conditioning coupons in this environment in the future when epoxy-epoxy bonded interfaces are concerned - this is of interest because conditioning in hot salt water is a difficult undertaking, as described in Chapter 3. This is very different from epoxy-metal 
interfaces, which, due to metal corrosion, are very differently affected by salt and fresh water (see Chapter I).

\subsection{Test Results: FaIluRE MODES}

In addition to mode I strain energy release rates, the failure mode of the specimens also proved to be of interest. As opposed to the study of fracture surfaces in metals, microscopy was difficult to apply to these tests. The relatively complex combination of materials (epoxy matrix, carbon fibres, epoxy adhesive and knit support carrier) and colours made the observations difficult to interpret. For example, Figure 68 shows an area of adhesive failure, where carbon fibres have become visible due to small areas of matrix failure. Figure 69 shows an area of mixed failure, where knit carrier, adhesive and laminate are visible. Connecting any of this local information to fracture energy data was impossible because the mechanical test provided global GIC data for a given crack length — in particular, local features across the width of the specimens could not be pin-pointed in the GIC data. 


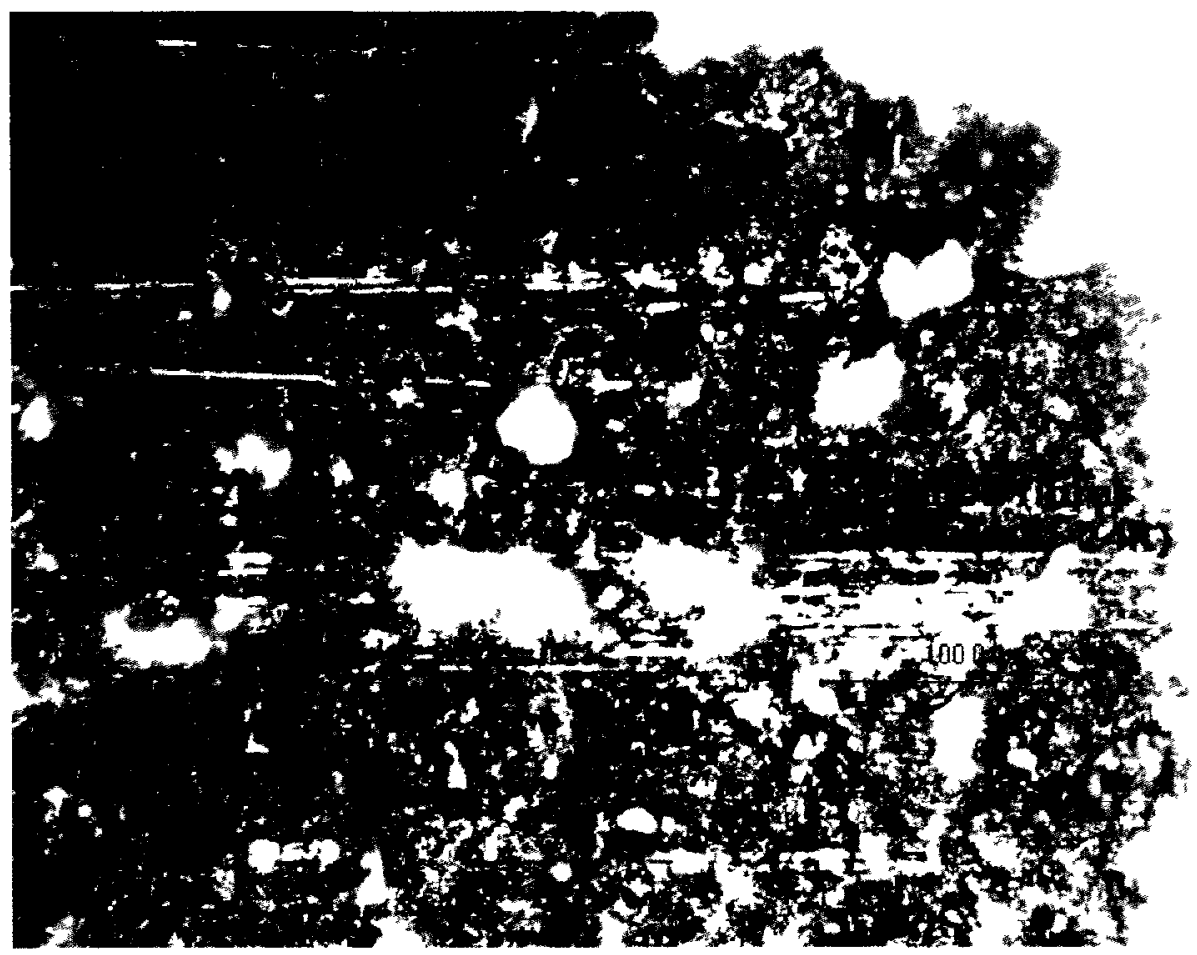

Figure 68: Some areas displayed a falure surface that included visible fibres.

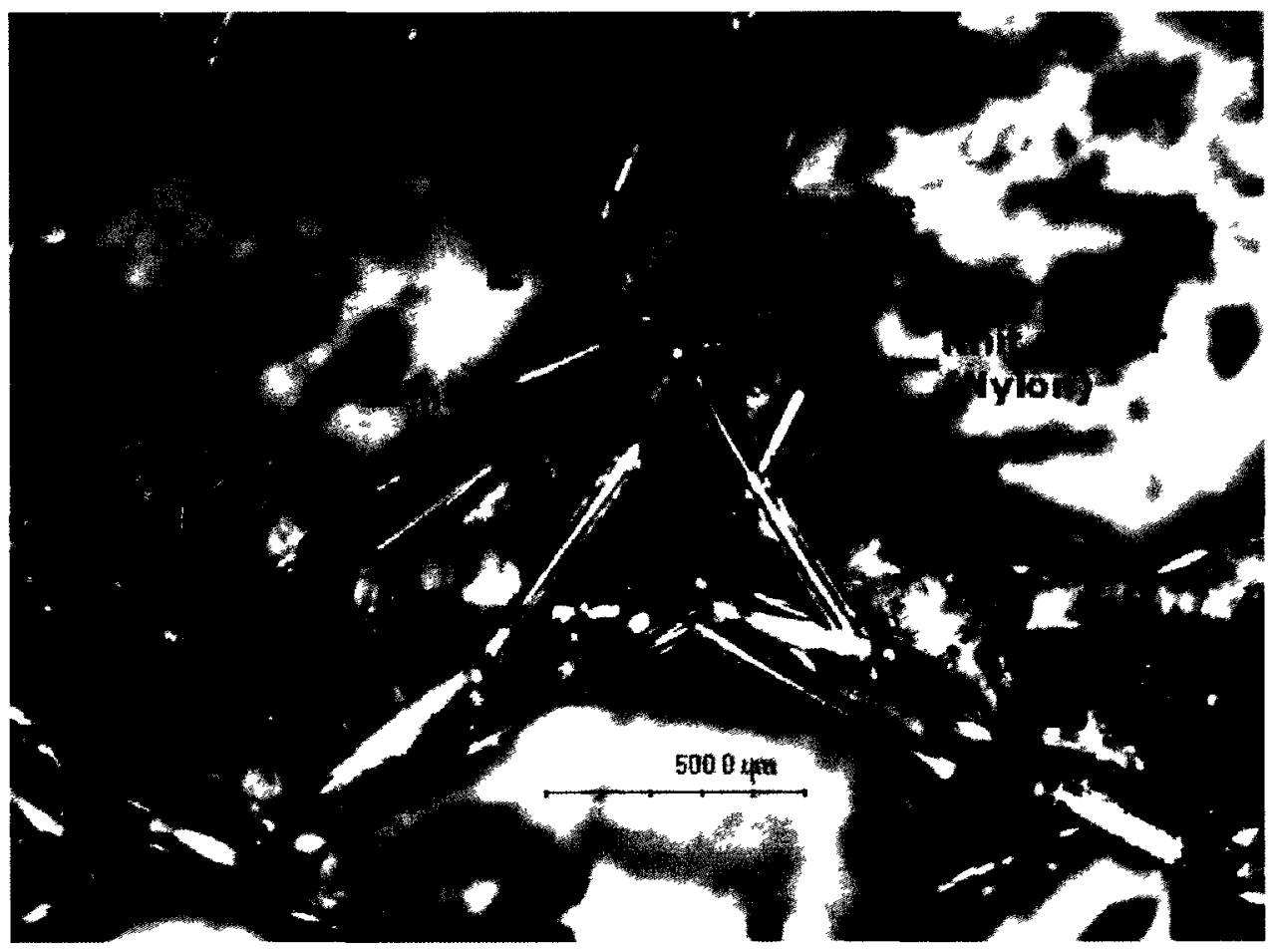

Figure 69: Most areas displayed a complex failure surface with visible laminate, adhesive and knit carner. 
More informative observations could be made at a macroscopic level. Indeed, certain features in some GIC results could easily be explained from simple comparisons with scaled pictures of the fracture surface. Often, as shown previously in Figure 67, areas with a high percentage of adhesive failure caused the GIC values to decrease in comparison with the areas of higher cohesive failure. The specimen photograph in Figure 67 was the result of some editing, which was used to combine all the "black" areas from both halves of the specimen in one picture in order to make the comparison between adhesive (visible as black on either side) and cohesive (pink on both sides) areas simpler. This editing will be described in more detail in Section 4.5 .2

As a reminder, the edited and combined photos are available on the Summary Data Sheets and are aligned with the x-axis of the GIC-a graphs.

\subsubsection{General Comments on Taking and Editing Specimen Photos}

In order to produce high quality images with accurate colours (since black areas in), certain procedures were used while taking specimen photos and subsequently editing them.

Firstly, the camera produced images in the compressed JPEG format, which introduced some loss in the image information from the camera sensor. Subsequent operations were performed by saving the images in a lossless format known as PNG (a patent-free, compressed, lossless format). This is because the JPEG format compresses the image every time it is saved, even at a quality setting of "IOO", gradually degrading the quality of the image [89]. A camera with the option of creating a RAW format image could have avoided JPEG compression altogether. 
Secondly, reducing noise from the sensor of the camera itself was important to avoid introducing noise (e.g. incorrect colours) and grain (e.g. rough edges) to the images. To achieve this, the lowest-available ISO setting, ISO-80, was used to reduce the sensitivity of the camera sensor. The effect can be seen in Figure 70, which is a comparison of a high and low ISO setting of the camera.

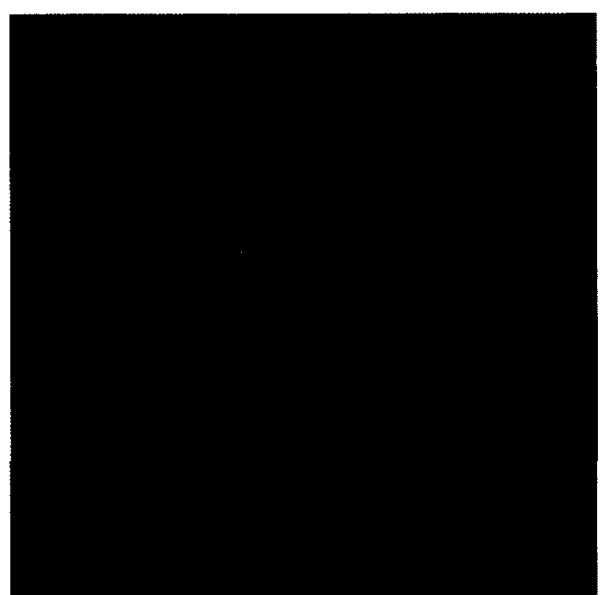

150-80

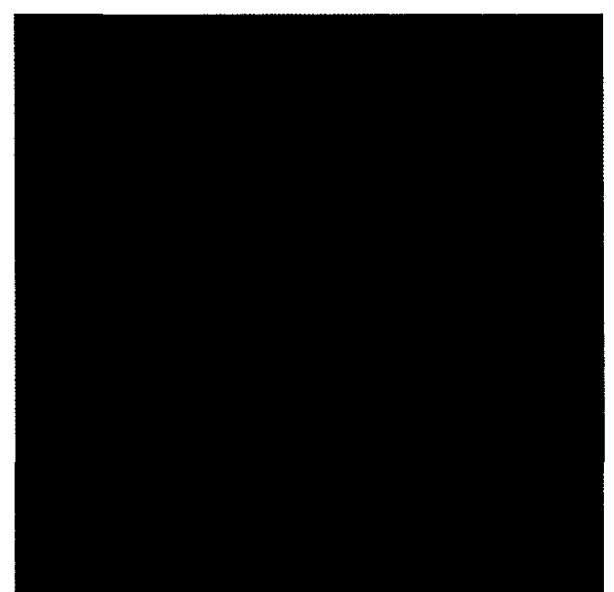

150-1010

Figute 70: The difference in colour and shatpness between these two photos is due only to a change in ISO setting

Using the lowest ISO setting of the camera meant that lower shutter speeds were required to take the pictures, thereby increasing the potential for producing blurry images from small vibrations of the camera. To avoid this problem, a strong tripod and the 2-second delay feature were used so that the operator would not be touching the camera while the shutter was open.

Thirdly, a white-balancing method was applied to the pictures manually through the photo-editing software to compensate for the artificial colouring introduced by the fluorescent lighting of the office in which the pictures were taken. A colour-mapping technique was applied in such a way that the white sheet of paper that was used as a background for the pictures would actually be white after its 
application. The automatic white balancing performed by the camera was quite consistent between pictures but not very accurate, introducing a slight red tint to the pictures.

By producing high-quality images of the fracture surface, certain analyses could be performed to observe the overall failure mode (combining both fracture surfaces into a single more informative one) and even estimate the percentage of cohesive versus adhesive failure. These analysis methods will be discussed in more detail in the Sections 4.5 .2 and 4.5.3.

\subsubsection{A Method to Observe Overall Cohesive and Adhesive Failure}

Simply visually observing the fracture surfaces of DCB specimens on a photograph such as Figure 7 I makes assessment of the failure mode difficult because an area of cohesive failure is pink on both surfaces, while an area of adhesive failure is black on either one of the two surfaces. Moreover, the matching areas of the surfaces are mirrored on the specimens. In order to make interpretation more straightforward, a photo-editing procedure was established using the freeware GNU Image Manipulation Program (GIMP 2.6). Repetitive tasks were automated with simple Python scripts. 
Chapter 4: The Effects of the Environment on the Fracture Toughness of Bonded Laminates I50

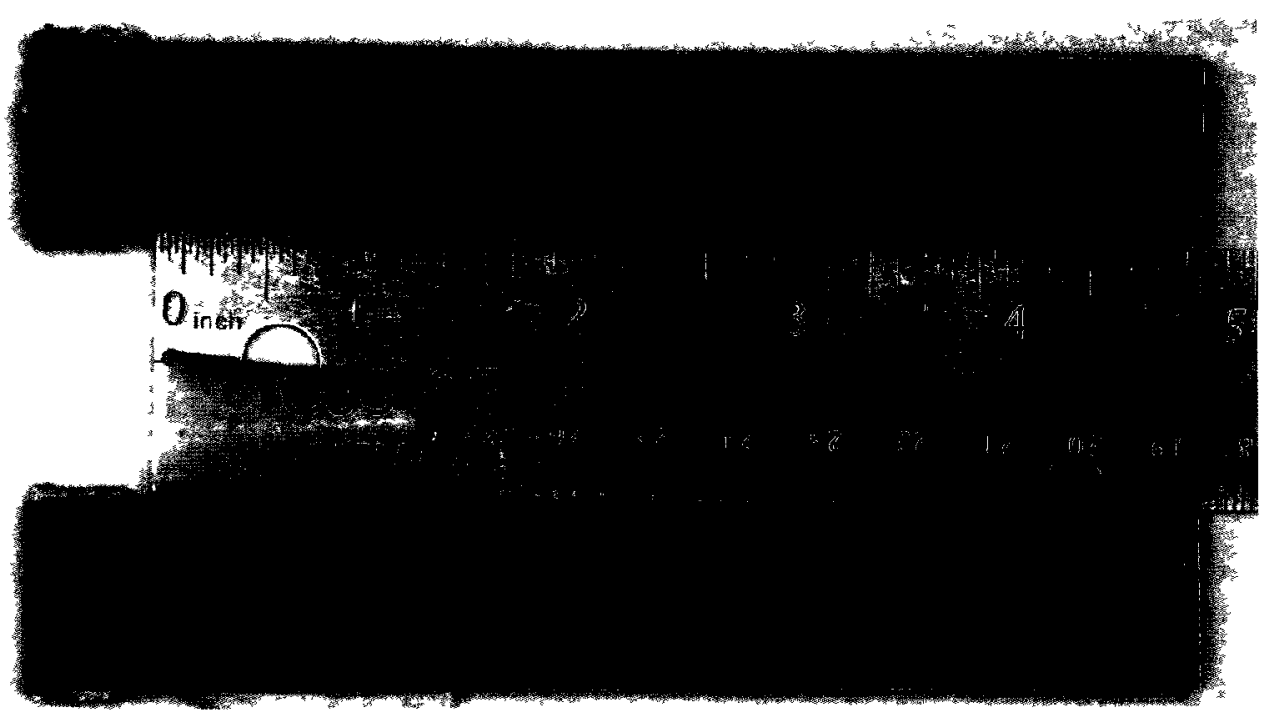

Figure 7I: Example of a photograph of specimen C03-05 with ruler for scale

The algorithm that was followed for each image, in GIMP, was:

I. Split image into two separate layers-one for each half of the specimen.

2. Align specimen halves to horizontal direction through precise rotation.

3. Select fracture area of each half and delete the rest of the image.

4. Use Select by Colour tool to select black areas of one of the halves, using these options:
a. Antialiasing: No
b. Feather Edges: No
c. Select Transparent Areas: No
d. Sample Merged: No
e. Threshold: 30
f. Select by: Composite
g. Clicked on: very dark grey pixel (adhesive failure area) 
5. Cut and paste selected area into a new layer, flip it vertically, then align it over the other layer (use Align tool).

6. Save image as XCF (GIMP format) for future modifications, and then as PNG for use in other programs (original JPEG produced by the camera is also kept).

7. Use original image with ruler to determine alignment of fracture area with respect to hinge (should be very consistent due to precision of manufacturing).

8. When pasting photo below Grc graph of specimen, align and resize specimen such that distance from the hinge of two points is the same on the photo and the GIC graph's x-axis.

The parameters used in Step 4 were the result of iterative trials and visual observation of the resulting selection. They were found to produce satisfactory results, similar to those shown in Figure 72, for every specimen photo that was edited.

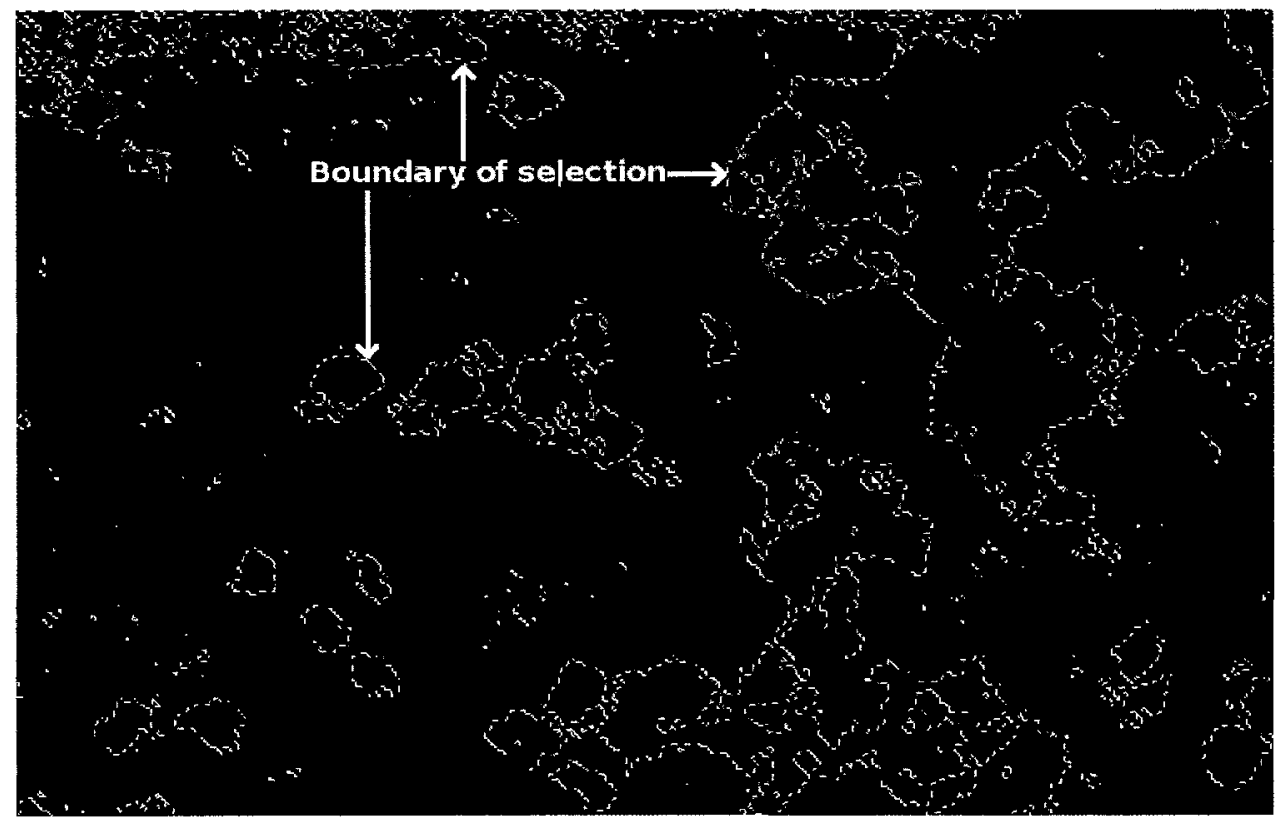

Figure 72: Selection resulting from "Select by Colour" tool with a threshold of 30 . 
These parameters will not necessarly work for other colour combinations or if the photographs are taken under different lighting conditions (contrast and white balance are important). Applying this algorithm to the photo of Figure 7I resulted in Figure 73.

Once the algorithm was applied to the photos, two analyses were of interest: (I) comparison to the GIC graphs as shown in Figure 67, and (2) extraction of a percentage of cohesive versus adhesive fallure to compare with average GIC data.

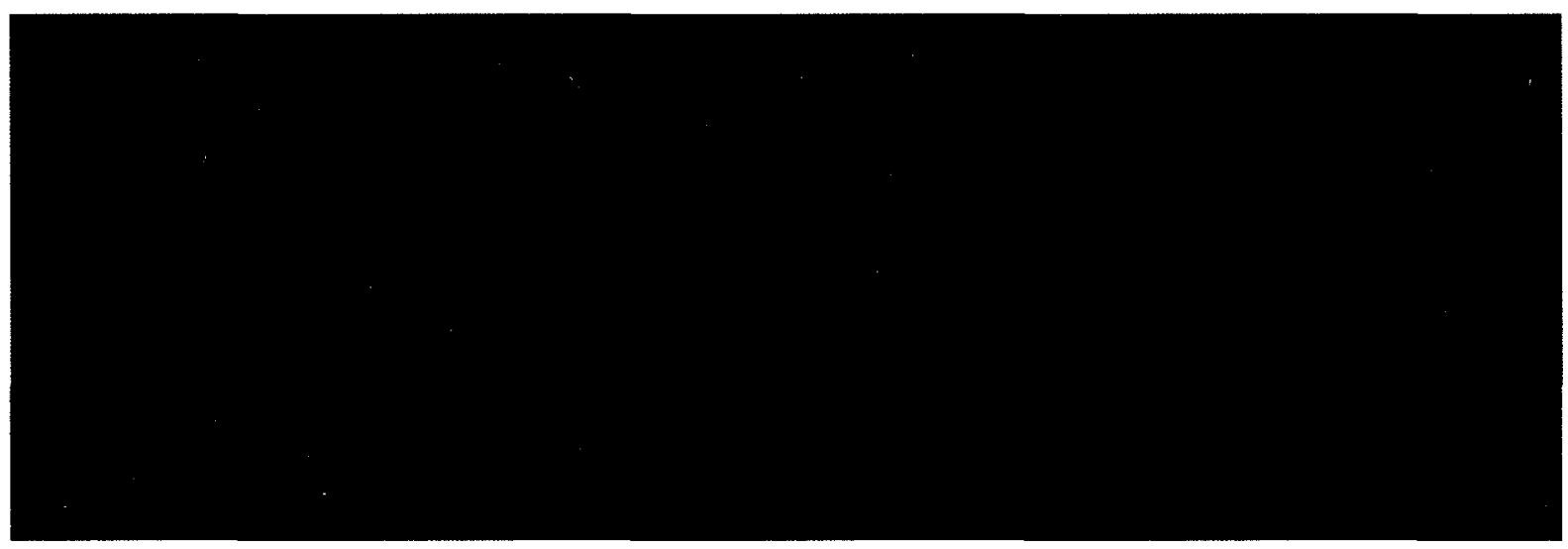

Figute 73: Composite image showing total ateas of cohesive (pink) and adhesive (black) fallure for specimen CO3-05

\subsubsection{A Method to Calculate the Percentage of Cohesive and Adhesive}

\section{Failure}

From images like the sample shown in Figure 73, a pixel-counting algorithm was used to sort and count pixels that represented adhesive fallure and cohesive failure, in order to obtain an estimate of the fraction of each mode. The most difficult task was that of sorting the pixels. In particular, borders between adhesive and cohesive fallure often included brown or purple pixels, and various shades of gray could represent adhesive or cohesive faulure. The sensor introducing false colours 
and the JPEG compression in the camera blending "black" and "pink" pixels likely produced some of these pixels. Fortunately, these areas were usually negligible in size.

The first step in configuring the algorithm involved defining ranges of colours as indicative of either adhesive failure or cohesive failure. The identification of colours by their RGB values (Red, Green and Blue) allowed pixels to be sorted by brightness and ratios of red to green and red to blue (the "pinkest" pixels generally had a very high red value, relatively high blue value, but relatively low green values). Figure 74 shows a close up of pixels and the variety of colours that the algorithm had to take into account.

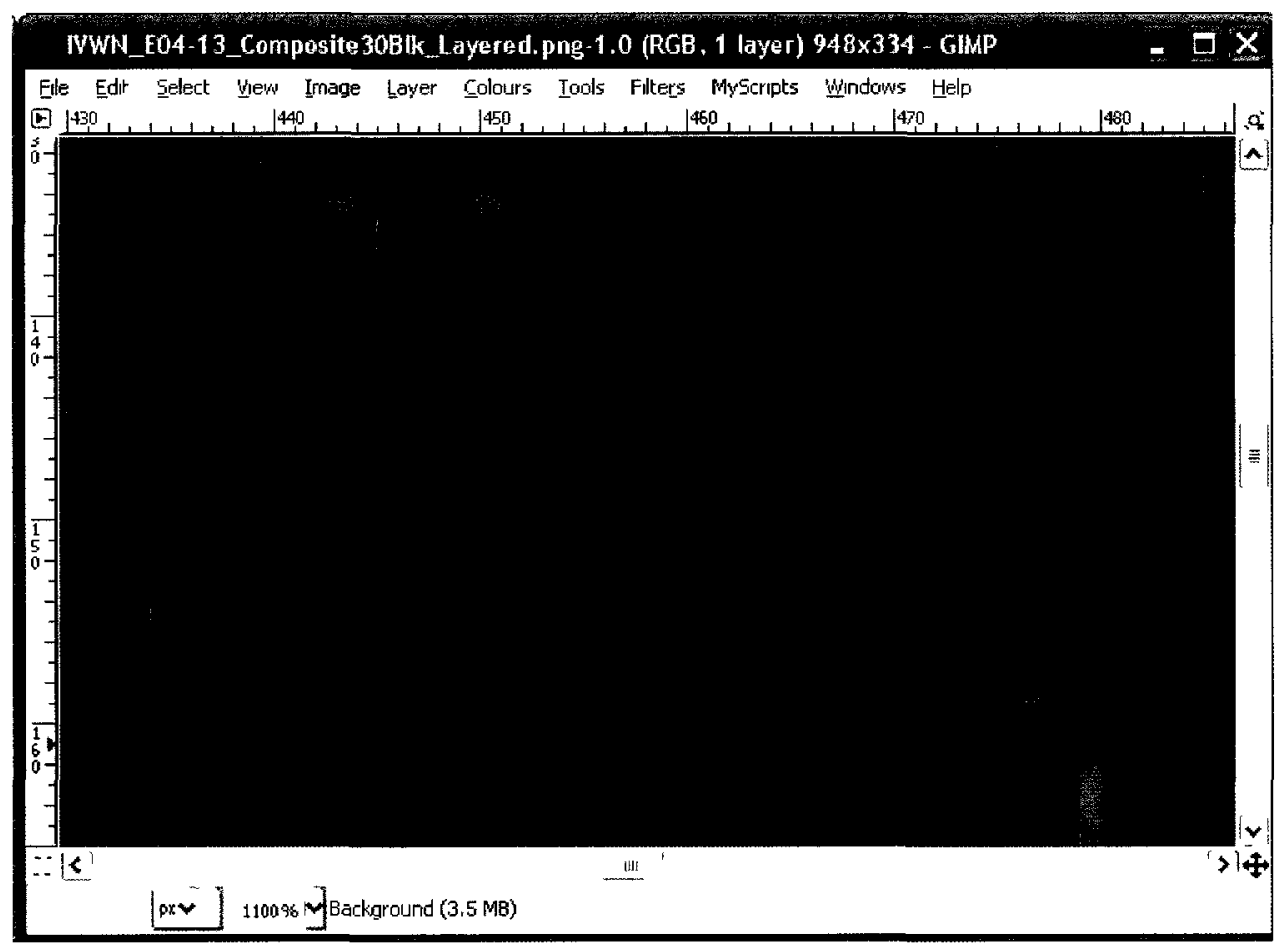

Figure 74: Close up of pixels on a picture edited as described in Section 4.5.2

From Figure 74 it is obvious that "black" actually means a variety of shades of grey, brown and other colours. Moreover, some "pink" areas are actually quite dark, 
making the task more than a simple matter of "dark pixels versus light pixels". The algorithm used was:

I. Check the red value (scale is from 0 to 255) and apply different conditions depending on it.

a. If Red CIIO: automatically adhesive (dark pixel)

b. If II $<\operatorname{Red}<$ I30 AND Green $<=0.7^{\star} \operatorname{Red}$ AND Blue $<=0.8^{\star} \operatorname{Red}$ : Cohesive

c. If I30<Red $<$ I50 AND Green $<0.8^{\star}$ Red AND Blue $<0.9^{\star}$ Red: Cohesive

d. If Red > I50 AND Green < Red AND Blue < Red: Cohesive

e. If Red > I30 AND (Red + Green + Blue) $>=400$ : Cohesive (bright grey pixels)

f. Otherwise, Adhesive.

2. Report the percentage of cohesive and adhesive failure and write them to a file every $x$ pixels, where $x$ is the image width divided by the number of strips the picture should be split into (to compare failure mode to $G_{C}-a$ graph strip-bystrip).

3. Open the data file in Excel and calculate the average \% Cohesive and $\%$ Adhesive for all the strips.

\subsubsection{Discussion of Failure Mode Results}

Each failure surface photo was separated into 10 strips, and the percentage of cohesive and adhesive failure area for each strip was calculated. The results were then graphed with respect to crack length and overlaid onto the GIC-a graph. In some cases, there was a visible correlation between failure mode and strain energy release rate, as shown in Figure 75. In others, there was no correlation, as shown in Figure 76. Since there were more specimens with good correlation than bad, an attempt was 
made to establish the relationship between falure mode and strain energy release rate. However, as an example will show, the relationship is not easily established and likely depends on more variables than the fallure mode alone.

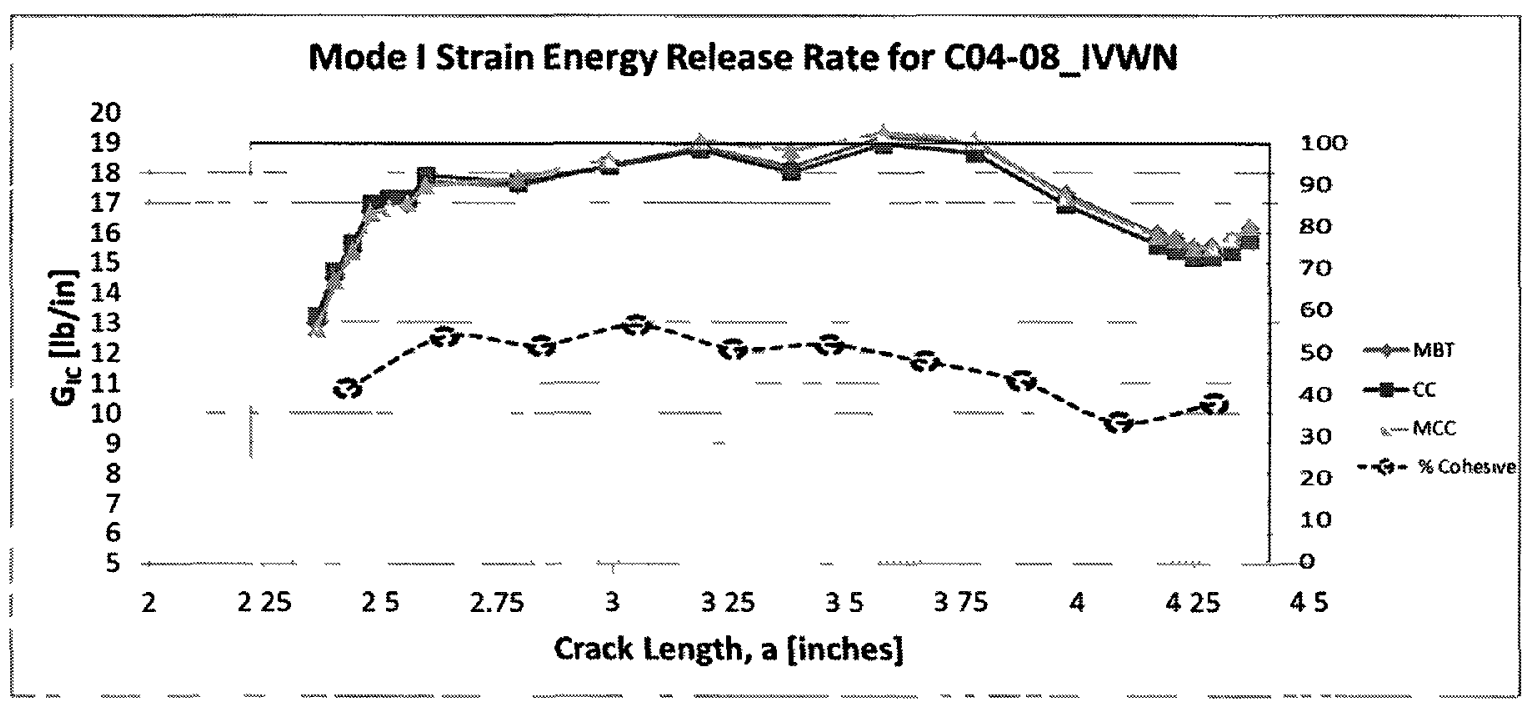

Figure 75: Strain energy release rate and \% cohesive fallure area versus crack length for specimen CO4-OS

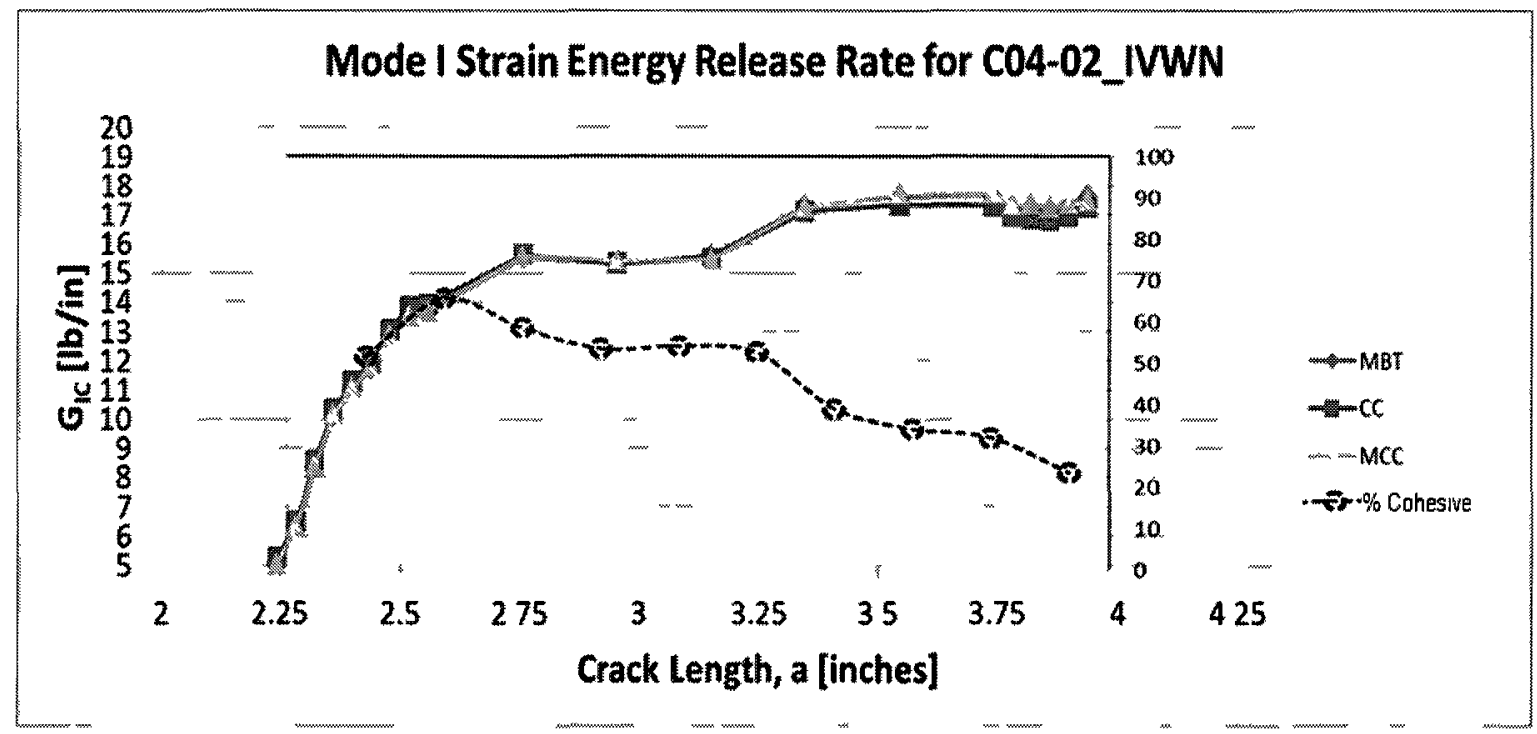

Figure 76: Strain energy release rate and \% cohesive fallure area for specimen CO4-02. In this case, the correlation is very poor. 
A first attempt at characterising the relationship between failure mode and strain energy release rate involved the assumption of a linear combination of the "cohesive GIC" and "adhesive GIC" and would consider specimens such as C04-02 to be outliers. To find these two GIC, two points on the graph were needed to create a system of equations of the form:

$$
\begin{aligned}
& \alpha x_{1}+\beta y_{1}=G_{I C, 1} \\
& \alpha x_{2}+\beta y_{2}=G_{I C, 2}
\end{aligned}
$$

where: $\alpha$ and $\beta$ are the strain energy release rates of cohesive and adhesive areas, and the points $(x, y)$ are the percentages of cohesive and adhesive failure $(y=100-x)$ for given points. Using this system of equations to solve for $\alpha$ and $\beta$ would yield values that could then be used to predict $G_{I C}$ based only on the failure mode of a given area. As the following example will show, however, this simple model would not be adequate for most specimens.

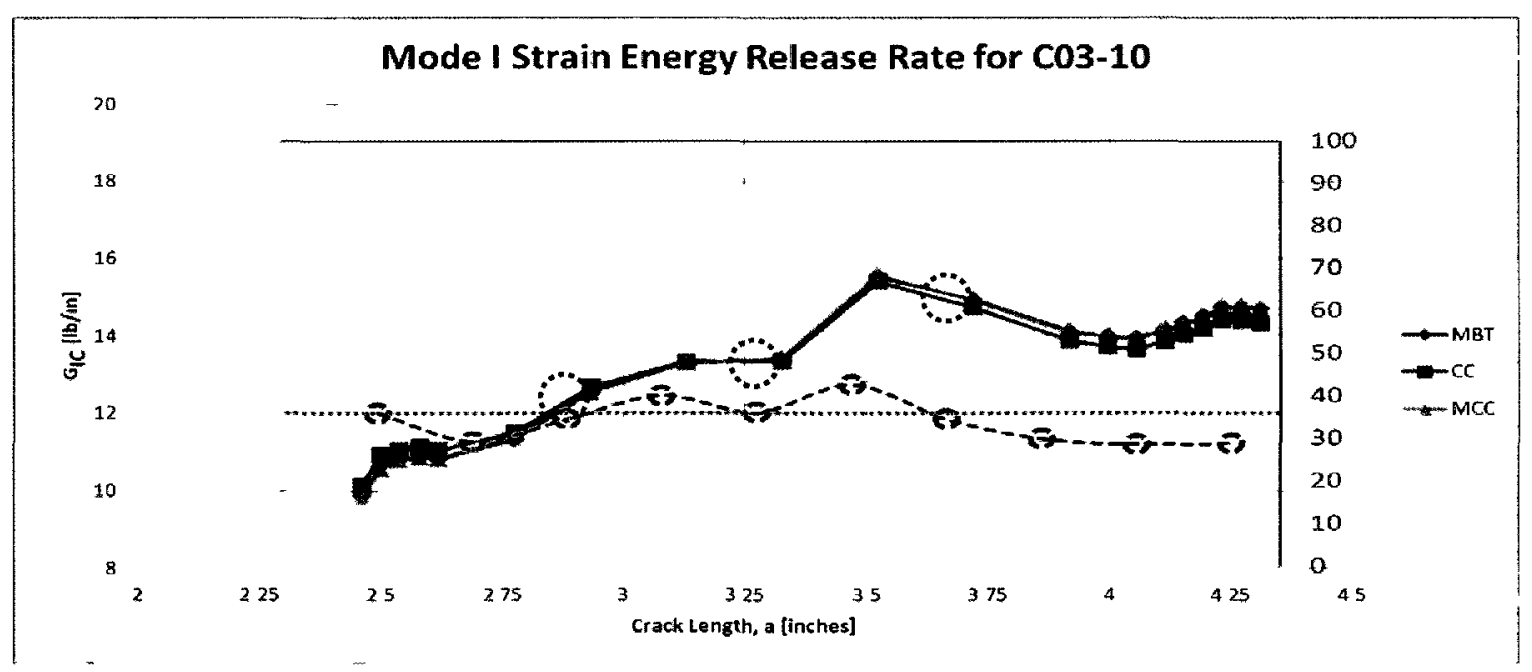

Figure 77: Comparison of failure mode and strain energy release rate in an attempt to determine the necessary parameters for a linear correlation between them. 
In Figure 77, a horizontal dashed line is placed at approximately $35 \%$ cohesive failure. Three points on the failure mode graph (dashed) represent approximately $35 \%$ cohesive failure areas. The three corresponding points on the solid GIC graph are highlighted with red circles and clearly do not represent the same GIC value. There can therefore be no direct linear relationship between these variables since three points with the same \% cohesive failure map to three different values of GIC. This was true of most specimens.

In addition to this difficulty, it was quite clear that some specimens would produce values of strain energy release rate that were much higher for adhesive failure areas than cohesive ones, and that 100\% cohesive failure would never be properly predicted ( $\alpha$ values of $28 \mathrm{lbf} /$ in were found for some specimens, meaning that I00\% cohesive failure should result in this strain energy release rate). Indeed, the RTA specimens, whose failure area was 100\% cohesive, had on average a lower GIC value than the IVWN and HVWN specimens, which had mixed failure mode. The evidence is indicative of a more complex relationship between conditioning environment, resulting failure mode and strain energy release rate. Unfortunately, the mechanical and visual observations made here would not be capable of quantifying the details of this relationship. To create a model capable of predicting what failure mode and what strain energy release rate an adhesive joint between polymer-matrix laminates will fail, a much deeper understanding of the physics and chemistry involved is required. Such a study would likely need to focus on the effects of surface drying, grit-blasting, cleaning, curing, etc. on the bulk of the adhesive and on the interfaces with the laminates, and then consider how environmental exposure affects chemical and physical changes in this system. This was beyond the scope of the work presented here. 


\subsection{CONCLUSIONS}

wis

The work and results presented in this Chapter form the bulk of this study. From these results, interesting questions regarding the behaviour of sandwich specimens after moisture exposure were raised and thereby provided some direction for the preliminary study on sandwich structure fracture, presented in Chapter 5.

The most notable conclusions to be drawn from the DCB testing of environmentally-conditioned specimens as presented here are:

- The MBT, CC and MCC methods for calculating GIC provide very similar results. In this work, the greatest difference between the three values was $1.47 \%$. The $\mathrm{CC}$ method was selected as the one to be reported because it produced the most conservative values for every specimen but one.

- The standard deviation was large for all conditions. Even unconditioned (RTA) specimens displayed a wide range of GIC values between specimens.

- The GIC value for RTA specimens tended to be consistent over crack length. The strain energy release rate of conditioned specimens was far less consistent over crack length, due to the variable mode of fracture observed on those specimens.

- For conditioned specimens, initiation values were often very low compared to the propagation values, but this fact is difficult to explain from the data obtained in these tests. 
- Vapour conditioning, which is the most realistic environment for aerospace structures, led to reduction in $G_{I C, o}$, but did not reduce the propagation $G_{I C}$ despite changing the failure mode in a similar way to what was observed in immersion-conditioned specimens. The physics and chemistry of the problem could not be studied from the data produced in these tests but would likely be required to explain this phenomenon.

- Among immersion specimens, conditioning temperature was an important factor: increasing the salt water and fresh water temperature from $70^{\circ} \mathrm{C}$ to $82^{\circ} \mathrm{C}$ decreased the nominal $G_{I C}$ value by $5 \%$ and $7 \%$, respectively.

- Salinity of immersion water did not appear to have an effect on the resulting strain energy release rate.

- Three outliers were identified and their high GIC values were found to be linked to their greater degree of moisture loss during specimen preparation and testing. Maintaining a high humidity environment around the specimen during testing would likely be beneficial in reducing the observed variability of GIC between specimens.

- A method of measuring the proportion of cohesive and adhesive failure from specimen photographs was used to show that this had an effect on the strain energy release rate of a number of specimens. However, other variables were likely involved, such that it was impossible to predict strain energy release rate from failure mode alone, even on a specimenby-specimen basis. 


\section{Chapter 5: Preliminary Study of the Effects of the Environment on the Disbond Fracture Toughness of Sandwich Structures}

In this Chapter, the testing procedure, data reduction, and results of the Single Cantilever Beam testing, performed on sandwich specimens, are presented. As in the preceding Chapter on DCB testing, two aspects of the results are covered: the calculated GIC values for specimens from 5 different conditions, and the observed failure mode. The GIC values were affected by environmental conditioning but the failure mode was unchanged. All specimens, including unconditioned ones, suffered failure by core fracture just below the adhesive fillets.

Chapter I Literature Review

Chapter 2 Manufacturing of $D$ CB and SCB Specimens

Chapter 3 Environmental Conditioning and Diffusion Data Analysis

Chapter 4 I'he Effects of the Environment on the tracture loughness of Bonded Laminates

Chapter 5 Preliminaty Study of the Effects of the Envitonment on the Disbond Fracture Toughness of Sandwich Structures

Chapter 6 Overview of Contribution and Recommendations for Future Work.

Appendix $\triangle$ Summary Sheets for DCB Specimens

Appendix B Summary Shects for SCB Specimens 


\section{I. INTRODUCTION ${ }^{\mathrm{I}}$}

The ultimate goal of the NRC project within which this work belongs is to better understand how the structure of SAR helicopters will degrade in the service environment. Modern SAR helicopters contain sandwich structures, and these have been found to be susceptible to fracture in control surfaces of fixed-wing aircraft [90-9I]. Although investigations into Air Transat 96I rudder failure demonstrated that ground-air-ground cycles (with the associated changes in pressure) were the leading cause of the catastrophic propagation of skin-core disbonds in thin-skinned, lightweight sandwich structures, the cause for the original initiation is not as well established [90-9I]. Based on the DCB test results discussed in Chapter 4, this preliminary study was intended to investigate whether moisture absorption would reduce mode I strain energy release rate near the bond and help explain how the initration of disbond under mode I peel might occur.

First, a brief overview of sandwich fallure modes will be presented to help the discussion in later Sections. Next, the mechanical testing and data reduction procedures will be briefly covered. Finally, discussion and conclusions on the test results will lead to recommendations for future work in this area based on these preliminary results.

\footnotetext{
${ }^{1}$ This work was presented at the Canadian Aeronautics and Space Institute AERO 2011 conference in Montréal, Qc in April 2011.
} 


\subsection{SANDWICH FAILURE MODES}

Often cited failure modes for sandwich panels are: skin compression failure, excessive deflection, panel buckling, shear crimping, skin wrinkling, intra-cell buckling, and local compression (see Figure 78).

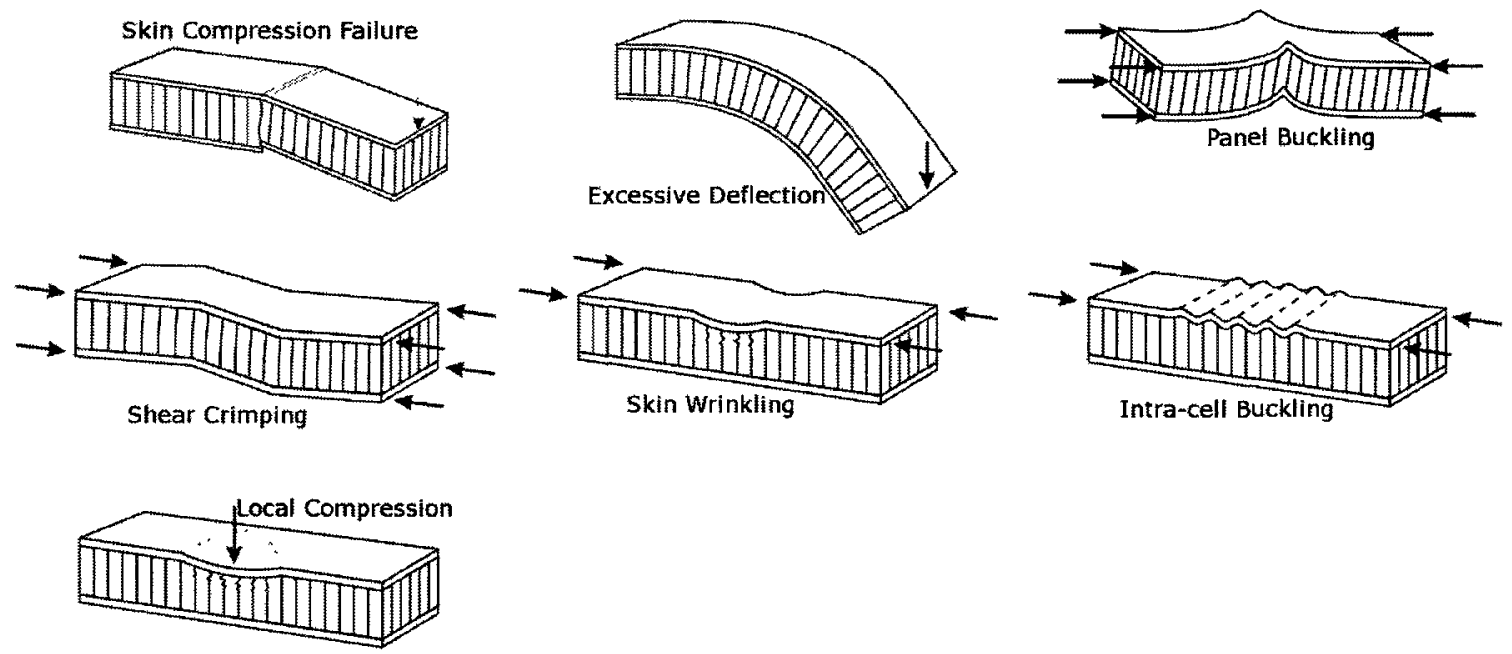

Figure 78: Typical sandwich failure modes (modified from [8]).

These modes of failure are used by designers to select materials and dimensions for the face sheets and core and are explained in more detail in [8].

The work presented here focuses on a different failure mode, which may not always have been taken into account in designing sandwich structures: face sheet-core disbonding. This mode may result from peeling loads being applied to the face sheet, improper manufacturing (more specifically, improper bonding) [93], corrosion of metallic core near facesheet-core bondline, or fluid degradation of adhesive at bondline [92]. Research into the origin of such loads and into the design of appropriate tests and inspection procedures to predict such failure continues to be of interest, due in part to failures observed on aircraft control surfaces. It has recently 
been established that ground-air-ground cycles are a major contributor to the separation of skin from honeycomb core. These cycles propagate cracks because of the difference in pressure between the cells of the core and the atmosphere outside the skin at operational altitudes [90].

Terminology surrounding this set of originally "unexpected" failure modes can lead to confusion, with the term "skin-core debonding" being used to describe a number of different phenomena, including fracture of the core in cases where the bonding (adhesive) performed adequately. For clarity, the terminology from Figure 79 will be adopted throughout this Chapter. Core fracture (not shown on Figure 79) was the only observed mode of failure in tests with dry specimens from the same set of panels. The objective of this preliminary work was to assess whether moisture diffusion into the bond area through the face sheets would cause sandwich specimens to sustain skin-adhesive disbond rather than core fracture.

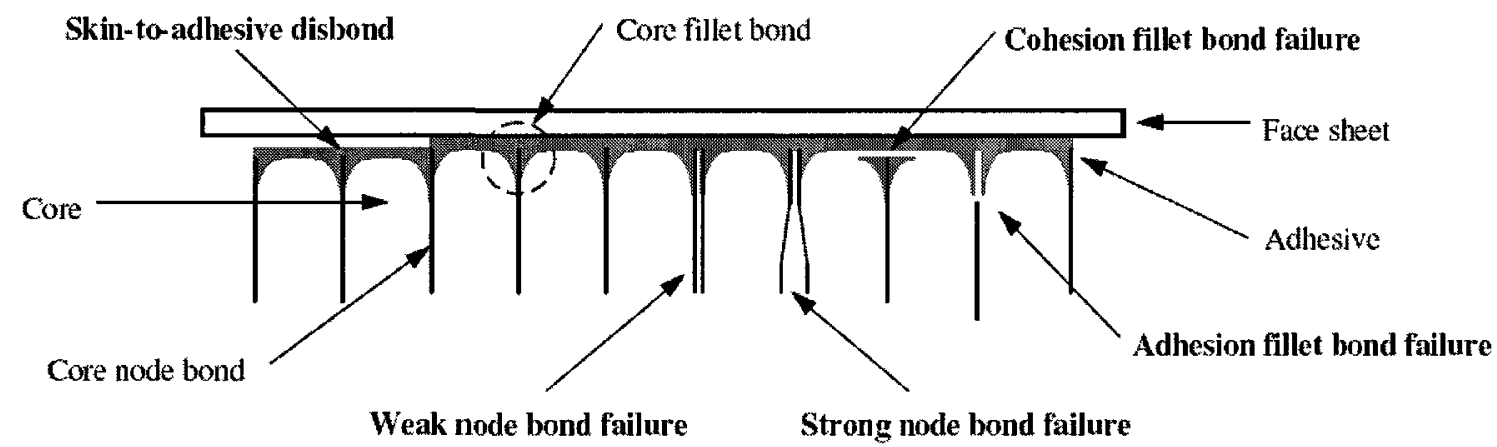

Figure 79: Common tetminology describing failute of sandwich specimens, including separation of skin and core. [93]

The terminology for failure modes having now been established, a brief overview of the mechanical testing procedure will be presented. 


\subsection{MEChäNical TeSting PROCEDURE}

In Chapters 2 and 3, the manufacturing and environmental conditioning of both DCB and SCB specimens was discussed. The discussion in this Chapter therefore starts with the specimen preparation that was required after environmental conditioning before describing mechanical testing and results.

\subsection{Specimen Preparations}

Following conditioning, the aluminum jackets used to protect the sandwich specimens' core (see Chapter 3 on Conditioning) were removed from the specimens and the sealant was cleaned off around the crack area. The next steps were very similar to those presented for DCB specimens, except that hinge bonding occurred after conditioning. This important divergence was a necessary modification of the procedure because sealing the specimens with hinges on would have been very difficult. However, as evidenced by the mass loss of DCB specimens during testing, the time spent outside the conditioning chamber before testing caused an important moisture loss and affected the results of the mechanical test. A standard procedure for hinge bonding was adopted and applied to all specimens to at least keep this variable controlled between specimens.

After removing the aluminum jacket and sealant from the specimen, it was quickly wrapped in a wet paper towel over most of its area (except the end where the hinge was to be bonded) and the wrapped area was sealed in a plastic bag with some tape. These boundary conditions-very high humidity, no air currents-were intended to slow the drying process. With the specimens so wrapped, the hinges were bonded on halfway along the initial 2 inch unbonded area (for an initial crack length of $I$ inch), using the same procedure as the DCB specimens, except that heat was 
applied locally with a heat gun rather than an oven. To keep the temperature in the range of $60-70^{\circ} \mathrm{C}$, a thermocouple was place near the hinge and the distance between the heat gun and specimen was adjusted to keep the local temperature in that range to minimize local drying. This arrangement was kept for I hour-under supervision for safety - to cure the adhesive. The specimen was then ready to be tested after unwrapping, painting, and bonding of the printed ruled line.

Unfortunately, the mass loss incurred by specimens during this preparation could not be quantified because of the addition of the hinge and adhesive. Recall that the mass loss was on the order of $0.03 \mathrm{~g}$ for $\mathrm{DCB}$ specimens, which would be impossible to measure precisely when considering the addition of an impreciselyknown mass of adhesive to the specimen.

With the hinge, paint and paper measurement scale applied to the specimen, mechanical testing could then be performed as described in the sections to follow.

\subsubsection{Use of Load Frame}

The prepared specimen was placed in the test frame using a fixture designed to grip its lower face sheet from the edges, as shown in Figure 80 and Figure 8I. As opposed to fixtures described by other researchers [72], this fixture did not have a translating base at the time of testing. Load was applied to the hinge through a I2 in (305 mm) cable rather than directly gripping the hinge to avoid loading in mode II as much as possible. This procedure was in line with that described by others and is said to be a mode I test [73]. The specimen was placed in the lower grip so as to align the initial crack tip (i.e. the edge of the insert) with the loading axis. 


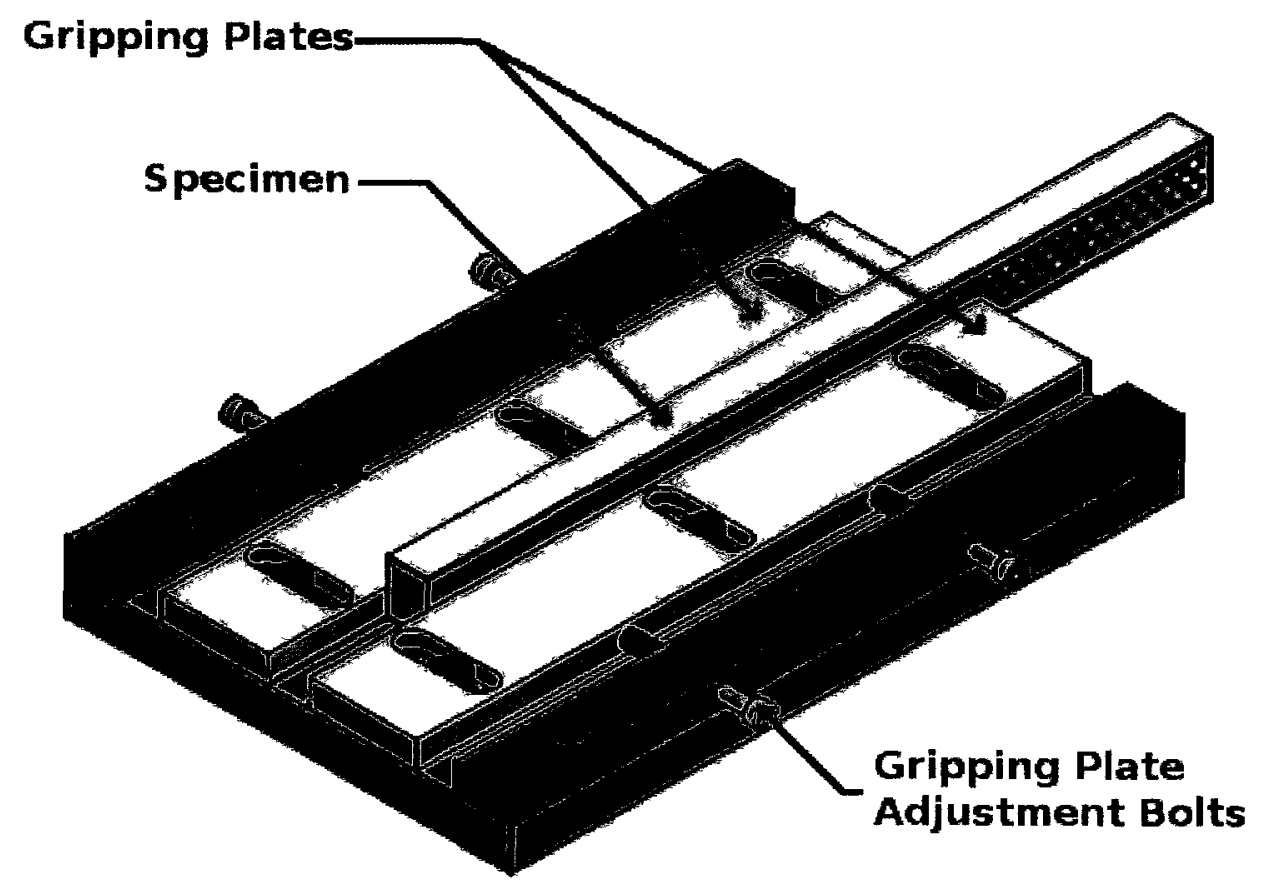

Figure 80: SCB gripping fixture.

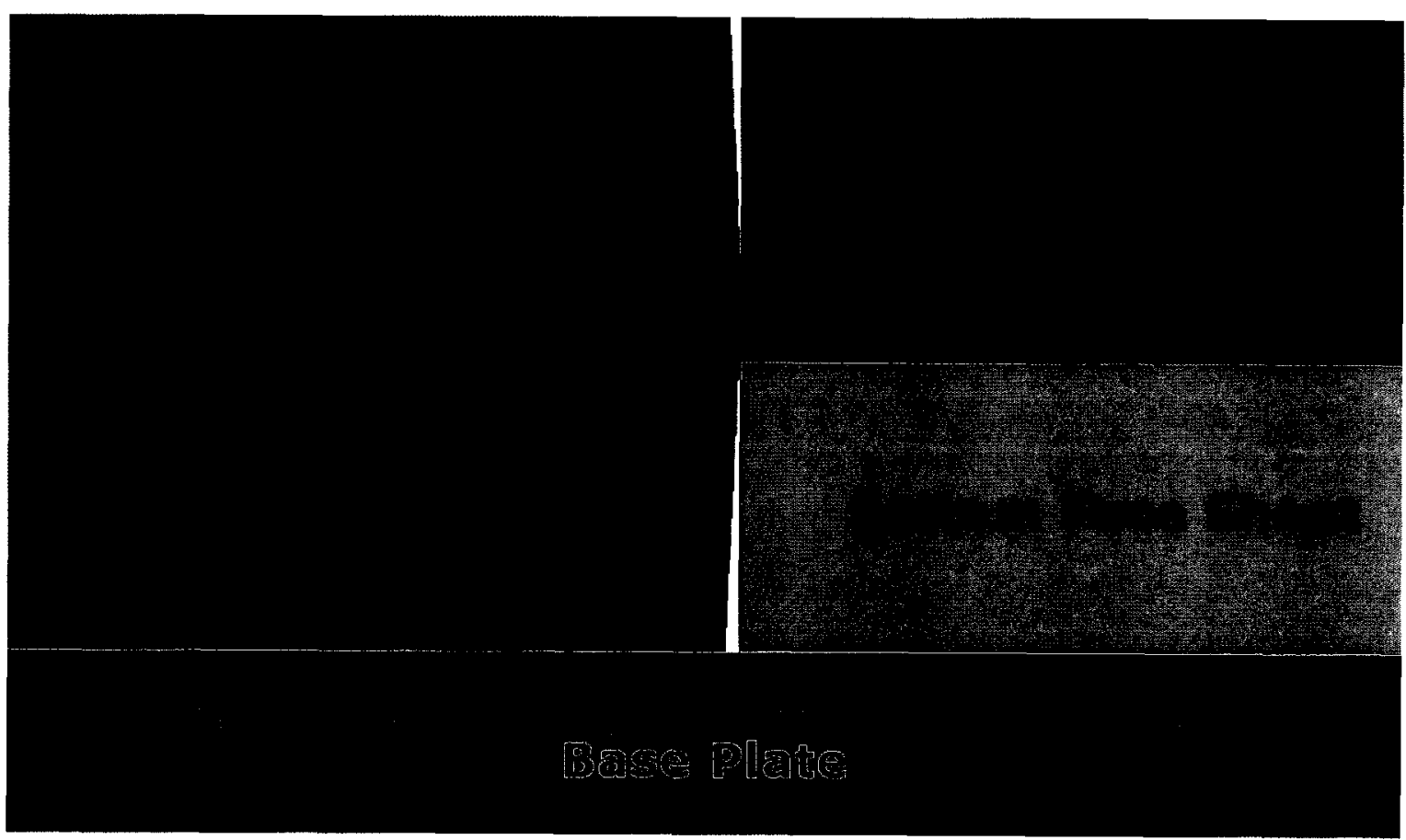

Figure 81: Detalled view of gripping plate chamfer. 
As with DCB tests, a digital camera was used to monitor the crack front in realtime. The load frame was operated in displacement control at a rate of 0.080 inch $/$ minute $(2.03 \mathrm{~mm} / \mathrm{minute})$ and load and displacement of the crosshead and cable were recorded by the system. A typical load-displacement graph is shown in Figure 82.

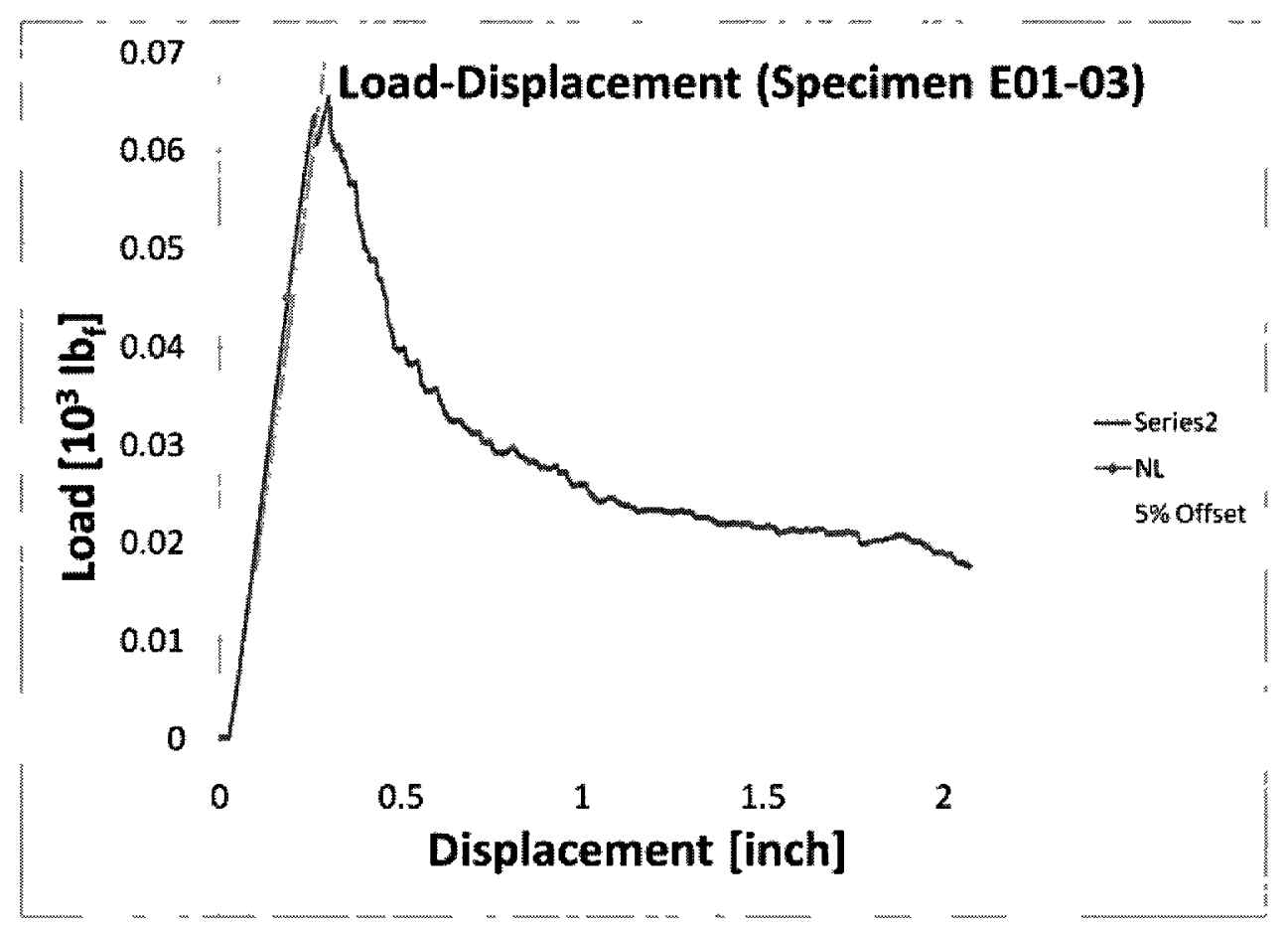

Figure 82: Typical load-displacement graph for SCB tests

Crack markers were again inserted in the data file by the user and later used to create a $G_{I C-a}$ graph.

\subsection{DATA ANALYSIS PROCEDURE}

The data analysis methods used for the DCB tests (Chapter 4) were also applied to the SCB data as described in this Chapter. Since the calculation of fracture toughness was made by assuming that the strain energy of the specimen was 
equivalent to the work applied by the load frame, this should be acceptable. The two calculations used for the SCB tests are the Modified Beam Theory (MBT) and the Compliance Calibration (CC) methods, described previously. The MCC value of GIC was not calculated because the beam thickness was difficult to determine. Due to the failure occurring in the core, as discussed in Section 5.5.2, the adhesive fillets and pieces of honeycomb core were attached to the bending face sheet, stiffening it in a way that the thickness measurement would not reflect. In this work, therefore, the CC method was preferred because it does not depend on the beams being symmetric or the crack front being planar. In SCB tests, selecting the best calculation method was important because the difference in GIC values from the MBT and CC methods was greater than in the DCB tests, as the results will show.

Recall that the correction factor for the DCB test configuration given in ASTM D5528 accounts for the shortening of the moment arm of the applied load as the face sheets bend. The offset loading caused by the thickness of the hinge is also considered. This correction factor was used on the SCB data.

\subsection{RESULTS AND DISCUSSION}

\subsection{Presentation of Results for SCB Specimens}

The SCB specimens took longer to manufacture and prepare for environmental conditioning than the DCB specimens. Additionally, the second environmental chamber intended for $80^{\circ} \mathrm{C}$ conditioning was not immediately available. This introduced delays in starting the conditioning, which meant that within the timeline of the work presented here, only unconditioned SCB specimens and those from the two $70^{\circ} \mathrm{C}$ conditions were tested. As the results for the few specimens that were tested will show, the core failure was very consistent (with low standard deviation); it 
was therefore decided to save some SCB specimens for later testing to see what the longer-term effects of exposure might be. Two specimens from each of the $82^{\circ} \mathrm{C}$ conditions were to be tested near the end of the project as well, but coincidental failures of the seals of the aquarium immersion tank and of the water boiler of the environmental chamber during the same weekend-immediately preceding the date of the planned tests ${ }^{2}$ - precluded any further testing within the thesis timeline. A new tank was set up and the chamber's boiler repaired, so that the specimens can be tested by colleagues at the NRC in the near future. One error to be noted here was the lack of traveller laminates to accompany the SCB specimens and provide data on moisture absorption and loss. The added aluminum and sealant meant that SCB specimen weight could not be used to reliably characterise the progress of moisture diffusion. Travellers were thought unnecessary because the required duration of conditioning to reach equilibrium could be estimated from other test data. As such, the drying caused by failures in the environmental conditioning systems could not be accounted for.

Despite the difficulties noted above regarding the number of specimens and the lack of data for $82^{\circ} \mathrm{C}$ conditioning, the preliminary results obtained will be presented. As in the previous Chapter, the failure mode and strain energy release rate will be discussed. As with DCB specimens, Appendix B contains summary data sheets that contain further details for each $\mathrm{SCB}$ specimen.

\footnotetext{
${ }^{2}$ Note: the author has witnesses and an alibi for that weekend!
} 


\subsubsection{Failure Mode}

The change in fallure mode that was reported for DCB specimens was not observed in SCB specimens after 3-4 months of conditioning in fresh water vapour and salt water immersion at $70^{\circ} \mathrm{C}$.

Despite the use of a Teflon insert to maintain an unbonded area between the face sheet and core, the crack did not extend from the tip of the insert. As shown in Figure 83, a new crack formed in the core rather than extending from the end of the Teflon insert. This was the case for all specimens.

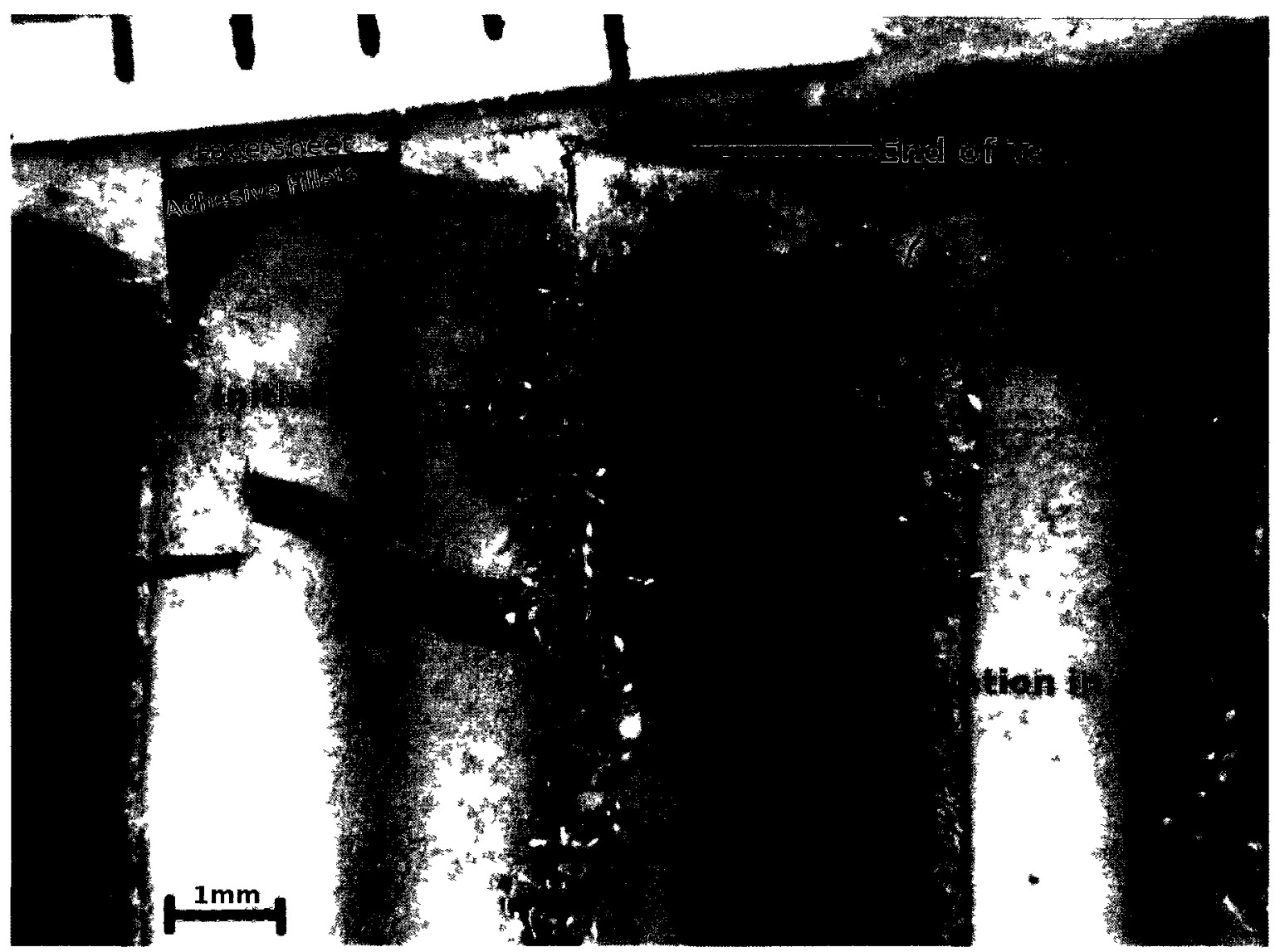

Figure 83: Duting intiation, a new crack was formed in the core of the specumen rather than extending from the existung unbonded area. 
Over most of the fracture area, both dry and environmentally-conditioned specimens failed by fracture of the core just below the adhesive fillets as shown in Figure 84. Thorough (macroscopic) examination of the fracture interface to find evidence of adhesion or cohesion fillet bond failure, as illustrated in Figure 79, was performed. The former was not found and the latter was only found in a small area near a particularly large void, as shown in Figure 85. Though not representative of the overall behaviour of these specimens, this shows the importance, as in most structural applications of polymers, of controlling void formation during cure.

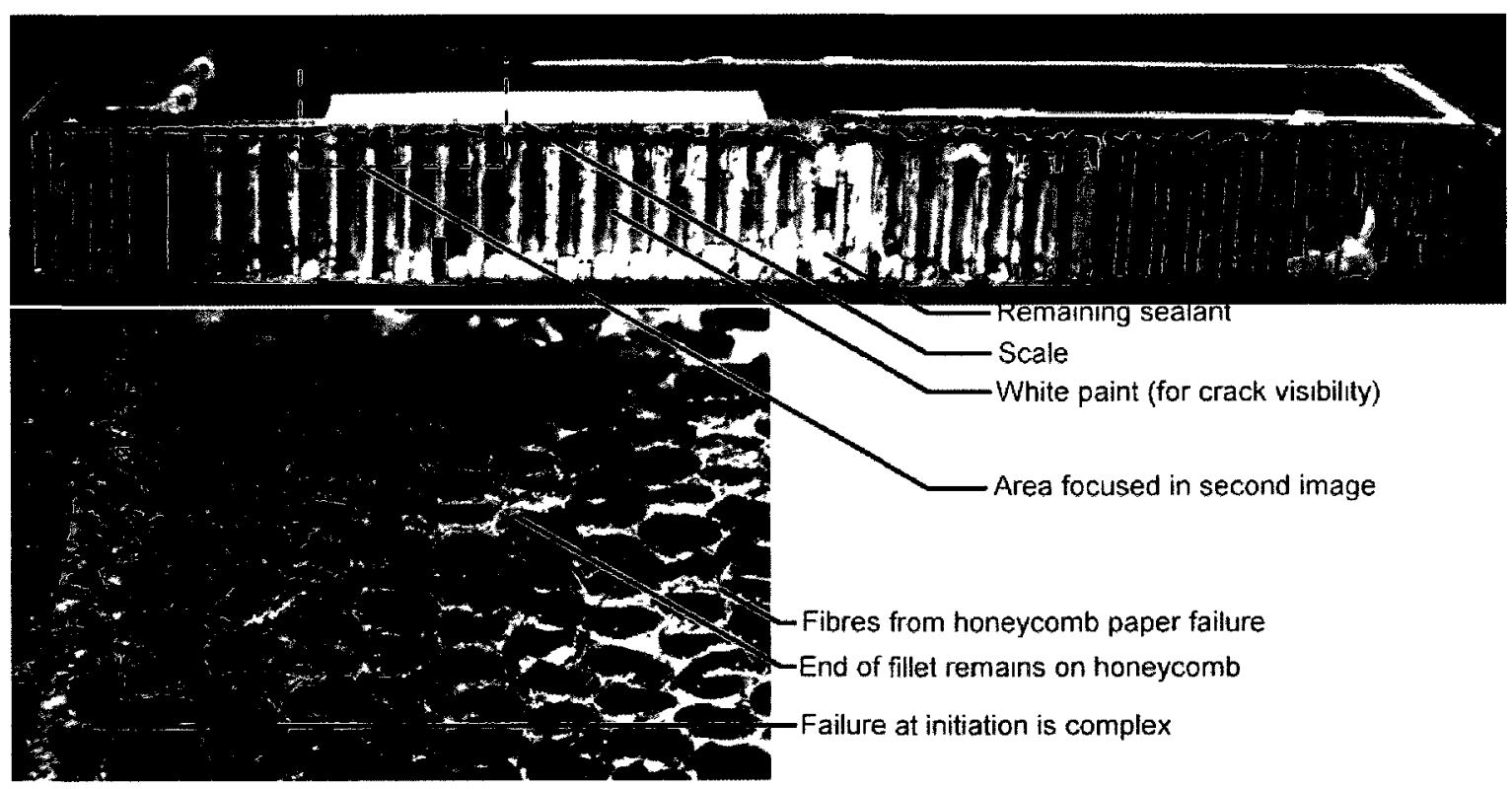

Figure 84: Failure of SCB specimens in this study was in the core, regardless of envitonmental exposure. For approximate scale, recall that fillets are $I / 8$ inch in diameter. 


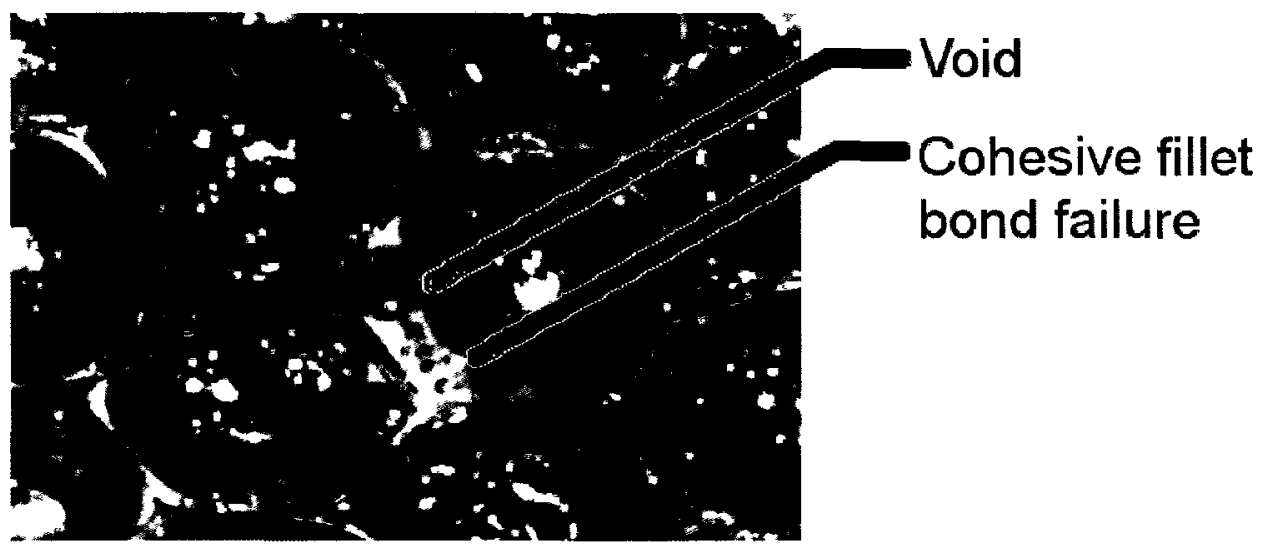

Figure 85: One area adjacent to a large void sustained cohesive failure of the fillet bond.

In brief, no distinction could be made between conditioned and dry specimens based on their mode of fracture after 3-4 months of conditioning. It was decided to leave some specimens in the conditioning environment to check whether more exposure time would lead to any changes; therefore, only two out of six specimens from each condition were tested.

Hence, based on the currently-available results and on the failures observed in the field (which were also in the core; see [90] and [9I]), it would appear that typical aerospace adhesives and bonding practices are sufficiently resistant to moisture to maintain integrity of the facesheet-adhesive interface under environmental conditioning.

\subsubsection{Fracture Toughness}

Fracture toughness results from the tested specimens are shown in Figure 86. The data obtained for GIC is reported here as a single value for initiation, and another for propagation. In fact, however, the latter varied with crack length as seen with the DCB specimens. All specimens exhibited the behaviour seen in Figure 88, namely an area of relatively high fracture toughness following initiation followed either by a 
progressive but relatively slow decline, or a variation about a nominal value. As seen in the analysis of the faulure mode (Section 5.5.2), the initiation area displays very different behaviour from the rest of the specimen area. Reporting separate initiation and propagation values is an attempt to account for this fact. As opposed to DCB specimens, the initiation values were higher than the propagation values. This is likely the result of the formation of a new crack in the core requiring more energy than its propagation once initiated.

The initiation value is calculated using the CC calculation and loaddisplacement data at the visible/audible onset of crack growth (for SCB specimens, the core cracking gave audible cues to initiation before visual ones). The propagation value is an average of the values obtained after the initial 0.5 inch $(12.7 \mathrm{~mm})$ of crack growth, again using the CC calculation, as shown in Figure 88. The major reason for ignoring the initial 0.5 inches of crack growth-and the explanation for the higher GIC values in this area-is the fact that the crack is growing in both directions (see Figure 83) but is only being measured in the direction that growth was expected (left on Figure 83). The newly-created surface area is therefore being underestimated, leading to an overestimated GIC value, since the crack length term, a, appears in the denominator of the GrC calculation. 


\section{Initiation}

12

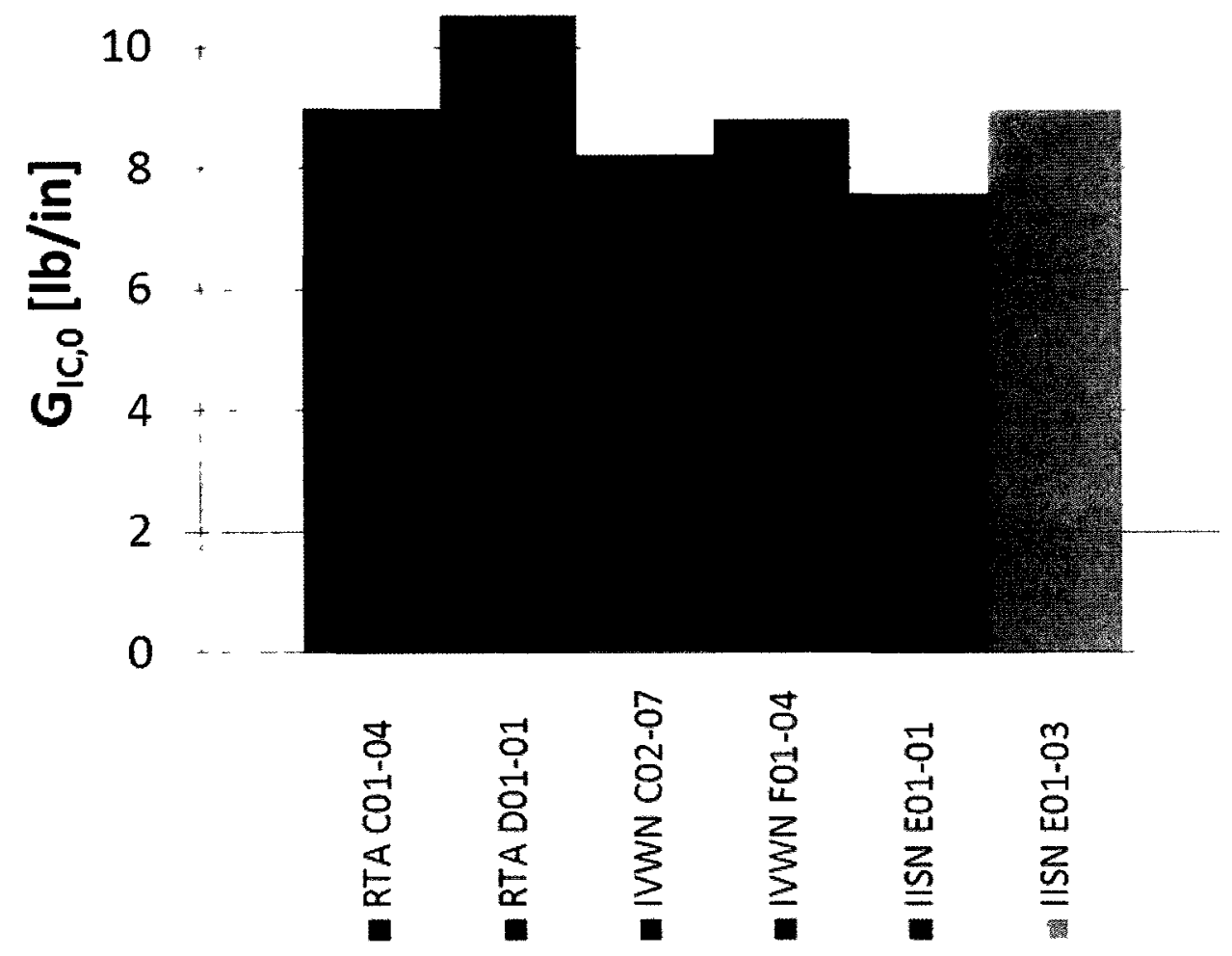

Figure 86: Initiation toughness data for 6 tested specimens using $C C$ calculation method and VIS initiation cnterion. 


\section{Propagation (Averaged)}

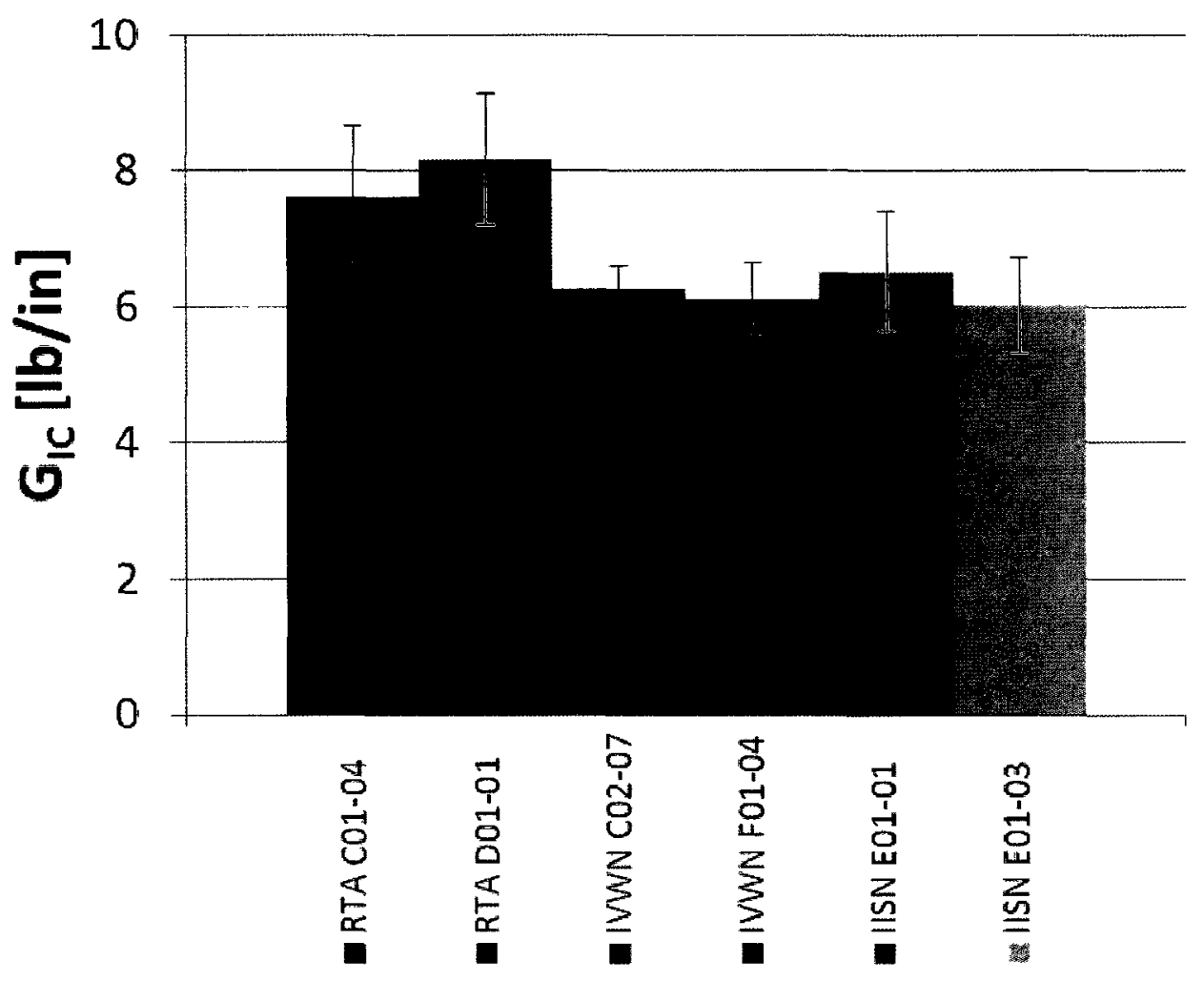

Figure 87: Propagation Gic values for 6 tested specimens. CC calculation method used, and average calculated from all points after the first 0.5 inches as shown in Figure 88.

As can be seen, measured fracture toughness of the conditioned specimens was lower than that of the dry specimens, but there was no difference between specimens immersed in salt water and those exposed to 95\% R.H. air. Because the failure occurred in the core, this would seem to indicate an effect of moisture on the core. There may be other explanations regarding changes in stiffness of the adhesive and face sheet due to moisture absorption that may increase the proportion of stress carried by the core for a given applied load, but further numerical and experimental analysis of this possibility would be required. This added complexity, compared to 
DCB specimens, stems from the nature of the sandwich structure: it is a combination of two very different materials and sets of properties.

Additionally, since the calculations in this study assume a mode I case, and only forces in the vertical direction are measured, it is possible that the GIC values are only accounting for a part of the overall behaviour. However, others have found that the SCB test is essentially a mode I test and this was assumed to be the case [72].

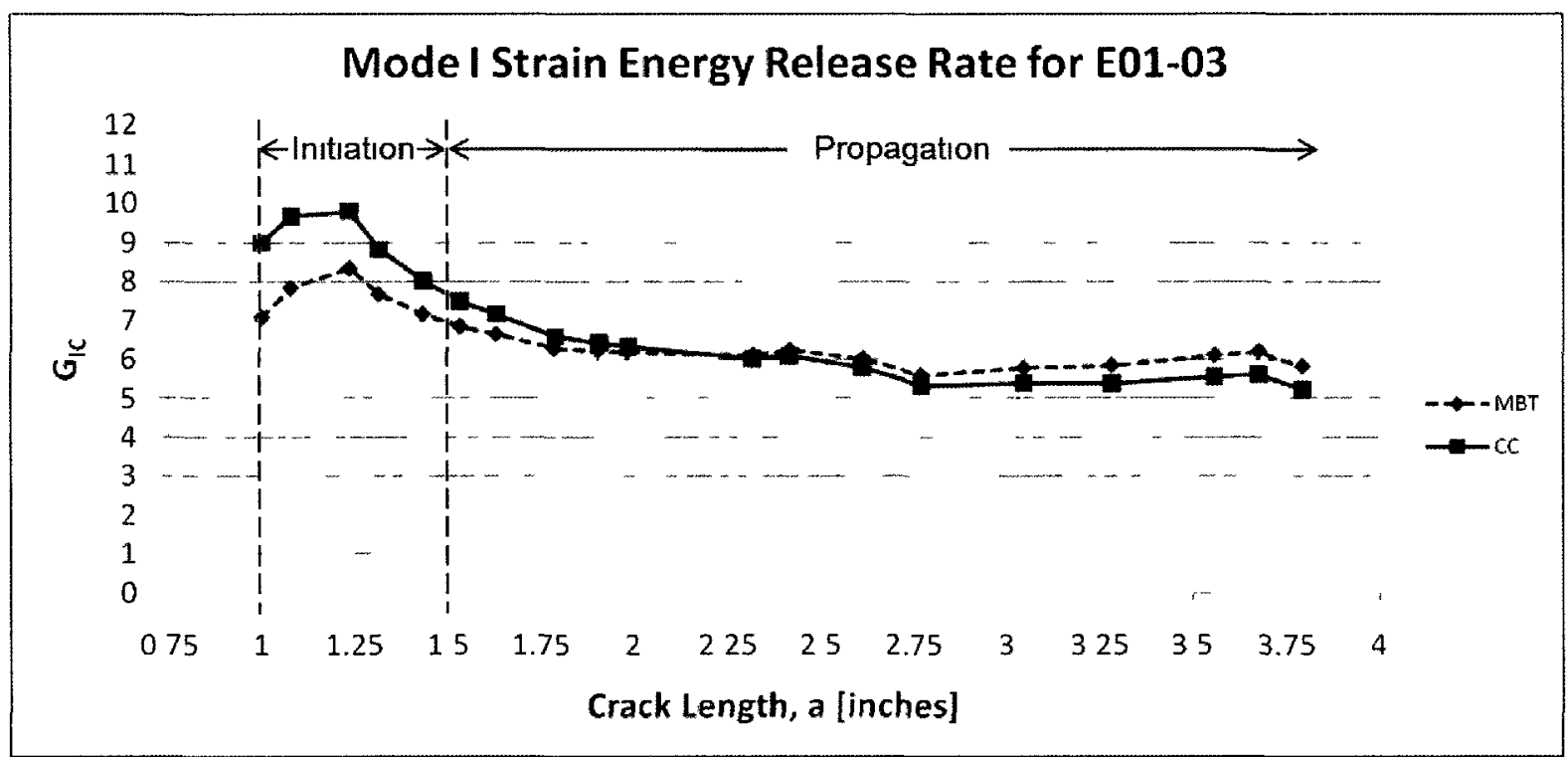

Figure 88: Curve of strain energy release rate with respect to crack length for specimen EOI-O3.

\subsection{CONCLUSIONS}

A number of conclusions and recommendations can be drawn from this work.

- The use of modern, toughened epoxy adhesives and proven bonding procedures seem sufficient to prevent a change in the failure mode from core fracture to skin-adhesive disbond in sandwich structures exposed to hot and wet environments. 
- Ongoing exposure of specimens is currently under way at NRC-IAR to confirm this continues to be the case in the long term.

- Core fracture strength appears to be reduced by exposure to moisture, but further analysis of the relative stiffness changes from moisture absorption in the face sheet and core is required for confirmation.

- A recently-published sizing and manufacturing procedure [73] should be used in designing future specimens, in order to ensure that data reduction procedures are adequate. In the future, face sheets without offaxis plies (or only $0^{\circ}$ and $90^{\circ}$ plies) will be used to simplify analysis.

- A translating base for gripping the SCB specimens, perhaps with an LVDT to measure its displacement, might further reduce concerns regarding the mode of fracture (i.e. to ensure it is predominantly mode I) and the observed variation of GIC over crack length. Such a modification to the current fixture is currently underway at NRC-IAR. 


\section{Chapter 6: Overview of Contribution and Future Work}

In this Chapter, an overview of the work presented will focus on the contributions made to the field of environmental degradation of bonded composites.

Chapter I Literature Review

Chapter 2 Manufacturing of DCB and SCB Specimens

Chapter 3 Environmental Conditioning and Diffusion Data Analysis

Chapter 4 The Effects of the Environment on the Fracture Toughness of Bonded Laminates

Chapter 5 Preliminary Study of the Effects of the Environment on the Disbond Fracture Toughness of Sandwich Structures

\section{Chapter 6 Overview of Contribution and Recommendations for Future Work}

Appendix A Summary Sheets for DCB Specimens

Appendix B Summary Sheets for SCB Specimens 


\subsection{CONCLUSIONS}

To help the interested reader, each Chapter had its own Conclusions section which highlighted the key points to be taken on each subject. This Chapter will focus on the results of greater importance and novelty.

\section{I.I. Chapter I: Literature Review}

- There are differences between marine and aerospace uses of composite materials in that the materials themselves, the way structures are manufactured and the properties of interest can vary. Therefore, the results from salt water degradation studies of marine composites may not be applicable to aerospace composites.

- Adhesive joints are particularly interesting for thin-skinned composite structures because they do not require holes to be drilled, which break fibres and cause stress concentrations.

- Adhesive joints require special care to manufacture, especially in terms of surface preparation, and are difficult to inspect for durability.

- Hot and humid environments have been found to degrade composites and bonds in a number of ways, including physical ageing, thermo-oxidative reactions, thermal degradations, hydrolysis and chain scission, matrix swelling and interface bond degradation.

- Salinity of the exposure environment has not been thoroughly studied for bonded composite materials.

\section{I.2. Chapter 2: Specimen Manufacturing}

- A carbon fibre/epoxy pre-preg was used to manufacture laminates, an epoxy was used as adhesive and a Nomex honeycomb core was used for SCB specimens.

- All laminate and adhesive curing took place in an autoclave for maximum quality. 
- Teflon inserts were used to create "pre-cracks" from which fracture would start during mechanical testing.

- Careful protection from the exposure environment was required for the hinge bond on DCB specimens and the core of SCB specimens and was provided by sealant and aluminum jackets.

- Dimension requirements for SCB specimens were published after the specimens for the present study were manufactured. The difference in face sheet thickness resulted in more compliant face sheets. A correction factor described in Chapter 4 was applied to help reduce the effects of this discrepency.

\section{I.3. Chapter 3: Environmental Conditioning}

- Specimen conditioning took place in chambers designed to maintain temperature and humidity as well as in specially-fabricated salt water tanks.

- Moisture equilibrium was found by making regular mass measurements, any increase in mass being attributed to absorbed moisture.

- Diffusion was non-Fickian but the Fickian procedure was used to illustrate how the artificial laboratory environment can be compared to more realistic use-environments.

- The specimens were all conditioned approximately 3-4 months.

\subsubsection{Chapter 4: DCB Tests}

- The CC method and NL point were selected as the best methods for calculating $G_{I C}$ and $G_{I C}, o_{\text {. }}$

- $G I C, o$ was affected by all conditioning environments, but vapour did not appear to affect GIC as immersion did.

- Salinity did not appear to play a role in degrading the mode I fracture properties of the bonded joints.

- The failure mode changed from $100 \%$ cohesive for unconditioned specimens to partly adhesive for conditioned specimens.

- Areas with a greater proportion of adhesive failure often had lower $G r C$ values. 
- All data had large standard deviations between specimens.

- Specimens immersed in water at $82^{\circ} \mathrm{C}$ sustained a $15 \%$ reduction in GIC, whereas $70^{\circ} \mathrm{C}$ caused a $6 \%$ drop in Grc, compared to unconditioned specimens.

\section{I.5. Chapter 5: SCB Tests}

- Because the face sheets were not as stiff as required by a SCB sizing procedure, the correction factor for large deflections provided in ASTM D5528 was especially important for SCB specimens.

- Failure mode was always core fracture.

- Only 6 specimens were tested.

- It appeared that immersion and vapour conditioning at $70^{\circ} \mathrm{C}$ caused the same decrease in GIC, which was about $20 \%$.

\subsection{CONTRIBUTION}

Specific results of this work were believed to be new contributions and are presented in this Section.

\subsection{The Effect of Salinity on Joints of Composite Laminates}

Little data was found in the literature to confirm whether salinity of water that joints were exposed to was only a concern with metal adherends, as many studies have focused on (e.g. [69-70]). Another study focused on the interlaminar shear stress (not a bonded joint) and found that salt water slowed the diffusion process and thus slowed the degradation of the joint [7I].

Given the likelihood that chemical and physical interactions are responsible for some of the observed degradation of properties in moisture-conditioned joints, the effects of salinity in the exposure environment was of interest. In this work, it was 
confirmed that salinity played little role in degrading the joint over a 3-4 month period of exposure at temperatures as high as $82^{\circ} \mathrm{C}$, both in the bonded laminate and sandwich configuration. Additionally, slowing of the diffusion process was not observed for the materials used in this study.

\subsubsection{Degradation of the Interface in Joints of Composite Laminates}

The literature provided some insight into the effects of moisture exposure on the mode of fracture of degraded joints of composite laminates. For example, in [68], very little interface degradation was reported when exposing adhesively-bonded composite laminates to moisture and temperature. The few instances of interfacial failure were attributed to inconsistencies in surface preparation. In [67], by the same author, some interfacial failure was observed over long exposure times and with specific combinations of adhesive and adherend.

In the work presented here, all specimens that were exposed to moisture and high temperature displayed a mix of adhesive and cohesive failure. Interestingly-but inexplicably - those specimens that were exposed to high humidity rather than immersion had a similar failure mode to immersed specimens, but the measured GIC values were not similarly degraded. The mechanical testing program presented here did not allow this phenomenon to be studied in greater depth.

\subsubsection{Environmental Effects on Sandwich Disbond}

Sandwich disbonds are being actively researched, with the current focus being on the creation of a standardized test method [72-73] and on assessing the effect of manufacturing methods on the resulting bond [9]. 
The work presented here on environmental effects on disbond has shown that: (1) the typical farlure mode for the specimen configuration used here is core fracture, and is unchanged by mossture exposure; and (11) the disbond energy release rate is reduced by moisture exposure. Too few specimens were tested to provide a confident estimate of the degree of this reduction. The specimens tested were also not in compliance with the preliminary requirements outlined in [73], and the plate supporting the SCB specimens did not translate as in [9] and [72], but used a cable of appropriate length, according to [73], to ensure mode I-dominated loading.

\subsubsection{Comparing Failure Mode to Fracture Toughness}

A method was presented which estimated the fallure mode from a picture of the fracture area, in terms of \% Cohesive fallure with respect to crack length. This allowed a comparison to be made with GIC data in order to reliably assess how much the variability in GIC over crack length for moisture-conditioned specimens was attributable to variability of failure mode alone. For many specimens, the curves displayed the same features (peaks and valleys), but a direct link between a given \% Cohesive faulure and GIC was not found. Furthermore, some specimens did not behave as expected, even resulting in increases in GIC where adhesive fallure dominated in some cases. Other variables are likely affecting the relationship between local joint properties and GIC, but could not be probed with this set of tests.

The Appendices to this work provide detalled data, photos and \% Cohesive graphs for future reference by other researchers, information which was difficult to find when preparing this study (especially fallure mode of moisture-conditioned bonded composites; most avallable information is for bonded metal joints). 
Highlighting these contributions provides an incomplete image of what was learned from this work. The mistakes made and learned from, as well as the incomplete understanding of certain observed phenomena have given rise to a number of recommendations for future work, as will be discussed next.

\subsection{FUTURE WORK}

\section{se}

\subsection{Chemical and Physical Effects of Moisture on Bonds}

None of the data presented here accounts for the chemical and physical changes that occur in a bonded joint and that might explain phenomena such as the change in failure mode in vapour-conditioned specimens that did not reduce the GIC of the joint, as discussed in Section 6.2.2. The discussion of bonding in Chapter I highlights the importance of surface chemistry and the methods used in preparing a surface for bonding. This preparation is particularly important in maintaining the durability - i.e. the conservation of strength over time and environmental exposureof joints. It thus follows that how the chemistry of the bond changes with time and exposure is of interest to predicting the degradation of joint properties.

\subsubsection{Further Probing the Degradation of Bonded Laminate Joints}

One variable that was not thoroughly studied in the DCB work presented here is the effect of subsequent drying on the failure mode to determine whether the observed degradation (i.e. increased proportion of adhesive failure) is permanent. Furthermore, drying the specimens after long-term exposure to moisture and testing them would provide information on the effect that plasticisation of the polymer adhesive and matrix due to absorbed moisture had. For example, the failure mode (e.g. adhesive versus cohesive) might be the same as for the specimens presented here, 
but the GIC might be higher-the outliers in this study suggest this may be the case-which may mean that plasticisation plays a greater role than failure mode in determining the nominal GIC value. Researchers at NRC are likely going to be studying this variable with some spare specimens that were conditioned with the ones in this study.

\subsubsection{Changing the Focus of Sandwich Disbond Research}

The SCB test results are leading to changes in the focus of research at NRC. Rather than considering only the effect of environmental conditioning, focus will be shifted toward the effects of manufacturing variations. Fillet geometry and core properties will be of particular interest, and efforts to create accurate numerical models to predict the mode of failure of face sheet-core separation (whatever form it may take: skin-adhesive disbond, core fracture, fillet fracture, etc.) will be increased. For example, the geometric effects of fillets should be assessed similarly to [9], which showed that a critical fillet size existed that determined whether the face sheet would separate from the core by fracture of the adhesive (at high energy absorption rates) or through the honeycomb (at relatively lower energy levels and in a similar way to the work presented here).

Furthermore, members of a Composite Materials Handbook (CMH-I7) working group on sandwich fracture have reported a variation of core properties among different suppliers and even among cores supplied by the same supplier to the same specification [90]. It should be noted that the variability of core properties could not be established in this study: all panels were made from a single sheet of honeycomb core. 
Studying the synergistic effects of moisture with such material and manufacturing factors will continue to be a part of this research. In particular, performing the mechanical tests at elevated temperature and humidity would be of interest, since the current procedure involved progressive drying of the specimens over the duration of the test. To this end and as mentioned previously for DCB specimens, the design of an environmental chamber that would fit the load frame is currently underway.

Finally, the gripping fixture was modified to translate during testing, so that the top grip of the load frame could directly grip the hinge rather than using a cable. This would bring the method in line with that used by others $[9,72]$. The modified fixture is shown in Figure 89.

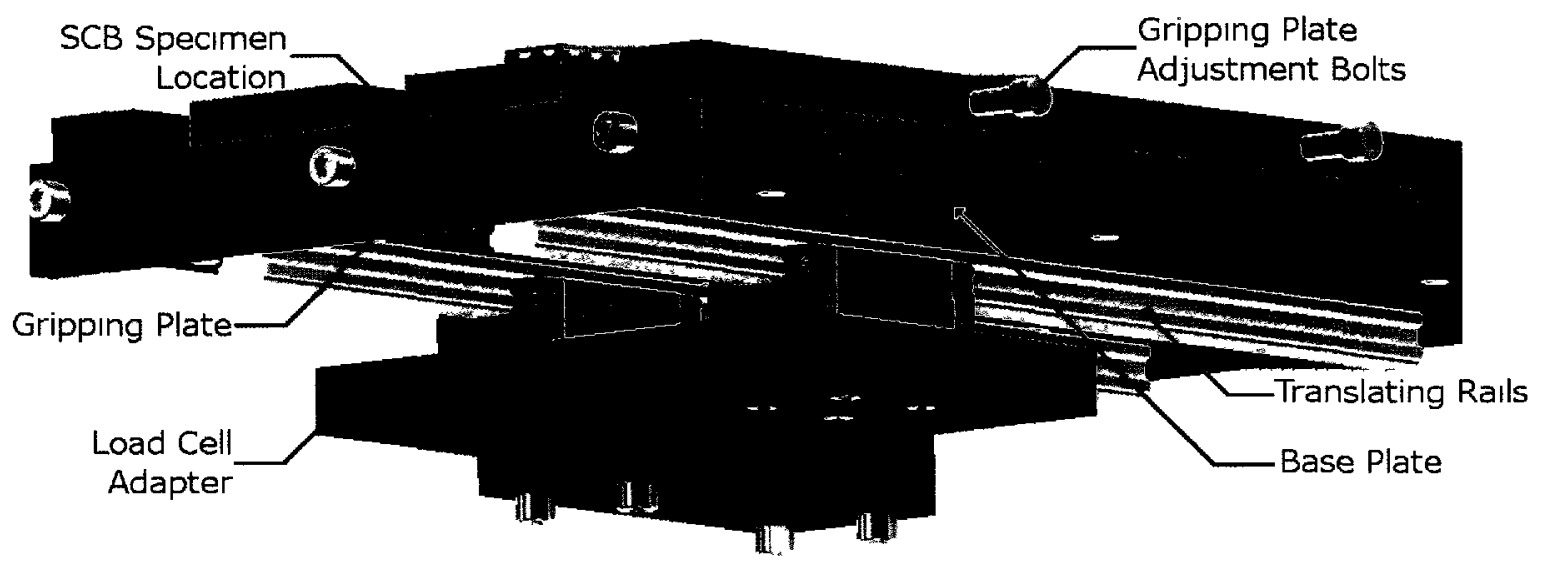

Figure 89: Modified SCB gripping fixture with translating base.

\subsubsection{Increasing the Role of Finite Element Analysis}

Because of the amount of time spent manufacturing and conditioning specimens in this study, then testing them, there was little effort made at applying some of the more recent FEA tools such as the Cohesive Zone Model to the problem of skin-core disbond (e.g. as discussed in [90]). Applying and perhaps even 
improving upon those tools will likely form a part of the future of this project at NRC. 


\section{References}

[I] Boeing: Commercial Airplanes, 787 Dreamliner - Program Fact Sheet.

[Online]. Available:

http://www.boeing.com/commercial/787family/programfacts.html [Accessed: June $\left.13^{\text {th }} 20 \mathrm{II}\right]$.

[2] I.M. Daniel, O. Ishai, Engineering Mechanics of Composite Materials, $2^{\text {nd }} \mathrm{ed}$. New York: Oxford University Press, 2006.

[3] P.D. Soden, A.S. Kaddour, M.J. Hinton, "Recommendations for designers and researchers resulting from the world-wide failure exercise," Composites Science and Technology, Vol. 64, 2004, pp. 589-604.

[4] M.J. Hinton and A.S. Kaddour, "The Second World-Wide Failure Exercise: Benchmarking of Failure Criteria under Triaxial Stresses for Fibre-Reinforced Polymer Composites," presented at the I $6^{\text {th }}$ International Conference on Composite Materials, Kyoto, Japan, 2007.

[5] A.S. Kaddour, M.J. Hinton, S. Li and P.A. Smith, "Damage Theories for Fibre-Reinforced Polymer Composites: The Third World-Wide Failure Exercise (WWFE-III)," presented at the I $6^{\text {th }}$ International Conference on Composite Materials, Kyoto, Japan, 2007.

[6] C.-H. Shen and G.S. Springer, "Moisture absorption and desorption of composite materials," Journal of Composite Materials, Vol. I0, 1976, pp. 2-20.

[7] A. Baker, S. Dutton and D. Kelly, Composite Materials for Aircraft Structures, $2^{\text {nd }}$ edition. Reston, VA: AIAA Education series, 2004.

[8] Hexcel Composites, HexWeb Honeycomb Sandwich Design Technology, Publication No. AGU 075b, 2000. [Online]. Available: http://www.hexcel.com/resources/technology-manuals.

[9] J. Forman, "Effects of Fillet Size on Bond Performance of Honeycomb Sandwich Panels," presented at the $42^{\text {nd }}$ International SAMPE Technical Conference, Salt Lake City, UT, 2010.

[10] Metallic Materials Properties Development and Standardization, MMPDS04, Federal Aviation Administration, Columbus, OH, 2009. 
[II] J.P. Komorowski, "Hygrothermal Effects in Continuous Fibre Reinforced Composites - Part I: Thermal and Moisture Diffusion in Composite Materials." National Research Council, Canada. Aeronautical Note NAE-AN-4, NRC No. 20974; January 1983.

[I2] A. Kootsookos, A. Mouritz, "Seawater durability of glass- and carbonpolymer composites," Composites Science and Technology, Vol. 64, 2004, pp. I503I5I I.

[I3] P. Davies, F. Mazéas, P. Casari, "Sea water ageing of glass reinforced composites: shear behaviour and damage modelling," Journal of Composite Materials, Vol. 35, No. I5, 200I, pp.1343-1372.

[I4] T.S. Grant, "Seawater degradation of polymeric composites," MSc thesis, Texas A\&M University, May I99I.

[I5] F.E. Sloan, "Investigations into the effects of long-term seawater exposure on graphite/epoxy composite materials," Ph.D dissertation, University of California, San Diego, I991.

[I6] W.H.E. Reynolds, "Degradation of Carbon Fiber Composites in the Maritime Environment," Ph.D dissertation, University of Rhode Island, 1996.

[17] Department of National Defence, "CH-I49 Cormorant: Technical Specifications," [Online]. Available: http://www.airforce.forces.gc.ca/v2/equip/chI49/specs-eng.asp.

[I8] Agusta Westland, "EH-IOI - Search and Rescue," Product Brochure. Document No. EH040II6.

[19] Composite Materials Handbook, Vol. I, Revision F, MIL-HDBK-I7-IF, Department of Defense, 2002.

[20] S.B. Kumar, I. Sridhar, S. Sivashanker, "Influence of humid environment on the performance of high strength structural carbon fibre composites," Materials Science and Engineering A, Vol. 498, 2008, pp. I74-I78.

[2I] K.J. Eyre, "Moisture Absorption and Stiffness Degradation of Carbon Fibre Reinforced Polymer Composite Specimens Exposed to Accelerated Environmental Aging Conditions," MSc thesis, University of Wyoming, May 2007.

[22] A.C. Garg, "Effect of moisture and temperature on fracture behavior of 
graphite-epoxy laminates," Engineering Fracture Mechanics, Vol. 29, No.2, I988, pp. I27-I 49 .

[23] C.E. Browning, G.E. Husman and J.M. Whitney, "Moisture effects in epoxy matrix composites,' Composite Materials: testing and design (4th Conference), ASTM STP 6I7, American Society for Testing and Materials, pp. 48I-496.

[24] A.P. Mouritz, E. Gellert, P. Burchill and K. Challis, "Review of advanced composite structures for naval ships and submarines", Composite Structures, Vol. 53, 200I, pp. 2I-4I.

[25] Transport Canada, "Factor of Safety," Canadian Aviation Regulations, Part V - Airworthiness Manual Chapter 525 - Transport Category Aeroplanes, Subchapter C, Standard 525.303, rev. June 30 2008 .

[26] G.M. Vandijk, J.B. Dejonge, Introduction to a Fighter Aircraft Loading Standard for Fatigue Evaluation (Falstaff), Technical Report No. NLR-MP-750I7$\mathrm{U}, \mathrm{I} 975$.

[27] J.C.P. Kam, "Wave action standard history (wash) for fatigue testing offshore structures," Applied Ocean Research, I4 (I992), pp. I-IO.

[28] L.A. Bisby, "Effects of Freeze-Thaw Cycling on Anchorage of FibreReinforced Polymer Sheets Bonded to Reinforced Concrete Beams," MS thesis, Dept. Civ. Eng., Queen's University, Kingston, ON, I999.

[29] K.V. Subramaniam, M. Ali-Ahmad, Michel Ghosn, "Freeze-thaw degradation of FRP-concrete interface: Impact on cohesive fracture response," Engineering Fracture Mechanics, Vol. 75, 2008, pp. 3924-3940.

[30] M.F. Green, L.A. Bisby, Y. Beaudoin, P. Labossière, "Effect of freeze-thaw cycles on the bond durability between fibre reinforced polymer plate reinforcement and concrete," Canadian Journal of Civil Engineering, Vol 27, 2000, pp. 949-959.

[3I] C. Baley, P. Davies, Y. Grohens and G. Dolto, "Application of Interlaminar Tests to Marine Composites. A Literature Review," Applied Composite Materials, Vol. I I, 2004, pp. 99-I26.

[32] P. Davies, "Ageing of composites in marine vessels", in Ageing of composites, R. Martin, Ed. Boca Raton: CRC Press LLC, 2008, pp.326-353.

[33] U.S. Navy NavSea Warfare Centers, Carderock Division, Marine Composites 
Branch, "Mission," [Online]. Available: http://www.dt.navy.mil/sur-str-mat/str$\mathrm{com} / \mathrm{mar}-\mathrm{com}-\mathrm{bra} /$ index.html. [Accessed: October $8^{\text {th }} 2009$ ].

[34] A. Higgins, "Adhesive bonding of aircraft structures," International Journal of Adhesion \& Adhesives, Vol. 20, 2000, pp. 367-376.

[35] A. Baldan, "Adhesively bonded joints and repairs in metallic alloys, polymers and composite materials: Adhesives, adhesion theories and surface pretreatment," Joutnal of Materials Science, Vol. 39, 2004, pp. I-49.

[36] M.D. Banea and L.F.M. da Silva, "Adhesively-bonded joints in composite materials: an overview," Proceedings of the Institution of Mechanical Engineers, Part L: Journal of Materials: Design and Application, Vol. 223, 2009, pp. I-I8.

[37] U.S. Department of Transportation-Federal Aviation Administration, "Composite Aircraft Structure," Advisory Circular AC 20-I07B incl. Change I, 2010.

[38] S.J. Hill, E. Frulloni, C. LoFaro, R. Maskell, "Composite Materials and Their Use," U.S. Patent No. 20I0/0247882 AI, Sep. 30, 2010.

[39] L.J. Hart-Smith, G. Redmond and M.J. Davis, "The Curse of the Nylon Peel-Ply," McDonnell Douglas Paper MDC 95K0072, Presented to the 4I ${ }^{\text {st }}$ SAMPE International Symposium and Exhibition in Anaheim, California, 1996.

[40] M. Davis and D. Bond, "Principles and practices of adhesive bonded structural joints and repairs," International Journal of Adhesion \& Adhesives, Vol I9, I999, pp. 9I-I05.

[4I] A.A. Griffith, "The Phenomena of Rupture and Flow in Solids," Philosophical Transactions of the Royal Society of London. Series A, Containing Papers of a Methematical or Physical Characters, Vol. 22I (I92I), pp. I63-I98.

[42] J.G. Williams, Fracture Mechanics of Polymers, West Sussex, England: Ellis Horwood Limited, 1984.

[43] E.E. Gdoutos, "Crack Growth Based on Energy Balance," Fracture Mechanics: An Introduction, $2^{\text {nd }}$ Edition, Dordrecht, The Netherlands: Springer, 2005.

[44] Standard Test Method for Mode I Interlaminar Fracture Toughness of Unidirectional Fiber-Reinforced Polymer Matrix Composites, ASTM D5528-0I, 2007. 
[45] D.C. Phillips and A.S. Tetelman, "The Fracture Toughness of Fibre Composites," Composites, Vol. 3, I972, pp. 216-223.

[46] A.L. Volynskii, A.V. Efimov and N.F. Bakeev, "Structural Aspects of Physical Aging of Polymer Glasses," Polymer Science, Ser. C, Vol. 49 (2007), No. 4, pp. 30I320.

[47] H.F. Brinson and L.C. Brinson, Polymer Engineering Science and Viscoelasticity: An Introduction, New York: Springer, 2008.

[48] B. Dao, J. Hodgkin, J. Krstina, J. Mardel, W. Tian, "Accelerated Aging Versus Realistic Ageing in Aerospace Composite Materials. I. The Chemistry of Thermal Aging in a Low-Temperature-Cure Epoxy Composite," Journal of Applied Polymer Science, Vol. I02, 2006, pp. 429I-4303.

[49] C. Damian, E. Espuche, M. Escoubes, "Influence of three ageing types (thermal oxidation, radiochemical and hydrolytic ageing) on the structure and gas transport properties of epoxy-amine networks," Polymer Degradation and Stability, Vol. 72 (200I), pp. 447-458.

[50] T. Kelen, Polymer Degradation, New York, NY: Van Nostrand Reinhold Company Inc., 1983.

[5I] T Gates, "The physical and chemical ageing of polymeric composites," Ageing of Composites, R. Martin, Ed. Cambridge, UK: Woodhead Publishing, 2008, pp. I29.

[52] C. Viswanathan, Individual and Interactive Influence of temperature, Stress, Physical Aging and Moisture on Creep, Creep Rupture and Fracture of Epoxy Matrix and its Composite, M.Sc Thesis, University of Manitoba, February 2001.

[53] V.J. McBrierty, S.J. Martin and F.E. Karasz, "Understanding Hydrated Polymers: the Perspective of NMR," Journal of Molecular Liquids, Vol. 80 (I999), pp. I79-205.

[54] M.K. Antoon and J.L. Koenig, "Fourier-Transform Infrared Study of the Reversible Interaction of Water and a Crosslinked Epoxy Matrix," Journal of Polymer Science: Polymer Physics Edition, Vol. I9 (198I), pp. I567-I575.

[55] J. Zhou and J.P. Lucas, "Hygorthermal effects of epoxy resin. Part I: the nature of water in epoxy," Polymer, Vol. 40 (I999), pp. 5505-55I2. 
[56] P. Moy and F.E. Karasz, "Epoxy-Water Interactions", Polymer Engineering and Science, Vol. 20 (I980), No. 4, pp. 3I5-3I9.

[57] L.W. Jelinski, J.J. Dumais, A.L. Cholli, T.S. Ellis and F.E. Karasz, "Nature of the Water-Epoxy Interaction," Macromolecules, Vol. I8 (I985), pp. I09I-I095.

[58] P. Musto, G. Ragosta, G. Scarinzi and L. Mascia, "Probing the Molecular Interactions in the Diffusion of Water through Epoxy and Epoxy-Bismaleimide Networks," Journal of Polymer Science: Part B: Polymer Physics, Vol. 40 (2002), pp. 922-938.

[59] G. LaPlante and P. Lee-Sullivan, "Moisture Effects on FM300 Structural Film Adhesive: Stress Relaxation, Fracture Toughness, and Dynamic Mechanical Analysis," Journal of Applied Polymer Science, Vol. 95 (2005), pp. I285-I294.

[60] H.M. Clancy and D.E. Lutfi, "Moisture in Composites - A Reminder," presented at the $18^{\text {th }}$ International SAMPE Technical Conference, Seattle, WA, I986.

[6I] G.Z. Xiao, M. Delamar and M.E.R. Shanahan, "Irreversible Interactions Between Water and DGEBA/DDA Epoxy Resin During Hygrothermal Aging," Journal of Applied Polymer Science, Vol. 65 (I997), pp. 449-458.

[62] A. Chatterjee, J.W. Gillespie, Jr. "Moisture Absorption Behavior of Epoxies and Their $\mathrm{S}_{2}$ Glass Composites," Journal of Applied Polymer Science, Vol. I08 (2008), pp. 3942-395I.

[63] A.J. Kinloch, "Interfacial Fracture Mechanical Aspects of Adhesive Bonded Joints-A Review," The Journal of Adhesion, Vol. I0 (1979), pp. I93-2I9.

[64] C.D.M. Liljedahl, A.D. Crocombe, M.A. Wahab, I.A. Ashcroft, "Modelling the environmental degradation of adhesively bonded aluminium and composite joints using a CZM approach," International Journal of Adhesion \& Adhesives, Vol. 27 (2007), pp. 505-5I8.

[65] I.G. Zewi, F. Flashner, H. Dodiuk and L. Drori, "Durability of structural adhesive joints," Interntional Journal of Adhesion \& Adhesives, Vol. 4 (I984), pp. I37-I39.

[66] A.A. Taib, R. Boukhili, S. Achiou, S. Gordon and H. Boukehili, "Bonded joints with composite adherends. Part I. Effect of specimen configuration, adhesive thickness, spew fillet and adherend stiffness on fracture," International Journal of 
Adhesion \& Adhesives, Vol. 26 (2006), pp. 226-236.

[67] B.M. Parker, "Some Effects of Moisture on Adhesively-Bonded CFRP_CFRP Joints," Composite Structures, Vol. 6 (1986), pp. I23-139.

[68] B.M. Parker, "The strength of bonded carbon fibre composite joints exposed to high humidity," International Journal of Adhesion \& Adhesives, Vol. I0 (I990), Pp. I87-I9I

[69] S.G. Prolongo and A. Urena, "Durability of Aluminium Adhesive Joints Bonded with a Homopolymerised Epoxy Resin," The Journal of Adhesion, Vol .83, Pp. I-I4.

[70] J.D. Minford, "Comparative Aluminium Joint Evaluations in Varying Saltwater Exposure Conditions," The Journal of Adhesion, Vol. I8, pp. I9-24.

[7I] J.R.M. d'Almeida, "Effects of distilled water and saline solution on the interlaminar shear strength of an aramid/epoxy composite," Composites, Vol. 22, No. 6 (I99I), pp. 448-450.

[72] D.O. Adams, J.A. Kessler, B. Kuramoto, J. Bluth, C. Weaver and A. Gill, "Development and Evaluation of Fracture Mechanics Test Methods for Sandwich Composites," Proceedings of the 2009 FAA JAMS Technical Review Meeting, Wichita, KS, July 2010. Available:

http://depts.washington.edu/amtas/events/jams_I0/pap2-Adams.pdf

[73] J. Ratcliffe, "Sizing Single Cantilever Beam Specimens for Characterizing Facesheet/Core Peel Debonding in Sandwich Structure," Proceedings of the $9^{h}$ International Conference on Sandwich Structures, 2010.

[74] C. Li, P. Krimbalis, A. Duncan and T. Benak, "Climbing Drum Peel Test Procedures and Results for Evaluation of Long-Term Environmental Degradation of Composite Sandwich Structures," Laboratory Memorandum LM-SMPL-2009_ 0043, National Research Council, Canada, 2009.

[75] Cytec Engineered Materials, CYCOM 5276-I Toughened Epoxy Resin: Technical Datasheet [Online]. Available:

http://www.cytec.com/engineered-materials/products/Datasheets/CYCOM\%205 276-I.pdf.

[76] 3M Aerospace and Aircraft Maintenance Department, Scotch-Weld 
Structural Adhesive Film AF 163-2: Technical Data Sheet, November 2009.

[77] Plascore, PN2 Aerospace Grade Aramid Fiber Honeycomb [Online]. Available: http://www.plascore.com/pdf/Plascore_PN2.pdf.

[78] Standard Test Method for Moisture Absorption Properties and Equilibrium Conditioning of Polymer Matrix Composite Materials, ASTM D5229-92, 2004.

[79] Composite Materials Handbook, "Volume I. Polymer matrix composites guidelines for characterization of structural materials," MIL-HDBK-I7-IF, Section 2.2.7.3, 2002 .

[80] Standard Practice for the Preparation of Substitute Ocean Water, ASTM DI I4I-98, 2003.

[8I] Q. Yang, G. Xian, V.M. Karbhari, "Hygrothermal Ageing of an Epoxy Adhesive Used in FRP Strengthening of Concrete," Journal of Applied Polymer Science, Vol. I07, 2008, pp. 2607-2617.

[82] W.L. Bradley and T.S. Grant, "The effect of the moisture absorption on the interfacial strength of polymeric matrix composites," Journal of Materials Science, Vol. 30, 1995, pp. 5537-5542.

[83] C.D. Shirrel and J. Halpin, "Moisture Absorption and Desorption in Epoxy Composite Laminates," ASTM STP 6I7, 1977.

[84] P. Musto, L. Mascia, G. Ragosta, G. Scarinzi and P. Villano, "The transport of water in a tetrafunctional epoxy resin by near-infrared Fourier transform spectroscopy," Polymer, Vol. 4I, 2000, pp. 565-574.

[85] S. Hashemi, A.J. Kinloch, J.G. Williams, "The Analysis of Interlaminar Fracture in Uniaxial Fibre-Polymer Composites," Proceedings of the Royal Society of London. Series A, Mathematial and Physical Sciences, Vol. 427, No. 1872, 1990, pp. I73-I99.

[86] J.P. Berry, "Determination of Fracture Surface Energies by the Cleavage Technique," Journal of Applied Physics, Vol. 34, No. I, 1963, pp. 62-68.

[87] K. Kageyama and T.-W. Chou, "Analytical Compliance Method for Mode I Interlaminar Fracture Toughness Testing of Composites," Composites, Vol. I8, No. 5, 1987, pp. 393-399. 
[88] K. Kageyama, M. Hojo, "Proposed Methods for Interlaminar Fracture Toughness Tests of Composite Laminates," Proceedings of the Fifth U.S./Japan Conference on Composite Materials, Tokyo, Japan, 1990, pp. 227-234.

[89] T.G. Lane. (1999, March 29). JPEG image compression FAQ, part I/2 [Online]. Available: http://www.faqs.org/faqs/jpeg-faq/partI/

[90] R. Hilgers, "Substantiation of Damage Growth within Sandwich Structures," presented at FAA Workshop for Composite Damage Tolerance \& Maintenance, Tokyo, 2009. Available:

http://www.niar.wichita.edu/niarworkshops/Workshops/WorkshopCACRCMeetin gJune2009Tokyo/tabid/I I4/Default.aspx

[9I] R. Thévenin, "Flight Control Sandwich Structures and Inspections," presented at Composite Materials Handbook 17 meeting, July 2010.

[92] T.C. Radtke, A. Charon and R. Vodicka, "Hot/Wet Environmental Degradation of Honeycomb Sandwich Structure Representative of F/A-I8: Flatwise Tension Strength," DSTO-TR-0908, 1999. [Online]. Available: http://dspace.dsto.defence.gov.au/dspace/bitstream/1947/4365/I/DSTO-TR0908.pdf

[93] M.J. Davis and D.A. Bond, "The Importance of Failure Mode Identification in the Adhesive Bonded Aircraft Structures and Repairs," presented at International Conference on Composite Materials I2, Paris, France, 2000. 


\section{Appendix A: Summary Sheets for DCB Specimens}

This Appendix contains summary sheets for every DCB specimen tested. It provides more details such as the results of all the Gic calculation methods and all 9 initiation values, the values of the $G_{I C}$ calculation parameters $\Delta, n$ and $A$, individual load displacement $(P-\delta)$ and $G_{I C-a}$ graphs, failure mode versus crack length graph and picture and experimental details.

Chapter I Litcrature Review

Chapter 2 Manufacturing of DCB and SCB Specimens

Chapter 3 Fnvironmental Conditioning and Diffusion Data Analysis

Chapter 4 The Effects of the Environment on the Fracture Toughness of Bonded Laminates

Chapter 5 Preliminary Study of the liffects of the linvironment on the Disbond Fracture Toughness of Sandwich Structures

Chapter 6 Overview of Contribution and Recommendations for Future Work.

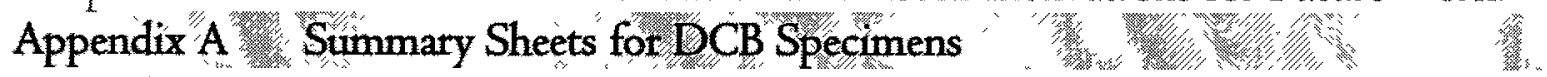
Appendix B Summary Sheets for SCB Specimens 
46SC-J009 (Helleopter Composites Degradation) - Double Cantilever Beam Testing of Bonded Composite Laminates - Test Rosults Materials: Cycom 5276-1/G40-800-24K prepreg (Lamınates), AF 163-2K (Adhesive)

Test Method: ASTM D5528

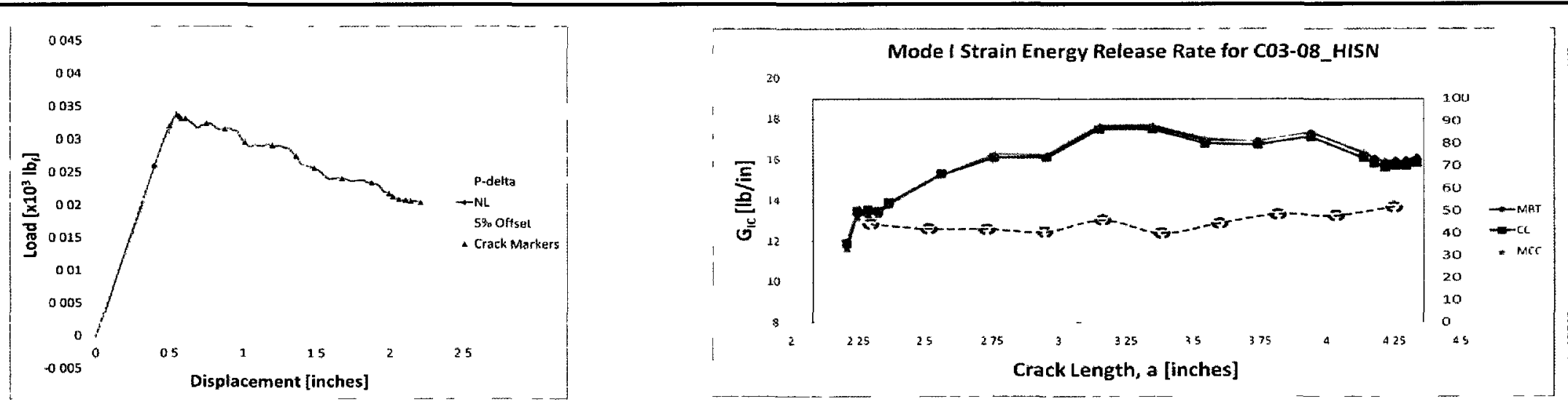

\begin{tabular}{|c|c|}
\hline Coupon ID: & C03-08 \\
\hline Test Date: & $11 / 3 / 2011$ \\
\hline Test Temperature: & ${ }^{\circ} \mathrm{C}\left({ }^{\circ} \mathrm{F}\right)$ \\
\hline \multicolumn{2}{|l|}{ Test Relative Humidity: } \\
\hline Environmental Conditioning*: & HISN \\
\hline Weight Gain - Conditioning (\%): & 108771132 \\
\hline Weight Loss - Testing (\%): & 033016016 \\
\hline
\end{tabular}

\begin{tabular}{|c|c|c|c|}
\hline \multicolumn{4}{|c|}{ Grimiation $\mathbb{G}_{1 \mathrm{G}}$} \\
\hline Method: & MBT & CC & MCC \\
\hline $\mathrm{NL}$ & 758 & 766 & 755 \\
\hline VIS & 1177 & 1190 & 1165 \\
\hline $5 \%$ Offset & 1261 & 1275 & 1243 \\
\hline \multicolumn{4}{|c|}{ Propagathom $\mathfrak{B}_{1 \mathrm{C}}$} \\
\hline Method: & MBT & $\mathrm{CC}$ & $M C C$ \\
\hline Average: & 1642 & 1633 & 1648 \\
\hline Stand. Dev.: & 118 & 110 & 120 \\
\hline
\end{tabular}

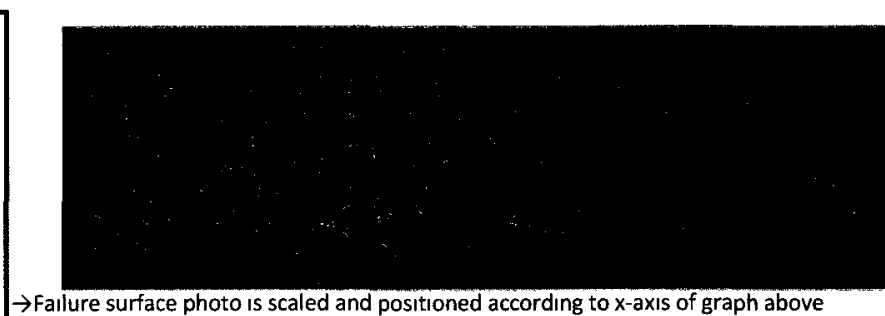

$\rightarrow$ Fallure surface photo is scaled and positioned according to $x$-axis of graph above $\rightarrow$ PInk indicates cohesive fallure and black ındicates adhesive fallure
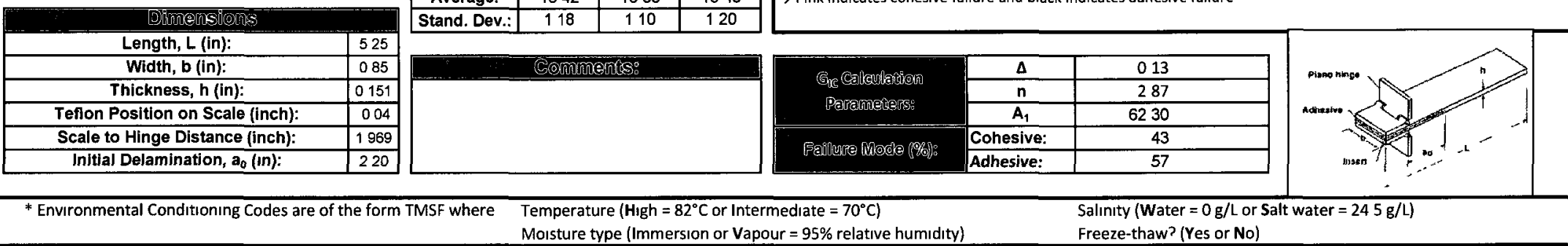

Temperature $\left(\mathbf{H}\right.$ Igh $=82^{\circ} \mathrm{C}$ or Intermediate $\left.=70^{\circ} \mathrm{C}\right)$

Moisture type (Immersion or Vapour $=95 \%$ relative humıdity)

Salınity (Water $=0 \mathrm{~g} /$ L or Salt water $=245 \mathrm{~g} / \mathrm{L})$ Freeze-thaw? (Yes or No) 


\section{CSEC-J003 (Helicopter Composites Degradation) - Double Cantlever Beam Testing of Bonded Composite Laminates - Test Results}

Materials: Cycom 5276-1/G40-800-24K prepreg (Laminates); AF 163-2K (Adhesive)

Test Method: ASTM D5528
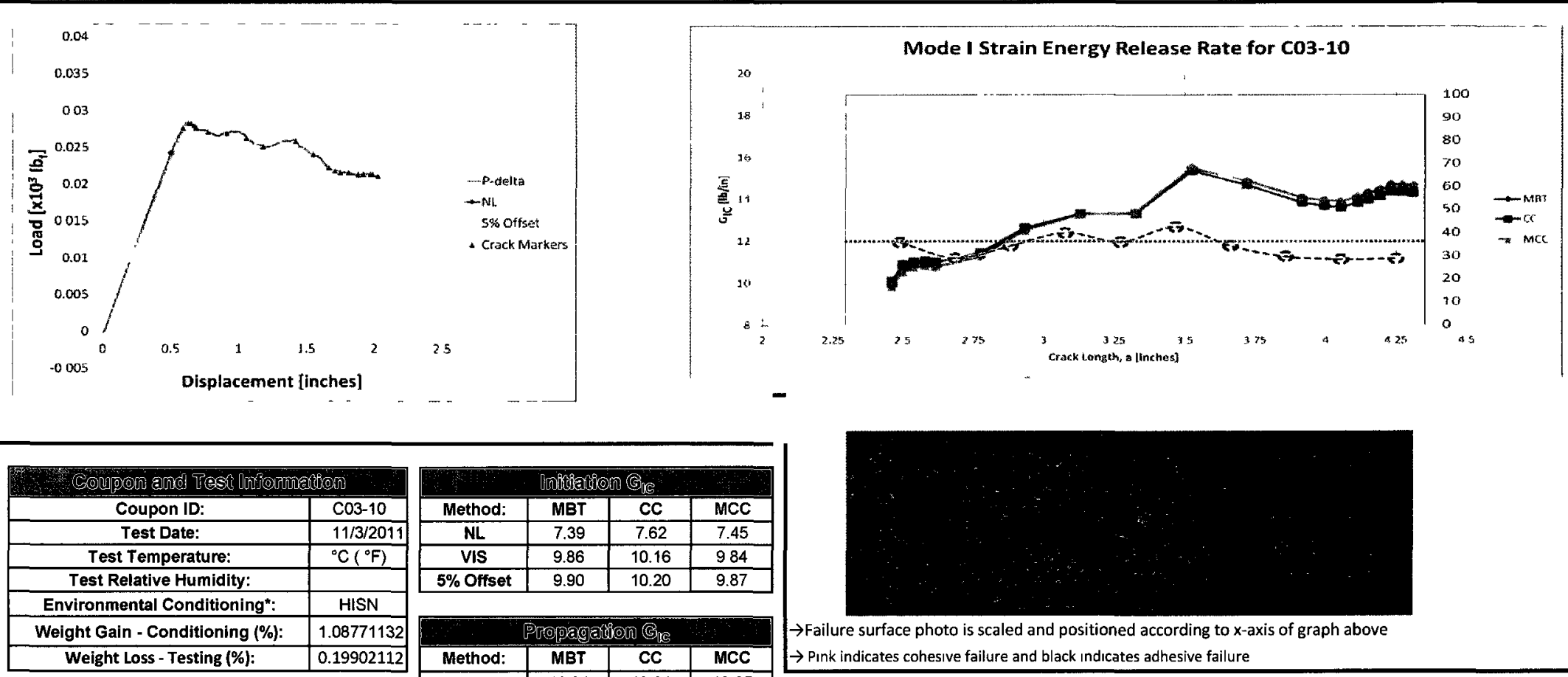

\begin{tabular}{|c|c|c|c|}
\hline \multicolumn{4}{|c|}{ 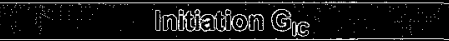 } \\
\hline Method: & $\overline{M B T}$ & $\mathrm{CC}$ & $\mathrm{MCC}$ \\
\hline $\mathrm{NL}$ & 7.39 & 7.62 & 7.45 \\
\hline VIS & 9.86 & 10.16 & 984 \\
\hline $5 \%$ Offset & 9.90 & 10.20 & 9.87 \\
\hline \multicolumn{4}{|c|}{ Propagation $\mathfrak{G}_{\mathbb{R}}$} \\
\hline Method: & MBT & CC & MCC \\
\hline Average: & 13.24 & 13.24 & 13.25 \\
\hline Stand. Dev. & 1.64 & 1.48 & 1.63 \\
\hline
\end{tabular}

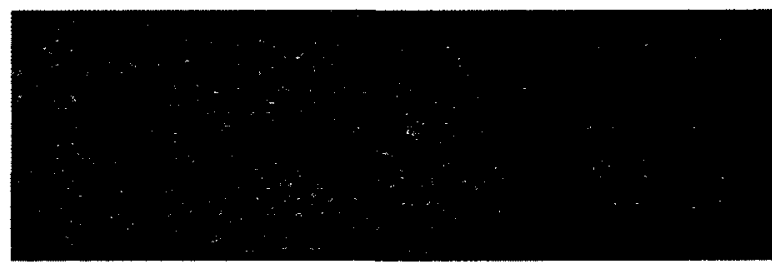

$\rightarrow$ Failure surface photo is scaled and positioned according to $x$-axis of graph above

$\rightarrow$ Pınk indicates cohesıve failure and black Indicates adhesive failure

\begin{tabular}{|c|c|}
\hline Dimensions \\
\hline Length, $\mathbf{L}$ (in): & 525 \\
\hline Width, $\mathbf{b}$ (in): & 0852 \\
\hline Thickness, $\boldsymbol{h}$ (in): & 0151 \\
\hline Tefion Position on Scale (inch): & 0354 \\
\hline Scale to Hinge Distance (inch): & 1949 \\
\hline Initial Delamination, $\mathbf{a}_{\mathbf{0}}$ (in): & 246 \\
\hline
\end{tabular}
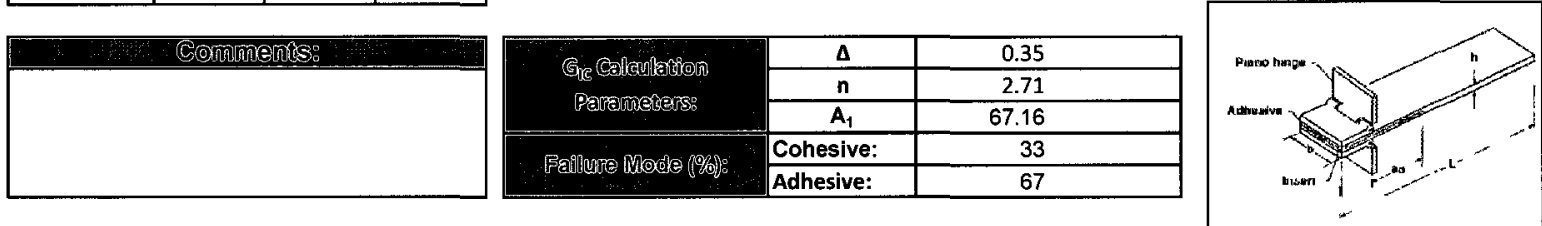

* Environmental Conditioning Codes are of the form TMSF where: Temperature (High $=82^{\circ} \mathrm{C}$ or Intermediate $=70^{\circ} \mathrm{C}$ ) Moisture type (Immersion or Vapour $=95 \%$ relative humidity) 
46SC-J009 (Helicopter Composites Degradation) - Double Cantilever Beam Testing of Bonded Composite Laminates - Test Results

Materials: Cycom 5276-1/G40-800-24K prepreg (Lamınates), AF 163-2K (Adhesive)

Test Method: ASTM D5528
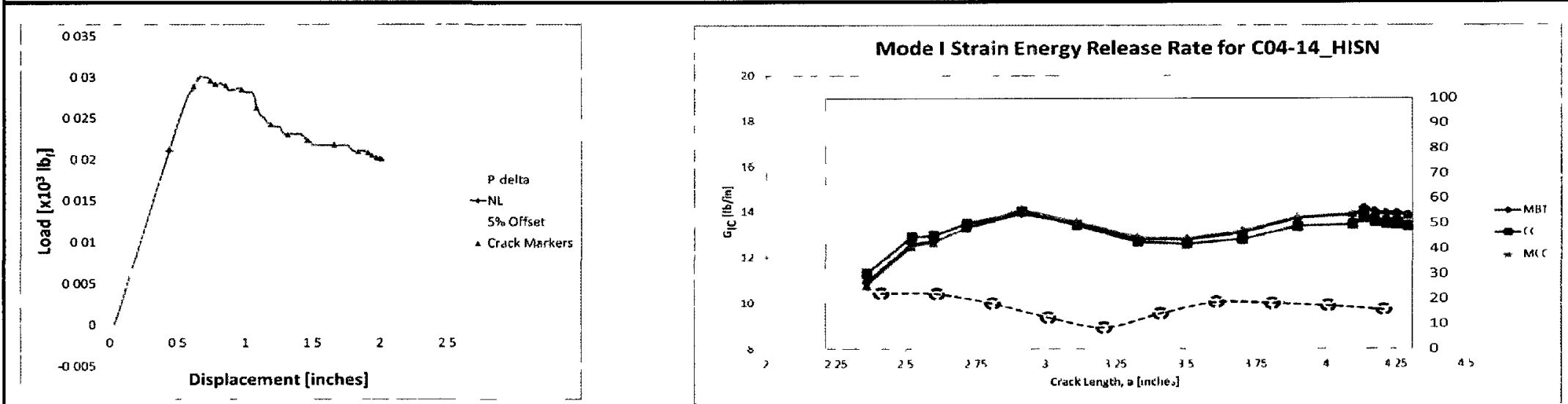

\begin{tabular}{|c|c|}
\hline Coupon amd vest linfeirnhation \\
\hline Coupon ID: & C04-14 \\
\hline Test Date: & $11 / 3 / 2011$ \\
\hline Test Temperature: & ${ }^{\circ} \mathrm{C}\left({ }^{\circ} \mathrm{F}\right)$ \\
\hline Test Relative Humidity: & \\
\hline Environmental Conditioning*: & HISN \\
\hline Weight Gain - Conditioning (\%): & 108771132 \\
\hline Weight Loss - Testing (\%): & N/A \\
\hline
\end{tabular}

\begin{tabular}{|c|c|}
\hline Length, $\mathbf{L}$ (in): & 525 \\
\hline Width, $\boldsymbol{b}$ (in): & 0848 \\
\hline Thickness, $\mathbf{h}$ (in): & 0151 \\
\hline Teflon Position on Scale (inch): & 0276 \\
\hline Scale to Hinge Distance (inch): & 1929 \\
\hline Initial Delamination, $\boldsymbol{a}_{\mathbf{0}}$ (in): & 236 \\
\hline
\end{tabular}

\begin{tabular}{|c|c|c|c|}
\hline \multicolumn{4}{|c|}{ linithation (G) } \\
\hline Method: & MBT & $\mathrm{CC}$ & MCC \\
\hline NL & 569 & 589 & 569 \\
\hline VIS & 1091 & 1130 & 1078 \\
\hline $5 \%$ Offset & 1087 & 1126 & 1075 \\
\hline & (Qpages & II $G_{0 \in}$ & \\
\hline Method: & MBT & $\mathrm{CC}$ & MCC \\
\hline Average: & 1329 & 1319 & 1337 \\
\hline & 048 & 047 & 051 \\
\hline
\end{tabular}

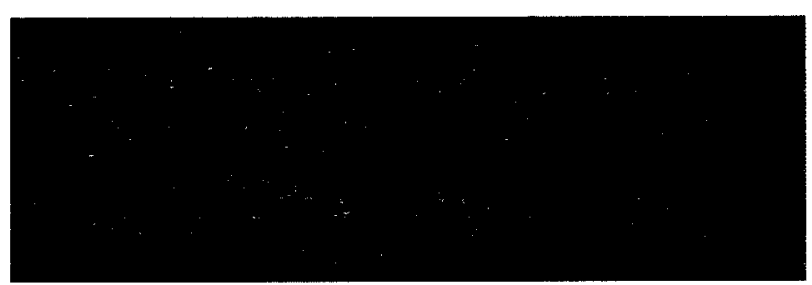

Fallure surface photo is scaled and positioned according to $x$-axis of graph above $\rightarrow$ Pink indicates cohesive fallure and black indıcates adhesive fallure
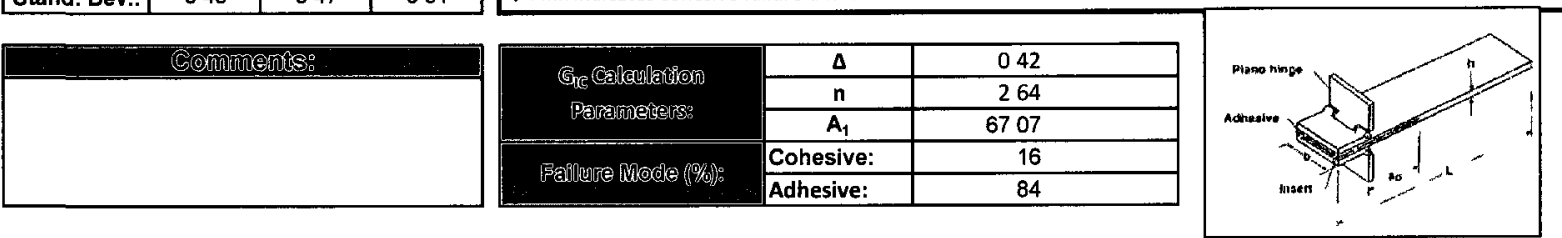

*Environmental Conditioning Codes are of the form TMSF where Temperature $\left(\mathrm{High}=82^{\circ} \mathrm{C}\right.$ or Intermediate $\left.=70^{\circ} \mathrm{C}\right)$ Moisture type (Immersion or Vapour $=95 \%$ relative humıdity) 


\section{SC-J009 (Helicopter Composites Degradation) - Double Cantilever Beam Testing of Bonded Composite Laminates - Test Results}

Materials: Cycom 5276-1/G40-800-24K prepreg (Laminates); AF 163-2K (Adhesive)

Test Method: ASTM D5528
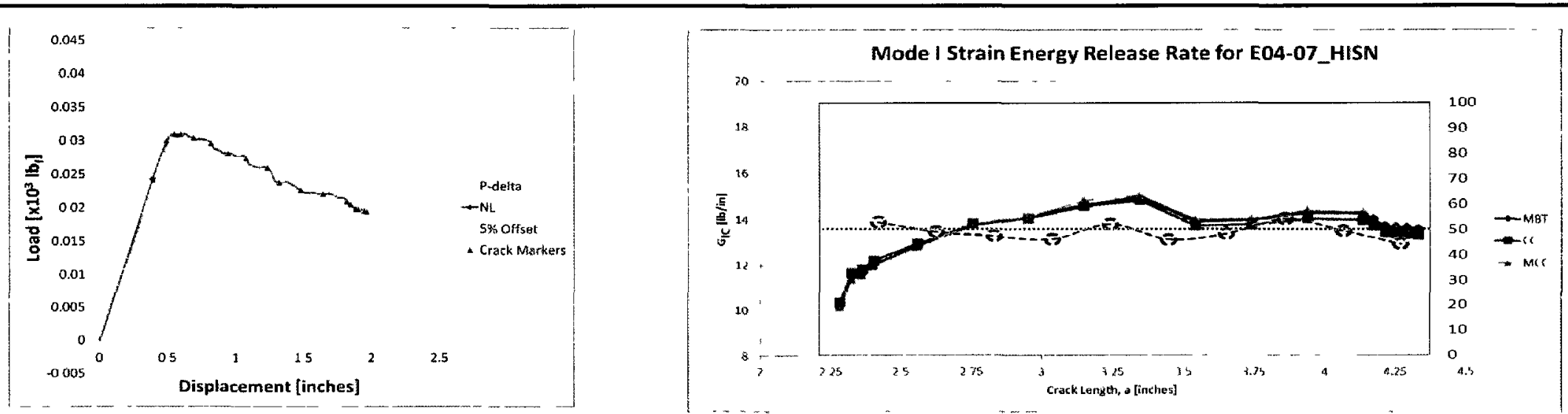

\begin{tabular}{|c|c|}
\hline Coupon and Test Information \\
\hline Coupon ID: & E04-07 \\
\hline Test Date: & $11 / 3 / 2011$ \\
\hline Test Temperature: & ${ }^{\circ} \mathrm{C}\left({ }^{\circ} \mathrm{F}\right)$ \\
\hline Test Relative Humidity: & \\
\hline Environmental Conditioning*: & HISN \\
\hline Weight Gain - Conditioning (\%): & 1.08771132 \\
\hline Weight Loss - Testing (\%): & 0.2085931 \\
\hline
\end{tabular}

\begin{tabular}{|c|c|}
\hline Delmensions \\
\hline Length, $\mathbf{L}$ (in): & 525 \\
\hline Width, $\mathbf{b}$ (in): & 0851 \\
\hline Thickness, $\boldsymbol{h}$ (in): & 0151 \\
\hline Teflon Position on Scale (inch): & 0197 \\
\hline Scale to Hinge Distance (inch): & 1969 \\
\hline Initial Delamination, $\mathbf{a}_{\mathbf{0}}$ (in): & $\mathbf{2 2 8}$ \\
\hline
\end{tabular}
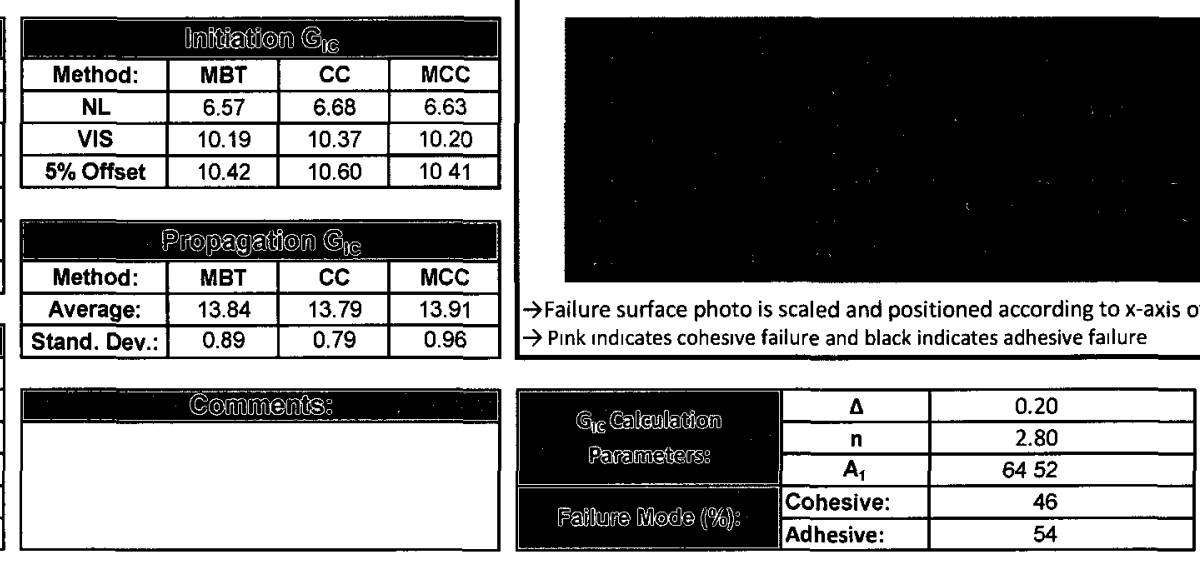

* Environmental Conditioning Codes are of the form TMSF where: Temperature (High $=82^{\circ} \mathrm{C}$ or Intermediate $=70^{\circ} \mathrm{C}$ ) 
465C-J009 (Hellcopter Composites Degradation) - Double Cantilever Beam Testing of Bonded Composits Laminates - Test Results Materials: Cycom 5276-1/G40-800-24K prepreg (Laminates); AF 163-2K (Adhesive)

Test Method: ASTM D5528
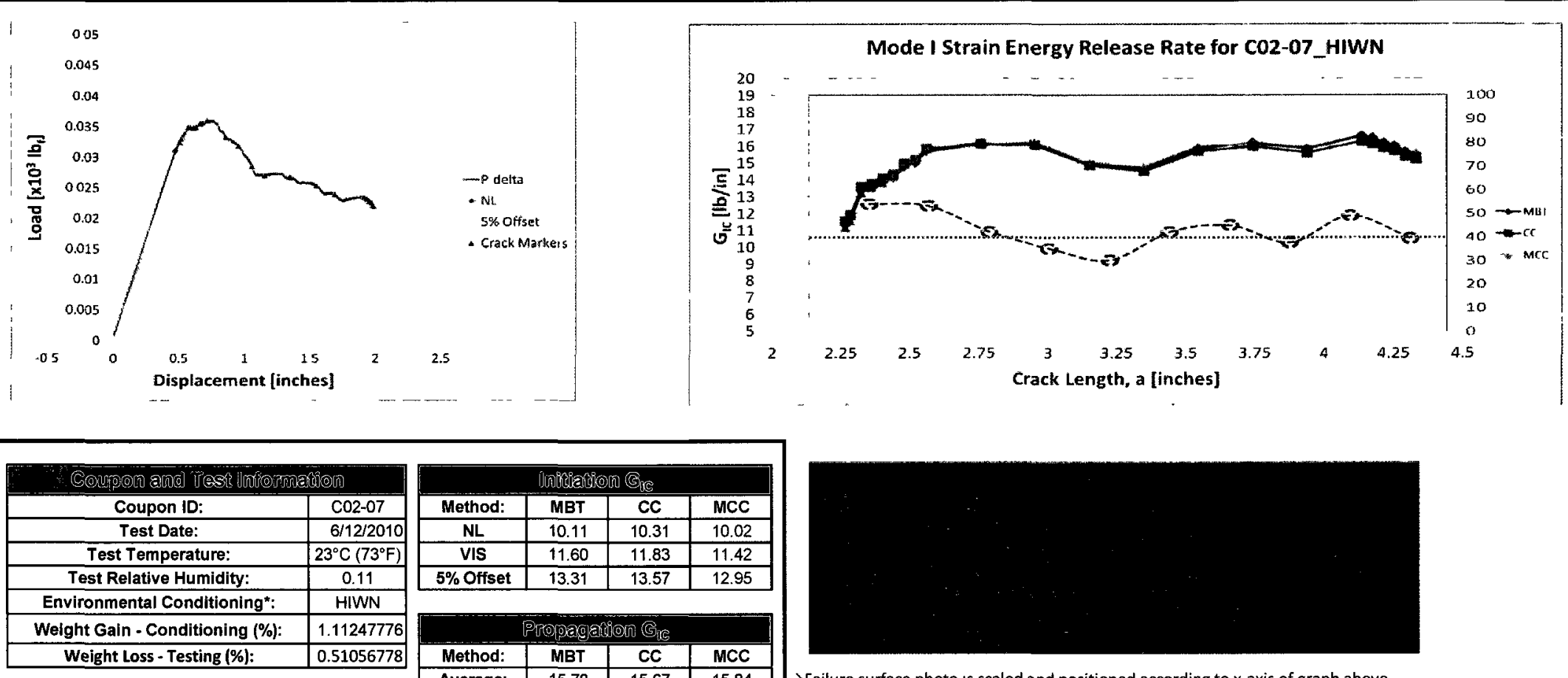

\begin{tabular}{|c|c|c|c|}
\hline \multicolumn{4}{|c|}{ 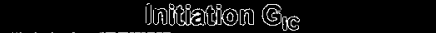 } \\
\hline Method: & MBT & CC & MCC \\
\hline $\mathrm{NL}$ & 10.11 & 10.31 & 10.02 \\
\hline VIS & 11.60 & 11.83 & 11.42 \\
\hline $5 \%$ Offset & 13.31 & 13.57 & 12.95 \\
\hline \multicolumn{4}{|c|}{ Propagation $\mathbb{G}_{1 \mathrm{~S}}$} \\
\hline Method: & MBT & CC & MCC \\
\hline Average: & 15.78 & 15.67 & 15.84 \\
\hline & 0.63 & 0.60 & 0.59 \\
\hline
\end{tabular}

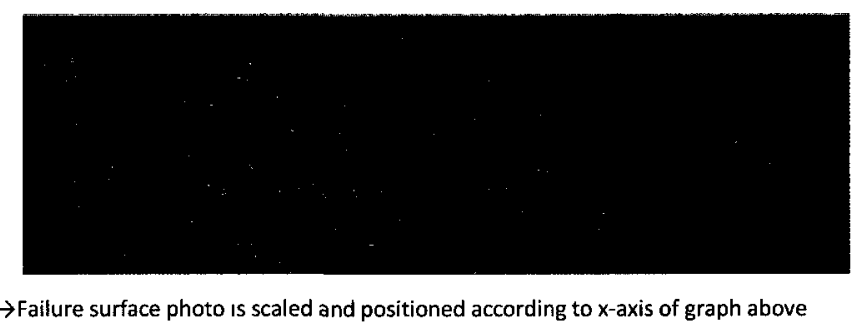

\begin{tabular}{|c|c|}
\hline D) & \\
\hline Length, $L$ (in): & 525 \\
\hline Width, b (in): & 0852 \\
\hline Thickness, $h$ (in): & 0157 \\
\hline Tefion Position on Scale (inch): & -02 \\
\hline Scale to Hinge Distance (lnch): & 2362 \\
\hline Initial Delamination, $a_{0}$ (in): & 226 \\
\hline
\end{tabular}
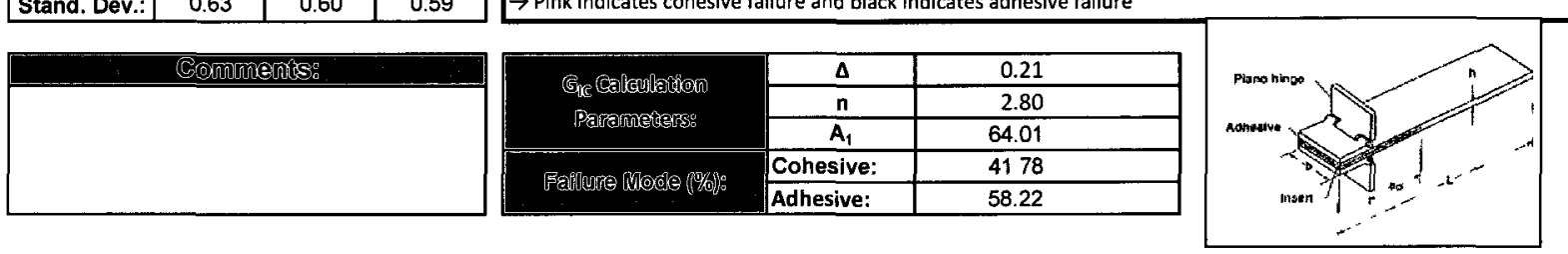

"Environmental Conditioning Codes are of the form TMSF where: Temperature (High $=82^{\circ} \mathrm{C}$ or Intermediate $=70^{\circ} \mathrm{C}$ ) Moisture type (Immersion or Vapour $=95 \%$ relative humidity) 
46SC-J009 (Hellcopter Composites Degradation) - Double Cantilever Beam Testing of Bonded Composite Laminates - Test Results Materials: Cycom 5276-1/G40-800-24K prepreg (Lamınates); AF 163-2K (Adhesive)

Test Method: ASTM D5528
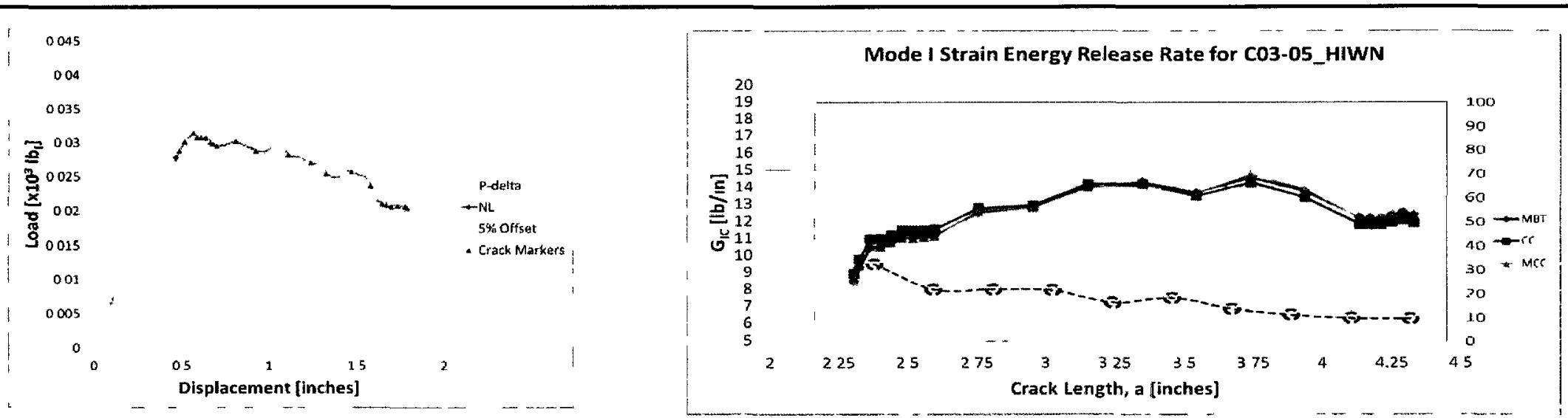

\begin{tabular}{|c|c|}
\hline Coupon ID: & C03-05 \\
\hline Test Date: & $1 / 12 / 2010$ \\
\hline Test Temperature: & $24^{\circ} \mathrm{C}\left(75^{\circ} \mathrm{F}\right)$ \\
\hline Test Relative Humidity: & 035 \\
\hline Environmental Conditioning*: & HIWN \\
\hline Weight Gain - Conditioning (\%): & 10516655 \\
\hline Weight Loss - Testing (\%): & 020597966 \\
\hline
\end{tabular}
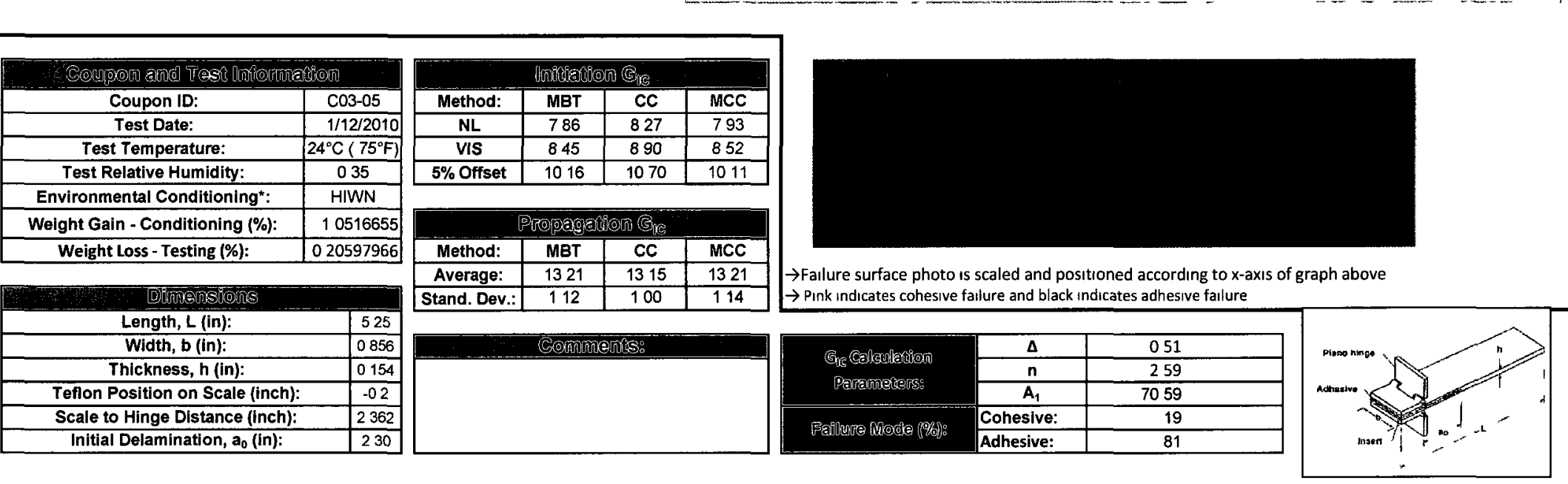

${ }^{*}$ Environmental Conditioning Codes are of the form TMSF where Temperature ( $\mathrm{High}=82^{\circ} \mathrm{C}$ or Intermediate $=70^{\circ} \mathrm{C}$ )

Salinity $($ Water $=0 \mathrm{~g} / \mathrm{L}$ or Salt water $=245 \mathrm{~g} / \mathrm{L})$ 
46SC-J009 (Helicopter Composites Degradation) - Double Cantilever Beam Teating of Bonded Composite Laminates - Test Results Materials: Cycom 5276-1/G40-800-24K prepreg (Laminates); AF 163-2K (Adhesive)

Test Method: ASTM D5528
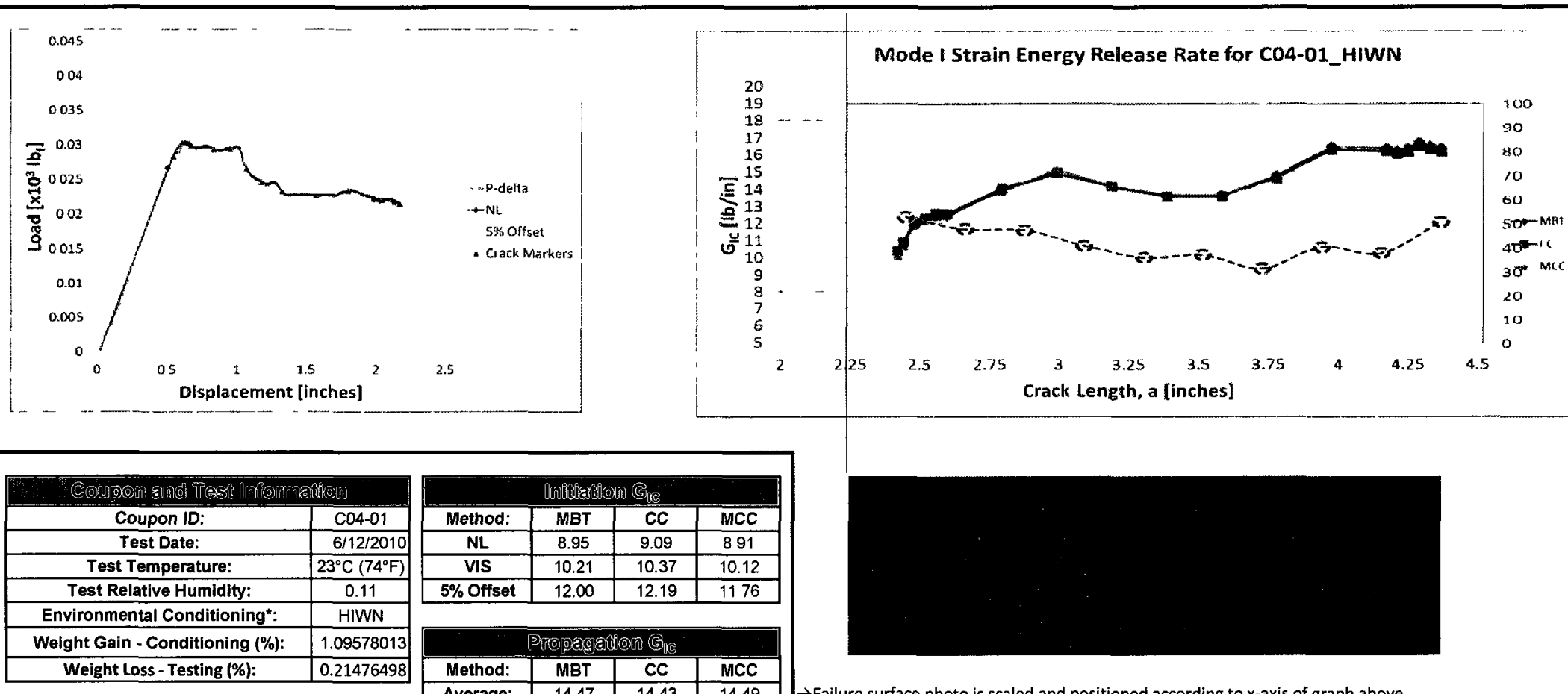

\begin{tabular}{|c|c|c|c|}
\hline \multicolumn{4}{|c|}{ Dinitharbon $\mathbb{G}_{\mathrm{S}}$} \\
\hline Method: & MBT & $\mathrm{CC}$ & MCC \\
\hline $\mathrm{NL}$ & 8.95 & 9.09 & 891 \\
\hline VIS & 10.21 & 10.37 & 10.12 \\
\hline $5 \%$ Offset & 12.00 & 12.19 & 1176 \\
\hline \multicolumn{4}{|c|}{ Propagakon (Ge } \\
\hline Method: & MBT & CC & $\mathrm{MCC}$ \\
\hline Average: & 14.47 & 14.43 & 14.49 \\
\hline Stand. Dev. & 1.33 & 1.23 & 1.32 \\
\hline
\end{tabular}
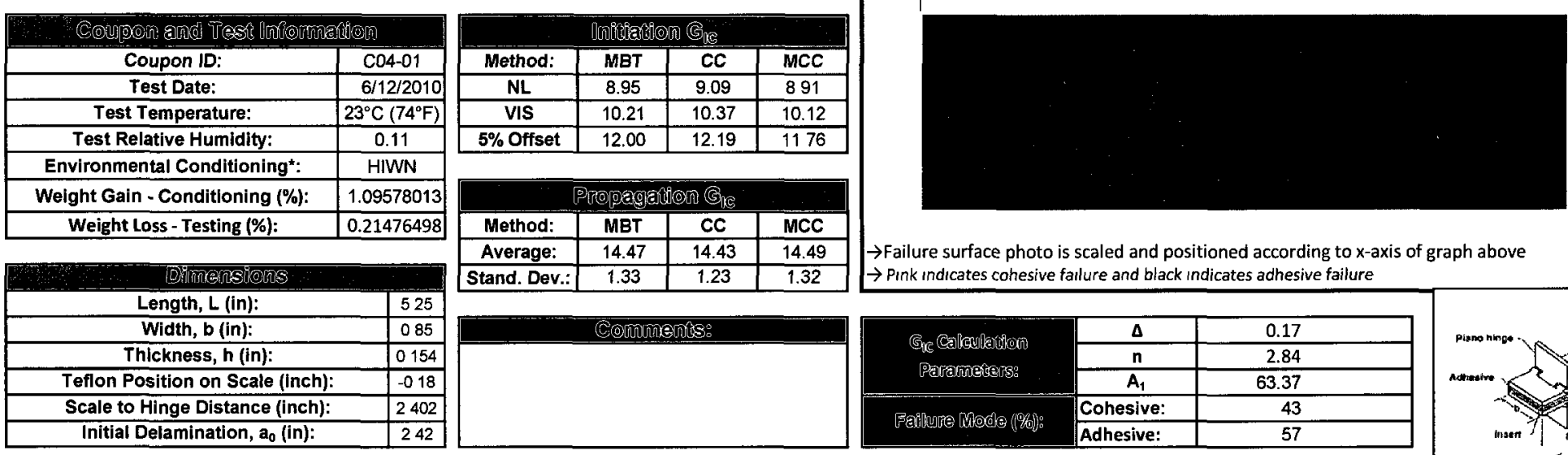

Falure surface photo is scaled and positioned according to $x$-axis of graph above $\rightarrow$ Pink indicates cohesive falure and black indicates adhesive failure
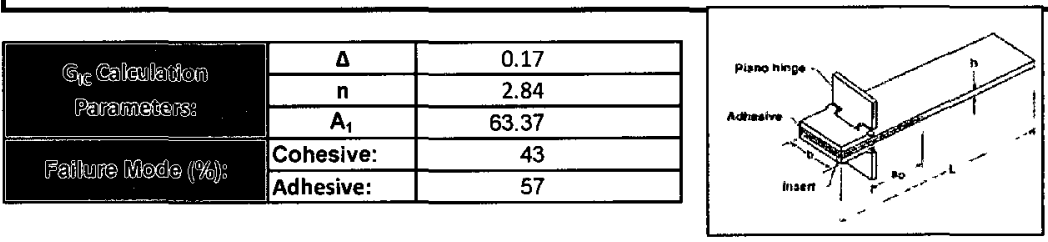

* Environmental Conditioning Codes are of the form TMSF where: Temperature (High $=82^{\circ} \mathrm{C}$ or Intermediate $=70^{\circ} \mathrm{C}$ ) Moisture type (Immersion or Vapour $=95 \%$ relative humidity) 
46SC-J009 (Hellcopter Composites Degradation) - Double Cantiever Beam Testing of Bonded Composite Laminates - Test Results Materials: Cycom 5276-1/G40-800-24K prepreg (Laminates); AF 163-2K (Adhesive)

Test Method: ASTM D5528
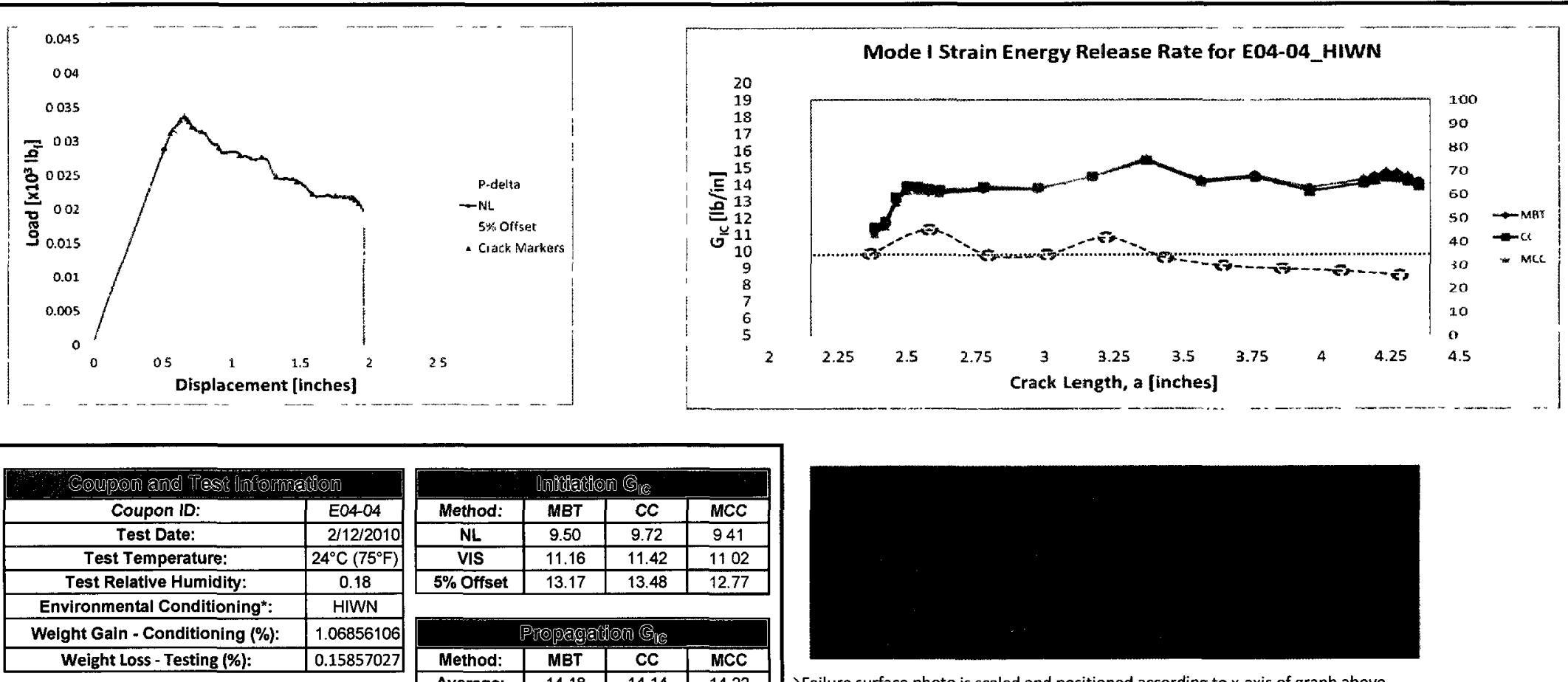

\begin{tabular}{|c|c|c|c|}
\hline \multicolumn{4}{|c|}{ 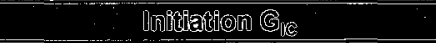 } \\
\hline Method: & MBT & $C C$ & MCC \\
\hline $\mathrm{NL}$ & 9.50 & 9.72 & 941 \\
\hline VIS & 11.16 & 11.42 & 1102 \\
\hline $5 \%$ Offset & 13.17 & 13.48 & 12.77 \\
\hline \multicolumn{4}{|c|}{ Propagathon G G } \\
\hline Method: & MBT & $\mathrm{Cc}$ & MCC \\
\hline Average: & 1418 & 14.14 & 14.22 \\
\hline & 0.62 & 0.57 & 0.62 \\
\hline
\end{tabular}
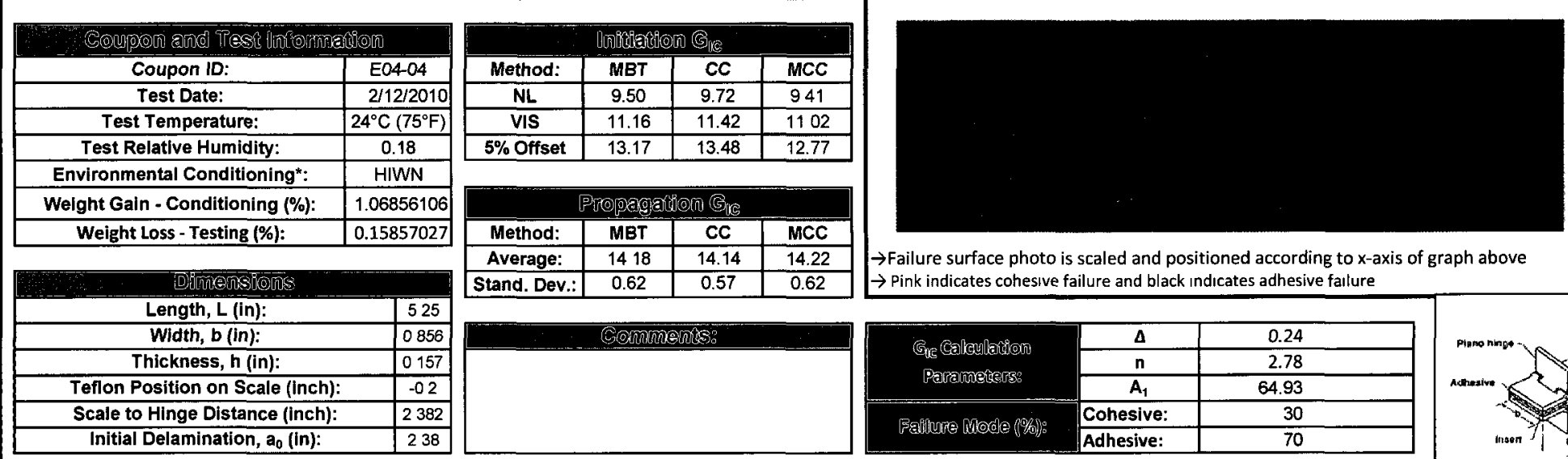

$\rightarrow$ Failure surface photo is scaled and positioned according to $x$-axis of graph above $\rightarrow$ Pink indicates cohesive failure and black Indicates adhesive falture
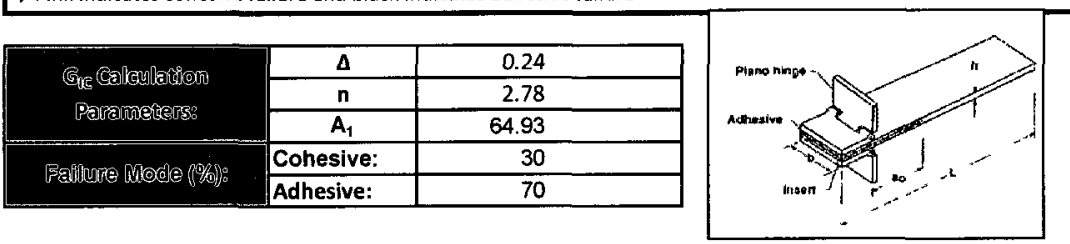

${ }^{*}$ Environmental Conditioning Codes are of the form TMSF where: Temperature (High $=82^{\circ} \mathrm{C}$ or Intermediate $=70^{\circ} \mathrm{C}$ ) Moisture type (Immersion or Vapour $=95 \%$ relative humidity) 
46SC-J008 (Helicopter Composites Degradation) - Double Cantlever Beam Testing of Bonded Composite Laminates - Test Results Materials: Cycom 5276-1/G40-800-24K prepreg (Lamınates), AF 163-2K (Adhesive)

Test Method: ASTM D5528
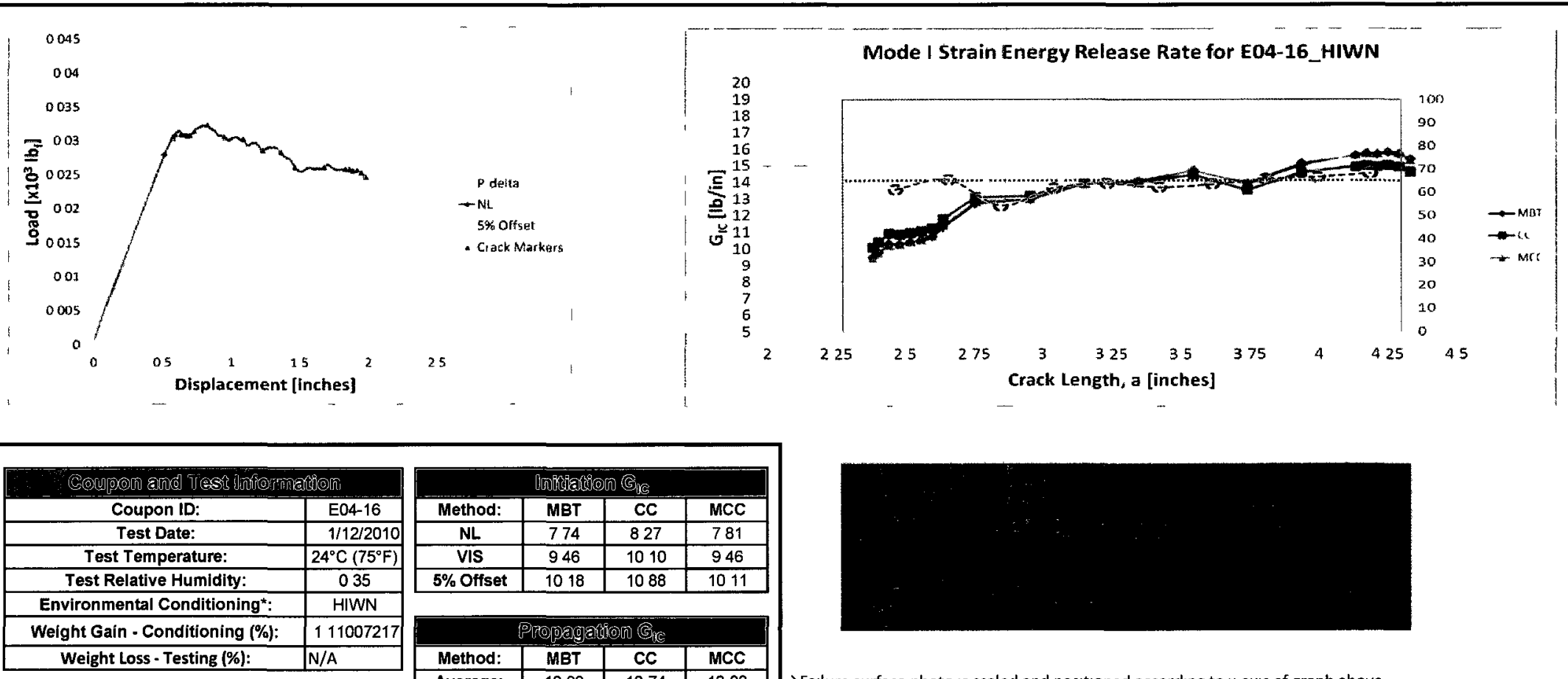

\begin{tabular}{|c|c|c|c|}
\hline \multicolumn{4}{|c|}{ linhtration $\mathbf{G}_{\mathrm{G}}$} \\
\hline Method: & MBT & CC & MCC \\
\hline $\mathrm{NL}$ & 774 & 827 & 781 \\
\hline VIS & 946 & 1010 & 946 \\
\hline $5 \%$ Offset & 1018 & 1088 & 1011 \\
\hline & opag & [i] (G) & \\
\hline Method: & MBT & CC & MCC \\
\hline Average: & 1383 & 1374 & 1383 \\
\hline Stand. Dev. & 133 & 095 & 128 \\
\hline
\end{tabular}
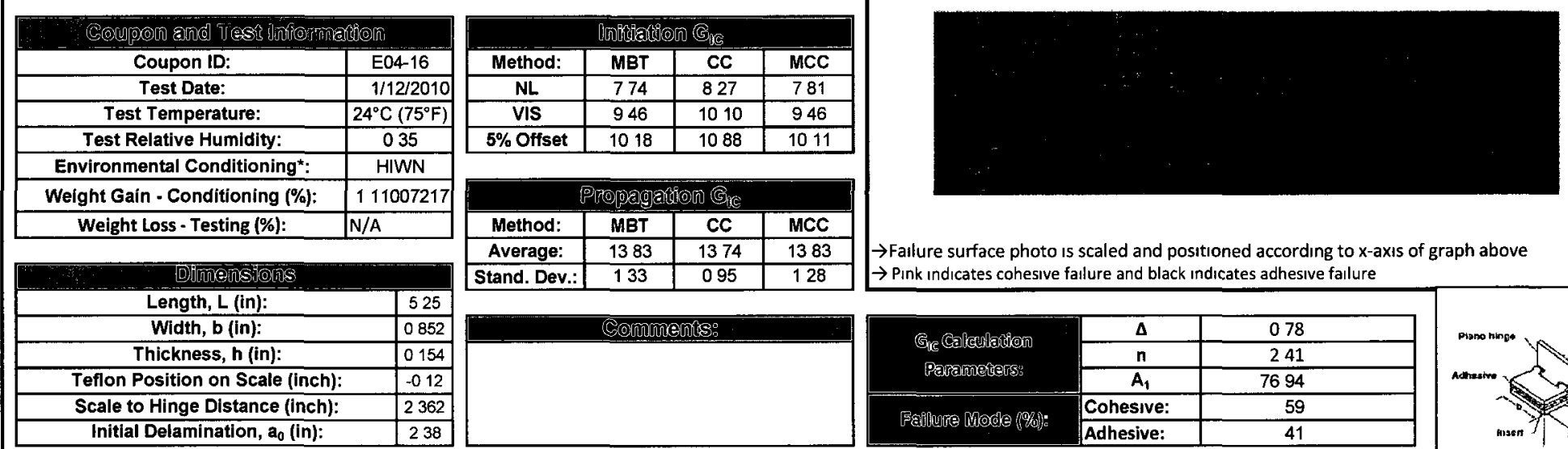

Pallo $\rightarrow$ Pink indicates cohesive falure and black indicates adhesive fallure
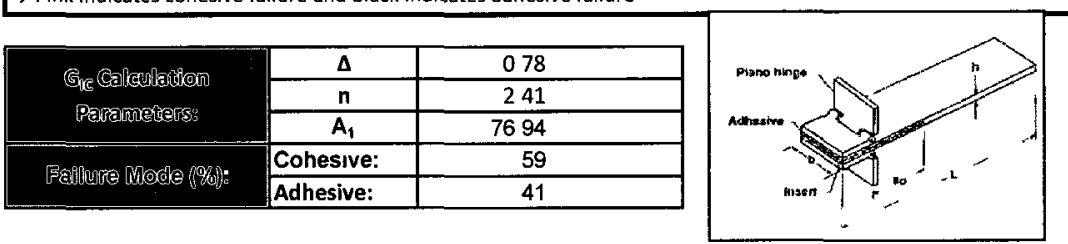

${ }^{*}$ Environmental Conditioning Codes are of the form TMSF where Temperature (HIgh $=82^{\circ} \mathrm{C}$ or Intermediate $\left.=70^{\circ} \mathrm{C}\right)$ Moisture type (Immersion or Vapour $=95 \%$ relative humidity) 


\section{SC-j009 (Helicopter Composites Degradation) - Double Cantilever Beam Testing of Bonded Composite Laminates - Test Resuits}

Materials: Cycom 5276-1/G40-800-24K prepreg (Laminates); AF 163-2K (Adhesive)

Test Method: ASTM D5528
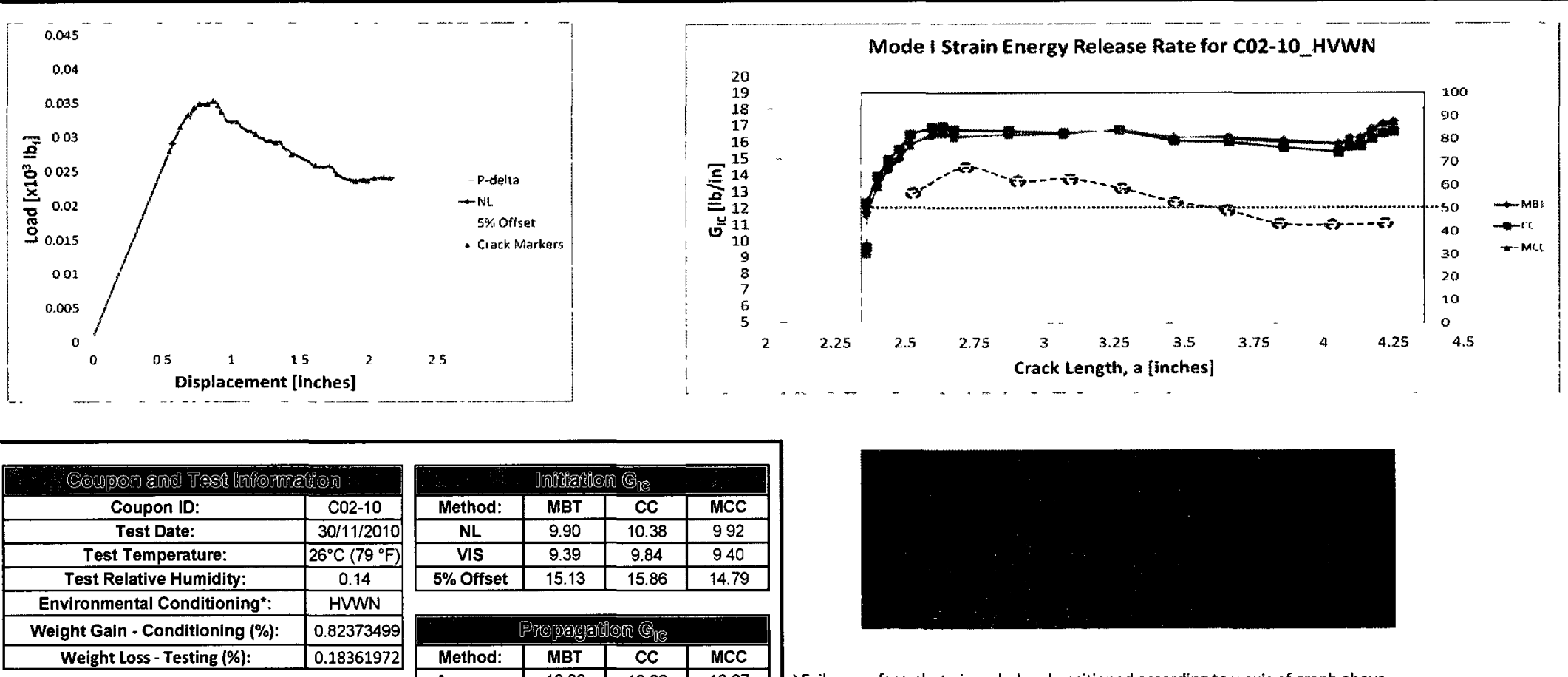

\begin{tabular}{|c|c|c|c|}
\hline \multicolumn{4}{|c|}{ Initrathom জ্E } \\
\hline Method: & MBT & CC & MCC \\
\hline $\mathrm{NL}$ & 9.90 & 10.38 & 992 \\
\hline VIS & 9.39 & 9.84 & 940 \\
\hline $5 \%$ Offset & 15.13 & 15.86 & 74.79 \\
\hline & opage & In] $\mathbb{G}_{\mathbb{E}}$ & \\
\hline Method: & MBT & CC & $M C C$ \\
\hline Average: & 16.30 & 16.22 & 1627 \\
\hline & 0.27 & 0.52 & 030 \\
\hline
\end{tabular}
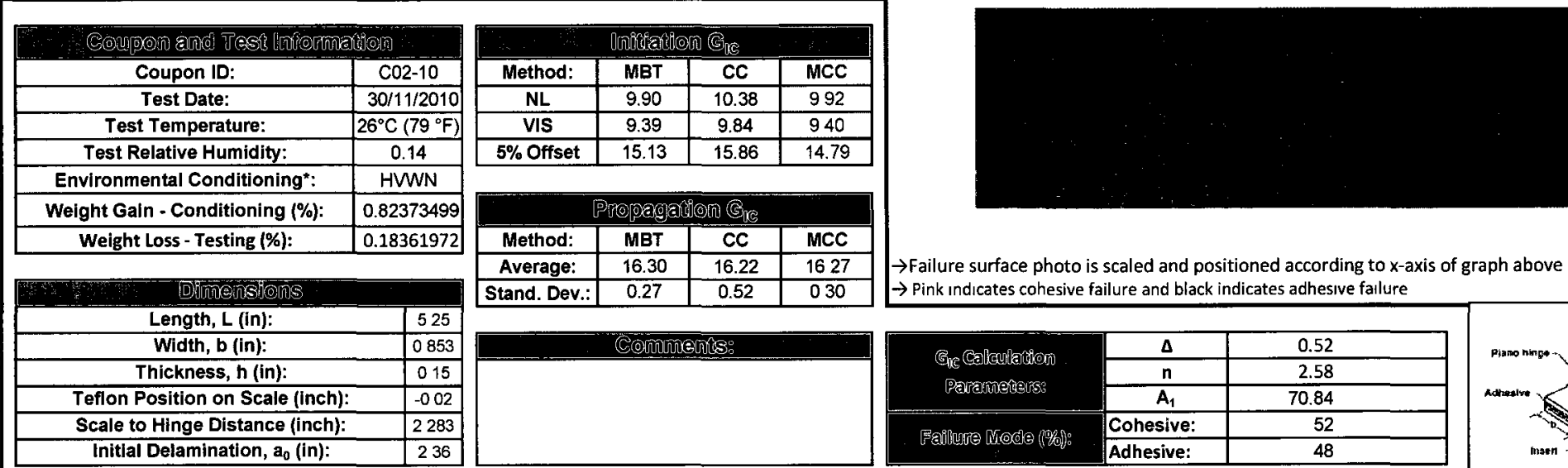
$\rightarrow$ Pink Indicates cohesive failure and black indicates adhesive fallure

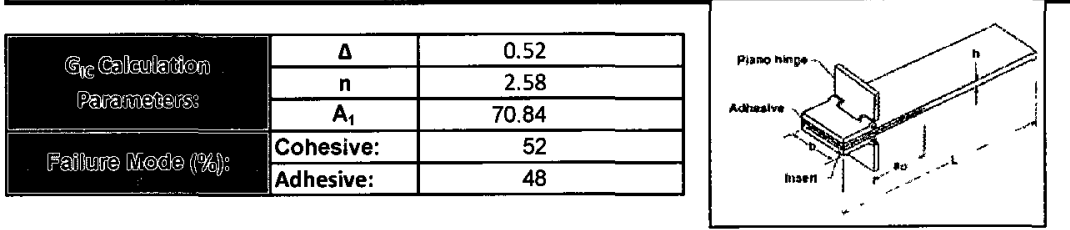

* Environmental Conditioning Codes are of the form TMSF where: Temperature (High $=82^{\circ} \mathrm{C}$ or Intermediate $\left.=70^{\circ} \mathrm{C}\right)$ Moisture type (Immersion or Vapour $=95 \%$ relative humidity 
46SC-J009 (Helleopter Composites Degradation) - Double Cantilever Beam Testing of Bonded Composite Laminates - Test Results Materials: Cycom 5276-1/G40-800-24K prepreg (Laminates); AF 163-2K (Adhesive)

Test Method: ASTM D5528
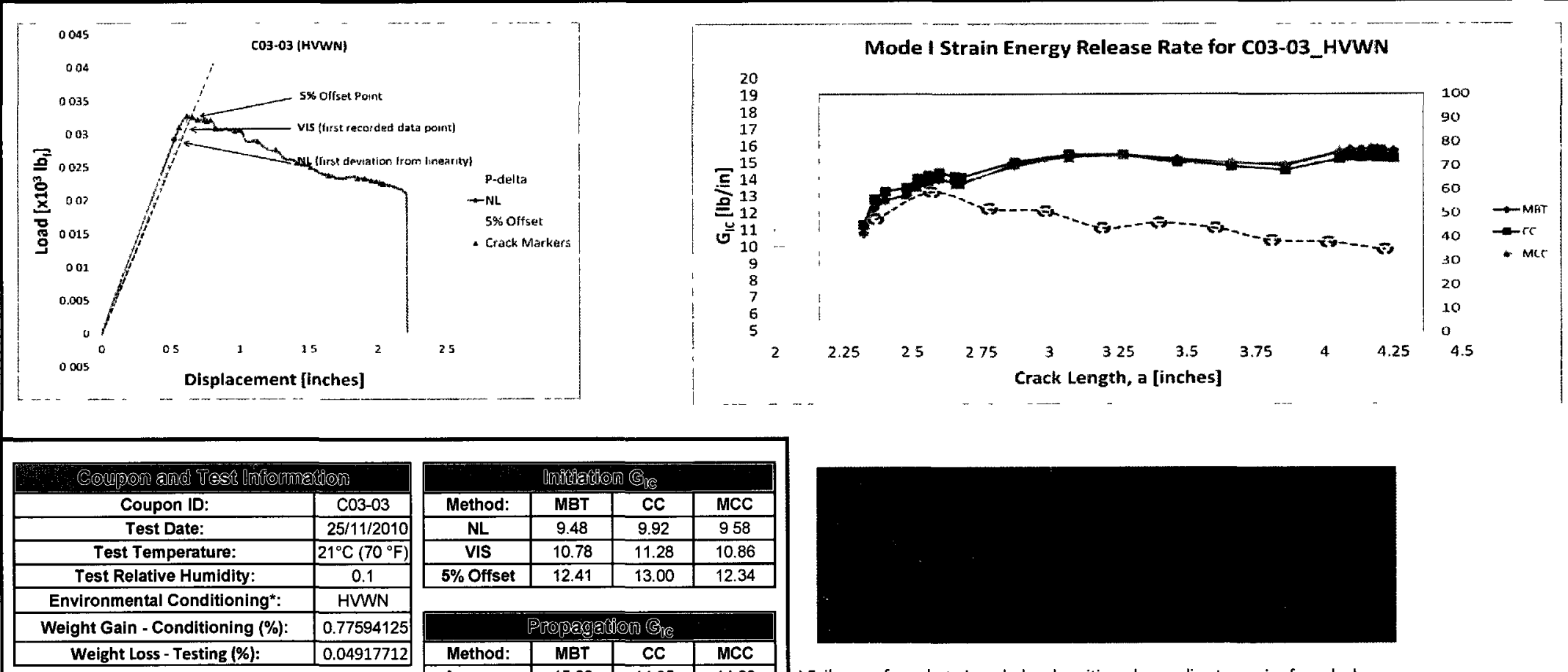

\begin{tabular}{|c|c|c|c|}
\hline \multicolumn{4}{|c|}{ Dinotitiantion (F) } \\
\hline Method: & MBT & $\mathrm{CC}$ & MCC \\
\hline $\mathrm{NL}$ & 9.48 & 9.92 & 958 \\
\hline VIS & 10.78 & 11.28 & 10.86 \\
\hline $5 \%$ Offset & 12.41 & 13.00 & 12.34 \\
\hline & $y=$ & (i) & \\
\hline Method: & MBT & CC & $\mathrm{MCC}$ \\
\hline Average: & 15.00 & 14.95 & 14.99 \\
\hline & & 0.47 & 0.59 \\
\hline
\end{tabular}
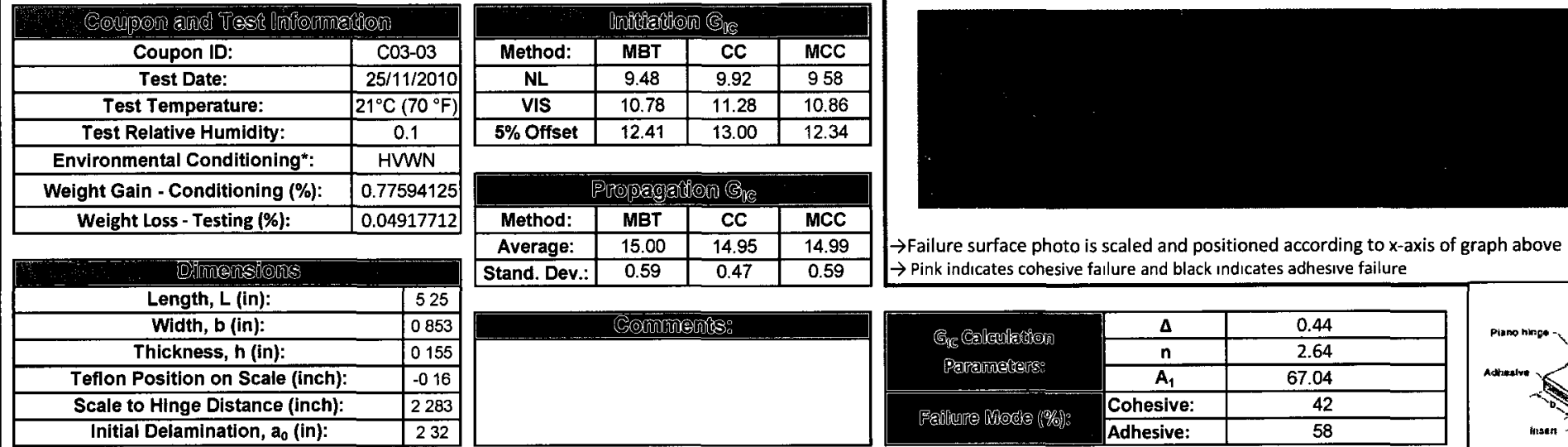

$\rightarrow$ Failure surface photo is scaled and positioned according to $x$-axis
$\rightarrow$ Pink indicates cohesive falure and black indicates adhesive failure
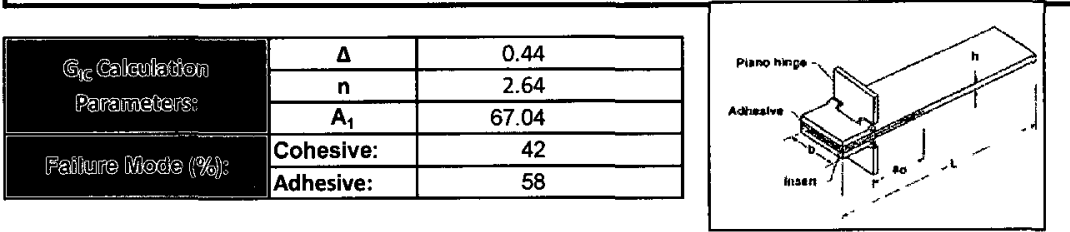

* Environmental Conditioning Codes are of the form TMSF where: Temperature (High $=82^{\circ} \mathrm{C}$ or Intermediate $=70^{\circ} \mathrm{C}$ ) Moisture type (Immersion or Vapour $=95 \%$ relative humidity) 
46SC-J009 (Hollicapter Composites Degradation) - Double Cantilever Beam Testing of Bonded Composite Laminates - Test Results Materials: Cycom 5276-1/G40-800-24K prepreg (Lamınates), AF 163-2K (Adhesive)

Test Method: ASTM D5528
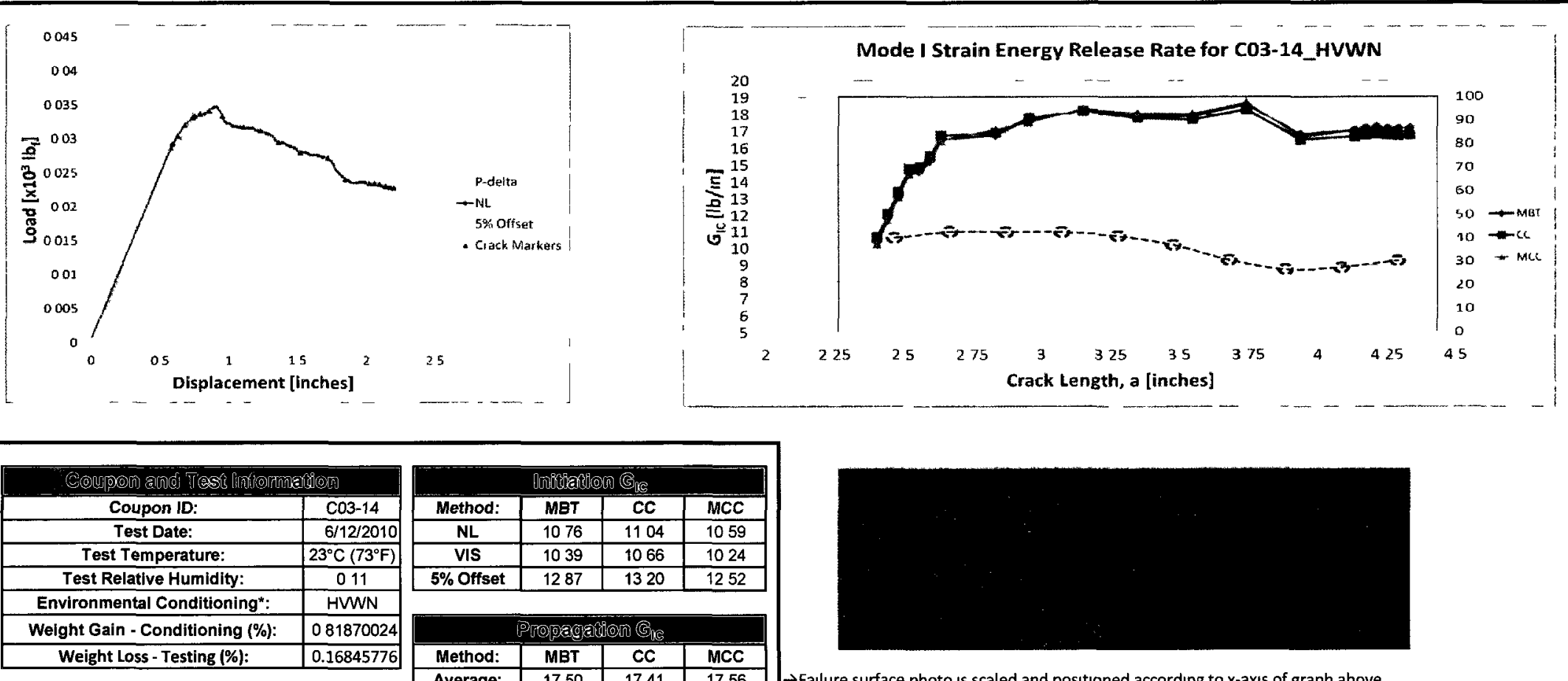

\begin{tabular}{|c|c|c|c|}
\hline \multicolumn{4}{|c|}{ Arithantlon $\mathfrak{G}_{\mid}$} \\
\hline Method: & MET & CC & MCC \\
\hline $\mathrm{NL}$ & 1076 & 1104 & 1059 \\
\hline VIS & 1039 & 1066 & 1024 \\
\hline $5 \%$ Offset & 1287 & 1320 & 1252 \\
\hline \multicolumn{4}{|c|}{ Propagarlon (se } \\
\hline Method: & MBT & CC & MCC \\
\hline Average: & 1750 & 1741 & 1756 \\
\hline Stand. Dev. & 074 & 070 & 079 \\
\hline
\end{tabular}
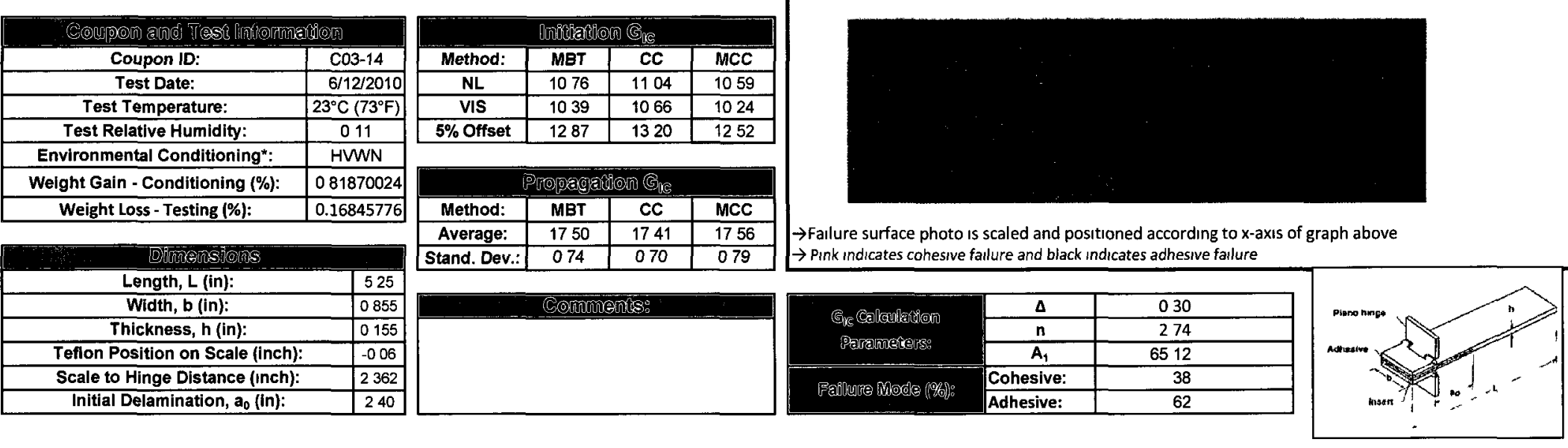

*Environmental Conditioning Codes are of the form TMSF where Temperature (High $=82^{\circ} \mathrm{C}$ or Intermediate $=70^{\circ} \mathrm{C}$ ) Moisture type (Immersion or Vapour $=95 \%$ relative humıdity) 


\section{SC-J009 (Hellcopter Composites Degradation) - Double Cantilever Beam Testing of Bonded Composite Laminates - Test Results}

Materials: Cycom 5276-1/G40-800-24K prepreg (Laminates); AF 163-2K (Adhesive)

Test Method: ASTM D5528
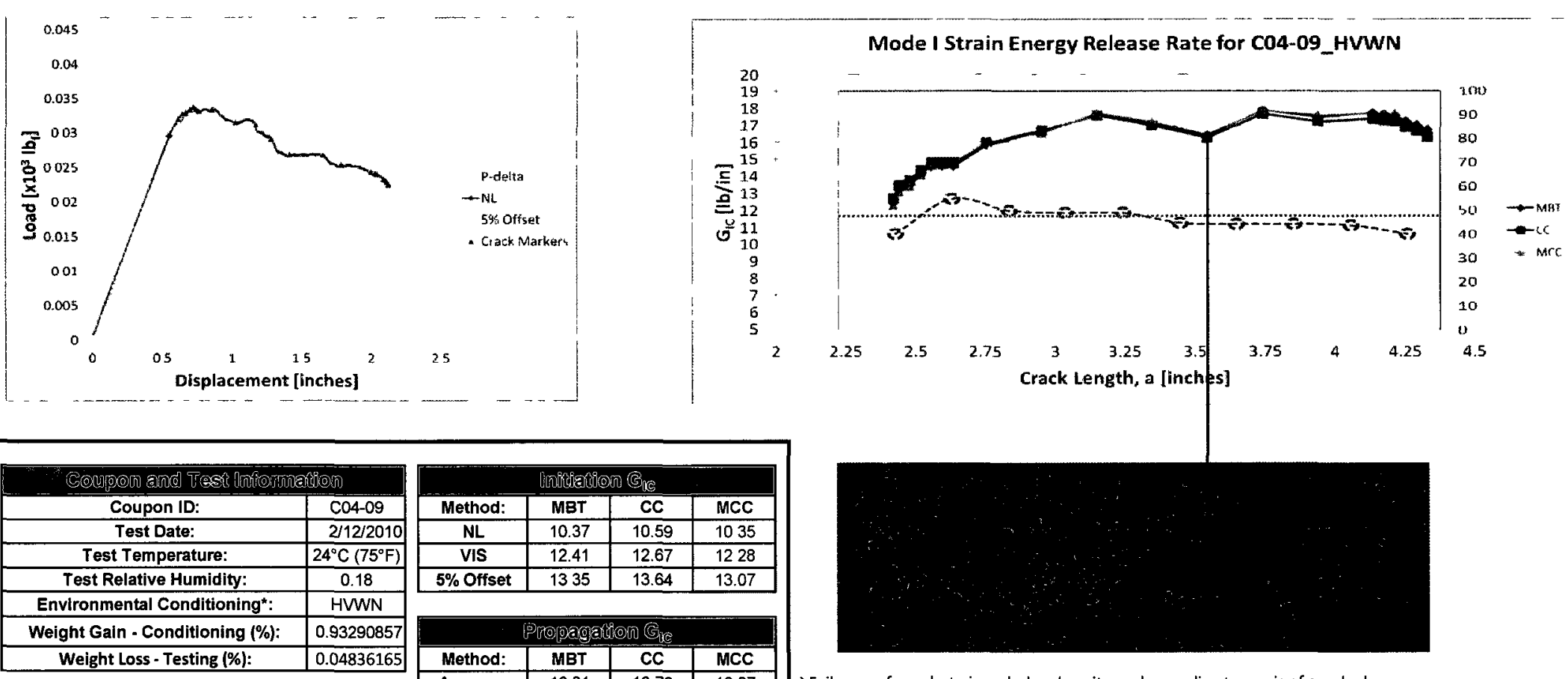

\begin{tabular}{|c|c|c|c|}
\hline \multicolumn{4}{|c|}{ 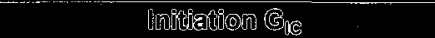 } \\
\hline Method: & MBT & CC & MCC \\
\hline $\mathrm{NL}$ & 10.37 & 10.59 & 1035 \\
\hline VIS & 12.41 & 12.67 & 1228 \\
\hline $5 \%$ Offset & 1335 & 13.64 & 13.07 \\
\hline & ay & & \\
\hline Method: & MBT & CC & MCC \\
\hline Average: & 16.81 & 16.72 & 16.87 \\
\hline & 1.08 & 0.93 & 1.05 \\
\hline
\end{tabular}
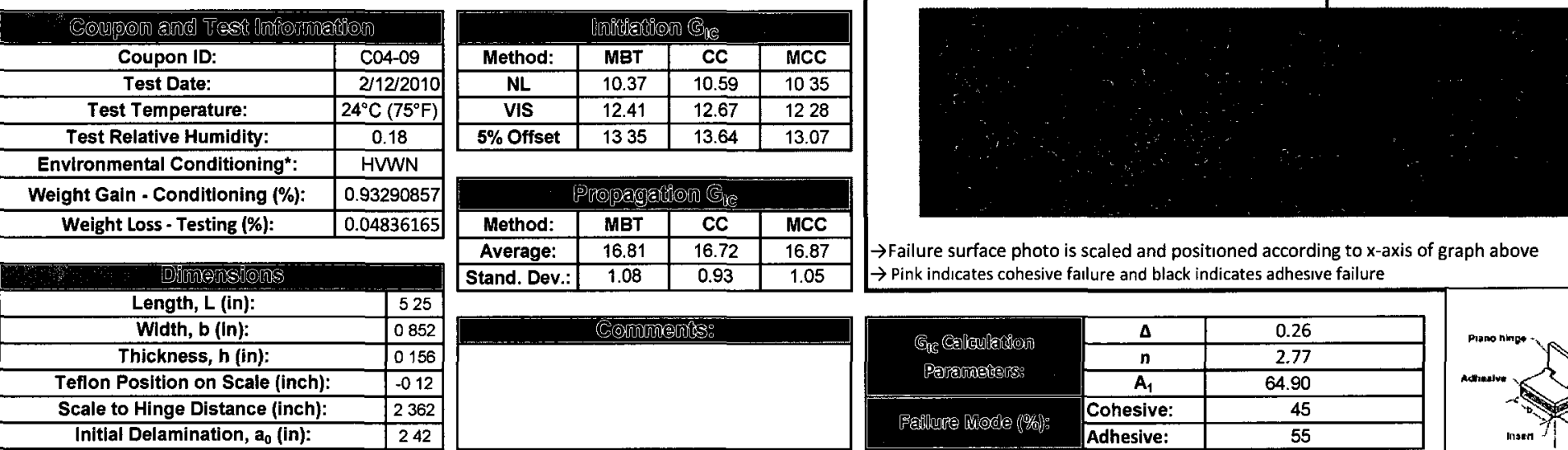

$\rightarrow$ Failure surface photo is scaled and positioned according to $x$-axis
$\rightarrow$ Pink indicates cohesive fallure and black indicates adhesive failure

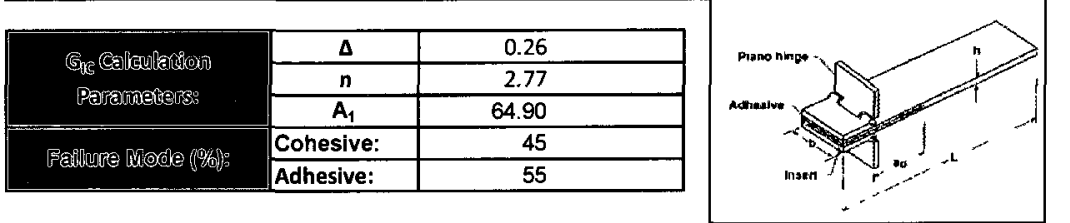

*Environmental Conditioning Codes are of the form TMSF where: Temperature (High $=82^{\circ} \mathrm{C}$ or Intermediate $=70^{\circ} \mathrm{C}$ ) Moisture type (Immersion or Vapour $=95 \%$ relative humidity 
48SC-J009 (Hellcopter Composites Degradation) - Double Cantilever Beam Testing of Bonded Composite Laminates - Test Results Materials: Cycom 5276-1/G40-800-24K prepreg (Laminates); AF 163-2K (Adhesive)

Test Method: ASTM D5528
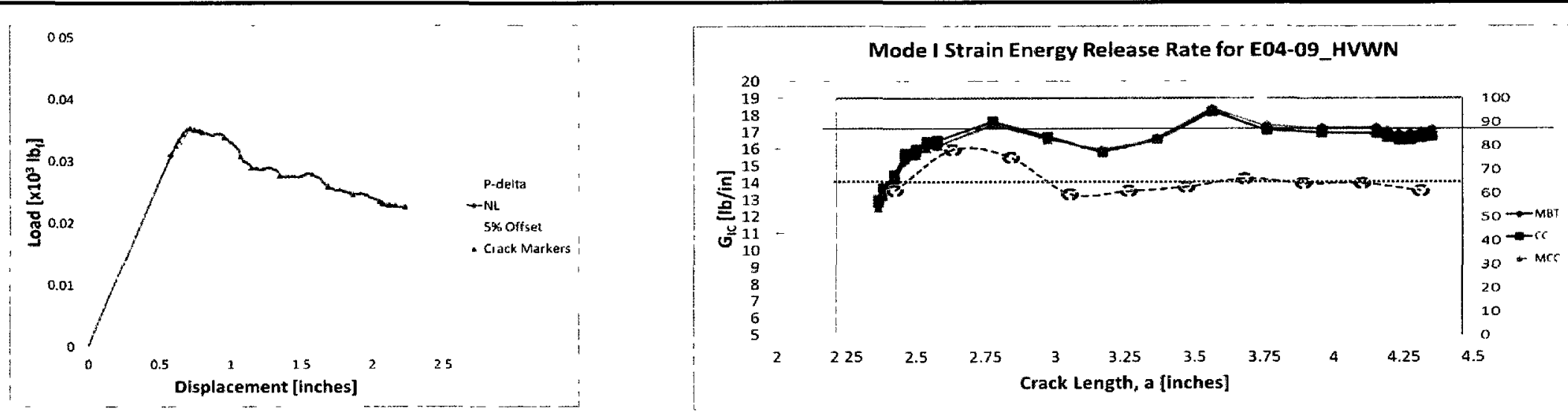

\begin{tabular}{|c|c|}
\hline$\frac{\text { Geupon aldid t/E }}{\text { Coupon ID: }}$ & E04-09 \\
\hline Test Date: & $6 / 12 / 2010$ \\
\hline Test Temperature: & $23^{\circ} \mathrm{C}\left(73^{\circ} \mathrm{F}\right)$ \\
\hline Test Relative Humidity: & 0.11 \\
\hline Environmental Conditioning*: & HWWN \\
\hline Weight Gain - Conditioning (\%): & 0.85761273 \\
\hline Weight Loss - Testing (\%): & 0.10676285 \\
\hline
\end{tabular}

\begin{tabular}{|c|c|c|c|}
\hline \multicolumn{4}{|c|}{ Irotilation $\mathrm{G}_{x \in}$} \\
\hline Method: & MBT & $\mathrm{CC}$ & MCC \\
\hline $\mathrm{NL}$ & 11.34 & 11.68 & 1129 \\
\hline VIS & 1262 & 13.00 & 12.52 \\
\hline $5 \%$ Offset & 15.20 & 15.66 & 14.88 \\
\hline \multicolumn{4}{|c|}{ Proparatidon $\mathbb{G}_{T}$} \\
\hline Method: & MBT & $\mathrm{Cc}$ & MCC \\
\hline Average: & 17.03 & 1695 & 17.03 \\
\hline & 0.74 & 0.66 & 0.71 \\
\hline
\end{tabular}

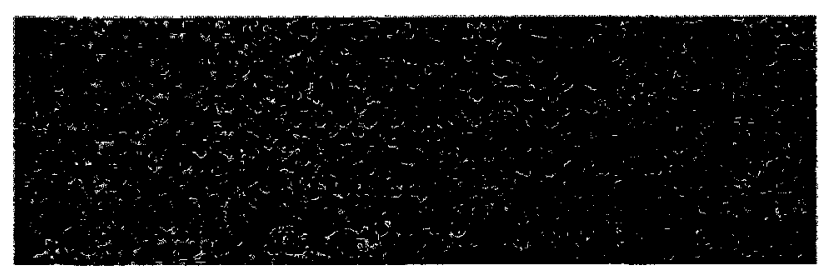

\begin{tabular}{|c|c|}
\hline \multicolumn{2}{|c|}{ Dilnonsions } \\
\hline Length, $\mathbf{L}$ (in): & 5.25 \\
\hline Width, $\mathbf{b}$ (in): & 0853 \\
\hline Thickness, $\boldsymbol{h}$ (in): & 0154 \\
\hline Teflon Position on Scale (inch): & -02 \\
\hline Scale to Hinge Distance (inch): & 2382 \\
\hline Initial Delamination, $\mathbf{a}_{0}$ (in): & 236 \\
\hline
\end{tabular}

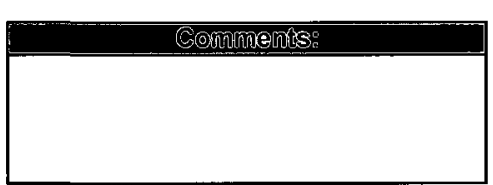

$\rightarrow$ Failure surface photo is scaled and positioned according to $x$-axis of graph above $\rightarrow$ Pink indicates cohesive failure and black indicates adhesive failure
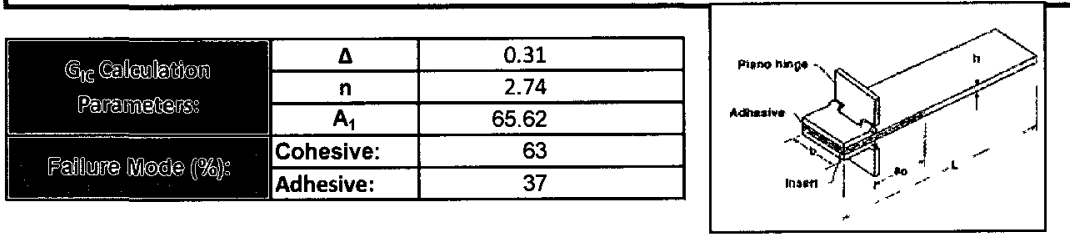

*Environmental Conditioning Codes are of the form TMSF where: Temperature (High $=82^{\circ} \mathrm{C}$ or Intermediate $\left.=70^{\circ} \mathrm{C}\right)$ Moisture type (Immersion or Vapour $=95 \%$ relative humidity) 
468C-J009 (Helicopter Composites Degradation) - Double Cantilever Beam Testing of Bonded Composite Laminates - Test Results Materials: Cycom 5276-1/G40-800-24K prepreg (Laminates); AF 163-2K (Adhesive)

Test Method: ASTM D5528
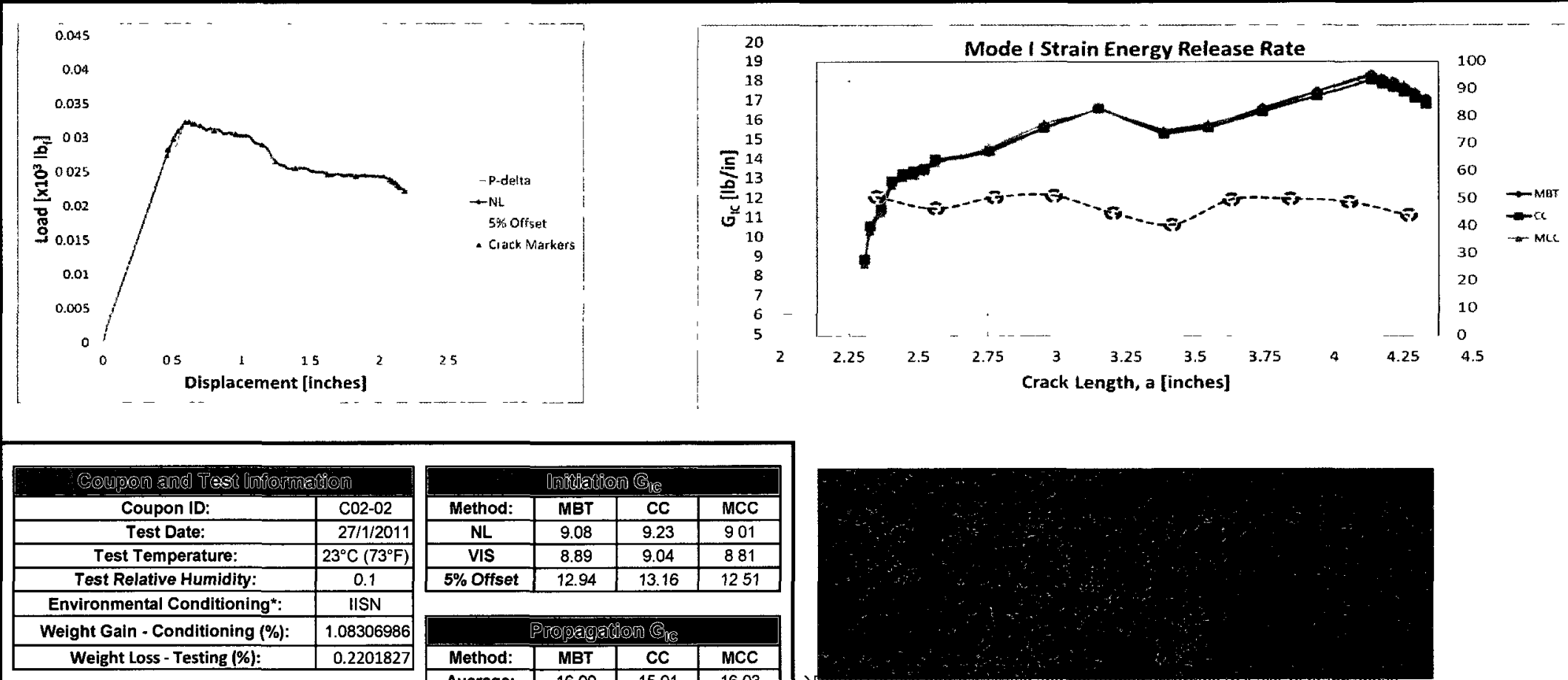

\begin{tabular}{|c|c|c|c|}
\hline \multicolumn{4}{|c|}{ Dmitiation $\mathrm{G}_{\mathrm{NS}}$} \\
\hline Method: & MBT & $\mathrm{CC}$ & MCC \\
\hline $\mathrm{NL}$ & 9.08 & 9.23 & 901 \\
\hline VIS & 8.89 & 9.04 & 881 \\
\hline $5 \%$ Offset & 12.94 & 13.16 & 1251 \\
\hline \multicolumn{4}{|c|}{ Propgaglation (GST } \\
\hline Method: & MBT & CC & $\mathrm{MCC}$ \\
\hline Average: & 16.00 & 15.91 & 16.03 \\
\hline Stand. Dev.: & 1.43 & 1.31 & 1.37 \\
\hline
\end{tabular}
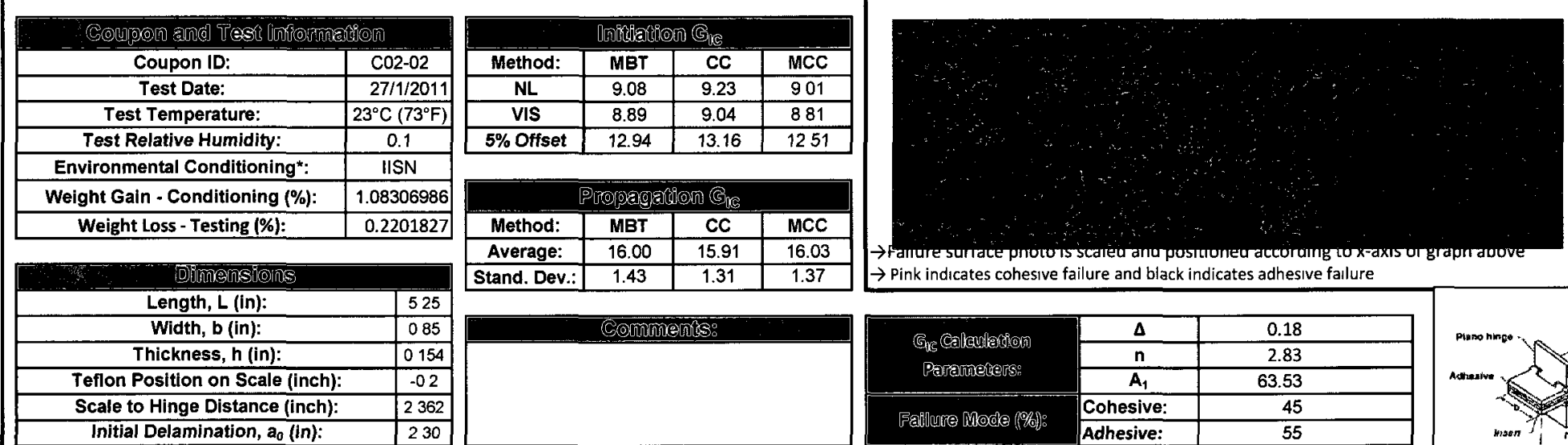

$\rightarrow$ Pink indicates cohesive failure and black indicates adhesive fallure
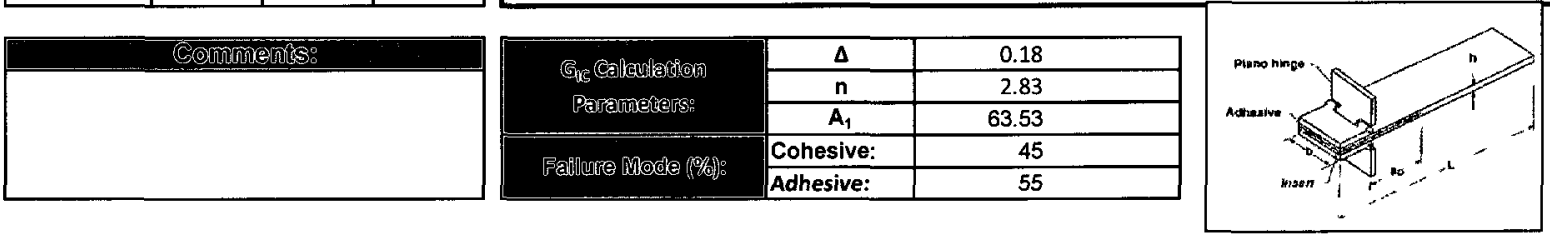

*Environmental Conditioning Codes are of the form TMSF where: Temperature (High $=82^{\circ} \mathrm{C}$ or Intermediate $=70^{\circ} \mathrm{C}$ ) Moisture type (Immersion or Vapour $=95 \%$ relative humidity) 
468C-J009 (Helicopter Composites Degradation) - Double Cantilever Beam Testing of Bonded Composite Laminates - Test Results Materials: Cycom 5276-1/G40-800-24K prepreg (Laminates); AF 163-2K (Adhesive)

Test Method: ASTM D5528
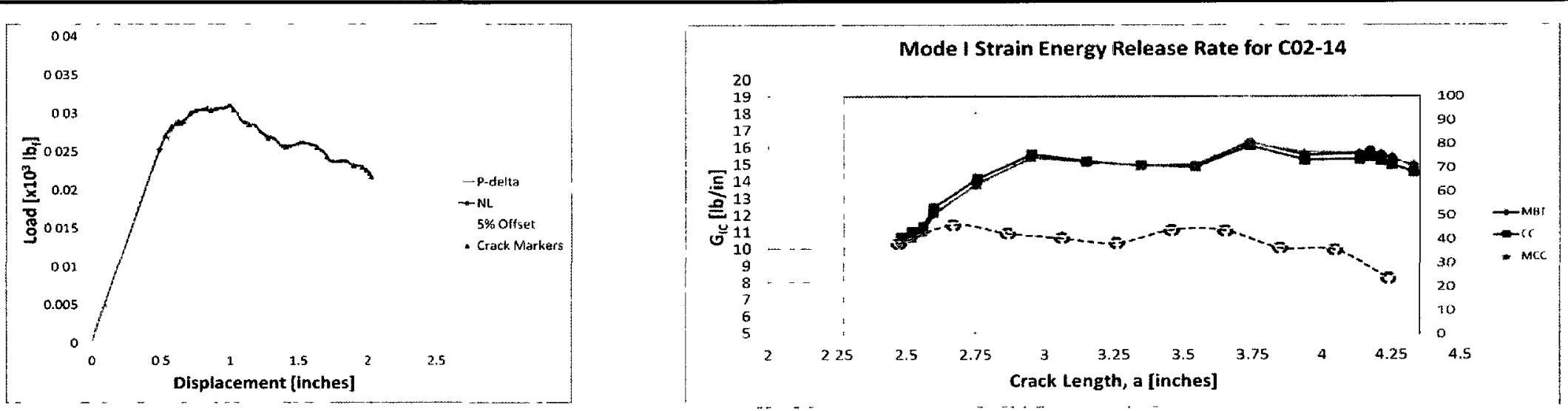

\begin{tabular}{|c|c|}
\hline Coupon ID: & $\mathrm{CO2}-14$ \\
\hline \multicolumn{2}{|l|}{ Test Date: } \\
\hline Test Temperature: & $23^{\circ} \mathrm{C}\left(73^{\circ} \mathrm{F}\right)$ \\
\hline Test Relative Humidity: & 0.1 \\
\hline Environmental Conditioning*: & IISN \\
\hline Weight Gain - Conditioning (\%): & 1.08306986 \\
\hline Weight Loss - Testing (\%): & 0.12406905 \\
\hline
\end{tabular}

\begin{tabular}{|c|c|c|c|}
\hline \multicolumn{4}{|c|}{ Donitfation $\mathbb{G}_{2}$} \\
\hline Method: & MBT & $\mathrm{CC}$ & MCC \\
\hline $\mathrm{NL}$ & 7.31 & 7.58 & 756 \\
\hline VIS & 8.54 & 8.85 & 878 \\
\hline $5 \%$ Offset & 9.64 & 9.99 & 976 \\
\hline & Bras & $\mathfrak{G}_{\text {Te }}$ & \\
\hline Method: & MBT & CC & MCC \\
\hline Average: & 14.86 & 14.85 & 14.88 \\
\hline & 1.24 & 1.05 & 1.24 \\
\hline
\end{tabular}

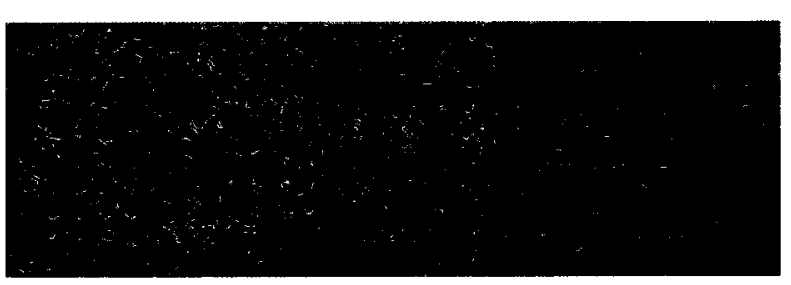

$\rightarrow$ Failure surface photo is scaled and positioned according to $x$-axis of graph above Pink indicates cohesive falure and black indicates adhesive failure

\begin{tabular}{|c|c|}
\hline \multicolumn{2}{|c|}{ Difinelisioris } \\
\hline Length, $\mathbf{L}$ (in): & 525 \\
\hline Width, $\mathbf{b}$ (in): & 0851 \\
\hline Thickness, $\mathbf{h}$ (in): & 015 \\
\hline Teflon Position on Scale (inch): & -008 \\
\hline Scale to Hinge Distance (inch): & 2362 \\
\hline Initial Delamination, $\mathbf{a}_{\mathbf{0}}$ (in): & 238 \\
\hline
\end{tabular}
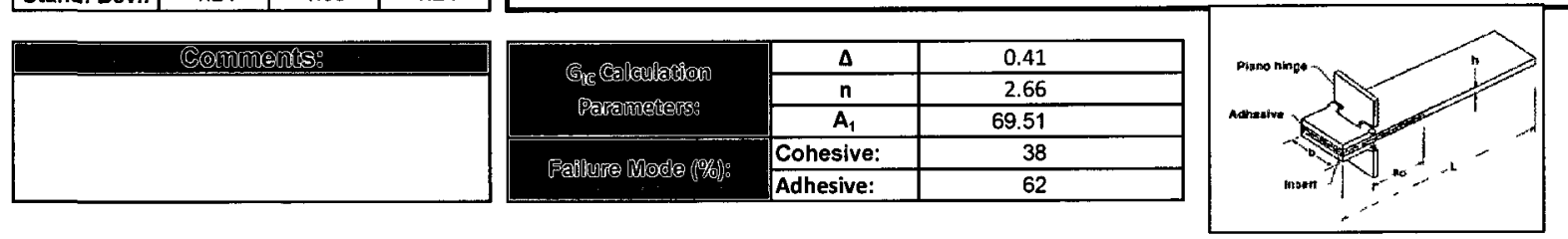

* Environmental Conditioning Codes are of the form TMSF where: Temperature (High $=82^{\circ} \mathrm{C}$ or Intermediate $=70^{\circ} \mathrm{C}$ ) Moisture type (Immersion or Vapour $=95 \%$ relative humidity

Salinity $($ Water $=0 \mathrm{~g} / \mathrm{L}$ or Salt water $=24.5 \mathrm{~g} / \mathrm{L})$ Freeze-thaw? (Yes or No) 
48SC 009 (Hallcopter Composites Degradation) - Double Cantilever Beam Testing of Bonded Composite Laminates - Teat Results Materials: Cycom 5276-1/G40-800-24K prepreg (Laminates); AF 163-2K (Adhesive)

Test Method: ASTM D5528

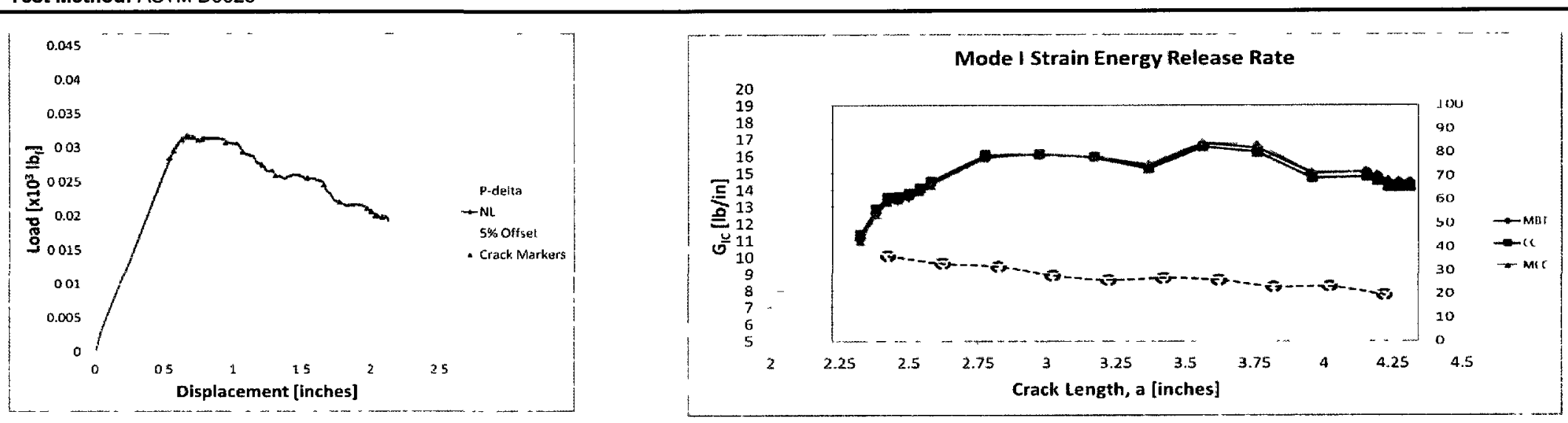

\section{Conpon and Test linforting

\begin{tabular}{|c|c|}
\hline Coupon ID: & $\mathrm{CO3-06}$ \\
\hline Test Date: & $27 / 1 / 2011$ \\
\hline Test Temperature: & $23^{\circ} \mathrm{C}\left(73^{\circ} \mathrm{F}\right)$ \\
\hline Test Relative Humidity: & 0.1 \\
\hline Environmental Conditioning*: & IISN \\
\hline Weight Gain - Conditioning (\%): & 1.08306986 \\
\hline Weight Loss - Testing (\%): & 0.1010581 \\
\hline
\end{tabular}

\begin{tabular}{|c|c|c|c|}
\hline \multicolumn{4}{|c|}{ lñtuthathon (G) } \\
\hline Method: & MBT & $\mathrm{CC}$ & $\mathrm{MCC}$ \\
\hline $\mathrm{NL}$ & 10.06 & 10.29 & 1000 \\
\hline VIS & 11.08 & 11.34 & 10.98 \\
\hline $5 \%$ Offset & 13.55 & 13.86 & 13.11 \\
\hline \multicolumn{4}{|c|}{ Propagation (G) } \\
\hline Method: & MBT & CC & MCC \\
\hline Average: & 15.67 & 15.58 & 15.73 \\
\hline Stand. Dev. & 0.78 & 0.76 & 0.81 \\
\hline
\end{tabular}

$\rightarrow$ Failure surface photo is scaled and positioned according to $x$-axis of graph above

\begin{tabular}{|c|c|}
\hline \multicolumn{2}{|c|}{ Dlimenstions } \\
\hline Length, L (in): & 525 \\
\hline Width, $\mathbf{b}$ (in): & 0855 \\
\hline Thickness, $\mathbf{h}$ (in): & 0149 \\
\hline Teflon Position on Scale (inch): & -02 \\
\hline Scale to Hinge Distance (inch): & 2382 \\
\hline Initial Delamination, $\mathbf{a}_{\mathbf{0}}$ (in): & 232 \\
\hline
\end{tabular}

$\rightarrow$ Pink indicates cohesive failure and black indicates adhesive failure
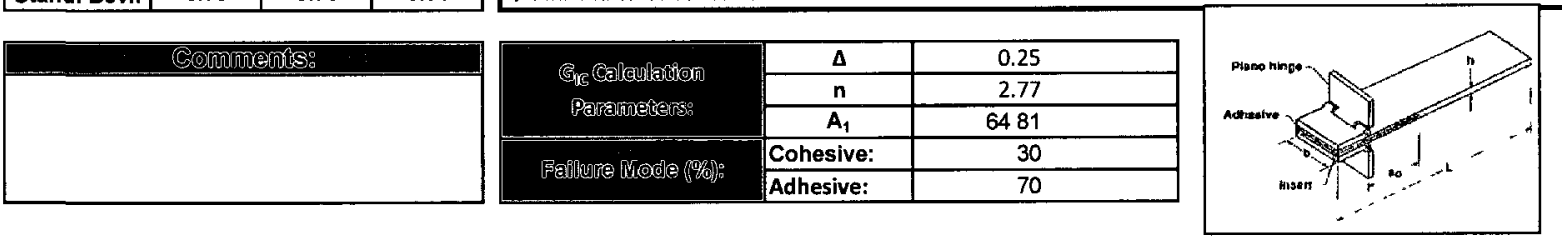

${ }^{*}$ Environmental Conditioning Codes are of the form TMSF where: Temperature (High $=82^{\circ} \mathrm{C}$ or Intermediate $\left.=70^{\circ} \mathrm{C}\right)$ Moisture type (Immersion or Vapour $=95 \%$ relative humidity)

Salinity (Water $=0 \mathrm{~g} / \mathrm{L}$ or Salt water $=24.5 \mathrm{~g} / \mathrm{L})$ Freeze-thaw? (Yes or No) 
468C 1009 (Helicopter Composites Degradation) - Double Cantlever Beam Testing of Bonded Composite Laminates - Test Results Materials: Cycom 5276-1/G40-800-24K prepreg (Laminates); AF 163-2K (Adhesive)

Test Method: ASTM D5528
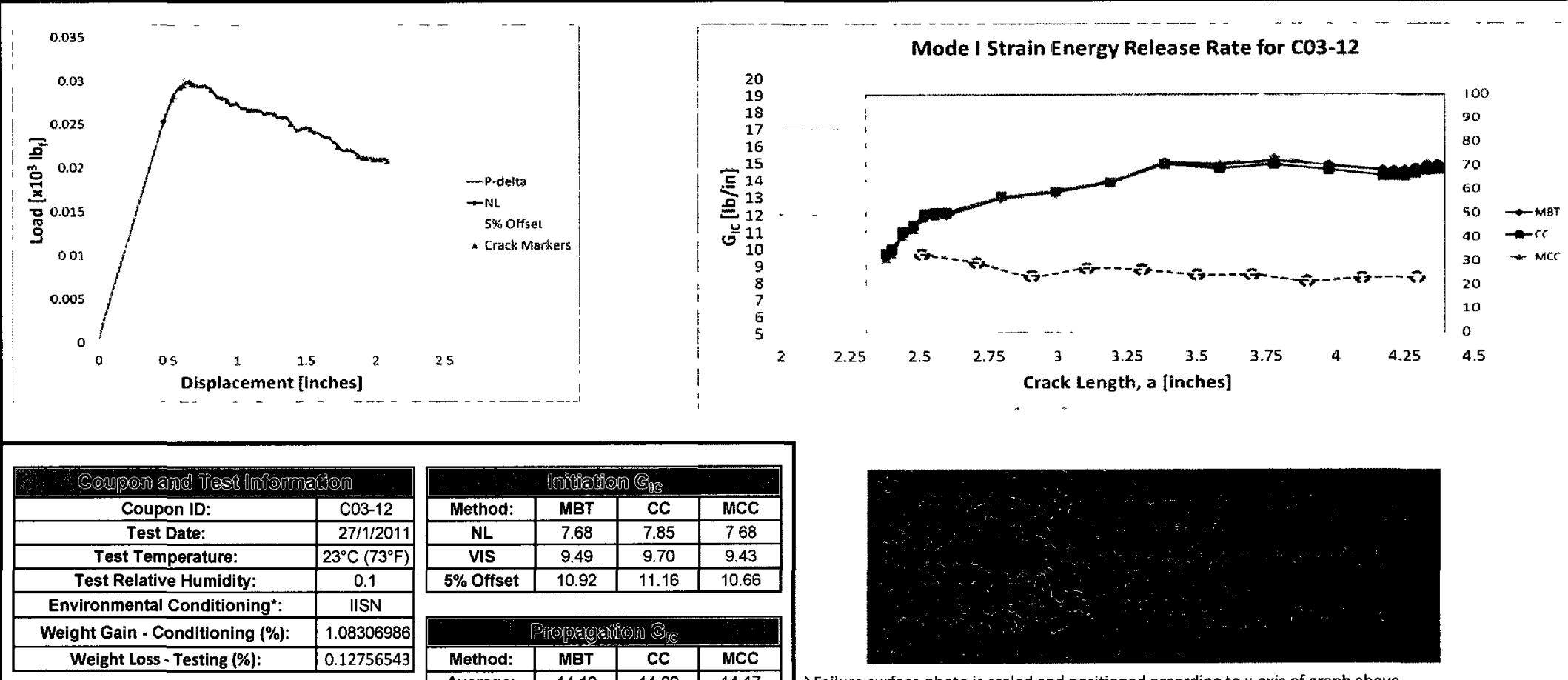

\begin{tabular}{|c|c|c|c|}
\hline \multicolumn{4}{|c|}{ Irritiatien $G_{B S}$} \\
\hline Method: & MBT & CC & MCC \\
\hline $\mathrm{NL}$ & 7.68 & 7.85 & 768 \\
\hline VIS & 9.49 & 9.70 & 9.43 \\
\hline $5 \%$ Offset & 10.92 & 11.16 & 10.66 \\
\hline \multicolumn{4}{|c|}{ Propargation Gic } \\
\hline Method: & MBT & CC & MCC \\
\hline Average: & 14.10 & 14.00 & 14.17 \\
\hline Stand. Dev & 1.13 & 0.98 & 1.13 \\
\hline
\end{tabular}
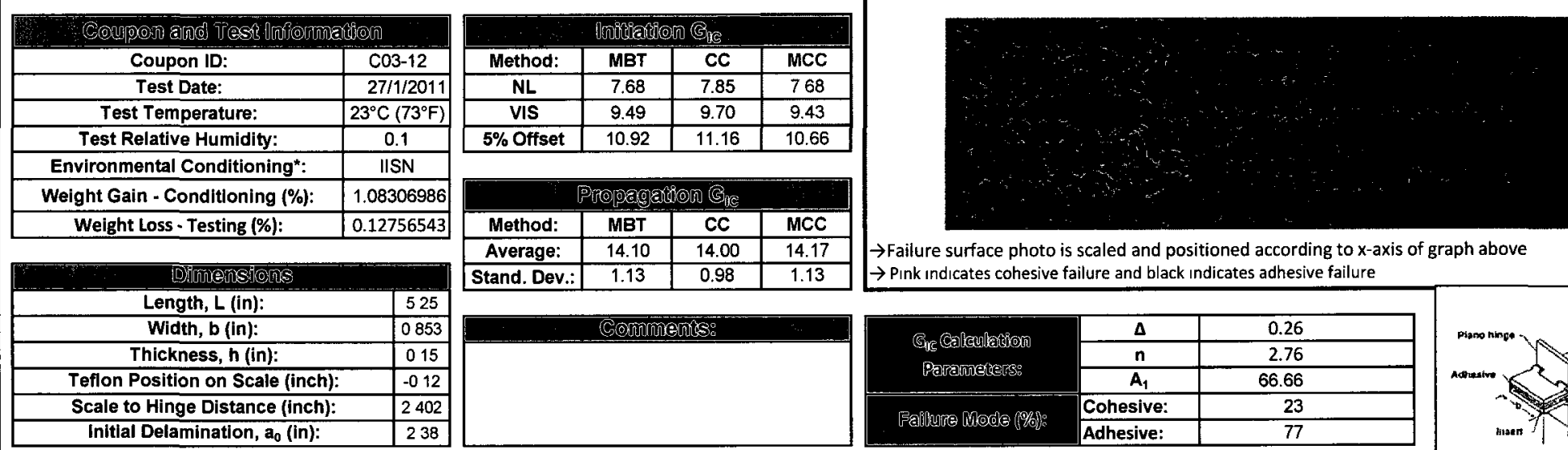

$\rightarrow$ Failure surface photo is scaled and positioned according to $x$-axis
$\rightarrow$ Pink Indicates cohesive failure and black Indicates adhesive failure
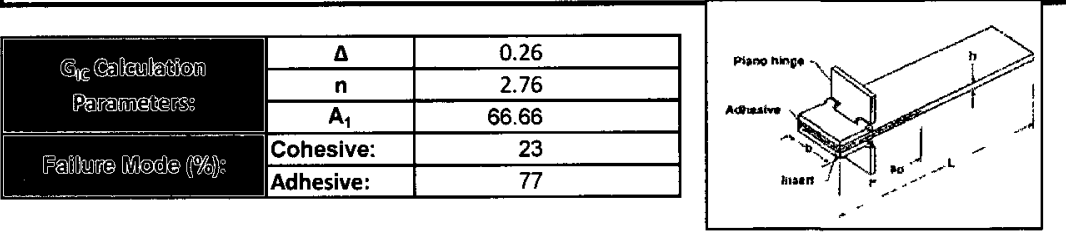

* Environmental Conditioning Codes are of the form TMSF where: Temperature (High $=82^{\circ} \mathrm{C}$ or Intermediate $=70^{\circ} \mathrm{C}$ ) Moisture type (Immersion or Vapour $=95 \%$ relative humidity) 
485C-J009 (Helicopter Composites Degradation) - Double Cantilever Beam Testing of Bonded Composite Laminates - Test Results Materials: Cycom 5276-1/G40-800-24K prepreg (Laminates); AF 163-2K (Adhesive)

Test Method: ASTM D5528
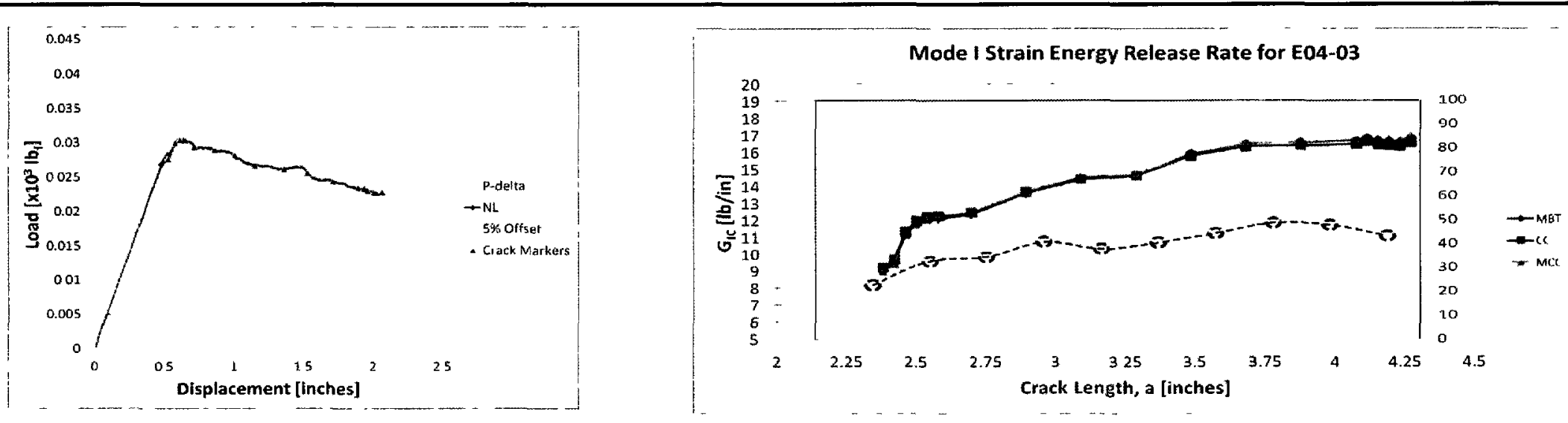

\begin{tabular}{|c|c|}
\hline Coupon ID: & E04-03 \\
\hline Test Date: & $27 / 1 / 2011$ \\
\hline Test Temperature: & $23^{\circ} \mathrm{C}\left(73^{\circ} \mathrm{F}\right)$ \\
\hline Test Relative Humidity: & 0.1 \\
\hline Environmental Conditioning*: & IISN \\
\hline Weight Gain - Conditioning (\%): & 1.08306986 \\
\hline Weight Loss - Testing (\%): & 0.14526738 \\
\hline
\end{tabular}

\begin{tabular}{|c|c|c|c|}
\hline \multicolumn{4}{|c|}{ 17xidatan (G. } \\
\hline Method: & MBT & CC & MCC \\
\hline NL & 8.55 & 8.70 & 8.52 \\
\hline VIS & 902 & 9.18 & 895 \\
\hline $5 \%$ Offset & 11.05 & 11.24 & 10.74 \\
\hline & (0parg & (n) (G) & \\
\hline Method: & MBT & Cc & MCC \\
\hline Average: & 14.76 & 14.70 & 1480 \\
\hline Stand. Dev.: & 1.79 & 1.66 & 174 \\
\hline
\end{tabular}

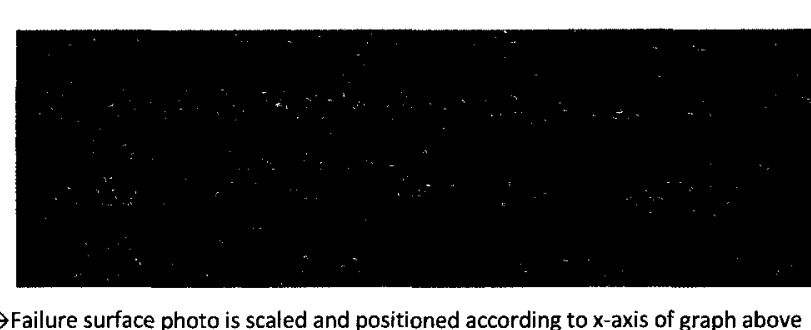
$\rightarrow$ Pink indicates cohesive fallure and black indicates adhesive failure
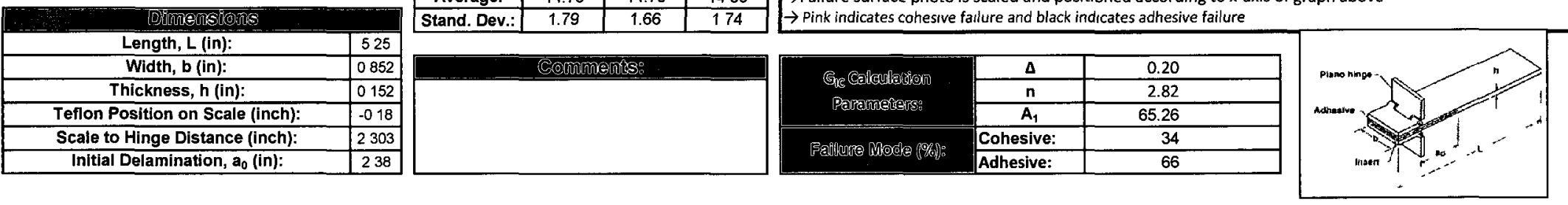

"Environmental Conditioning Codes are of the form TMSF where: Temperature (High $=82^{\circ} \mathrm{C}$ or Intermediate $=70^{\circ} \mathrm{C}$ ) Moisture type (Immersion or Vapour $=95 \%$ relative humidity) Salinity (Water $=0 \mathrm{~g} / \mathrm{L}$ or Salt water $=24.5 \mathrm{~g} / \mathrm{L}$ Freeze-thaw? (Yes or No) 
CosC-J009 (Hollcopter Composites Degradation) - Double Cantilever Beam Testing of Bonded Composite Laminates - Test Results Materials: Cycom 5276-1/G40-800-24K prepreg (Laminates); AF 163-2K (Adhesive)

Test Method: ASTM D5528
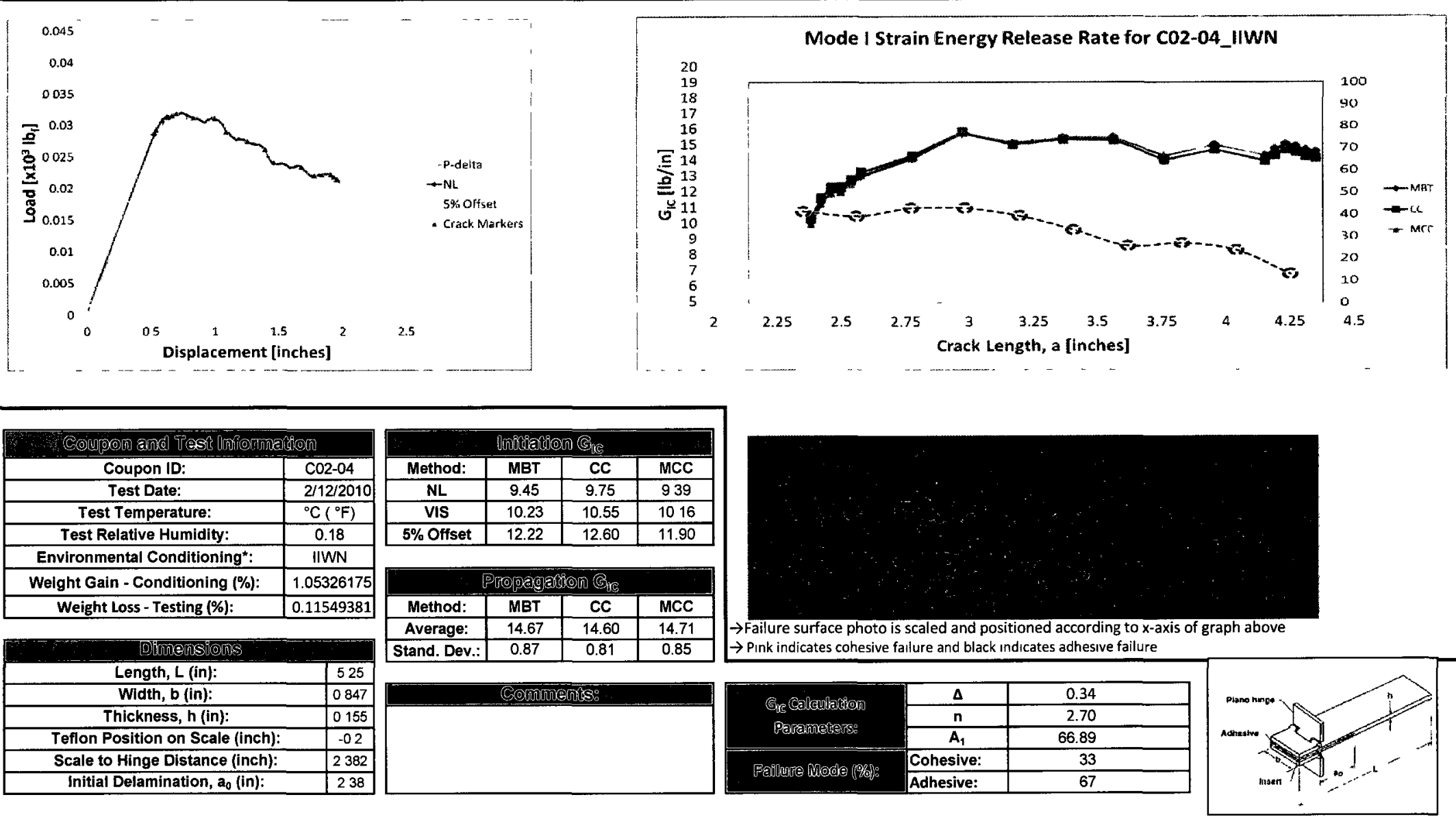

Environmental Conditioning Codes are of the form TMSF where: Temperature (High $=82^{\circ} \mathrm{C}$ or Intermediate $=70^{\circ} \mathrm{C}$ ) Moisture type (Immersion or Vapour $=95 \%$ relative humidity) 


\section{SC-J009 (Helicopter Composites Degradation) - Double Cantilever Beam Testing of Bonded Composite Laminates - Test Results}

Materials: Cycom 5276-1/G40-800-24K prepreg (Laminates); AF 163-2K (Adhesive)

Test Method: ASTM D5528
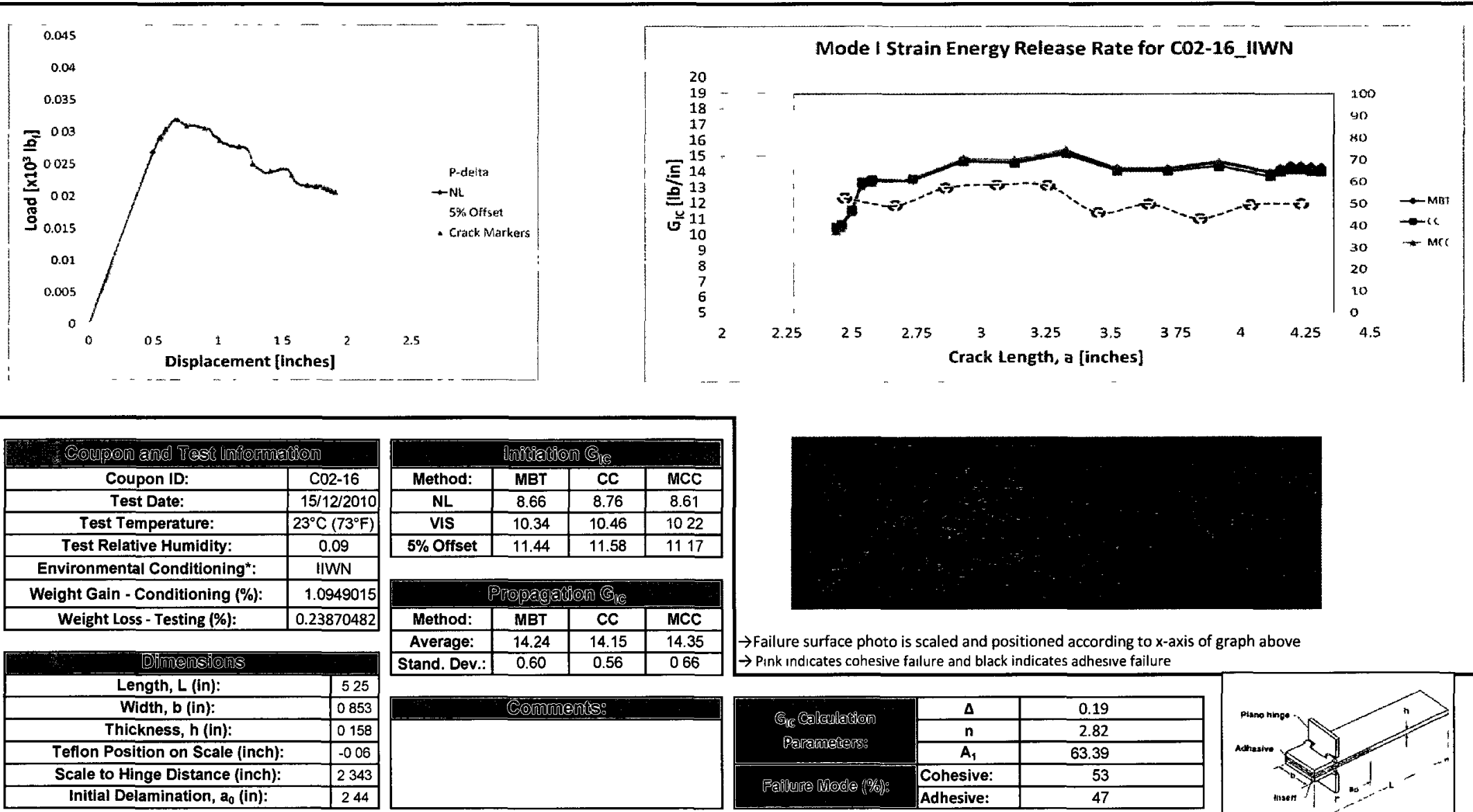

$\rightarrow$ Failure surface photo is scaled and positioned according to $x$-axis of graph above $\rightarrow$ Pink indicates cohesive fallure and black indicates achesive failure

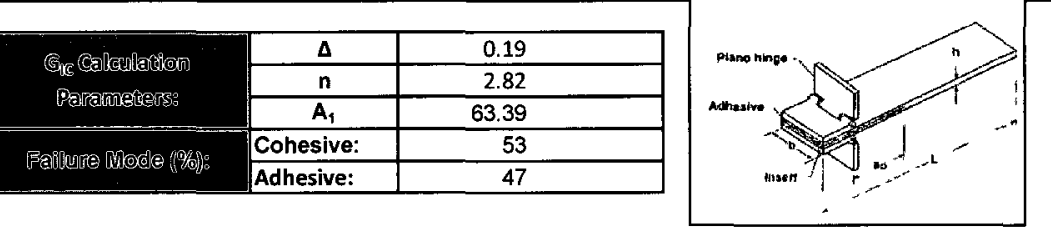

* Enviranmental Conditioning Codes are of the form TMSF where: Temperature (High $=82^{\circ} \mathrm{C}$ or Intermediate $=70^{\circ} \mathrm{C}$ ) Moisture type (Immersion or Vapour $=95 \%$ relative humidity) 


\section{C-J009 (Helicopter Composites Degradation) - Double Cantilever Beam Testing of Bonded Composite Laminates - Test Results}

Materials: Cycom 5276-1/G40-800-24K prepreg (Laminates); AF 163-2K (Adhesive)

Test Method: ASTM D5528
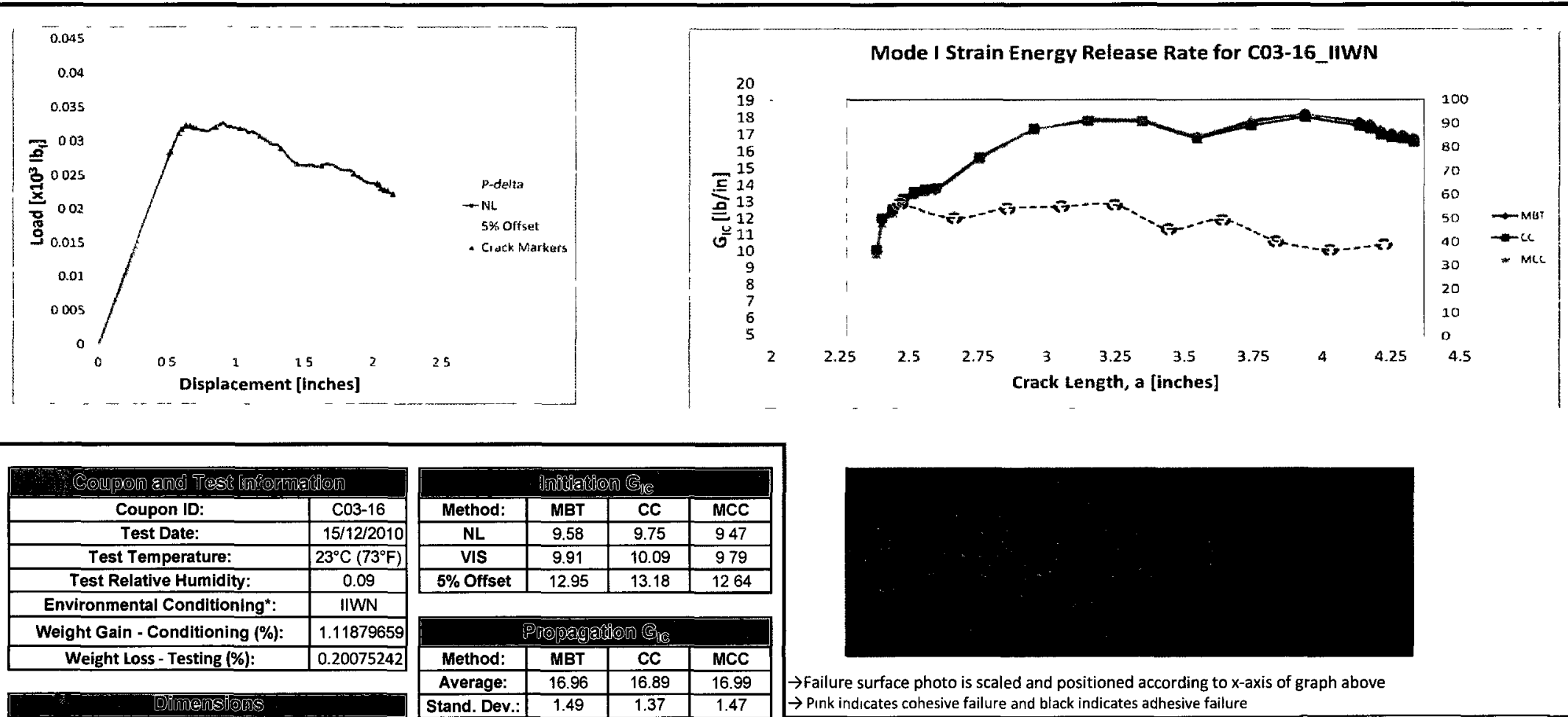

$\rightarrow$ Failure surface photo is scaled and positioned according to $x$-axis of graph above

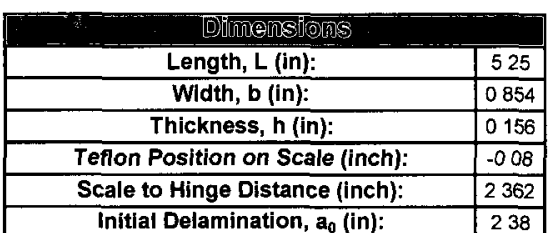

\begin{tabular}{|c|c|c|c|}
\hline Average: & 16.96 & 16.89 & 16.99 \\
\hline Stand. Dev.: & 1.49 & 1.37 & 1.47 \\
\hline
\end{tabular}
$\rightarrow$ Pink indicates cohesive failure and black indicates adhesive failure
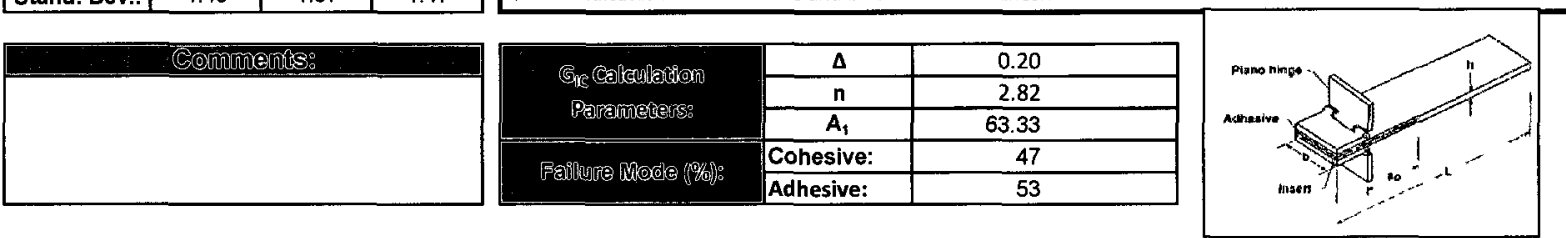

* Environmental Conditioning Codes are of the form TMSF where: Temperature (High $=82^{\circ} \mathrm{C}$ or Intermediate $=70^{\circ} \mathrm{C}$ ) Moisture type (Immersion or Vapour $=95 \%$ relative humidity

Salinity (Water $=0 \mathrm{~g} / \mathrm{L}$ or Salt water $=\mathbf{2 4 . 5} \mathrm{g} / \mathrm{L})$ Freeze-thaw? (Yes or No) 


\section{C-J009 (Helicopter Composites Degradation) - Double Cantilever Beam Testing of Bonded Composite Laminates - Test Results}

Materials: Cycom 5276-1/G40-800-24K prepreg (Laminates); AF 163-2K (Adhesive)

Test Method: ASTM D5528
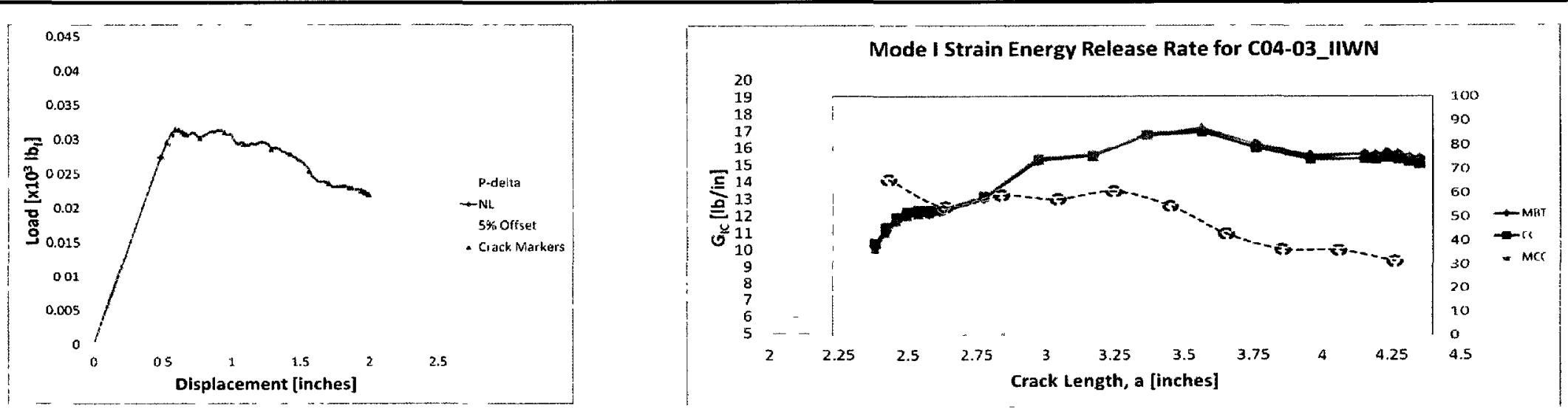

\begin{tabular}{|c|c|}
\hline Coupon ID: & CO4-03 \\
\hline Test Date: & $6 / 12 / 2010$ \\
\hline Test Temperature: & $\left.25^{\circ} \mathrm{C} 77^{\circ} \mathrm{F}\right)$ \\
\hline Test Relative Humidity: & \begin{tabular}{|l|}
0.1 \\
\end{tabular} \\
\hline Environmental Conditioning*: & $\| W N$ \\
\hline Weight Gain - Conditioning (\%): & 0.99431968 \\
\hline Weight Loss - Testing (\%): & 0.21199707 \\
\hline
\end{tabular}
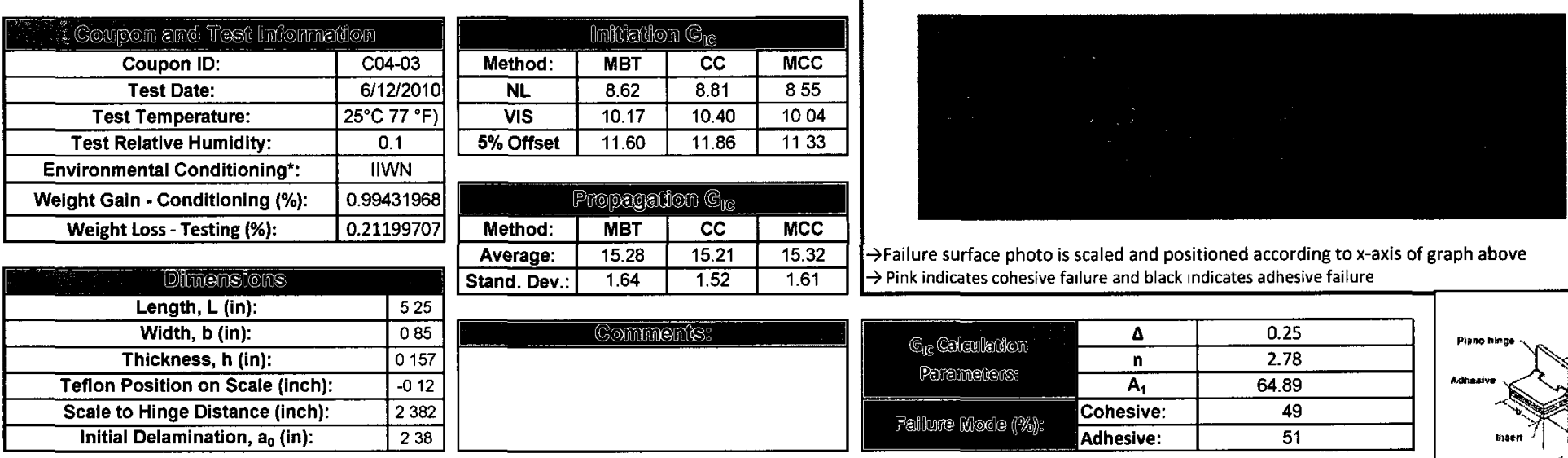

\begin{tabular}{|c|c|c|c|}
\hline Method: & MBT & CC & MCC \\
\hline Average: & 15.28 & 15.21 & 15.32 \\
\hline Stand. Dev.: & 1.64 & 1.52 & 1.61 \\
\hline
\end{tabular}

Failure surface photo is scaled and positioned according to $x$-axis of graph above $\rightarrow$ Pink indicates cohesive fallure and black Indicates adhesive failure
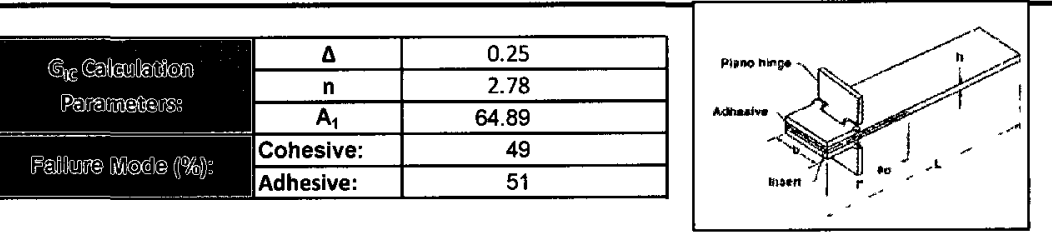

* Environmental Conditioning Codes are of the form TMSF where: Temperature (High $=82^{\circ} \mathrm{C}$ or Intermediate $=70^{\circ} \mathrm{C}$ ) Moisture type (Immersion or Vapour $=95 \%$ relative humidity 
468C-J009 (Hellcopter Composites Degradation) - Double Cantilever Beam Testing of Bonded Composite Laminates - Test Results Materials: Cycom 5276-1/G40-800-24K prepreg (Laminates); AF 163-2K (Adhesive)

Test Method: ASTM D5528
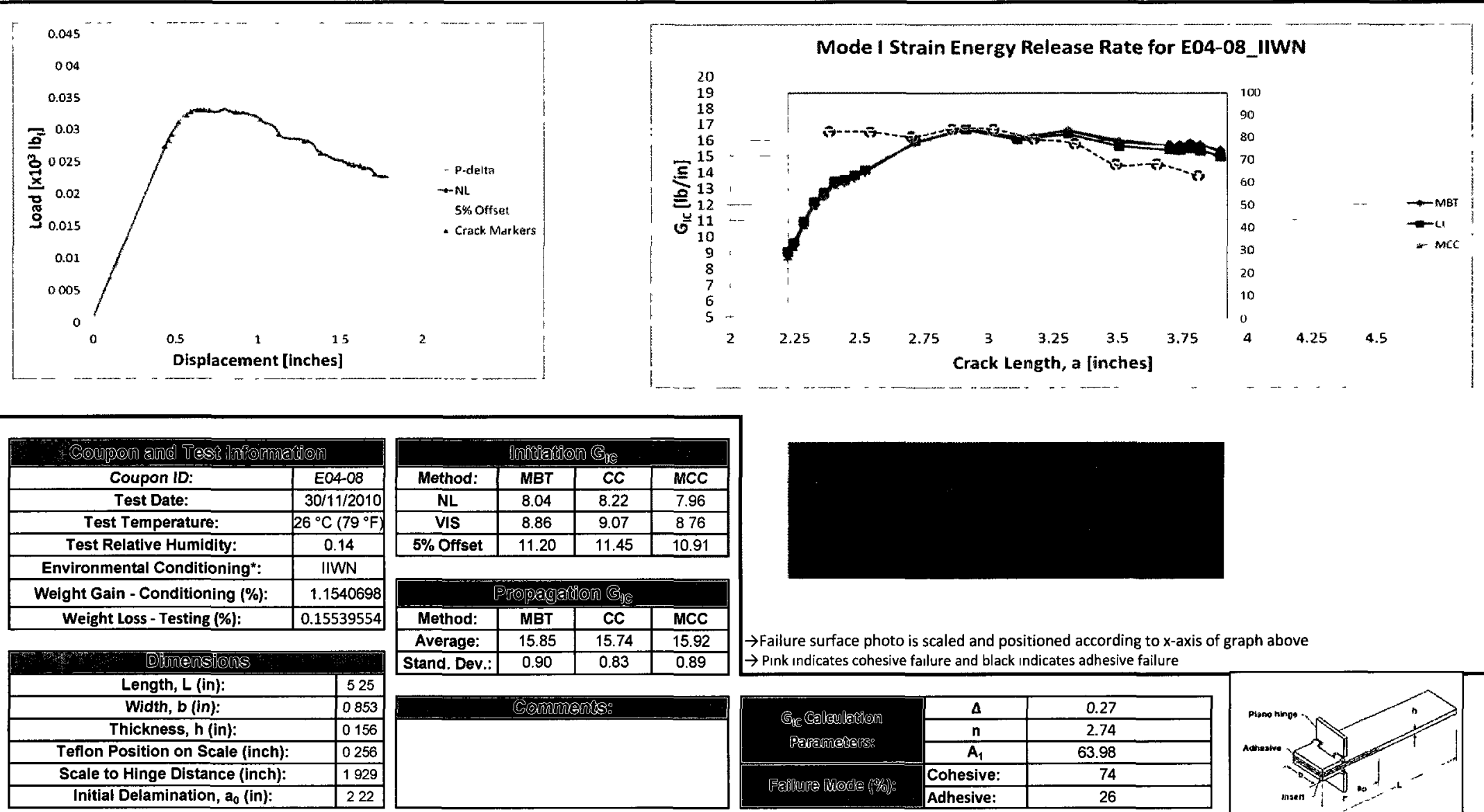

$\rightarrow$ Fallure surface photo is scaled and positioned according to $x$-axis of graph above $\rightarrow$ PInk Indicates cohesive fallure and black Indicates adhesive failure
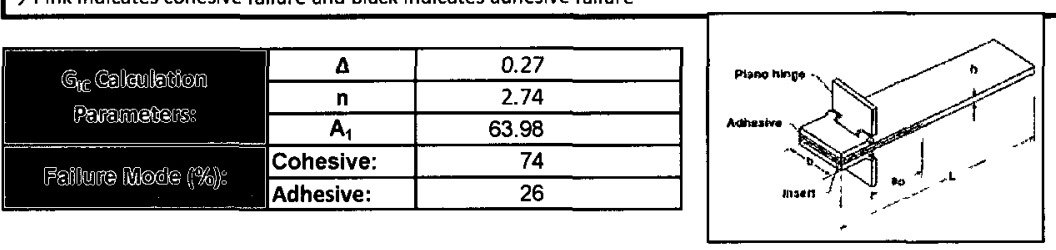

* Environmental Conditioning Codes are of the form TMSF where: Temperature (High $=82^{\circ} \mathrm{C}$ or Intermedlate $=70^{\circ} \mathrm{C}$ ) Moisture type (Immersion or Vapour $=95 \%$ relative humidity) Salinity (Water $=0 \mathrm{~g} / \mathrm{L}$ or Salt water $=24.5 \mathrm{~g} / \mathrm{L})$ Freeze-thaw? (Yes or No) 
46SC-J009 (Helicopter Composites Degradation) - Double Cantilever Beam Testing of Bonded Composite Laminates - Test Results Materials: Cycom 5276-1/G40-800-24K prepreg (Laminates); AF 163-2K (Adhesive)

Test Method: ASTM D5528
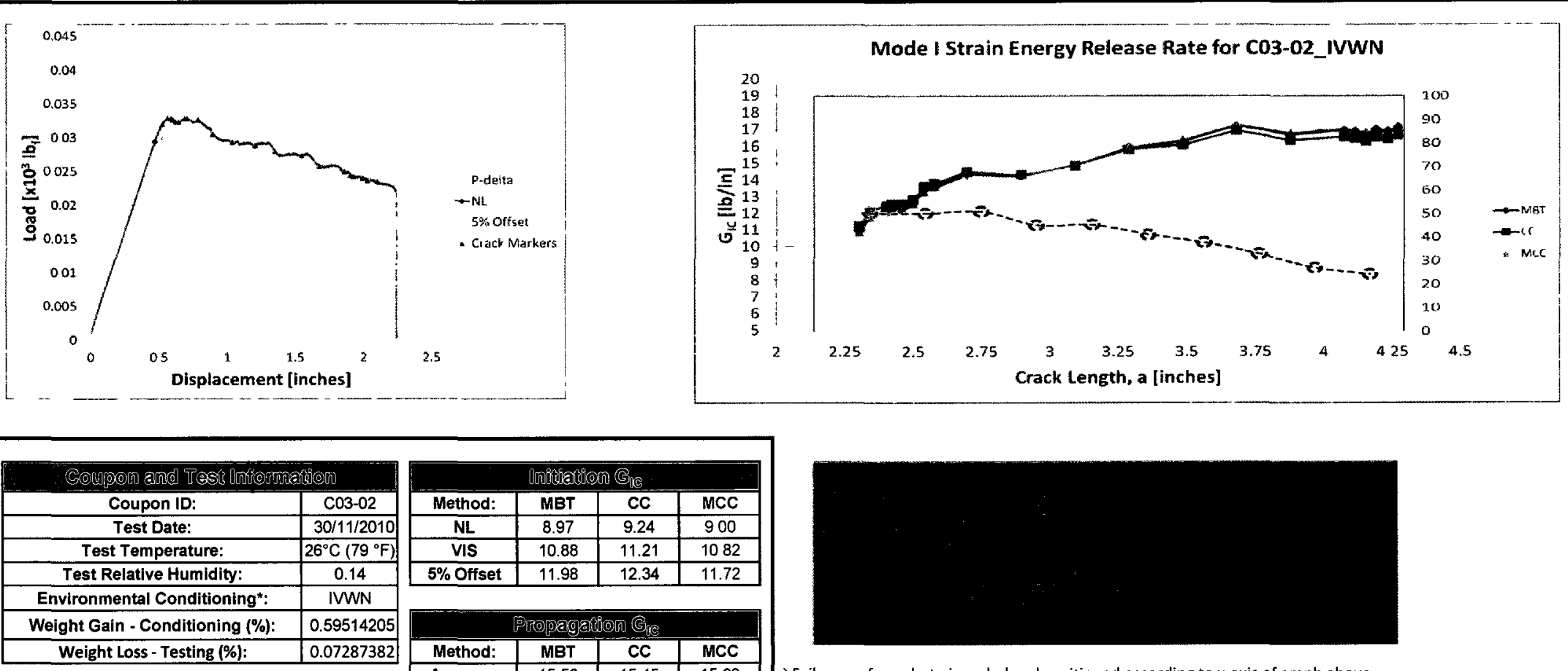

\begin{tabular}{|c|c|c|c|}
\hline \multicolumn{4}{|c|}{ 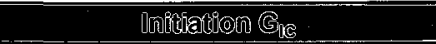 } \\
\hline Method: & MBT & CC & MCC \\
\hline NL & 8.97 & 9.24 & 900 \\
\hline VIS & 10.88 & 11.21 & 1082 \\
\hline $5 \%$ Offset & 11.98 & 12.34 & 11.72 \\
\hline \multicolumn{4}{|c|}{ Propagation $G_{p e}$} \\
\hline Method: & MBT & $\mathrm{CC}$ & MCC \\
\hline Average: & 15.56 & 15.45 & 15.63 \\
\hline & 1.35 & 1.13 & 1.37 \\
\hline
\end{tabular}

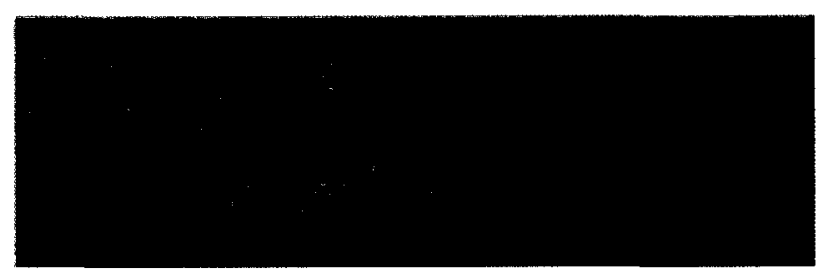

\begin{tabular}{|c|c|}
\hline Lengthinefnsions \\
\hline L (in): & 525 \\
\hline Width, $\mathbf{b}$ (in): & 0854 \\
\hline Thlckness, $\mathbf{h}$ (in): & 0155 \\
\hline Teflon Position on Scale (inch): & -016 \\
\hline Scale to Hinge Distance (inch): & 2303 \\
\hline Initial Delamination, $\mathbf{a}_{\mathbf{0}}$ (in): & 230 \\
\hline
\end{tabular}

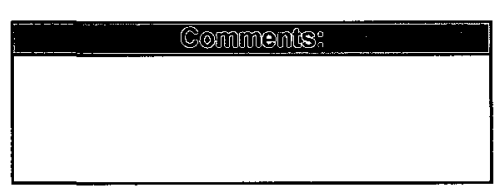

$\rightarrow \rightarrow$ Fallure surface photo is scaled and positioned according to $x$-axis
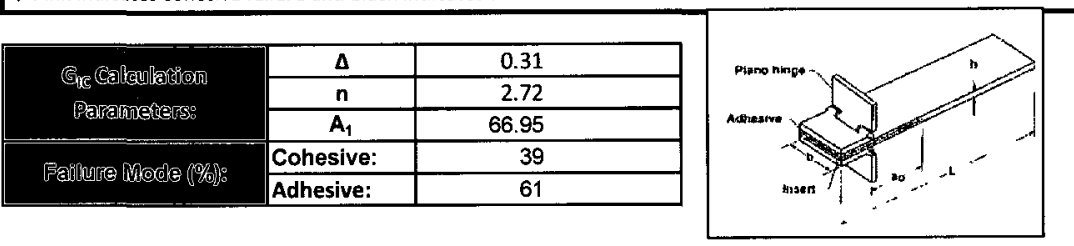

* Environmental Conditioning Codes are of the form TMSF where: Temperature (High $=82^{\circ} \mathrm{C}$ or Intermediate $=70^{\circ} \mathrm{C}$ ) Moisture type (Immersion or Vapour $=95 \%$ relative humidity) 


\section{SC-J009 (Helicopter Composites Degradation) - Double Cantilever Beam Testing of Bonded Composite Laminates - Test Results}

Materials: Cycom 5276-1/G40-800-24K prepreg (Lamınates), AF 163-2K (Adhesive)

Test Method: ASTM D5528
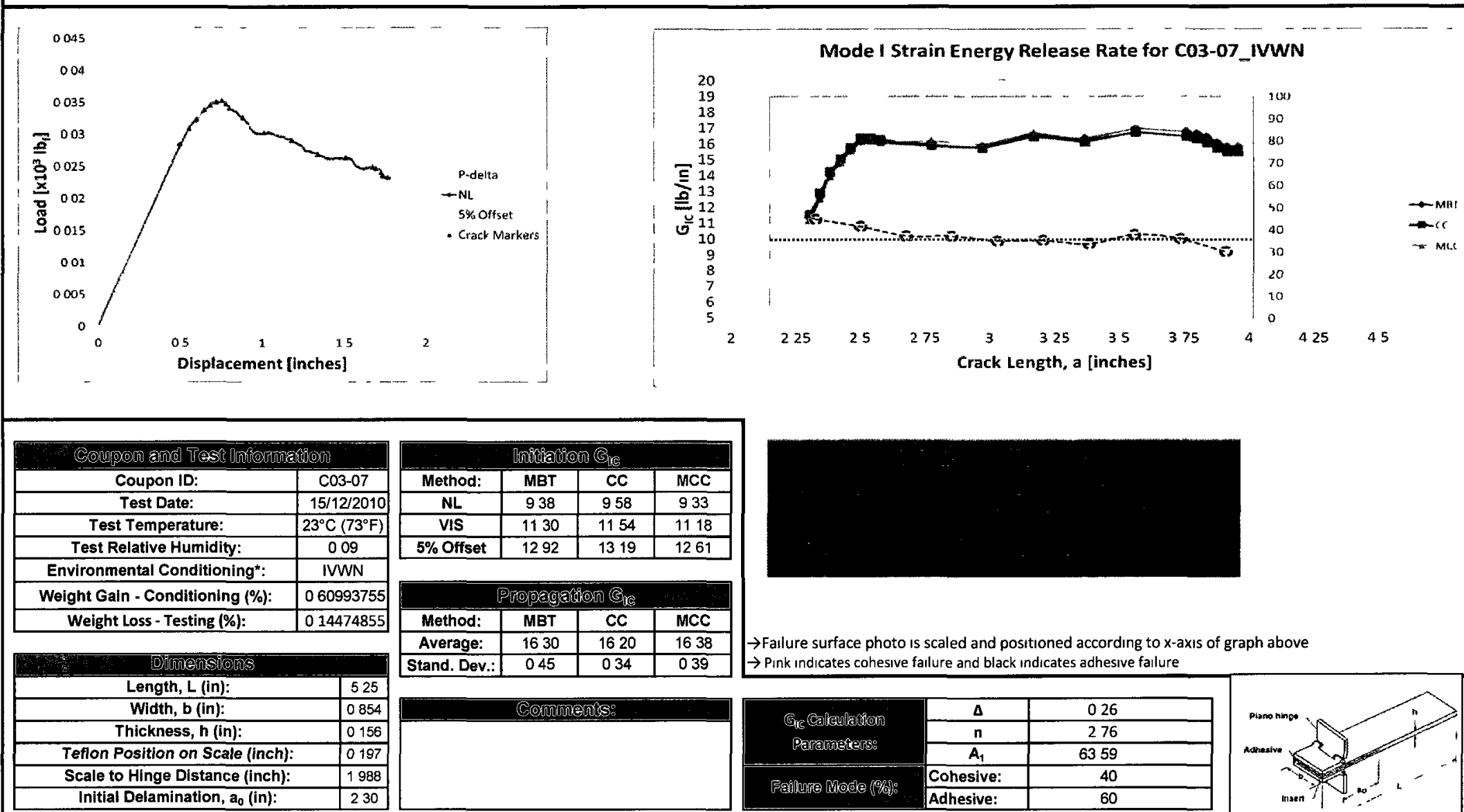

$\rightarrow$ Fallure surface photo is scaled and positioned according to $x$-axis of graph above $\rightarrow$ Pink indicates cohesive fallure and black indicates adhesive fallure
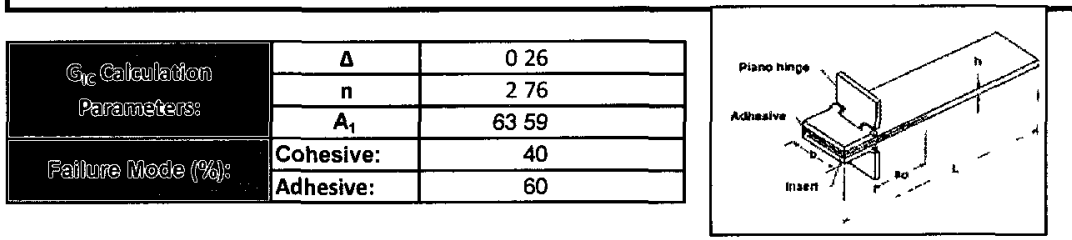

"Environmental Conditioning Codes are of the form TMSF where Temperature (High $=82^{\circ} \mathrm{C}$ or Intermediate $=70^{\circ} \mathrm{C}$ ) Moisture type (Immersion or Vapour $=95 \%$ relative humidity) 
465C-J009 (Helicopter Composites Degradation) - Double Cantilever Beam Testing of Bonded Composite Laminates - Test Results Materials: Cycom 5276-1/G40-800-24K prepreg (Laminates); AF 163-2K (Adhesive)

Test Method: ASTM D5528
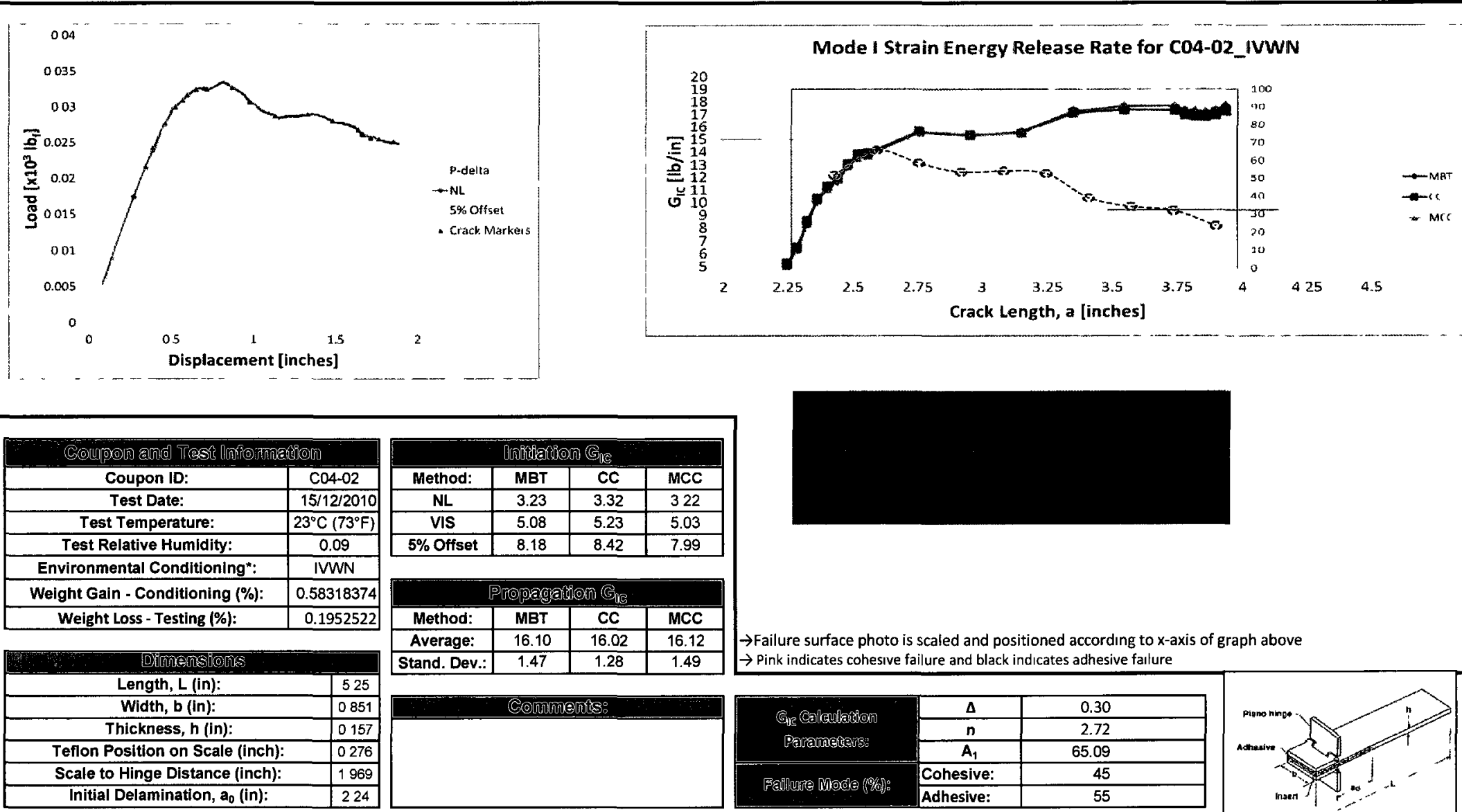

$\rightarrow$ Fallure surface photo is scaled and positioned according to $x$-axis of graph above $\rightarrow$ Pink indicates cohesive failure and black indicates adhesive falture

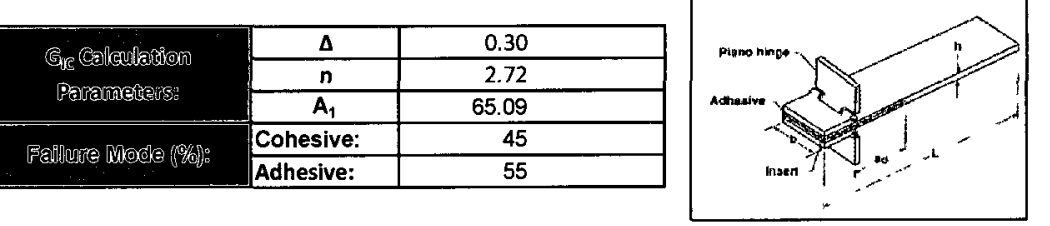

* Environmental Conditioning Codes are of the form TMSF where: Temperature (High $=82^{\circ} \mathrm{C}$ or Intermediate $=70^{\circ} \mathrm{C}$ ) Moisture type (Immersion or Vapour $=95 \%$ relative humidity) Salinity $($ Water $=0 \mathrm{~g} / \mathrm{L}$ or Salt water $=24.5 \mathrm{~g} / \mathrm{L})$ Freeze-thaw? (Yes or No) 
46SC-J009 (Helleapter Composites Degradation) - Double Cantilever Beam Testing of Bonded Composite Laminates - Test Results Materials: Cycom 5276-1/G40-800-24K prepreg (Laminates); AF 163-2K (Adhesive)

Test Method: ASTM D5528
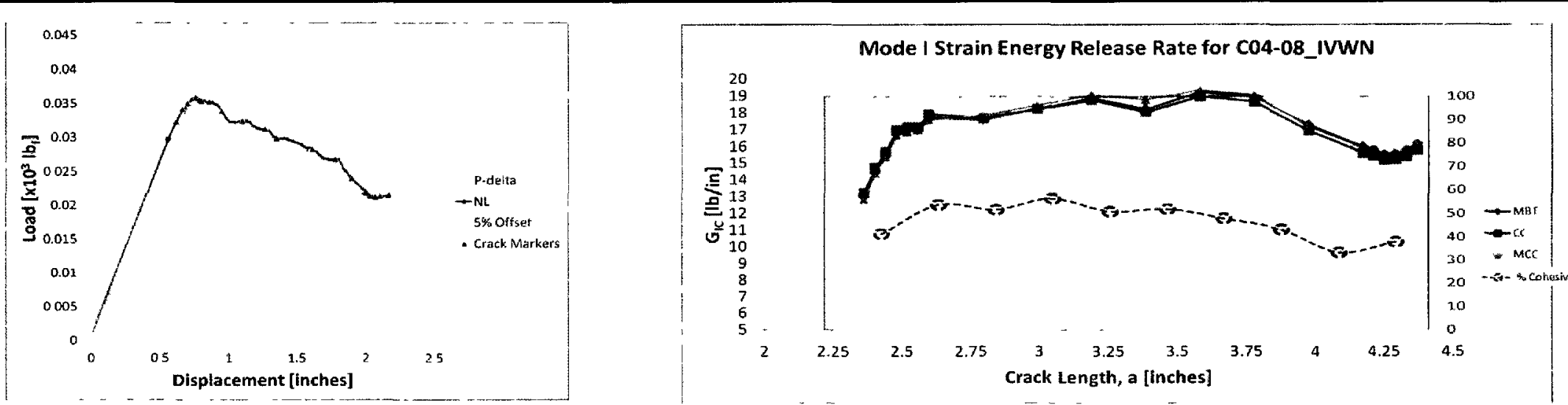

\begin{tabular}{|c|c|}
\hline Coupon ID: & $\mathrm{CO4-08}$ \\
\hline Test Date: & $2 / 12 / 2010$ \\
\hline Test Temperature: & $24^{\circ} \mathrm{C}\left(75^{\circ} \mathrm{F}\right)$ \\
\hline Test Relatlve Humidity: & 0.18 \\
\hline Environmental Conditioning*: & IVWN \\
\hline Weight Gain - Conditioning (\%): & 0.61978064 \\
\hline Weight Loss - Testing (\%): & 0.39658842 \\
\hline
\end{tabular}

\begin{tabular}{|c|c|c|c|}
\hline \multicolumn{4}{|c|}{ Inithtation $G_{\mathbb{G}}$} \\
\hline Method: & MBT & CC & MCC \\
\hline $\mathrm{NL}$ & 10.80 & 11.02 & 1072 \\
\hline VIS & 12.98 & 13.24 & $\overline{1281}$ \\
\hline $5 \%$ Offset & 15.43 & 15.73 & 15.01 \\
\hline & (a) & $\mathbb{E}_{\mathrm{rg}}$ & \\
\hline Method: & MBT & CC & MCC \\
\hline Average: & 17.99 & 17.85 & 18.11 \\
\hline & 1.01 & 1.05 & 1.12 \\
\hline
\end{tabular}

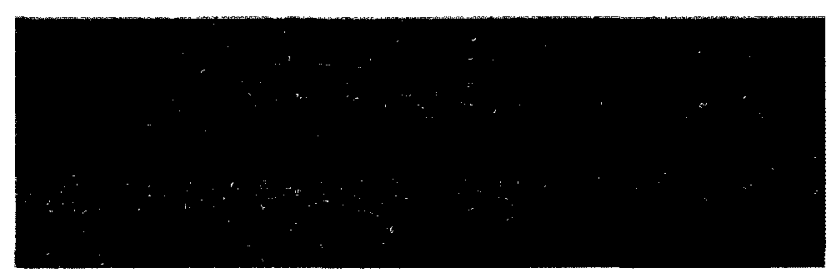

\begin{tabular}{|c|c|}
\hline Length, $\boldsymbol{L}$ (in): & 525 \\
\hline Width, $b$ (in): & 0851 \\
\hline Thickness, $\boldsymbol{h}$ (in): & 0155 \\
\hline Teflon Position on Scale (inch): & -016 \\
\hline Scale to Hinge Distance (inch): & 2402 \\
\hline Initial Delamination, $\mathbf{a}_{0}$ (in): & 236 \\
\hline
\end{tabular}

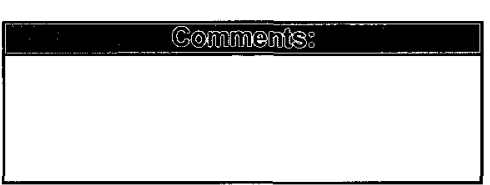

Falure surface photo is scaled and positioned according to $x$-axis of graph above $\rightarrow$ PInk indicates cohesive fallure and black Indicates adhesive fallure
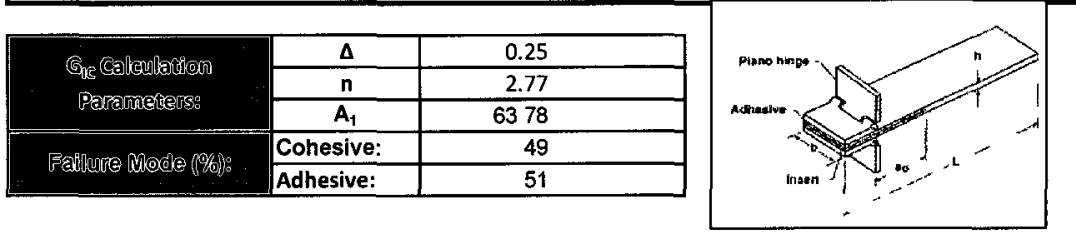

* Environmental Conditioning Codes are of the form TMSF where; Temperature (High $=82^{\circ} \mathrm{C}$ or Intermediate $\left.=70^{\circ} \mathrm{C}\right)$ Moisture type (Immersion or Vapour $=95 \%$ relative humidity) 
46SC-J009 (Helicopter Composites Degradation) - Double Cantilever Beam Testing of Bonded Composite Laminates - Test Results Materials: Cycom 5276-1/G40-800-24K prepreg (Laminates); AF 163-2K (Adhesive)

Test Method: ASTM D5528
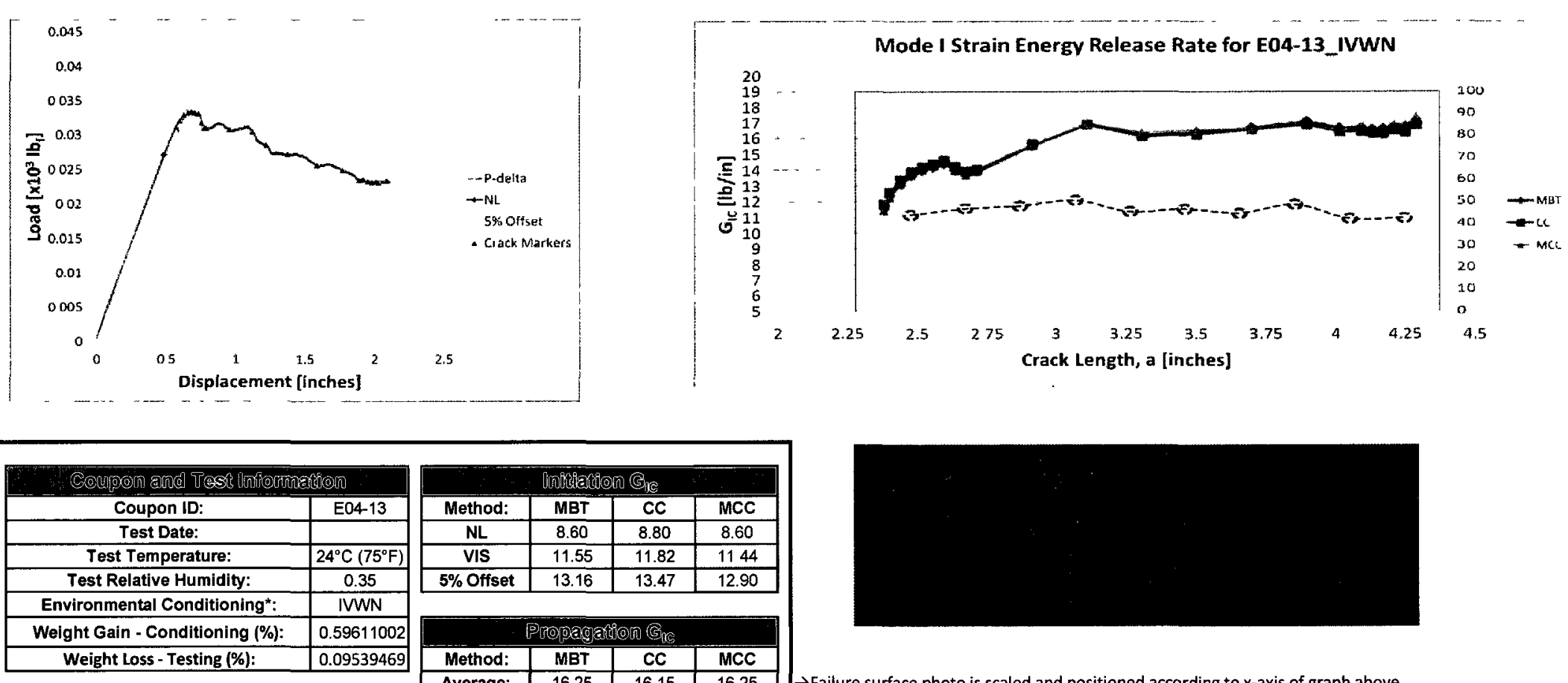

\begin{tabular}{|c|c|c|c|}
\hline \multicolumn{4}{|c|}{ limathenton $\mathrm{G}_{\mathrm{B}}$} \\
\hline Method: & MBT & CC & $M C C$ \\
\hline $\mathrm{NL}$ & 8.60 & 8.80 & 8.60 \\
\hline VIS & 11.55 & 11.82 & 1144 \\
\hline $5 \%$ Offset & 13.16 & 13.47 & 12.90 \\
\hline \multicolumn{4}{|c|}{ Propagarion Ge } \\
\hline Method: & MBT & CC & MCC \\
\hline Average: & 16.25 & 16.15 & 16.25 \\
\hline tand. Dev. & 1.00 & 0.88 & 0.98 \\
\hline
\end{tabular}
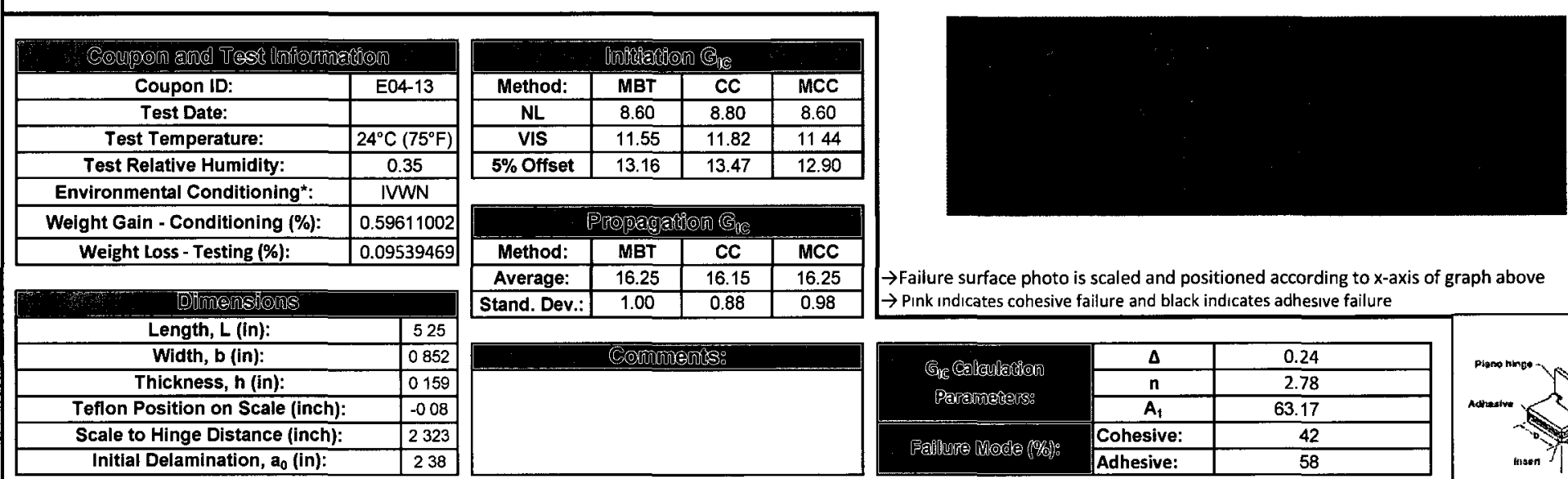

\section{$\rightarrow$ Failure surface photo is scaled and positioned according to $x$-axis of graph above} $\rightarrow$ Pink Indicates cohesive failure and black indicates adhesıve failure

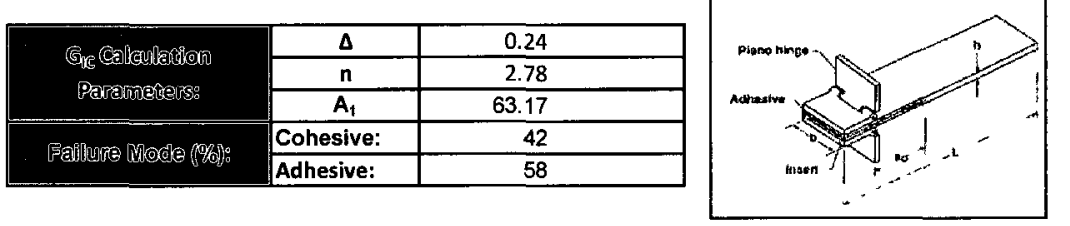

* Environmental Conditioning Codes are of the form TMSF where: Temperature $\left(\right.$ High $=82^{\circ} \mathrm{C}$ or Intermediate $\left.=70^{\circ} \mathrm{C}\right)$ Moisture type (Immersion or Vapour $=95 \%$ relative humıdity) 
46SC-J009 (Helleopter Composites Degradation) - Double Cantilever Beam Testing of Bonded Composite Laminates - Teat Results Materials: Cycom 5276-1/G40-800-24K prepreg (Lamınates); AF 163-2K (Adhesive)

Test Method: ASTM D5528
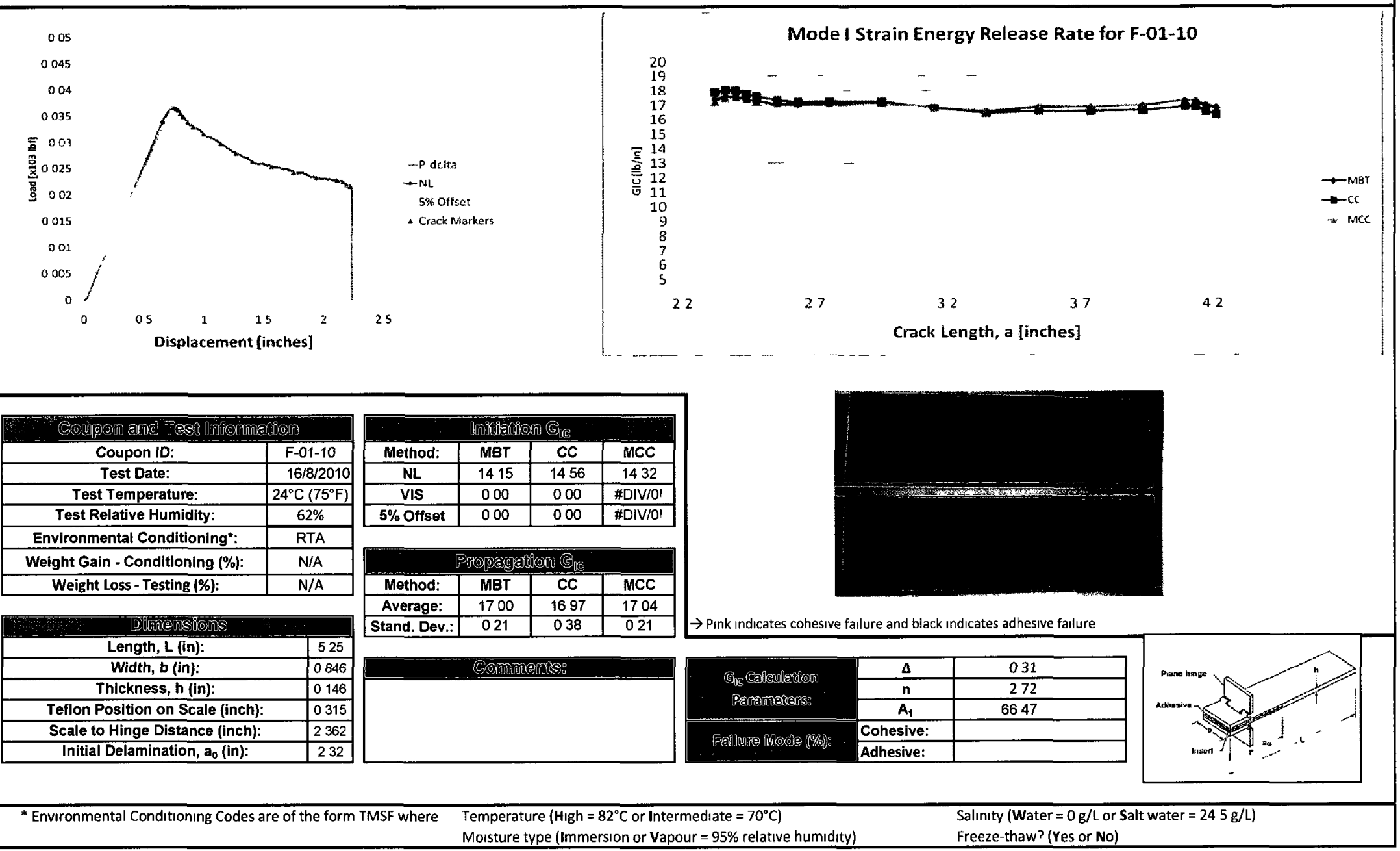
46SC-J009 (Hellcopter Composites Degradation) - Double Cantilever Beam Testing of Bonded Composite Laminates - Test Results Materials: Cycom 5276-1/G40-800-24K prepreg (Laminates); AF 163-2K (Adhesive)

Test Method: ASTM D5528
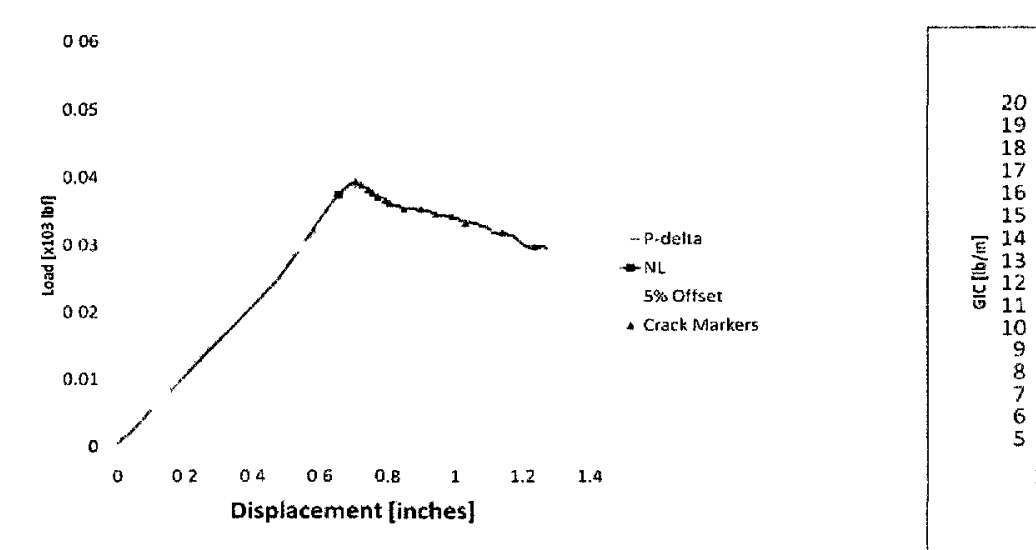

\begin{tabular}{|c|c|}
\hline & \\
\hline \multicolumn{2}{|l|}{$\begin{array}{l}\text { Coupon ID: } \\
\text { Test Date: }\end{array}$} \\
\hline Test Temperature: & ${ }^{\circ} \mathrm{C}\left({ }^{\circ} \mathrm{F}\right)$ \\
\hline Test Relative Humidity: & \\
\hline Environmental Conditioning": & \\
\hline Welght Gain - Conditioning (\%): & $\mathrm{N} / \mathrm{A}$ \\
\hline Weight Loss - Testing (\%): & N/A \\
\hline
\end{tabular}

\begin{tabular}{|c|c|c|c|}
\hline \multicolumn{4}{|c|}{ mittatipon $\mathbb{G}_{n S}$} \\
\hline $\mathrm{NL}$ & 13.01 & 13.56 & 13.12 \\
\hline VIS & 14.63 & 15.25 & 1466 \\
\hline $5 \%$ Offset & 14.53 & 15.14 & 14.53 \\
\hline & & & \\
\hline Method: & MBT & CC & MCC \\
\hline Average: & 14.77 & 14.65 & 1477 \\
\hline Stand. Dev. & 0.32 & 034 & 0.33 \\
\hline
\end{tabular}

\begin{tabular}{|c|c|}
\hline Length, $\mathbf{L}$ (in): & 525 \\
\hline Width, $\mathbf{b}$ (in): & 0848 \\
\hline Thickness, $\mathbf{h}$ (in): & 0151 \\
\hline Teflon Position on Scale (inch): & -008 \\
\hline Scale to Hinge Distance (inch): & 2205 \\
\hline Initial Delamination, $\mathbf{a}_{0}$ (in): & 236 \\
\hline
\end{tabular}
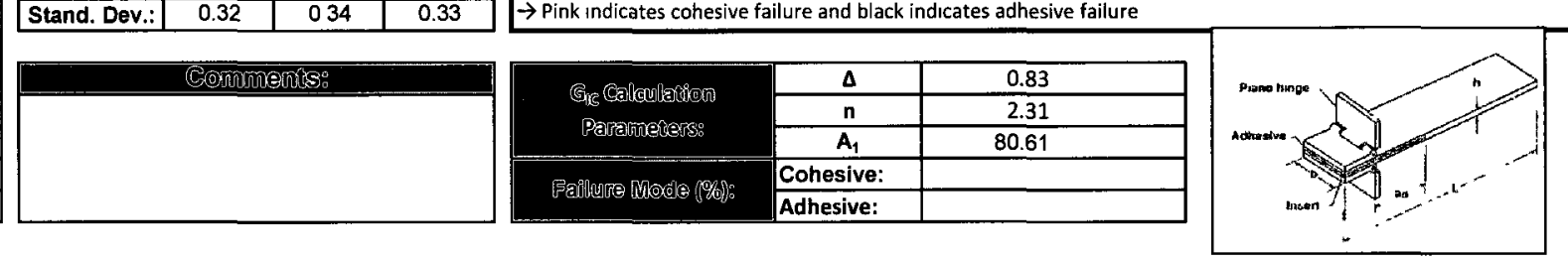

*Environmental Conditioning Codes are of the form TMSF where: Temperature (High $=82^{\circ} \mathrm{C}$ or Intermediate $=70^{\circ} \mathrm{C}$ ) Moisture type (Immersion or Vapour $=95 \%$ relative humidity) 


\section{C $\sqrt{009}$ (Helicopter Composites Degradation) - Double Cantilever Beam Testing of Bonded Composite Laminates - Test Results}

Materials: Cycom 5276-1/G40-800-24K prepreg (Lamınates), AF 163-2K (Adhesive)

Test Method: ASTM D5528
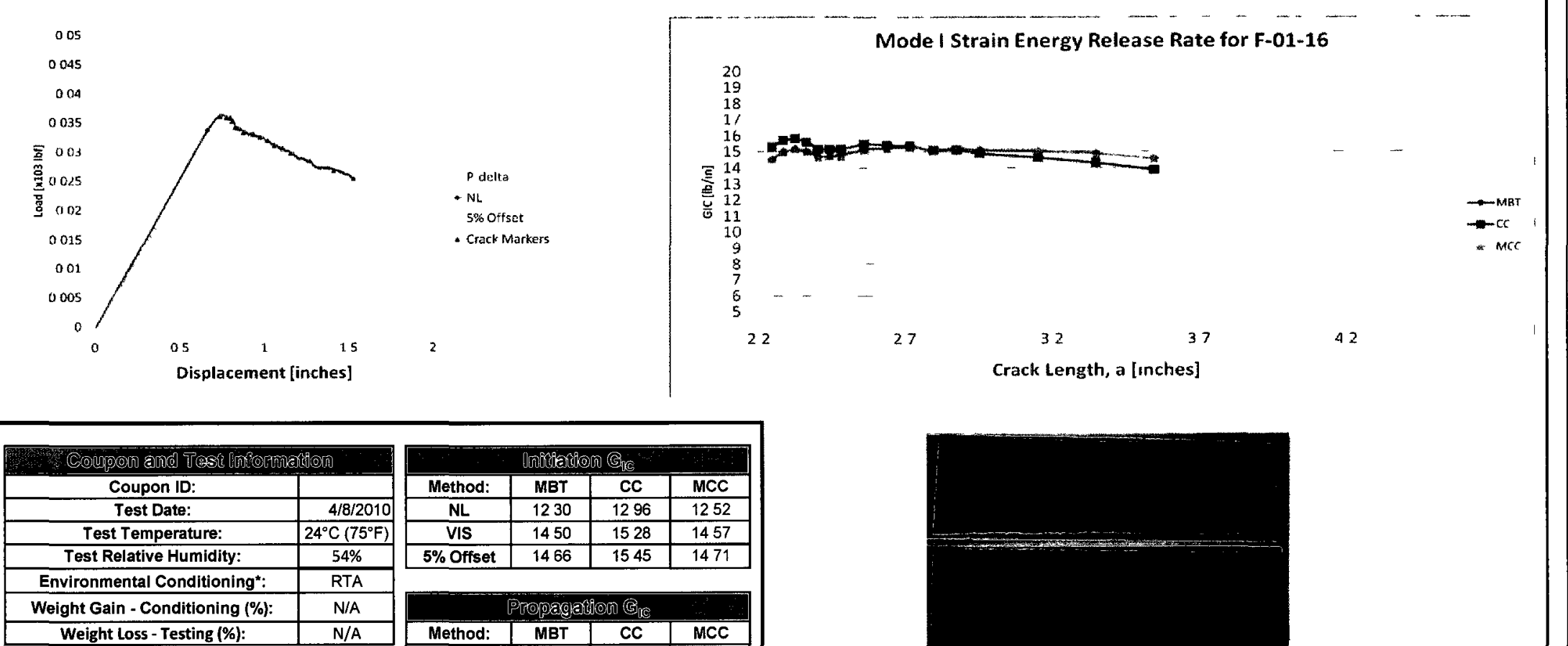

\begin{tabular}{|c|c|c|c|}
\hline \multicolumn{4}{|c|}{ Denithantom $\mathbb{G}_{1 \mathrm{C}}$} \\
\hline Method: & MBT & $\mathrm{CC}$ & $M C C$ \\
\hline $\mathrm{NL}$ & 1230 & 1296 & 1252 \\
\hline VIS & 1450 & 1528 & 1457 \\
\hline $5 \%$ Offset & 1466 & 1545 & 1471 \\
\hline \multicolumn{4}{|c|}{ Propagation $\mathrm{G}_{\mathrm{LS}}$} \\
\hline Method: & MBT & $\mathrm{CC}$ & MCC \\
\hline Average: & 1503 & 1493 & 1503 \\
\hline & 023 & 052 & 024 \\
\hline
\end{tabular}

\begin{tabular}{|c|c|}
\hline [)thiensi@is & \\
\hline Length, $\mathbf{L}$ (in): & 525 \\
\hline Width, $\boldsymbol{b}$ (in): & 0848 \\
\hline Thickness, $\boldsymbol{h}$ (in): & 015 \\
\hline Teflon Position on Scale (inch): & 0492 \\
\hline Scale to Hinge Distance (inch): & 2165 \\
\hline Initial Delamination, $\mathbf{a}_{\mathbf{0}}$ (in): & 224 \\
\hline
\end{tabular}
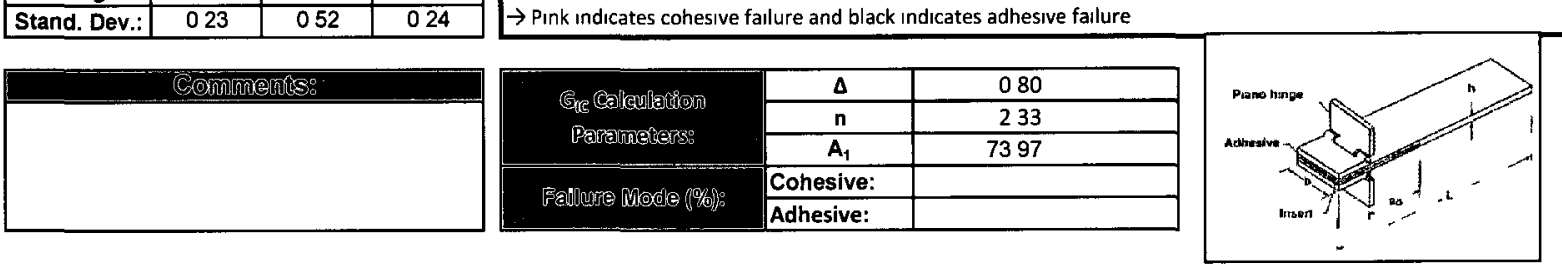

* Environmental Conditioning Codes are of the form TMSF where Temperature ( $\mathrm{HIgh}=82^{\circ} \mathrm{C}$ or Intermediate $\left.=70^{\circ} \mathrm{C}\right)$ Mosture type (Immersion or Vapour $=95 \%$ relative humıdity) 
46SC-J009 (Hellcopter Composites Degradation) - Double Cantilever Beam Testing of Bonded Composite Laminates - Test Results Materials: Cycom 5276-1/G40-800-24K prepreg (Lamınates), AF 163-2K (Adhesive)

Test Method: ASTM D5528
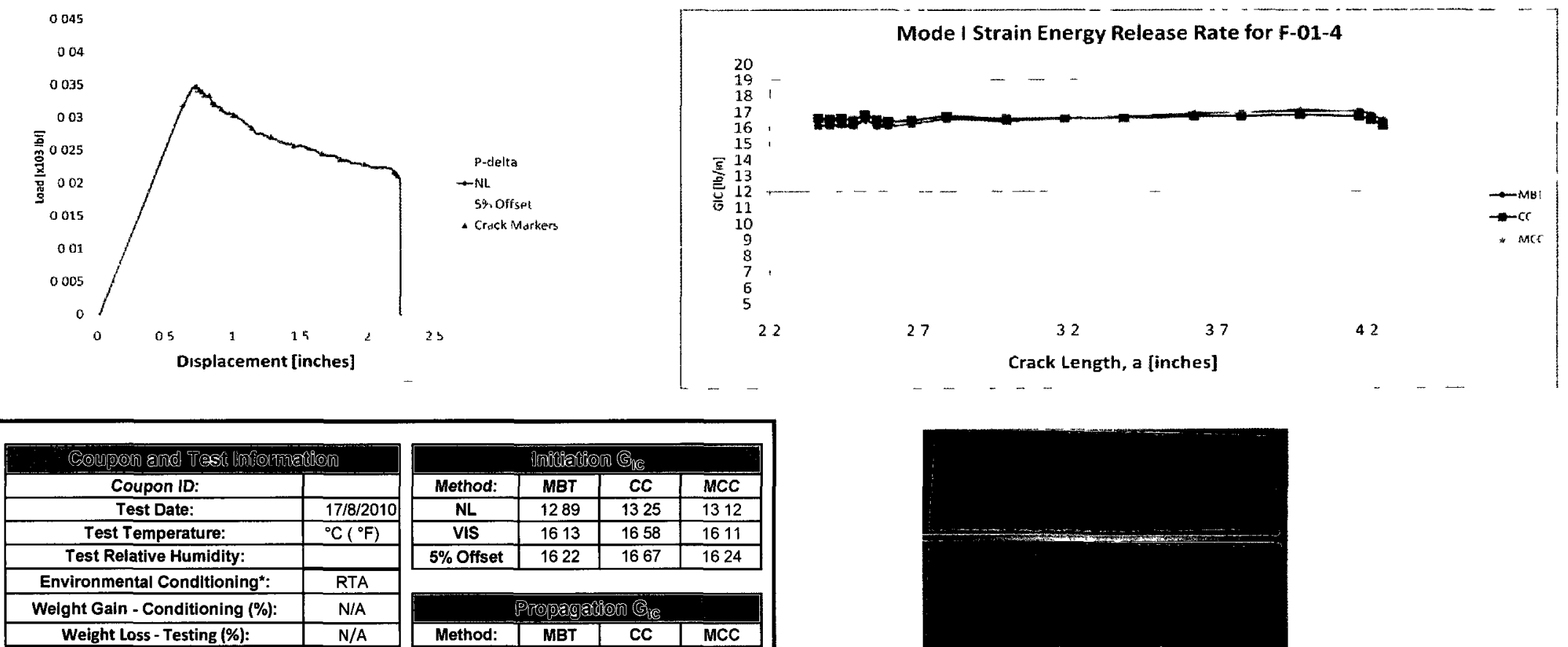

\begin{tabular}{|c|c|c|c|}
\hline \multicolumn{4}{|c|}{ Innitabon (Ge } \\
\hline Method: & MBT & $C C$ & MCC \\
\hline NL & 1289 & 1325 & 1312 \\
\hline VIS & 1613 & 1658 & 1611 \\
\hline $5 \%$ Offset & 1622 & 1667 & 1624 \\
\hline \multicolumn{4}{|c|}{ Propagation G } \\
\hline Method: & MBT & CC & MCC \\
\hline Average: & 1665 & 1662 & 1664 \\
\hline Stand. Dev.: & 034 & 014 & 035 \\
\hline
\end{tabular}

\begin{tabular}{|c|c|}
\hline Length, L (in): & 525 \\
\hline Width, $\mathbf{b}$ (in): & 0846 \\
\hline Thickness, $\mathbf{h}$ (in): & 0146 \\
\hline Teflon Position on Scale (inch): & 0276 \\
\hline Scale to Hinge Distance (inch): & 2402 \\
\hline Initial Delamination, $\mathbf{a}_{\mathbf{0}}$ (in): & 236 \\
\hline
\end{tabular}
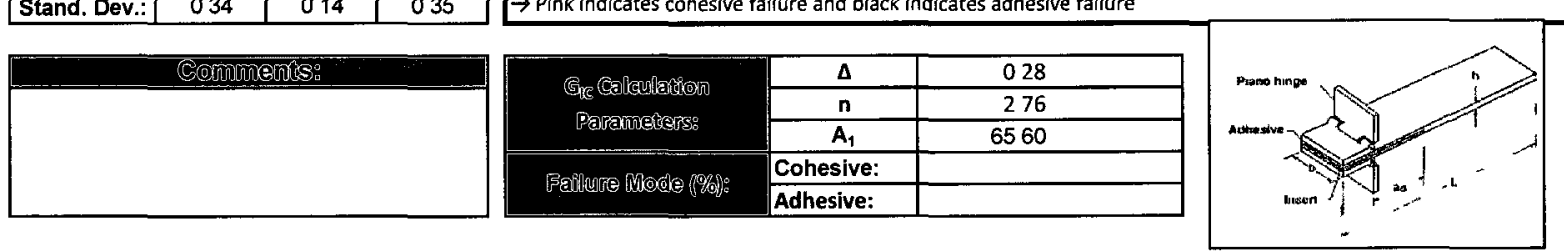

${ }^{*}$ Environmental Conditioning Codes are of the form TMSF where Temperature $\left(\mathrm{High}=82^{\circ} \mathrm{C}\right.$ or Intermediate $\left.=70^{\circ} \mathrm{C}\right)$ Moisture type (Immersion or Vapour $=95 \%$ relative humıdity) 
488C-J009 (Hellcopter Composites Degradation) - Double Cantilever Beam Testing of Bonded Composite Laminates - Test Results Materials: Cycom 5276-1/G40-800-24K prepreg (Laminates); AF 163-2K (Adhesive)

Test Method: ASTM D5528
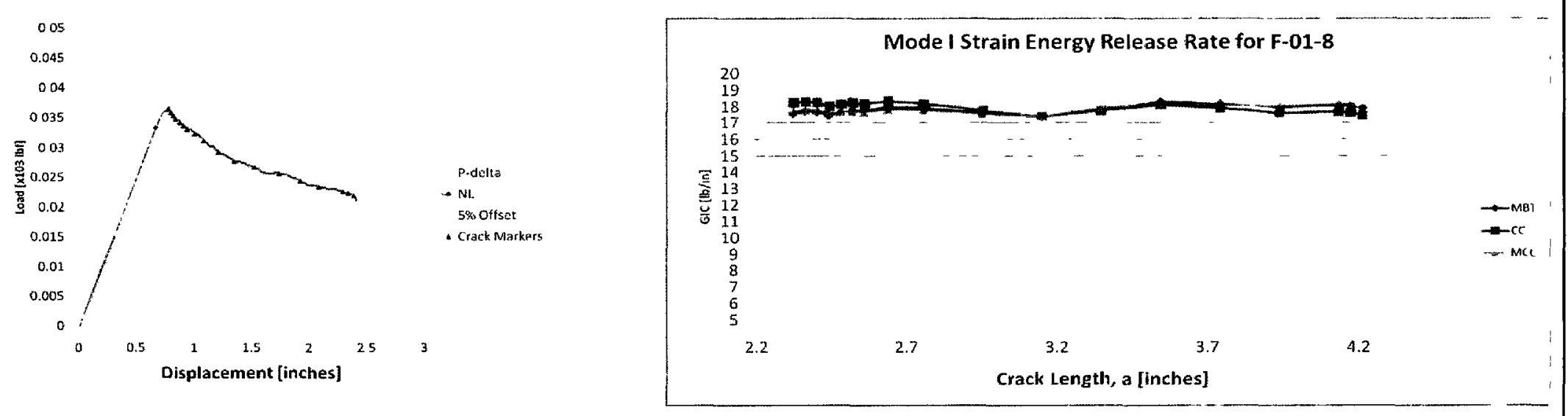

\begin{tabular}{|c|c|}
\hline Coupon 1D: & \\
\hline Test Date: & $16 / 8 / 2010$ \\
\hline Test Temperature: & $24^{\circ} \mathrm{C}\left(75^{\circ} \mathrm{F}\right)$ \\
\hline Test Relative Humidity: & $62 \%$ \\
\hline Environmental Conditioning*: & RTA \\
\hline Weight Gain - Conditioning (\%): & N/A \\
\hline Weight Loss - Testing (\%): & N/A \\
\hline
\end{tabular}

\begin{tabular}{|c|c|}
\hline \multicolumn{2}{|l|}{ Drmensions } \\
\hline Length, $L$ (in): & 525 \\
\hline Width, b (in): & 0846 \\
\hline Thickness, $\mathbf{h}(\mathbf{l n})$ : & 0146 \\
\hline Teflon Position on Scale (inch): & 0295 \\
\hline Scale to Hinge Distance (inch): & 2362 \\
\hline Initial Delamination, $a_{0}$ (in): & 232 \\
\hline
\end{tabular}

\begin{tabular}{|c|c|c|c|}
\hline \multicolumn{4}{|c|}{ flinibation $\mathrm{G}_{\mathrm{re}}$} \\
\hline Method: & MBT & CC & MCC \\
\hline NL & 14.07 & 14.59 & 14.43 \\
\hline VIS & 0.00 & 0.00 & \#DIV/01 \\
\hline $5 \%$ Offset & 0.00 & 0.00 & \#DIV/01 \\
\hline \multicolumn{4}{|c|}{ P:ropagation $\mathbb{E}_{1 \mathrm{G}}$} \\
\hline Method: & MBT & CC & $\mathrm{MCC}$ \\
\hline Average: & 17.89 & 17.88 & 17.86 \\
\hline Stand. Dev.: & 0.26 & 0.30 & 0.27 \\
\hline \multirow{2}{*}{\multicolumn{4}{|c|}{ Concunts: }} \\
\hline & & & \\
\hline & & & \\
\hline
\end{tabular}

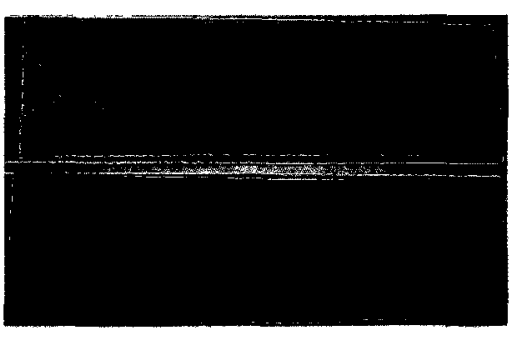

$\rightarrow$ Pink Ind icates cohesive fallure and black indicates adhesive fallure
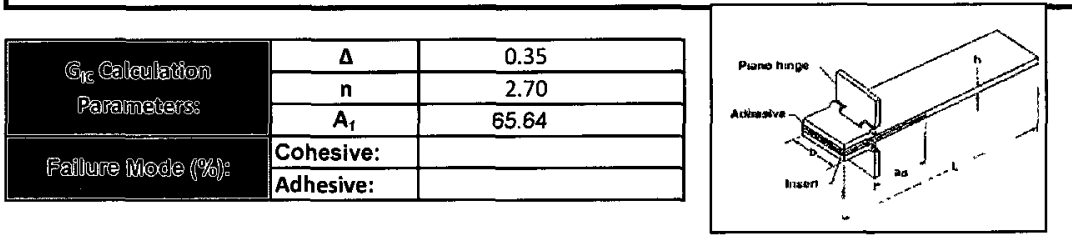

"Environmental Conditioning Codes are of the form TMSF where: Temperature (High $=82^{\circ} \mathrm{C}$ or Intermediate $=70^{\circ} \mathrm{C}$ )

Salinity (Water $=0 \mathrm{~g} / \mathrm{L}$ or Salt water $=24.5 \mathrm{~g} / \mathrm{L})$ Moisture type (Immersion or Vapour $=95 \%$ relative humidity) Freeze-thaw? (Yes or No) 


\section{Appendix B: Summary Sheets for SCB Specimens}

This Appendix contains summary data sheets for the $6 \mathrm{SCB}$ specimens tested. They are similar to the DCB sheets but contain less information because some was not relevant to this test.

Chapter I Litcrature Revicw

Chapter 2 Manufacturing of I C B and SCB Specimens

Chapter 3 Environmental Conditioning and Diffusion Data Analysis

Chapter 4 The liffects of the Environment on the Fracture Toughness of

Bonded L aminates

Chapter 5 Preliminary Study of the Effects of the Environment on the

Disbond Fracture Ioughness of Sandwich Structures

Chapter 6 Overview of Contribution and Recommendations for Future Work.

Appendix A Summary Sheets for ICCB Specimens

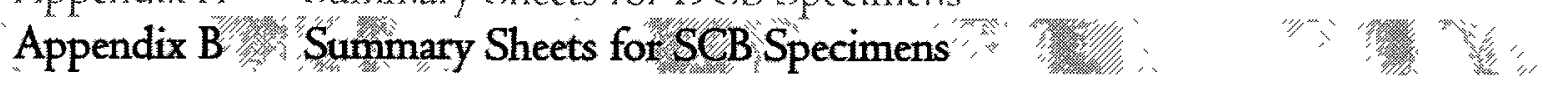




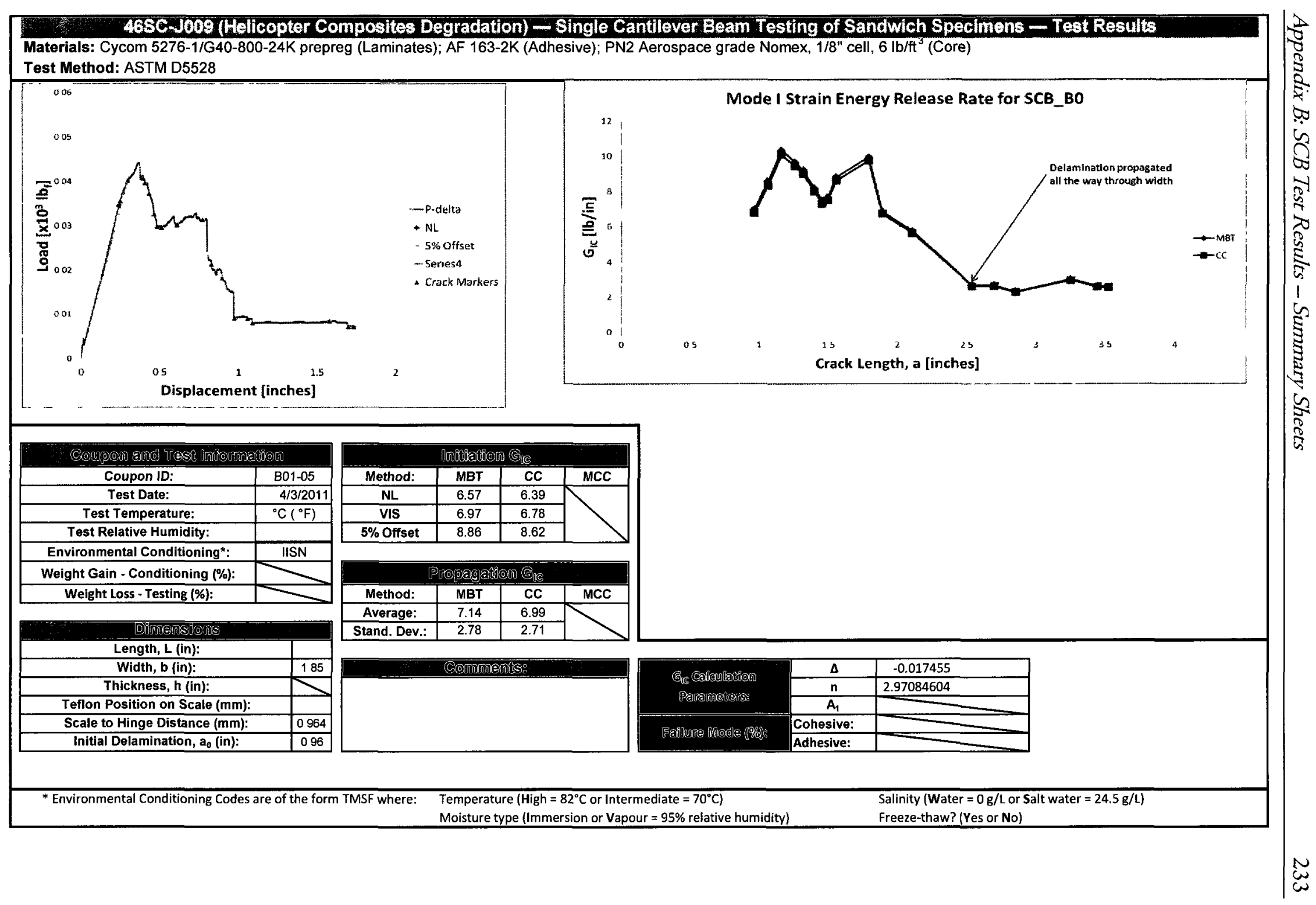


46SC-J009 (Helicopter Composites Degradation) - Single Cantilever Beam Testing of Sandwich Specimens - Test Results Materials: Cycom 5276-1/G40-800-24K prepreg (Laminates); AF 163-2K (Adhesive); PN2 Aerospace grade Nomex, 1/8" cell, 6 lb/ft ${ }^{3}$ (Core)

Test Method: ASTM D5528

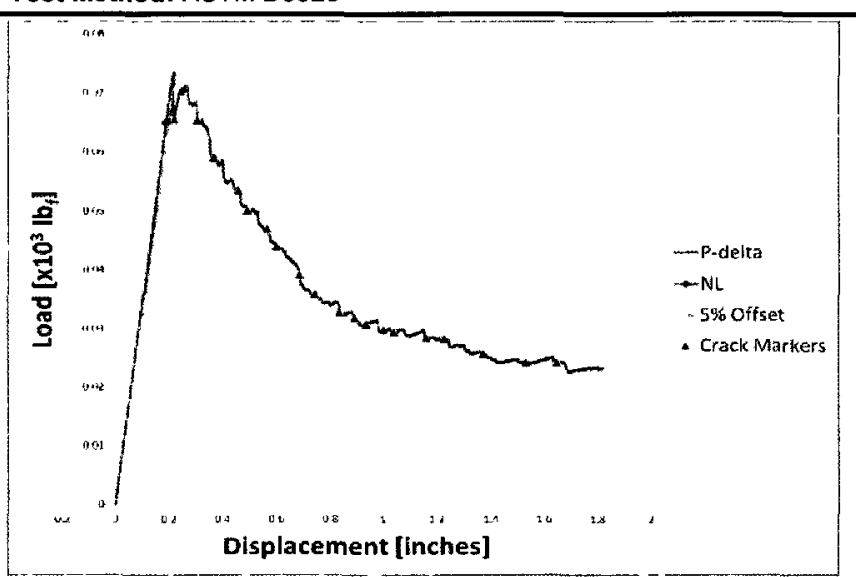

Mode I Strain Energy Release Rate for C01-04_RTA
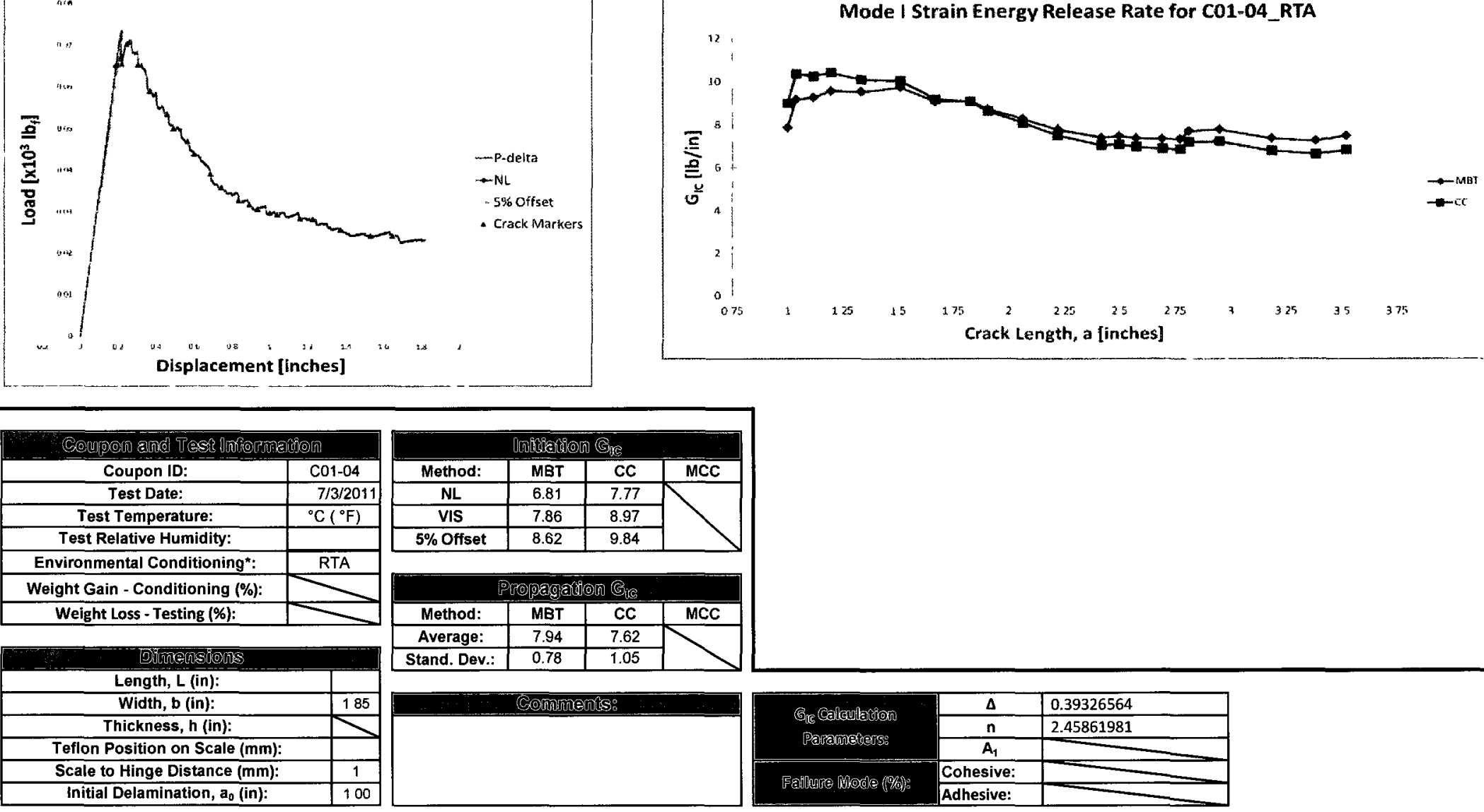

* Environmental Conditioning Codes are of the form TMSF where:

Temperature (High $=82^{\circ} \mathrm{C}$ or Intermediate $\left.=70^{\circ} \mathrm{C}\right)$ Moisture type (Immersion or Vapour $=95 \%$ relative humidity)

Salinity (Water $=0 \mathrm{~g} / \mathrm{L}$ or Salt water $=24.5 \mathrm{~g} / \mathrm{L})$

Freeze-thaw? (Yes or No) 
468C-J009 (Hellcopter Composites Degradation) - Single Cantllever Beam Testing of Sandwich Specimens - Test Results Materials: Cycom 5276-1/G40-800-24K prepreg (Laminates); AF 163-2K (Adhesive); PN2 Aerospace grade Nomex, 1/8" cell, $6 \mathrm{lb} / \mathrm{ft}^{3}$ (Core) Test Method: ASTM D5528

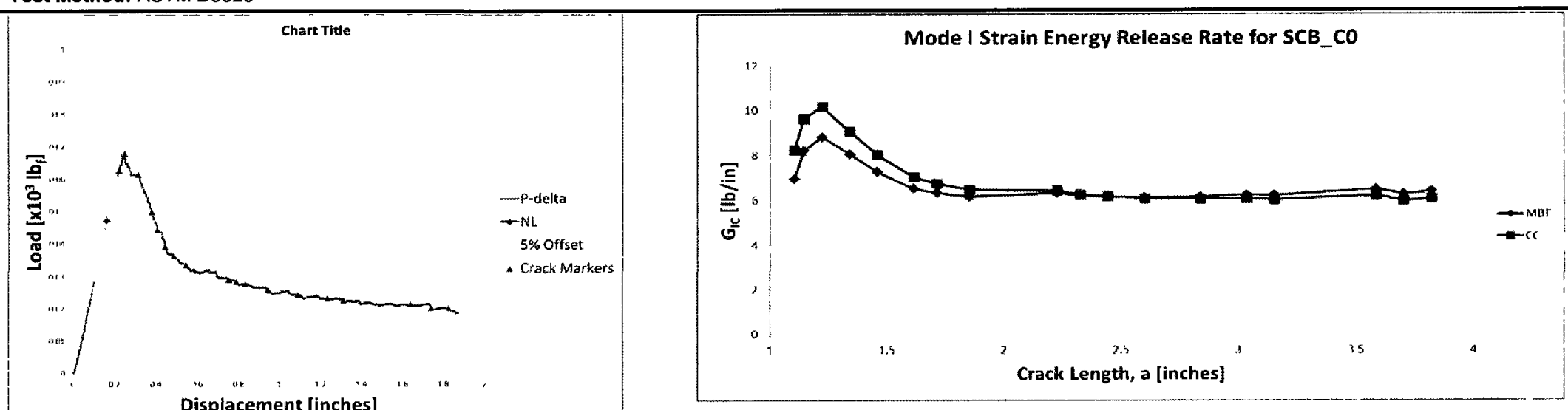

Displacement [inches]

\begin{tabular}{|c|c|c|c|c|c|}
\hline \multicolumn{2}{|c|}{ (Conpan and Testi lnformation } & \multicolumn{4}{|c|}{ Inothathon (G)/S } \\
\hline Coupon ID: & $\mathrm{CO2-07}$ & Method: & MBT & $\mathrm{CC}$ & MCC \\
\hline Test Date: & 1/3/2011 & $\mathrm{NL}$ & 3.87 & 459 & \\
\hline Test Temperature: & ${ }^{\circ} \mathrm{C}\left({ }^{\circ} \mathrm{F}\right)$ & VIS & 0.00 & 000 & \\
\hline Test Relative Humidity: & & $5 \%$ Offset & 0.00 & 0.00 & \\
\hline \multicolumn{6}{|l|}{ Environmental Conditioning*: } \\
\hline Weight Gain - Conditioning (\%): & \multirow{2}{*}{$\rightarrow$} & \multicolumn{4}{|c|}{ Propagation $G_{n}$} \\
\hline \multirow[t]{2}{*}{ Weight Loss - Testing (\%): } & & Method: & MBT & CC & MCC \\
\hline & $=$ & Average: & 6.25 & 6.27 & \\
\hline \multicolumn{2}{|l|}{ Domensions } & Stand. Dev.: & 0.13 & 0.32 & \\
\hline \multicolumn{6}{|l|}{ Length, L (in): } \\
\hline & 185 & & gonn & & \\
\hline \multicolumn{6}{|l|}{ Thickness, $h$ (in): } \\
\hline \multicolumn{2}{|l|}{ Tefion Position on Scale $(\mathrm{mm}):$} & & & & \\
\hline Scale to Hinge Distance $(\mathrm{mm})$ & 1026 & & & & \\
\hline Initial Delamination, $a_{0}(\mathrm{in})$ : & 110 & & & & \\
\hline
\end{tabular}

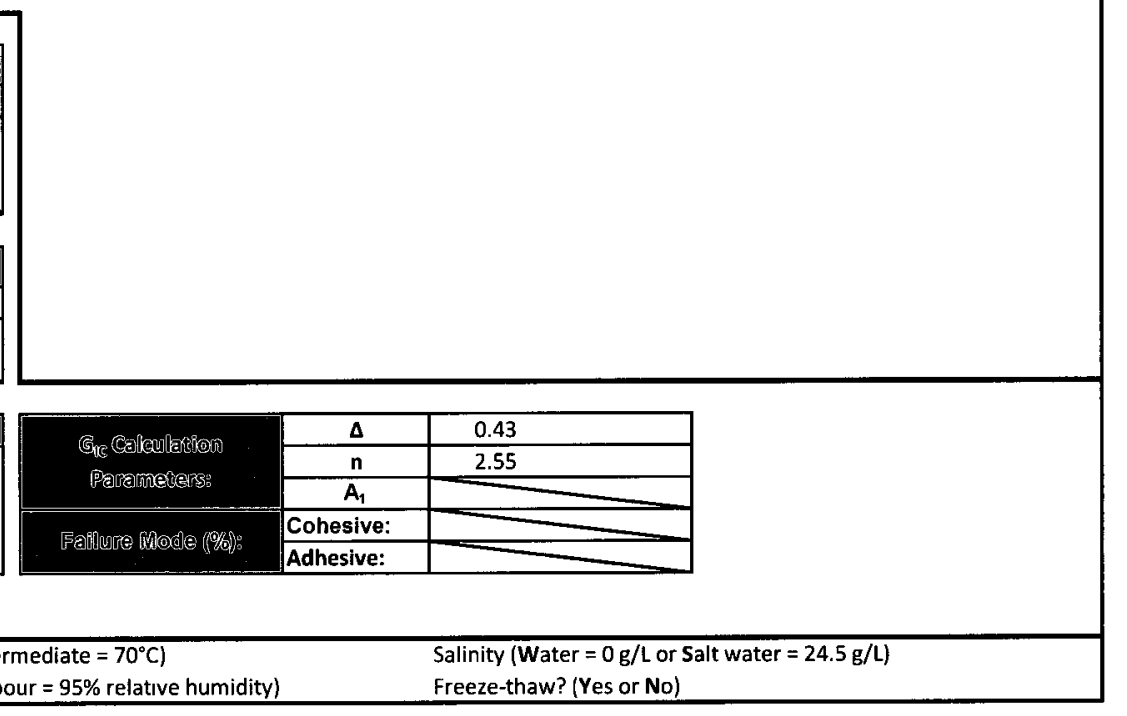

$\begin{array}{ll}\text { * Environmental Conditioning Codes are of the form TMSF where: } & \begin{array}{l}\text { Temperature (High }=82^{\circ} \mathrm{C} \text { or Intermediate }=70^{\circ} \mathrm{C} \text { ) } \\ \text { Moisture type (Immersion or Vapour }=95 \% \text { relative humidity) }\end{array}\end{array}$ Freeze-thaw? (Yes or No) 
46SC-J008 (Hellcopter Composites Degradation) - Single Cantlever Beam Testing of Sandwich Specimuns - Test Results

Materials: Cycom 5276-1/G40-800-24K prepreg (Laminates); AF 163-2K (Adhesive), PN2 Aerospace grade Nomex, 1/8" cell, $6 \mathrm{lb} / \mathrm{ft}^{3}$ (Core)

Test Method: ASTM D5528
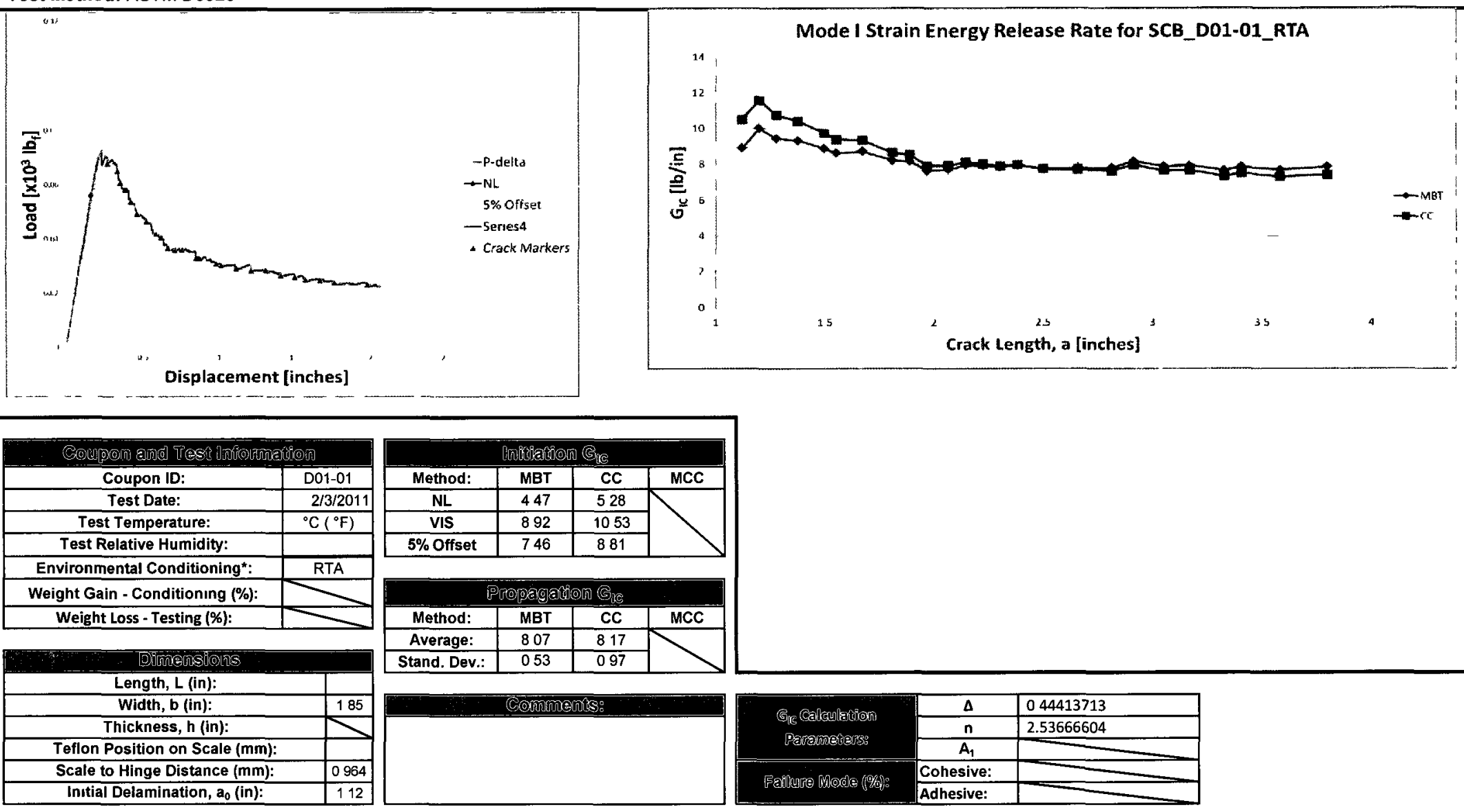

* Environmental Conditioning Codes are of the form TMSF where: Temperature (HIgh $=82^{\circ} \mathrm{C}$ or Intermediate $\left.=70^{\circ} \mathrm{C}\right)$ 
46SC-J009 (Helicopter Composites Degradation) - Single Cantilever Beam Testing of Sandwich Specimens - Test Results

Materials: Cycom 5276-1/G40-800-24K prepreg (Laminates); AF 163-2K (Adhesive); PN2 Aerospace grade Nomex, 1/8" cell, 6 lb/ft ${ }^{3}$ (Core)

Test Method: ASTM D5528
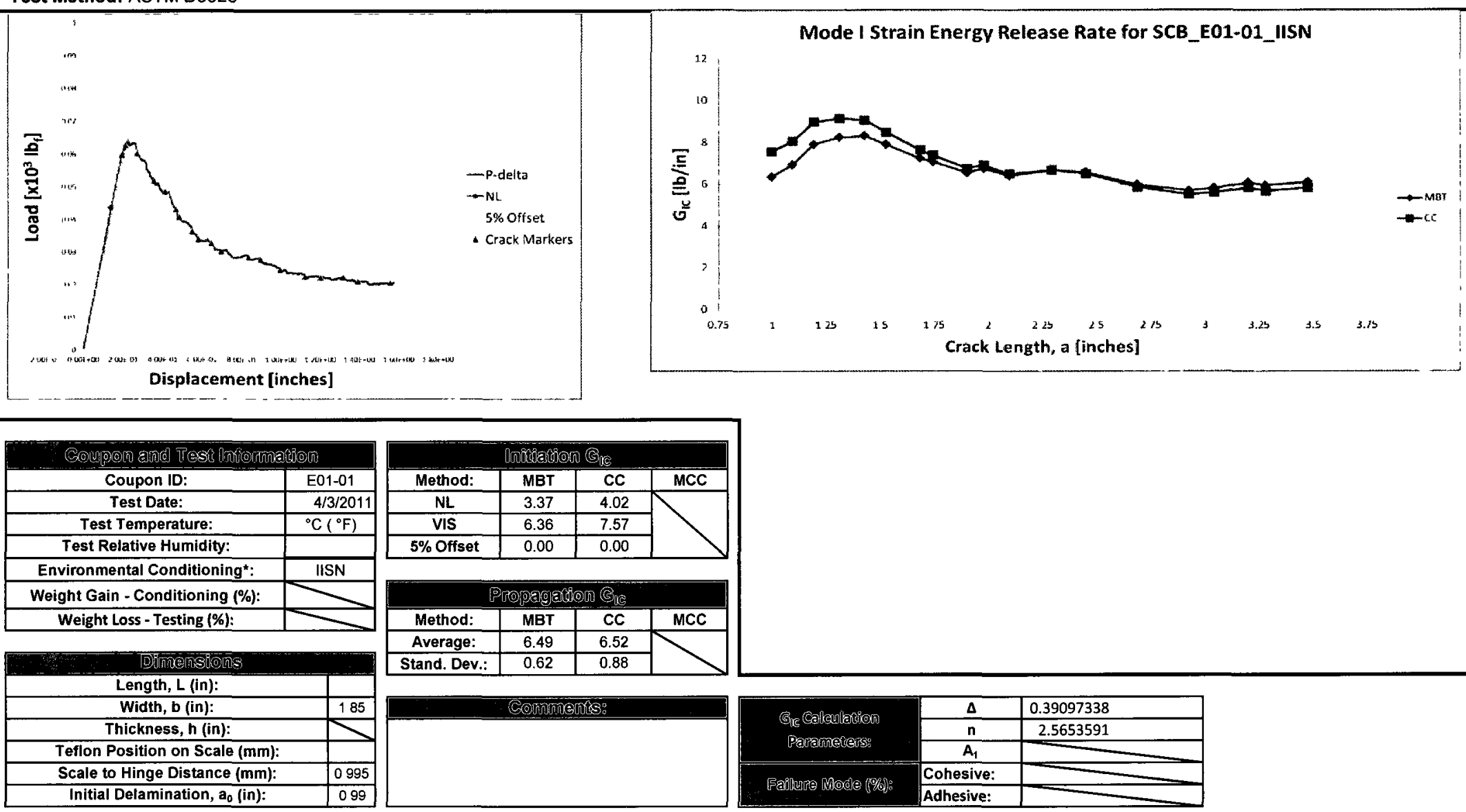

* Environmental Conditioning Codes are of the form TMSF where: Temperature (High $=82^{\circ} \mathrm{C}$ or Intermediate $=70^{\circ} \mathrm{C}$ ) 


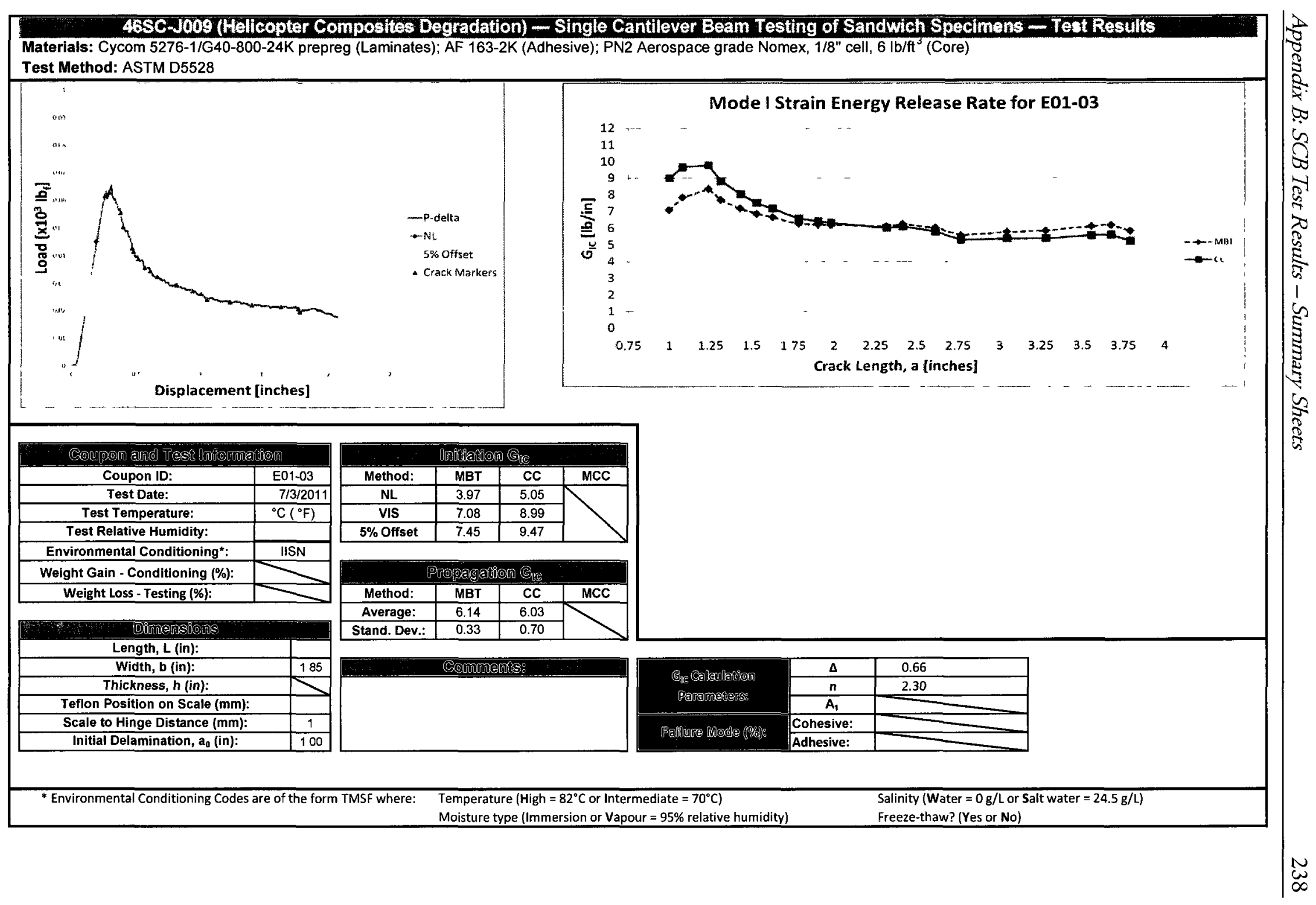




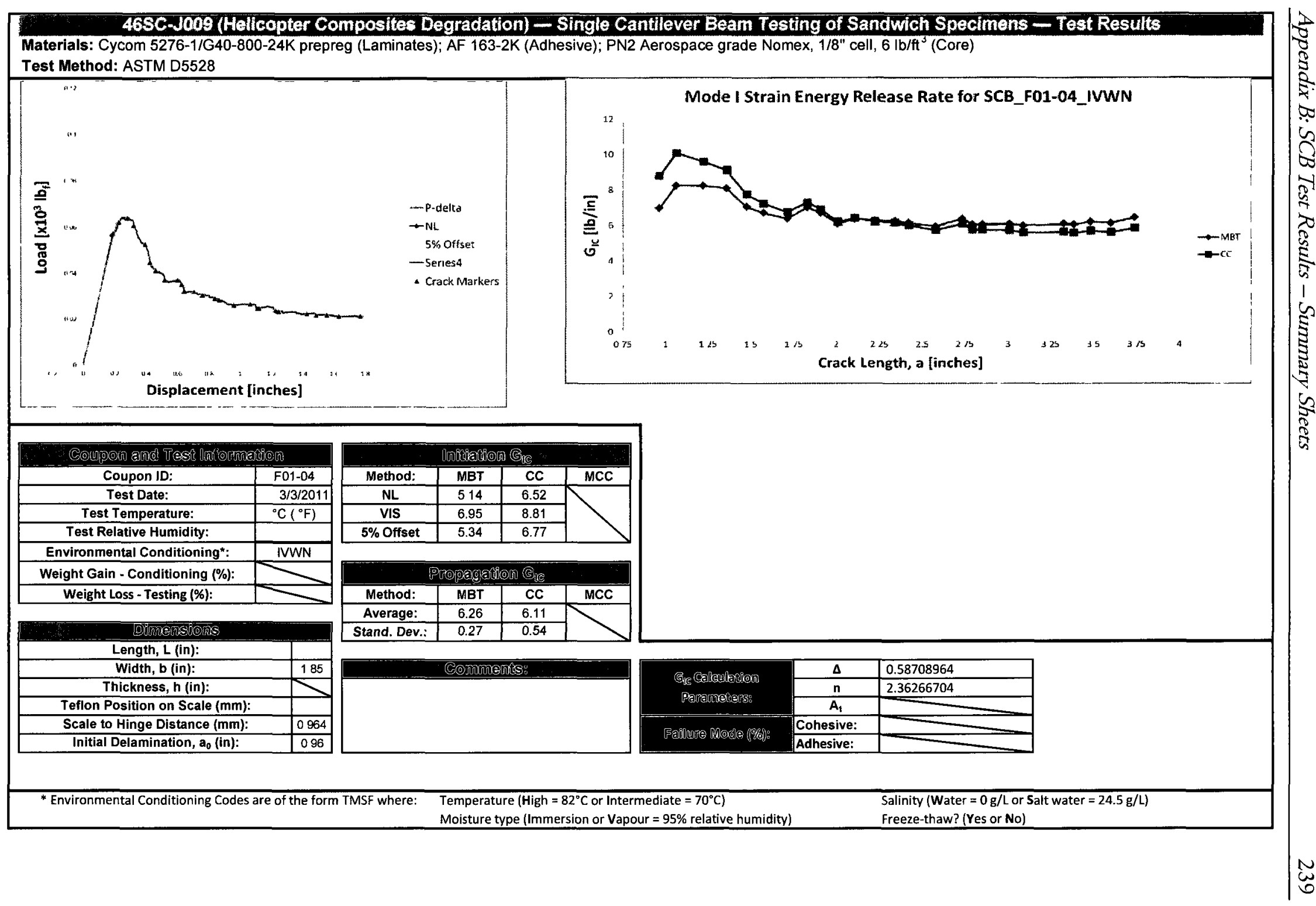

